\author{
UNIVERSIDADE DE SÃO PAULO \\ INSTITUTO DE QUÍMICA DE SÃO CARLOS \\ DEPARTAMENTO DE FÍSICO-QUÍMICA
}

ANELISSE BRUNCA DA SILVA

\title{
INVESTIGAÇÃO DO EFEITO DA MODIFICAÇÃO DA HEMATITA POR ÓXIDOS METÁLICOS QUE ATUAM EM DIFERENTES FUNÇÕES PARA O AUMENTO DA ATIVIDADE FOTO-ELETROCATALÍTICA
}




\section{INVESTIGAÇÃO DO EFEITO DA MODIFICAÇÃO DA HEMATITA POR ÓXIDOS METÁLICOS QUE ATUAM EM DIFERENTES FUNÇÕES PARA O AUMENTO DA ATIVIDADE FOTO-ELETROCATALÍTICA}

Dissertação apresentada ao Instituto de Química de São Carlos da Universidade de São Paulo como parte dos requisitos para obtenção do título de mestre em Ciência.

Área de concentração: Físico-Química

Orientador: Prof. Dr. Fabio Henrique Barros de Lima

SÃO CARLOS, SP 
À minha família: minha mãe Maria Virginia, meu irmão Gabriel Adonis e minha avó Ana Piton pelo carinho, amor, incentivo e apoio para que eu chegasse até aqui. 


\section{AGRADECIMENTOS}

Primeiramente à Deus, por estar sempre ao meu lado e por colocar anjos da guarda e pessoas iluminadas no meu caminho, que me ajudaram a superar todos os desafios sem perder a fé e a esperança.

Ao Instituto de Química de São Carlos, pelo apoio e infraestrutura.

Ao CNPq pela bolsa concedida e à FAPESP e CAPES pelo apoio financeiro no projeto.

Ao professor Dr. Fabio Henrique Barros de Lima pela orientação, oportunidade e auxílio no desenvolvimento desta pesquisa.

Ao Dr. Francisco Willian de Souza Lucas, pela contribuição fundamental no processo de elaboração deste trabalho juntamente com a Camila por estarem, mesmo de longe, sempre dispostos a ajudar.

Ao Grupo de Eletroquímica pela estrutura e apoio intelectual, em especial ao Dr. Valdecir pela disposição, ensinamentos e risadas.

Aos colegas do laboratório do Q1 Carlos, Enrique, James, Nícolas, Carlos André, Diego, Ana Cecília e Caio pelos momentos de discussões e risadas. E aos colegas do Q10 Jéssica, Paula, Rapher, Seiti e Vitória agradeço por tonarem meus dias mais leves e divertidos.

À minha mãe Maria Virginia e ao meu irmão, Gabriel Adonis, pelo apoio, incentivo, e por não medirem esforços, mesmo nos momentos mais difíceis que passamos, para que eu conseguisse vencer mais uma etapa da minha vida acadêmica.

Ao meu amor Eduardo Arizono por ser meu companheiro, pelo incentivo, pela paciência e pelo apoio em todos os sentidos.

A todos os meus familiares e amigos que estão na torcida para que eu consiga realizar meus sonhos, pela admiração e por possibilitarem que este estudo fosse concluído.

Por fim, a todos que indiretamente ou diretamente contribuíram para a realização deste trabalho, a todos os professores que contribuíram para minha formação e aos amigos que fiz de outros laboratórios, meu muito obrigada a todos. 


\section{RESUMO}

A fotoeletrólise da água, ou photoelectrochemical (PEC) water splitting, a partir da energia solar é uma estratégia promissora para a produção de gás hidrogênio e substituir a utilização de combustíveis fósseis. Neste cenário, a hematita $\left(\alpha-\mathrm{Fe}_{2} \mathrm{O}_{3}\right)$ é considerada um excelente material de fotoanodo devido ao seu band gap adequado $(1,9 \sim 2,2 \mathrm{eV})$, e por ser formada por elementos abundantes, ter baixa toxicidade e alta estabilidade química. Entretanto, baixo tempo de vida dos portadores de cargas, a baixa condutividade elétrica e lenta cinética de transferência de carga na interface eletrodo/eletrólito resultam em baixa eficiência de conversão de energia. A modificação da superfície da hematita por deposição de cocatalisadores e/ou por camadas de passivação, e modificações do bulk por nanaoestruturação com ATO (óxido de estanho e antimônio) são estratégias interessantes para superar essas limitações. Neste trabalho, filmes de hematita foram preparados a partir da eletrodeposição catódica de ferro metálico em substratos de óxido de estanho dopados com flúor (FTO) seguidos por tratamento térmico (TT). Inicialmente foram otimizados os parâmetros de síntese do filme de hematita: temperatura de tratamento térmico $\left(600^{\circ} \mathrm{C}, 650^{\circ} \mathrm{C}\right.$ e $\left.700^{\circ} \mathrm{C}\right)$ e carga de Fe metálico depositado $(300,500$ e 1000 $\mathrm{mC})$. A melhor resposta fotoeletroquímica foi obtida para o filme preparado com $500 \mathrm{mC}$ de Fe eletrodepositado e tratado termicamente a $650^{\circ} \mathrm{C}$ (TT), o qual apresentou densidade de fotocorrente de $0,83 \mathrm{~mA} \mathrm{~cm}^{-2}$ a $1,23 \mathrm{~V}$ (vs. ERH). A modificação superficial do filme de hematita com $\mathrm{Sn}\left(\mathrm{Fe}_{2} \mathrm{O}_{3} / \mathrm{Fe}_{\mathrm{x}} \mathrm{Sn}_{1-\mathrm{x}} \mathrm{O}_{4}\right)$ foi feita a partir da eletrodeposição de $\mathrm{Sn}$ metálico sobre o filme de $\mathrm{Fe}$ metálico seguido de TT. Já a modificação com $\mathrm{NiOOH}$ foi feita por eletrodeposição anódica sobre o filme de hematita $\left(\mathrm{Fe}_{2} \mathrm{O}_{3} / \mathrm{NiO}_{\mathrm{x}}\right)$. Ambas as estratégias de modificação foram avaliadas individualmente e foram posteriormente combinadas no filme $\mathrm{Fe}_{2} \mathrm{O}_{3} / \mathrm{Fe}_{\mathrm{x}} \mathrm{Sn}_{1-\mathrm{x}} \mathrm{O}_{4} / \mathrm{NiO}_{\mathrm{x}}$. As modificações avaliadas tiveram baixa influência no band gap dos filmes e em suas propriedades morfológicas-estruturais. Os experimentos de PEC foram realizados em eletrólito alcalino com e sem iluminação solar simulada. Os resultados das curvas de densidade de fotocorrente vs. potencial mostraram que as densidades de fotocorrente dos filmes $\mathrm{Fe}_{2} \mathrm{O}_{3} / \mathrm{Fe}_{\mathrm{x}} \mathrm{Sn}_{1-\mathrm{x}} \mathrm{O}_{4}, \mathrm{Fe}_{2} \mathrm{O}_{3} / \mathrm{NiO}_{\mathrm{x}}$ e $\mathrm{Fe}_{2} \mathrm{O}_{3} / \mathrm{Fe}_{\mathrm{x}} \mathrm{Sn}_{1-\mathrm{x}} \mathrm{O}_{4} / \mathrm{NiO}_{\mathrm{x}}$ aumentaram 48\%, $22 \%$ e 60\%, respectivamente, a 1,23 V (vs. EHR) em comparação ao filme de hematita não modificado. A partir de ensaios de Mott-Schottky, transiente de potencial de circuito aberto e espectroscopia de impedância fotoeletroquímica, pode-se constatar que a melhora na performance PEC observada para os filmes modificados está associado a passivação dos estados superficiais, aumentando o tempo de vida e diminuindo a recombinação de cargas. Através de experimentos realizados na presença de $\mathrm{H}_{2} \mathrm{O}_{2}$ no eletrólito, um captador de buracos, verificou-se que as 
modificações superficiais melhoraram a eficiência de injeção de cargas através interface eletrodo/eletrólito. Testes de estabilidade de fotoeletrólise com simulador solar e a 1,6 V vs. ERH em KOH 1,0 mol L ${ }^{-1}$ demonstraram que os filmes modificados permaneceram estáveis por pelo menos $15 \mathrm{~h}$. Além da modificação superficial, avaliou-se o efeito da modificação do bulk da hematita com nanopartículas de óxido de estanho e antimônio (ATO) na melhora da performance do fotoanodo. O filme ATO- $/ \mathrm{Fe}_{2} \mathrm{O}_{3}$ apresentou aumento de $50 \%$ na densidade de fotocorrente a 1,23V (vs. ERH), em comparação ao filme de hematita não modificado. Análises de MS demonstraram que a adição da subcamada de ATO promoveu aumento da densidade de portadores de carga indicando a dopagem dos filmes com o antimônio ( $\mathrm{Sb}$ ) proveniente da subcamada. Além disso, a modificação com ATO diminuiu consideravelmente a resistência total, aumentou as eficiências de separação e injeção de carga devido à diminuição da resistência do bulk. Assim, em suma, as modificações aplicadas nos fotoanodos de hematita apresentaram melhora nas propriedades fotoeletroquímicas dos filmes de hematita. 


\begin{abstract}
The photoelectrochemical (PEC) water splitting for hydrogen production using solar energy is one of the most promising strategies to overcome the global fossil fuel dependence. In this scenario, Hematite $\left(\alpha-\mathrm{Fe}_{2} \mathrm{O}_{3}\right)$ is considered an excellent photoanode material for PEC due to its suitable band gap $(1.9 \sim 2.2 \mathrm{eV})$, earth-abundant elements, low toxicity and good chemical stability. However, the short lifetime of photogenerated carriers, low electrical conductivity and slow charge transfer kinetics at electrode/electrolyte interface results in low energy conversion to hydrogen efficiency. The surface modification of hematite by cocatalyst deposition and/or passivation layers and bulk modification by ATO nanostructuring are interesting strategies to overcome these limitations. In this work, hematite films were prepared by cathodic electrodeposition of metallic iron on fluoride-doped tin oxide (FTO) substrates followed by heat treatment. Initially, hematite film synthesis parameters were optimized: The parameters studied were thermic treatment temperature $\left(600^{\circ} \mathrm{C}, 650^{\circ} \mathrm{C}\right.$ and $\left.700{ }^{\circ} \mathrm{C}\right)$ and deposited metallic Fe load (300, 500 and $1000 \mathrm{mC})$. PEC experiments were performed on alkaline electrolyte in the absence and under solar simulated illumination. The best photoelectrochemical response was obtained for the film prepared with $500 \mathrm{mC}$ electrodeposited $\mathrm{Fe}(0)$ annealed at $650{ }^{\circ} \mathrm{C}$, which showed photocurrent density of $0.83 \mathrm{~mA} \mathrm{~cm}^{-}$ 2 at $1.23 \mathrm{~V}$ (vs. RHE). The surface modification of the hematite film by $\mathrm{Sn}\left(\mathrm{Fe}_{2} \mathrm{O}_{3} / \mathrm{Fe}_{\mathrm{x}} \mathrm{Sn}_{1-\mathrm{x}} \mathrm{O}_{4}\right)$ was made by $\mathrm{Sn}(0)$ electrodeposition on the $\mathrm{Fe}(0)$ film before thermic treatment. The modification by $\mathrm{NiOOH}$ was made by anodic electrodeposition directly on the hematite film $\left(\mathrm{Fe}_{2} \mathrm{O}_{3} / \mathrm{NiO}_{\mathrm{x}}\right)$. Both modification strategies were evaluated individually and were later combined in $\mathrm{Fe}_{2} \mathrm{O}_{3} / \mathrm{Fe}_{\mathrm{x}} \mathrm{Sn}_{1-\mathrm{x}} \mathrm{O}_{4} / \mathrm{NiO}_{\mathrm{x}}$ film. The modifications evaluated had low influence on the band gap of the films and on their morphological and structural properties. The photocurrent-voltage measurements results showed that photocurrent densities of $\mathrm{Fe}_{2} \mathrm{O}_{3} / \mathrm{Fe}_{\mathrm{x}} \mathrm{Sn}_{1-\mathrm{x}} \mathrm{O}_{4}, \mathrm{Fe}_{2} \mathrm{O}_{3} / \mathrm{NiO}_{\mathrm{x}}$ and $\mathrm{Fe}_{2} \mathrm{O}_{3} / \mathrm{Fe}_{\mathrm{x}} \mathrm{Sn}_{1-\mathrm{x}} \mathrm{O}_{4} / \mathrm{NiOx}$ films increased by $48 \%, 22 \%$ and $60 \%$, respectively, at $1.23 \mathrm{~V}$ (vs. RHE) compared to bare hematite photoanode. From MottSchottky analysis, open circuit potential transient and photoelectrochemical impedance spectroscopy experiments, it was verified that the PEC performance improvement observed for the modified films is associated with surface states passivation, that increase charge carrier lifetime, and hence decrease the charge recombination. From experiments performed in the presence of $\mathrm{H}_{2} \mathrm{O}_{2}$ at the electrolyte it was possible to understand that the surface modifications improved the charge injection efficiency at the interface. Photoelectrolysis stability tests performed at $1.6 \mathrm{~V}$ vs. ERH in $1.0 \mathrm{~mol} \mathrm{~L}^{-1} \mathrm{KOH}$ demonstrated that the modified films remained
\end{abstract}


stable for at least $15 \mathrm{~h}$. In addition to surface modification investigation, the effect of hematite bulk modification by tin oxide antimony (ATO) nanoparticles were evaluated. The ATO/ $\mathrm{Fe}_{2} \mathrm{O}_{3}$ film prepared by $200 \mathrm{uL}$ of the modifier solution showed an increase of $50 \%$ increase in the photocurrent density at $1.23 \mathrm{~V}$ (vs. RHE) compared to bare hematite film. MS analysis showed that the addition of the ATO sublayer leaded to an increase at charge carrier density indicating hematite doping by antimony ( $\mathrm{Sb}$ ) from the ATO sublayer. In addition, ATO modification considerably decreased the total resistance, increased the charge separation and injection efficiencies due to the decreased at the bulk resistance. Thus, from the obtained results, the evaluated hematite photoanode modifications strategies improved the optoelectronic and photoelectrochemical properties of hematite films. 


\section{LISTA DE FIGURAS}

Figura 1- Representação esquemática de um diagrama de bandas para semicondutores extrínsecos do tipo n (a) e tipo p (b).

Figura 2- Junção semicondutor-eletrólito em um semicondutor tipo n como fotoanodo: (a) condição de pré-equilíbrio, (b) pós equilíbrio no escuro e (c) pós equilíbrio no claro (baixa potência luminosa).

Figura 3- Ilustração de uma célula fotoeletroquímica contendo um eletrodo de trabalho semicondutor tipo n e um contra eletrodo metálico.

Figura 4- Posições de band gap de semicondutores em contato com o eletrólito aquoso em pH $=0$ em relação ao Eletrodo Padrão de Hidrogênio EPH.

Figura 5-Célula unitária da hematita (esquerda) e dímeros $\mathrm{Fe}_{2} \mathrm{O}_{9}$ (à direita). Nos dímeros estão representadas as ligações longas (vermelho) e as ligações curtas (marrom).

Figura 6- Performance fotoeletroquímica de um fotoanodo de hematita ideal alcançado por meio da combinação de controle morfológico e/ou dopagem e modificação da superfície do semicondutor.

Figura 7- Comparação da estrutura de banda de um fotoanodo de semicondutor tipo na ausência e na presença de camadas passivadoras: (a) estados superficiais, (b) camada passivadora não-catalítica e (c) camada de catalisador ativo para REO

Figura 8-Representação esquemática da célula de três eletrodos com janela de quartzo utilizada nos experimentos fotoeletroquímicos

Figura 9 - Voltametria cíclica do FTO em solução de $0,05 \mathrm{~mol} \mathrm{~L}^{-1}$ de $\left(\mathrm{NH}_{4}\right)_{2} \mathrm{Fe}\left(\mathrm{SO}_{4}\right)_{2}+0,1$ mol L ${ }^{-1} \mathrm{Na}_{2} \mathrm{SO}_{4}$ em 1:8 etilenoglicol e água. $\mathrm{v}=20 \mathrm{mV} \mathrm{s}-1 . \mathrm{T}=25^{\circ} \mathrm{C}$

Figura 10 - Micrografias obtidas por MEV das superfícies dos filmes de hematita preparados com $500 \mathrm{mC}$ submetidos a diferentes temperaturas de tratamento térmico: (a) não-tratado, (b) $600{ }^{\circ} \mathrm{C}$, (c) $650^{\circ} \mathrm{C}$ e (d) $700^{\circ} \mathrm{C}$. 
Figura 11- Difratogramas de Raios $X$ dos filmes de hematita crescidos com diferentes temperaturas. Os padrões de difração de $\mathrm{SnO}_{2}$ (representando FTO, JCPDS 77-451) e $\alpha$ - $\mathrm{Fe}_{2} \mathrm{O}_{3}$ (JCPDS 33-664) são mostrados na região inferior do gráfico para comparação.

Figura 12-(a) Espectro de absorção dos filmes de hematita crescidos a diferentes temperaturas e (b) Gráfico de $(\alpha h v)^{1 / 2}$ vs. energia do fóton para os filmes de hematita crescidos em diferentes temperaturas de TT.

Figura 13- (a) Voltamogramas lineares registrados a $20 \mathrm{mVs}^{-1}$ no escuro (linha tracejada) e sob iluminação com simulador solar $\left(100 \mathrm{~mW} \mathrm{~cm}^{-1}\right.$, com filtro A.M. 1.5) (linha contínua) para os filmes de $\mathrm{Fe}_{2} \mathrm{O}_{3}$ tratados com diferentes temperaturas em $\mathrm{KOH} \mathrm{1,0} \mathrm{mol} \mathrm{L}{ }^{-1}$ e (b) Valores de densidades de fotocorrentes anódicas em 1,23 V vs. ERH.

Figura 14- Micrografias obtidas por MEV das superfícies do substrato de FTO (a) e dos filmes de hematita preparados com diferentes cargas de deposição: (b) 300 mC, (c) 500C e (d) 800 $\mathrm{mC}$.

Figura 15- Difratogramas de Raios $\mathrm{X}$ dos filmes de hematita crescidos com diferentes cargas de deposição de Fe. Os padrões de difração de $\mathrm{SnO}_{2}$ (representando FTO, JCPDF 77-451) e $\alpha$ $\mathrm{Fe}_{2} \mathrm{O}_{3}$ (JCPDF 33-664) são mostrados na região inferior do gráfico para comparação.

Figura 16- (a) Espectro de absorção dos filmes de hematita crescidos a diferentes cargas e (b) Gráfico de $(\alpha h v)^{1 / 2}$ vs. energia do fóton para os filmes de hematita crescidos com diferentes cargas de Fe depositado.

Figura 17 - (a) Voltamogramas lineares registrados a $20 \mathrm{mVs}^{-1}$ no escuro (linha tracejada) e sob iluminação com simulador solar (100 $\mathrm{mW} \mathrm{cm}^{-1}$, com filtro A.M. 1.5) (linha contínua) para os filmes de $\mathrm{Fe}_{2} \mathrm{O}_{3}$ preparados com diferentes cargas de deposição de $\mathrm{Fe}$ em $\mathrm{KOH} \mathrm{1,0} \mathrm{mol} \mathrm{L-1}$ e (b) Valores de densidades de fotocorrentes anódicas em 1,23 V vs. ERH.

Figura 18-Micrografias obtidas por MEV-FEG das superfícies do dos filmes de hematita nãodopados e dopados com diferentes cargas de estanho: (a) não-dopado, (b) $5 \mathrm{mC}$, (c) $10 \mathrm{mC} \mathrm{e}$ (d) $20 \mathrm{mC}$.

Figura 19- Difratogramas de Raios $X$ dos filmes de hematita sem modificação e modificados com diferentes cargas de Sn. Os padrões de difração de $\mathrm{SnO}_{2}$ (representando FTO, JCPDS 77- 
451), $\alpha-\mathrm{Fe}_{2} \mathrm{O}_{3}$ (JCPDS 33-664) e $\mathrm{Fe}_{1,727} \mathrm{Sn}_{0,205} \mathrm{O}_{3}$ (JPDS 01-088-0434) são mostrados na região inferior do gráfico para comparação

Figura 20-(a) Espectro de absorção dos filmes de hematita modificados com diferentes cargas de Sn e (b) Gráfico de $(\alpha h v)^{1 / 2}$ vs. energia do fóton para os filmes de hematita modificados com diferentes cargas de $\mathrm{Sn}$.

Figura 21- Gráficos de Mott-Schottky registrados com frequência de $1 \mathrm{kHz}$ em KOH 1 mol L${ }^{1}$ (pH 13,6) para os filmes: (a) $\mathrm{Fe}_{2} \mathrm{O}_{3}$, (b) $\mathrm{Fe}_{2} \mathrm{O}_{3} / \mathrm{Fe}_{\mathrm{x}} \mathrm{Sn}_{1-\mathrm{x}} \mathrm{O}_{4}-5 m \mathrm{mC}$, (c) $\mathrm{Fe}_{2} \mathrm{O}_{3} / \mathrm{Fe}_{\mathrm{x}} \mathrm{Sn}_{1-\mathrm{x}} \mathrm{O}_{4}-10 m \mathrm{mC}$ e (d) $\mathrm{Fe}_{2} \mathrm{O}_{3} / \mathrm{Fe}_{\mathrm{x}} \mathrm{Sn}_{1-\mathrm{x}} \mathrm{O}_{4}-20 \mathrm{mC}$.

Figura 22-Voltamogramas lineares registrados a $20 \mathrm{mVs}^{-1}$ no escuro (linha tracejada) e sob iluminação com simulador solar (100 $\mathrm{mW} \mathrm{cm}^{-1}$, com filtro A.M. 1.5) (linha contínua) para os filmes de hematita não-modificados e modificados com diferentes cargas de Sn em $\mathrm{KOH} 1,0$ mol L-1.

Figura 23-Cronoamperogramas registrados a 1,6 V (vs. ERH) em hidróxido de potássio 1,0 mol L ${ }^{-1}$ sob iluminação solar simulada para os filmes de $\mathrm{Fe}_{2} \mathrm{O}_{3}$ e $\mathrm{Fe}_{2} \mathrm{O}_{3} / \mathrm{Fe}_{\mathrm{x}} \mathrm{Sn}_{1-\mathrm{x}} \mathrm{O}_{4}-10$ mC. . 48

Figura 24- Curvas de OCP para os filmes de hematita não-modificado e modificados com diferentes níveis de $\mathrm{Sn}$ em hidróxido de potássio $1 \mathrm{~mol} \mathrm{~L}^{-1}$ ( $\mathrm{pH} \mathrm{13,6)} \mathrm{com} \mathrm{intervalo} \mathrm{de}$ iluminação:10 s escuro-140s claro-150 s escuro.

Figura 25- Voltamogramas lineares registrados a $20 \mathrm{mVs}^{-1}$ no escuro (linha tracejada) e sob iluminação com simulador solar (100 $\mathrm{mW} \mathrm{cm}^{-1}$, com filtro A.M. 1.5) (linha contínua) para os filmes de hematita não-modificados e modificados com diferentes ciclos de deposição de $\mathrm{NiO}_{\mathrm{x}}$ em KOH 1,0 $\mathrm{mol} \mathrm{L}^{-1}$

Figura 26- Gráfico de Mott-Schottky registrados com frequência de $1 \mathrm{kHz}$ em KOH 1 mol L${ }^{1}$ (pH 13,6) para os filmes: (a) $\mathrm{Fe}_{2} \mathrm{O}_{3}$, (b) $\mathrm{Fe}_{2} \mathrm{O}_{3} / \mathrm{NiO}_{\mathrm{x}}$, (c) $\mathrm{Fe}_{2} \mathrm{O}_{3} / \mathrm{Fe}_{\mathrm{x}} \mathrm{Sn}_{1-\mathrm{x}} \mathrm{O}_{4}-10 \mathrm{mC}$ e (d) $\mathrm{Fe}_{2} \mathrm{O}_{3} /$ $\mathrm{Fe}_{\mathrm{x}} \mathrm{Sn}_{1-\mathrm{x}} \mathrm{O}_{4}-10 \mathrm{mC} / \mathrm{NiO}_{\mathrm{x}}$

Figura 27- Voltamogramas lineares registrados a $20 \mathrm{mVs}^{-1}$ no escuro (linha tracejada) e sob iluminação com simulador solar (100 $\mathrm{mW} \mathrm{cm}^{-1}$, com filtro A.M. 1.5) (linha contínua) para os filmes modificados com $\mathrm{NiO}_{\mathrm{x}} \mathrm{em} \mathrm{KOH} \mathrm{1,0} \mathrm{mol} \mathrm{L-1.}$ 55 
Figura 28- Cronoamperogramas registrados a 1,6 V (vs. ERH) em hidróxido de potássio 1,0 mol L-1 sob iluminação simulada para os filmes de $\mathrm{Fe}_{2} \mathrm{O}_{3}, \mathrm{Fe}_{2} \mathrm{O}_{3} / \mathrm{Fe}_{\mathrm{x}} \mathrm{Sn}_{1-\mathrm{x}} \mathrm{O}_{4}-10 \mathrm{mC}, \mathrm{Fe}_{2} \mathrm{O}_{3} / \mathrm{NiO}_{\mathrm{x}}$

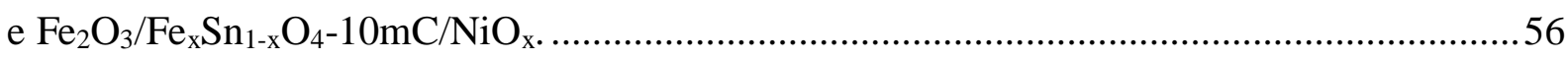

Figura 29 -Curvas de OCP para os filmes modificados pela deposição de $\mathrm{NiO}_{\mathrm{x}}$ como cocatalisador em hidróxido de potássio $1 \mathrm{~mol} \mathrm{~L}^{-1}(\mathrm{pH} \mathrm{13,6)} \mathrm{com} \mathrm{intervalo} \mathrm{de} \mathrm{iluminação:10} \mathrm{s}$ escuro-140s claro-150 s escuro.

Figura 30- (a) Gráficos de Nyquist para os fotoanodos de hematita registrados a 1,23V (vs. RHE) em $1 \mathrm{~mol} \mathrm{~L}^{-1} \mathrm{KOH}$ sob iluminação com simulador solar $\left(100 \mathrm{~mW} \mathrm{~cm}^{-1}\right.$, com filtro A.M. 1.5). Os valores experimentais estão representados pelos símbolos e os ajustados matematicamente estão apresentados por linhas. (b) Circuito equivalente. .58

Figura 31-(a) Gráficos de Nyquist para os fotoanodos de hematita registrados a 1,23V (vs. RHE) em $1 \mathrm{~mol} \mathrm{~L}^{-1} \mathrm{KOH}+0,5 \mathrm{~mol} \mathrm{~L}^{-1}$ de $\mathrm{H}_{2} \mathrm{O}_{2}$ sob iluminação com simulador solar (100 mW $\mathrm{cm}^{-1}$, com filtro A.M. 1.5). Os valores experimentais estão representados pelos símbolos e os ajustados matematicamente estão apresentados por linhas. (b) Circuito equivalente.

Figura 32- Gráfico da eficiência de separação e eficiência de injeção de carga dos fotoanodos de hematita não-modificado e modificados à $1,23 \mathrm{~V}$ vs. ERH em KOH 1 mol L-1. 63

Figura 33- Micrografias obtidas por MEV-FEG das superfícies dos filmes de hematita depositados sobre o substrato não-modificado (a) e modificado com diferentes quantidades de nanopartículas de ATO: (b) $100 \mu \mathrm{L}$, (c) $200 \mu \mathrm{L}$ e (d) $300 \mu \mathrm{L}$. 65

Figura 34- Difratogramas de Raios X dos filmes de hematita preparados sobre o substrato sem modificação e modificados com diferentes cargas de ATO. Os padrões de difração de $\mathrm{SnO}_{2}$ (representando FTO, JCPDS 77-451), $\alpha-\mathrm{Fe}_{2} \mathrm{O}_{3}$ (JCPDS 33-664) são mostrados na região inferior do gráfico para comparação.

Figura 35-(a) Espectro de absorção dos filmes de hematita sintetizados sobre o substrato não modificado e modificados com diferentes cargas ATO e (b) Gráfico de $(\alpha h v)^{1 / 2}$ vs. energia do fóton para os filmes de hematita sintetizados sobre o substrato não modificado e modificados com diferentes cargas ATO. 68 
Figura 36- Gráfico de Mott-Schottky registrados com frequência de $1 \mathrm{kHz}$ em KOH $1 \mathrm{~mol} \mathrm{~L}^{-}$ 1 (pH 13,6) para os filmes: (a) ATO- $100 \mu \mathrm{L} / \mathrm{Fe}_{2} \mathrm{O}_{3}$, (b ATO- $200 \mu \mathrm{L} / \mathrm{Fe}_{2} \mathrm{O}_{3}$, (c) ATO$300 \mu \mathrm{L} / \mathrm{Fe}_{2} \mathrm{O}_{3} \mathrm{e}(\mathbf{d}) \mathrm{FTO} / \mathrm{ATO}$.

Figura 37- Voltamogramas lineares registrados a $20 \mathrm{mVs}^{-1}$ no escuro (linha tracejada) e sob iluminação com simulador solar (100 $\mathrm{mW} \mathrm{cm}^{-1}$, com filtro A.M. 1.5) (linha contínua) para os filmes modificados com ATO em KOH 1,0 $\mathrm{mol} \mathrm{L}^{-1}$.

Figura 38-Curvas de OCP para os filmes de hematita preparados em substrato não-modificado e modificado com diferentes quantidades de ATO em hidróxido de potássio $1 \mathrm{~mol} \mathrm{~L}^{-1}$ (pH 13,6) com intervalo de iluminação:10 s escuro-140s claro-150 s escuro.

Figura 39- Gráficos de Nyquist para os fotoanodos de hematita registrados a 1,23V (vs. RHE) em $1 \mathrm{~mol} \mathrm{~L}^{-1} \mathrm{KOH}$ sob iluminação com simulador solar (100 mW cm${ }^{-1}$, com filtro A.M. 1.5). Os valores experimentais estão representados pelos símbolos e os ajustados matematicamente estão apresentados por linhas.

Figura 40- Gráfico da eficiência de separação e eficiência de injeção de carga dos fotoanodos de hematita preparados no substrato não-modificado e modificado com ATO à 1,23 V vs. ERH em KOH 1 mol L ${ }^{-1}$ 75 


\section{LISTA DE TABELAS}

Tabela 1- Lista da procedência e pureza dos reagentes utilizados. 18

Tabela 2- Largura à meia altura (FWHM), coeficiente de textura relativo $\left(\mathrm{CT}_{\mathrm{Rel}}\right)$, composição e energia de band gap $\left(\mathrm{E}_{\mathrm{g}}\right)$ para os filmes $\alpha-\mathrm{Fe}_{2} \mathrm{O}_{3}$ submetidos a diferentes temperaturas de tratamento térmico.

Tabela 3- Largura à meia altura (FWHM), coeficiente de textura relativo $\left(\mathrm{CT}_{\mathrm{Rel}}\right)$, composição e energia de band gap $\left(\mathrm{E}_{\mathrm{g}}\right)$ para os filmes $\alpha-\mathrm{Fe}_{2} \mathrm{O}_{3}$ crescidos com diferentes cargas de $\mathrm{Fe}$.....36

Tabela 4- Largura à meia altura (FWHM), composição e energia de band gap ( $\left.E_{\mathrm{g}}\right)$ para os filmes $\alpha-\mathrm{Fe}_{2} \mathrm{O}_{3}$ modificados com diferentes cargas de $\mathrm{Sn}$

Tabela 5- Potencial de banda plana $\left(\mathrm{E}_{\mathrm{fb}}\right)$ e densidade de portadores $\left(\mathrm{N}_{\mathrm{D}}\right)$ para filmes de hematita não modificado e modificados com diferentes cargas de Sn.

Tabela 6- Parâmetros da performance fotoeletroquímica dos filmes de hematita não modificados e modificados com diferentes cargas de Sn.

Tabela 7- Potencial de banda plana $\left(\mathrm{E}_{\mathrm{fb}}\right)$ e densidade de portadores $\left(\mathrm{N}_{\mathrm{D}}\right)$ para filmes de hematita e hematita dopada com $\mathrm{Sn}$ modificados com $\mathrm{NiO}_{\mathrm{x}}$

Tabela 8- Parâmetros da performance fotoeletroquímica dos filmes de hematita não modificados e modificados com diferentes cargas de $\mathrm{Sn}$

Tabela 9- Parâmetros matematicamente ajustados ao circuito equivalente para os fotoanodos de hematita em $1 \mathrm{~mol} \mathrm{~L}^{-1} \mathrm{KOH}$.

Tabela 10- Parâmetros matematicamente ajustados ao circuito equivalente para os fotoanodos de hematita em $1 \mathrm{~mol} \mathrm{~L}^{-1} \mathrm{KOH}+0,5 \mathrm{~mol} \mathrm{~L}^{-1} \mathrm{H}_{2} \mathrm{O}_{2}$

Tabela 11- Largura à meia altura (FWHM), composição e energia de band gap $\left(\mathrm{E}_{\mathrm{g}}\right)$ para os filmes $\alpha-\mathrm{Fe}_{2} \mathrm{O}_{3}$ preparados sobre o substrato não-modificado e modificados com diferentes cargas de ATO.

Tabela 12- Potencial de banda plana $\left(\mathrm{E}_{\mathrm{fb}}\right)$ e densidade de portadores $\left(\mathrm{N}_{\mathrm{D}}\right)$ para filmes de hematita preparados no substrato não modificado e modificado com ATO. 
Tabela 13- Parâmetros da performance fotoeletroquímica dos filmes de hematita modificados com diferentes cargas de ATO.

Tabela 14- Parâmetros matematicamente ajustados ao circuito equivalente para os fotoanodos de hematita em $1 \mathrm{~mol} \mathrm{~L}^{-1} \mathrm{KOH}$. ..... 


\section{LISTA DE ABREVIATURAS}

ALD - Atomic layer deposition

APCDV - Deposição química na fase vapor a pressão atmosférica

ATO - Óxido de estanho e antimônio

BC - Banda de condução

BV - Banda de valência

DRX - Difratometria de raio X

EPH - Eletrodo Padrão de Hidrogênio

ERH - Eletrodo de Referência de Hidrogênio

FTO - Óxido de estanho dopado com flúor

FWHM - Largura total à meia-altura (Full Width at Half Maximum-FWHM)

HOMO - Highest occupied molecular orbital

ITO - Óxido de estanho dopado com índio

LUMO - Lowest unoccupied molecular orbital

MEV - Microscopia Eletrônica de Varredura

MEV-FEG - Microscopia Eletrônica de Varredura com fonte de emissão de campo

MJ - Megajoule

MS - Mott Schottky

OCPT - Transiente de potencial de circuito aberto

PEIS - Espectroscopia de Impedância Fotoeletroquímica

$\mathbf{P i}$ - Tampão fosfato

REO - Reação de Evolução de Oxigênio

STH - Energia solar a gás hidrogênio (Solar to Hydrogen)

TT - Tratamento térmico

TW - Terawatts

UV - Ultravioleta

VIS- Visível 


\section{SUMÁRIO}

1. INTRODUÇÃO ........................................................................................ 1

1.1 CONSIDERAÇÕES INICIAIS ....................................................................................... 1

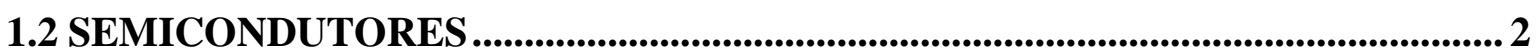

1.2.1 Junção semicondutor-eletrólito ....................................................................................... 4

1.3 DISPOSITIVOS FOTOELETROQUÍMICOS............................................................ 6

1.4 FOTOELETROCATALISADORES PARA A REO ................................................. 7

1.4.1 Hematita .................................................................................................................................9

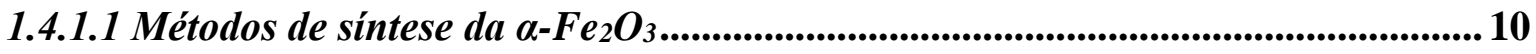

1.5 DESAFIOS E PERSPECTIVAS DA APLICAÇÃO DA $\alpha$-Fe $\mathrm{F}_{2} \mathrm{O}_{3}$ EM PEC ...........11

1.5.1 Estratégias para a modificação do bulk da $\alpha-\mathrm{Fe}_{2} \mathrm{O}_{3}$.................................................. 12

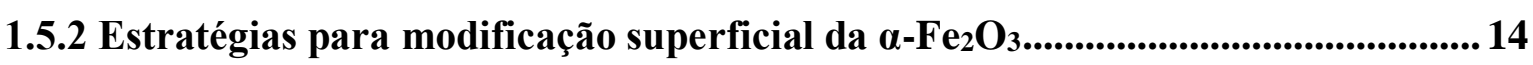

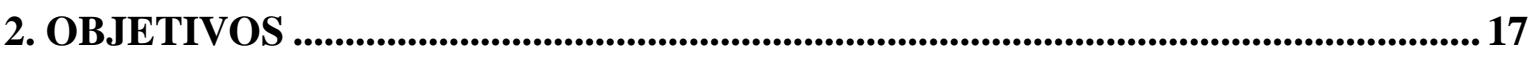

3. MATERIAIS E MÉTODOS .......................................................................................... 18

3.1 REAGENTES E SOLUÇÕES ................................................................................... 18

3.2 INSTRUMENTAÇÃO ............................................................................................. 19

3.3 PARTE EXPERIMENTAL ......................................................................................... 20

3.3.1 Limpeza dos substratos .......................................................................................... 20

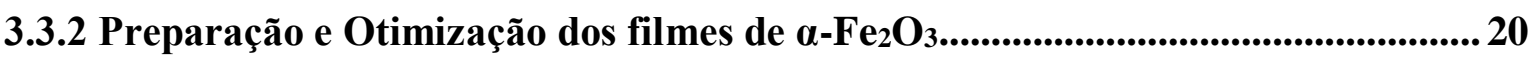

3.3.3 Dopagem do filme de $\alpha-\mathrm{Fe}_{2} \mathrm{O}_{3} \mathrm{com} \mathrm{Sn}$...................................................................... 21

3.3.4 Deposição de $\mathrm{NiOOH}$ em filmes de $\alpha$ - $\mathrm{Fe}_{2} \mathrm{O}_{3}$ e $\alpha$ - $\mathrm{Fe}_{2} \mathrm{O}_{3} / \mathrm{Sn}$-dopado........................ 22

3.3.5 Nanoestruturação do filme de $\alpha-\mathrm{Fe}_{2} \mathrm{O}_{3}$ pela modificação do substrato FTO com ATO 22

3.3.6 Caracterização Física ..................................................................................................... 23

3.3.7 Caracterização Eletroquímica e Fotoeletroquímica...................................................23

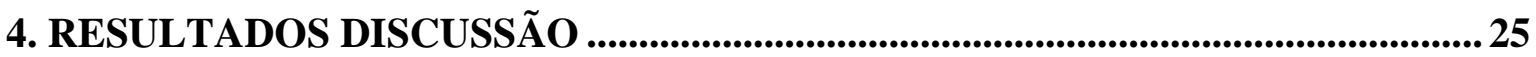

4.1 PARTE A: ESTUDO DOS PARÂMETROS DE SÍNTESE DOS FILMES DE

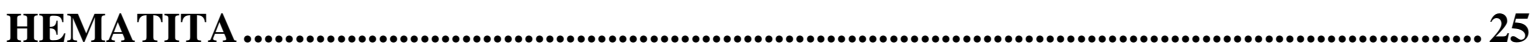

4.2.1 Obtenção dos filmes de hematita................................................................................. 25

4.1.2 Otimização dos parâmetros de síntese..........................................................................2 27

4.1.2.1 Efeito da temperatura de tratamento térmico ............................................................. 27 
4.1.2.1.1 Caracterização Fúsica ...................................................................................27

4.1.2.1.2 Caracterização Fotoeletroquímica ........................................................... 31

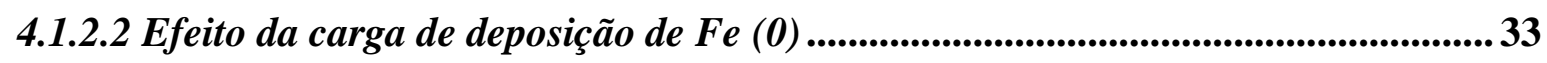

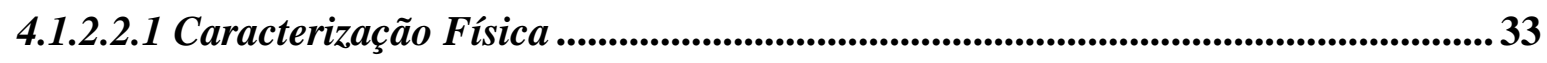

4.1.2.2.2 Caracterização Fotoeletroquímica ..................................................................... 37

4.2 PARTE B: ESTUDO DA MODIFICAÇÃO SUPERFICIAL PELA DOPAGEM COM Sn E DEPOSIÇÃ̃ DE NiOOH............................................................................ 39

4.2.1 Estudo da dopagem com diferentes quantidades de $\mathrm{Sn}$....................................39

4.2.1.1 Caracterização Física ..............................................................................................39

4.2.1.1 Caracterização Eletroquímica e Fotoeletroquímica ...........................................43

4.2.2.1 Otimização da carga NiOOH depositado ...................................................50

4.3 PARTE C: ESTUDO DO EFEITO DA NANOESTRUTURAÇÃO DE FILMES DE

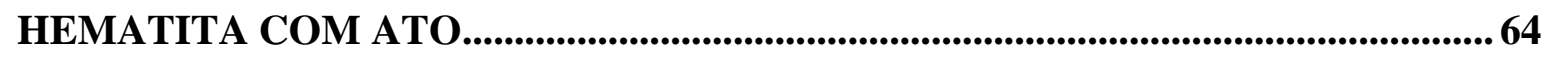

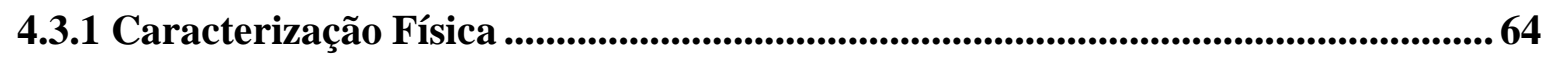

4.3.1 Caracterização Eletroquímica e Fotoeletroquímica.............................................. 68

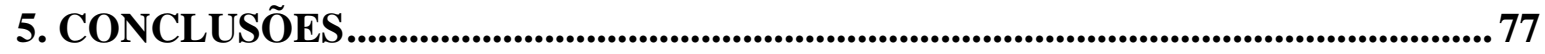

6. REFERÊNCIAS BIBLIOGRÁFICAS ....................................................................... 79

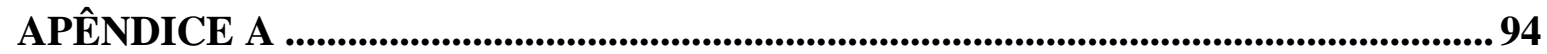

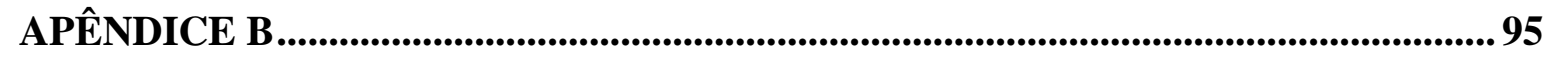

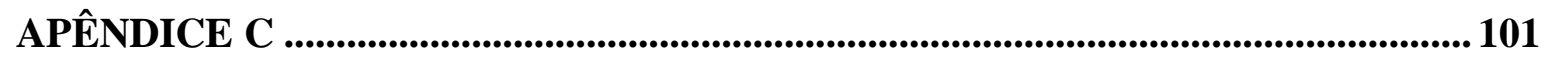

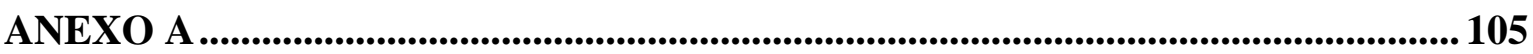




\section{INTRODUÇÃO}

\subsection{CONSIDERAÇÕES INICIAIS}

Desde os últimos séculos, o desenvolvimento econômico e rápido crescimento populacional, cerca de 7,7 bilhões de pessoas em 2019, tem estimulado um expressivo aumento do consumo energético [1]. Segundo o relatório da U.S. Energy Information Administration de 2019, cerca de $85 \%$ da matriz energética mundial é proveniente de fontes de energia não renovável, como o petróleo, carvão e gás natural [2]. O aumento dos impactos ambientais e sociais em consequência da extensiva utilização destes combustíveis, principalmente correlacionados com o aumento das emissões de gases do efeito estufa, em conjunto com a diminuição das reservas fósseis são fatores que evidenciam a necessidade de desenvolvimento de tecnologias de produção e armazenamento de energia à partir de fontes mais eficientes, limpas e sustentáveis [3,4]. A utilização das fontes energéticas renováveis, como eólica, hidráulica, geotérmica, marés e solar, apresenta vantagens que abrangem diversas vertentes da sustentabilidade, transcendendo a redução significativa dos impactos ambientais. O fácil acesso à energia limpa e segura pode permitir melhor qualidade de vida e a independência energética de países em desenvolvimento [5].

Dentre as fontes de energia sustentável, o sol é considerado a mais promissora para o futuro devido ao seu elevado potencial energético, alta disponibilidade e abundância. A energia solar irradiada na superfície terrestre equivale a $1,3 \times 10^{5} \mathrm{TW}$ de potência sendo superior em

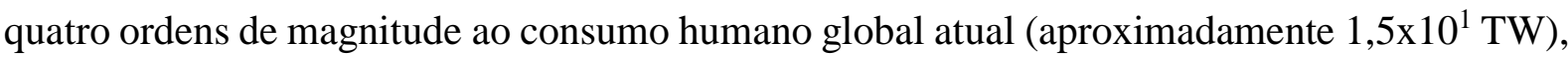
podendo assim ser suficiente para atender a demanda energética mundial [6,7]. Entretanto, o aproveitamento do elevado potencial do sol é limitado por consequência da inconstância nas coletas energéticas, tornando assim o armazenamento de energia fundamental para melhorar a utilização desta fonte e controlar as diferenças na produção e consumo, melhorando a distribuição e o transporte da energia gerada [8,9]. A energia solar radiante pode ser convertida diretamente em energia elétrica através do emprego de dispositivos denominados células fotovoltaicas. $\mathrm{O}$ armazenamento de energia solar pode ser feito através da conversão da mesma em energia química, na forma de ligações químicas em combustíveis, como em gás hidrogênio $\left(\mathrm{H}_{2}\right)[8]$.

$\mathrm{O}$ gás hidrogênio $\left(\mathrm{H}_{2}\right)$ é considerado um promissor combustível alternativo para os combustíveis fósseis devido a sua alta densidade energética $\left(143 \mathrm{MJ} \mathrm{kg}^{-1}\right)$ e principalmente às 
características renováveis, tendo em vista que sua combustão resulta apenas em água pura, podendo ser aplicados em células a combustível para a geração de energia elétrica de maneira eficaz e limpa [4,9]. O gás hidrogênio pode ser obtido a partir do processo de Water Splitting, que se baseia na quebra das ligações da molécula de água para formar $\mathrm{H}_{2}$ e gás oxigênio $\left(\mathrm{O}_{2}\right)$ (Equação 1) por intermédio do fornecimento de $237,2 \mathrm{~kJ} \mathrm{~mol}^{-1}$ de energia ou 1,23V vs. ERH por elétron transferido, sem emissão de poluentes para a atmosfera [10, 11].

$$
2 \mathrm{H}_{2} \mathrm{O}_{(l)} \rightarrow 2 \mathrm{H}_{2(g)}+\mathrm{O}_{2(g)}
$$

A utilização do grande potencial energético solar para a obtenção de $\mathrm{H}_{2}$ através do Water Splitting se apresenta como uma importante estratégia para alcançar a sustentabilidade energética [12]. Dentre os diversos meios de converter a energia solar em gás hidrogênio, destaca-se o baseado no emprego de células fotoeletroquímicas (PEC) [3]. Estes dispositivos são considerados uma alternativa, limpa e economicamente viável, para armazenar energia solar, pois utilizam fotoeletrodos de semicondutores, principalmente como fotoanodos, capazes de captar e converter energia solar em energia química, com a produção de $\mathrm{O}_{2}$ no fotoanodo e de $\mathrm{H}_{2}$ no catodo, mimetizando o processo de fotossíntese natural [12,13].

\subsection{SEMICONDUTORES}

O semicondutor é o principal componente de um dispositivo fotoeletroquímico pois os processos que envolvem a conversão de energia solar em energia química dependem da capacidade de absorção de luz, geração e transporte de portadores de carga desse material [7]. Deste modo, para o entendimento das propriedades PEC e os desafios que envolvem o alcance de elevada eficiência nestes dispositivos, é de extrema importância o entendimento das propriedades optoeletrônicas dos semicondutores.

Os materiais sólidos podem ser classificados como condutores, semicondutores e isolantes em função de suas propriedades elétricas tendo em vista que o comportamento elétrico dos materiais é consequência do arranjo das estruturas das bandas eletrônicas e distribuição dos elétrons [14]. Os materiais semicondutores são aqueles que apresentam uma faixa de diferença de energia entre a banda de valência (BV) e banda de condução (BC) com energia $<4 \mathrm{eV}$ [15]. Esta faixa de energia na qual não há estados permitidos é denominada energia de band gap $\left(E_{g}\right)$ [16]. Devido a esta diferença de energia, quando $\mathrm{T}=0 \mathrm{~K}$ estes materiais atuam como isolantes, pois os elétrons ocupam os estados de menor energia e os estados de maior energia estão vazios [14]. O estabelecimento de condutividade elétrica nos semicondutores é feita a partir do 
fornecimento de energia térmica ou radiante com magnitude igual ou superior ao seu band gap, os elétrons da BV são excitados para a BC, promovendo a formação de buracos positivamente carregados na BV ( ou estados com alto potencial) e a injeção de elétrons na BC, sendo que, a mobilidade dos portadores de cargas gerados estabelece a condutividade elétrica no material $[14,17]$.

A condutividade elétrica de materiais semicondutores pode ser elevada pela incorporação de impurezas em sua rede cristalina, dependendo da natureza do átomo incorporado podem ser classificados em semicondutores tipo $n$ e tipo $p$ [16]. Caso a substituição seja feita por átomos doadores de elétrons, ou seja, com um número de elétrons maior que o átomo do material, o material adquire um excesso de elétrons que apresentam níveis de energia próximos à $\mathrm{BC}$, sendo necessário menor energia para promovê-los [14,18]. Estes materiais semicondutores são denominados extrínsecos tipo $\mathrm{n}$, e o transporte de carga é feito majoritariamente por elétrons. É válido ressaltar que semicondutores de óxidos metálicos, são propensos a ser do tipo n não devido a presença de impurezas (a $0 \mathrm{~K}$ ) em sua rede cristalina, mas pela alta densidade de defeitos que está associada com a formação dos mesmos [17]. No entanto, se o átomo substituinte da rede cristalina é aceptor de elétrons, buracos são formados na BC com níveis de energia próximos a BV $[14,18]$. Assim, os portadores de carga majoritários são os buracos, e os semicondutores são denominados semicondutores extrínsecos tipo p [17,18]. Como pode ser observado na Figura 1, a posição do nível de Fermi é deslocada em função do tipo de dopagem. Em semicondutores tipo n, o nível de Fermi se encontra próximo a banda de condução (Figura 1a) e em semicondutores tipo p próximo a banda de valência (Figura 1b).

Figura 1- Representação esquemática de um diagrama de bandas para semicondutores extrínsecos do tipo n (a) e tipo $\mathrm{p}(\mathrm{b})$.
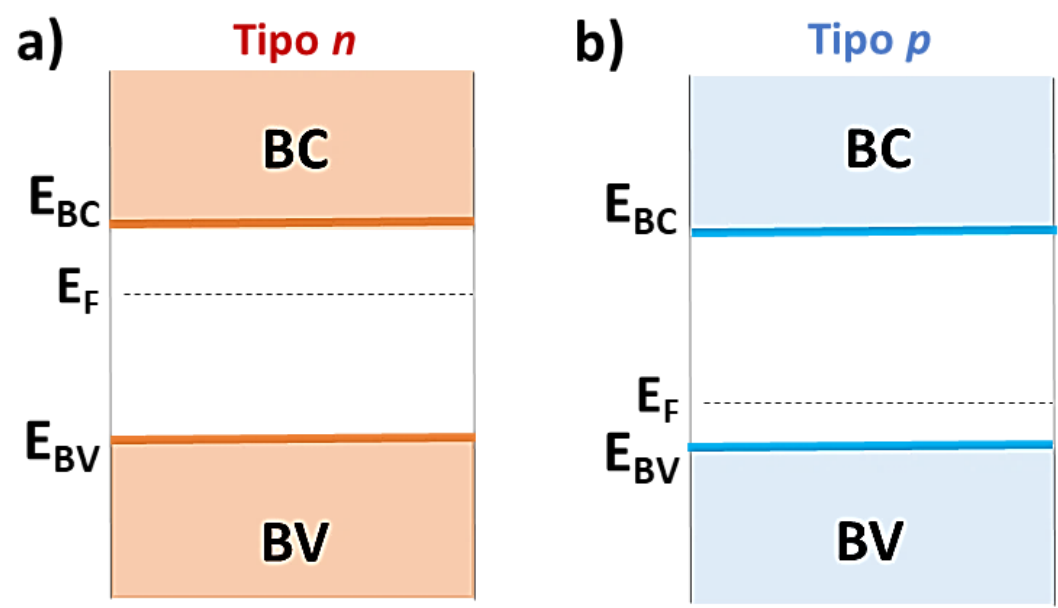

Fonte: Baseado em Baccaro \& Gutz, 2018 [14]. 
Os semicondutores do tipo $\mathrm{n}$ podem ser utilizados como fotoanodos para células fotoeletroquímicas, pois os buracos deixados na BV, após a foto-excitação dos elétrons, podem migrar para a superfície deste material e promover reações de oxidação de espécies cujo orbital de maior energia desocupado (HOMO) apresenta energia superior a banda de valência do semicondutor [18]. Já os semicondutores tipo p, podem ser utilizados como fotocatodos devido aos elétrons fotogerados que migram para a superfície para promover a redução de qualquer espécie que possua o orbital LUMO abaixo da energia da banda de condução $[3,19]$.

\subsubsection{Junção semicondutor-eletrólito}

O entendimento do processo de transferência de carga na interface semicondutoreletrólito é fundamental para melhorar a eficiência de conversão de energia em dispositivos fotoeletroquímicos. Quando um eletrodo semicondutor é imerso em um eletrólito espontaneamente é formada uma heterojunção [20]. O potencial eletroquímico dos portadores de carga dos semicondutores é associado ao nível de Fermi, e o potencial químico no eletrólito, o dado pelo potencial do par redox em solução [17]. Nesta interface estabelece-se o fluxo de cargas, levando à formação de um campo elétrico interfacial que equilibra a diferença de potencial eletroquímico existente entre as fases [17]. A transferência dos portadores majoritários na interface altera localmente a energia de equilíbrio do semicondutor, levando ao dobramento nas energias de borda das bandas do semicondutor (band bending) [20]. A região na qual a banda está dobrada é denominada zona de depleção e é caracterizada pelo acúmulo de portadores de cargas minoritários [7].

No caso dos semicondutores tipo n, antes do equilíbrio o nível de Fermi encontra-se próximo da banda de condução (Figura 2a). A transferência dos portadores de cargas majoritários (elétrons) na junção semicondutor-eletrólito, causa o band bending (Figura 2b) e, assim, ocorrendo o acúmulo de cargas positivas (buracos) na zona de depleção do semicondutor (região designada por W) [21]. Em consequência desse acúmulo de buracos, na camada de Helmholtz próxima ao eletrodo há um excesso de espécies com cargas negativas estabelecendo um gradiente de potencial que auxilia na separação dos transportadores de carga $[7,20]$. 
Figura 2- Junção semicondutor-eletrólito em um semicondutor tipo n como fotoanodo: (a) condição de préequilíbrio, (b) pós equilíbrio no escuro e (c) pós equilíbrio no claro (baixa potência luminosa).

a) Pré-Equilíbrio

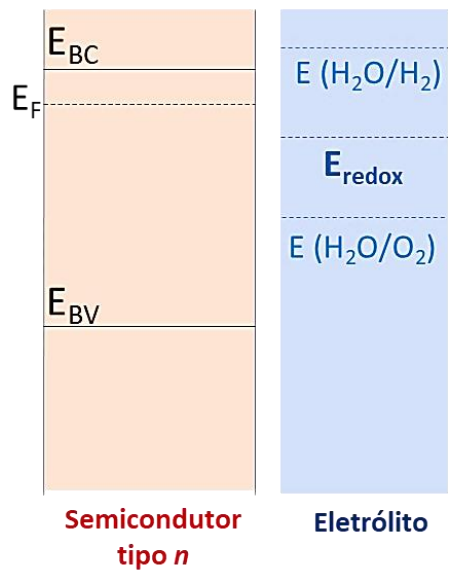

b) Equilíbrio no Escuro

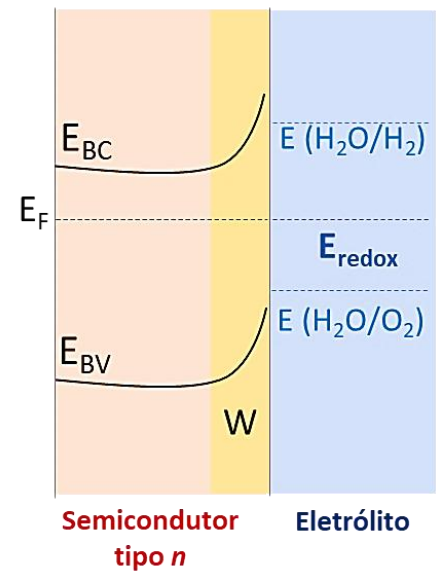

c) lluminado

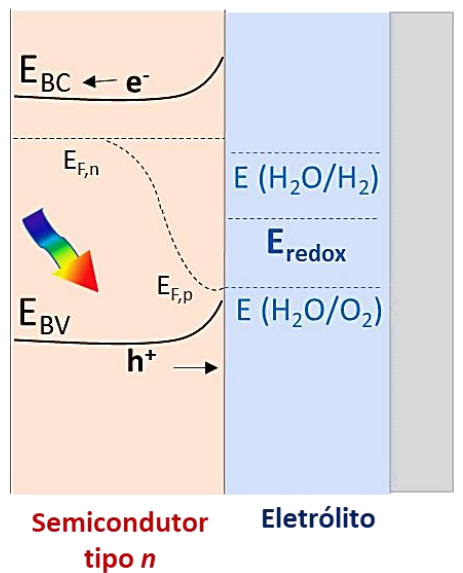

Fonte: Adaptado de Tamirat et al., $2016\left[{ }^{7}\right]$.

$\mathrm{O}$ processo de band bending dos semicondutores pode ser induzido através da aplicação de um potencial externo entre o eletrodo de trabalho (semicondutor) e o eletrodo de referência [22]. Quando um potencial externo é aplicado, o nível de Fermi do semicondutor bem como as energias das bandas irão variar em função desse potencial [20]. A um determinado potencial aplicado, o potencial de banda plana $\left(E_{f b}\right)$, a diferença de potencial entre a superfície e o bulk do eletrodo vai a zero, e assim não há mais a região de depleção, excesso de carga, e consequentemente campo elétrico [7]. A aplicação de qualquer potencial mais positivo que o potencial de banda plana, em um semicondutor tipo n, aumentará a flexão de bandas no eletrodo direcionando os buracos para a superfície [22].

A absorção de luz no semicondutor resulta na criação de pares dos transportadores de carga gerados tanto na zona de depleção quanto no bulk do fotoeletrodo [12,20]. O campo elétrico na zona de depleção induz a separação dos pares formados, direcionando os buracos para o eletrólito e os elétrons para o contra eletrodo através de um circuito externo. Grande parte dos portadores de cargas gerados no bulk do eletrodo se recombinam, porém uma fração desses portadores conseguem ser transportados pela zona de depleção, chegar na superfície e participar do processo redox [20]. Com a absorção de luz, o equilíbrio entre o semicondutor e eletrólito é perturbado e o nível de Fermi do semicondutor é dividido em dois quase níveis de Fermi um referente aos elétrons $\left(E_{F, n}\right)$ e um referente aos buracos $\left(E_{F, p}\right)$ (Figura 2c) [23]. O gradiente de níveis de Fermi resulta no desenvolvimento de um campo elétrico na superfície do semicondutor e consequentemente de uma fotovoltagem $\left(V_{\mathrm{OC}}\right)$ que, experimentalmente, é a 
diferença de potencial de circuito aberto na presença e na ausência de iluminação do semicondutor [17].

\subsection{DISPOSITIVOS FOTOELETROQUÍMICOS}

A introdução do Water Splitting fotoeletroquímico para a produção de gás hidrogênio ocorreu na década de 70 através da publicação do trabalho de Fujishima e Honda na Nature [24]. Desde então, tem se investigado o desenvolvimento, aperfeiçoamento de materiais semicondutores a fim de melhorar o desempenho de células fotoeletroquímicas e assim viabilizar a aplicação dessa tecnologia. Existem diferentes configurações de células fotoeletroquímicas, em sua configuração mais simples é constituída basicamente de três eletrodos: um eletrodo de trabalho, que pode ser constituído de um material semicondutor ou material fotoativo, um contra-eletrodo metálico ou semicondutor, e um eletrodo de referência, conectados por um circuito externo e imersos em eletrólito contendo um par redox [17,25]. Na Figura 3, está ilustrada uma célula fotoeletroquímica construída a partir de um semicondutor tipo n (fotoanodo), no qual ocorre a reação de oxidação da água e formação de $\mathrm{O}_{2}$, conectado a um contra-eletrodo metálico (catodo), no qual a água é reduzida a $\mathrm{H}_{2}$.

Figura 3- Ilustração de uma célula fotoeletroquímica contendo um eletrodo de trabalho semicondutor tipo n e um contra eletrodo metálico.

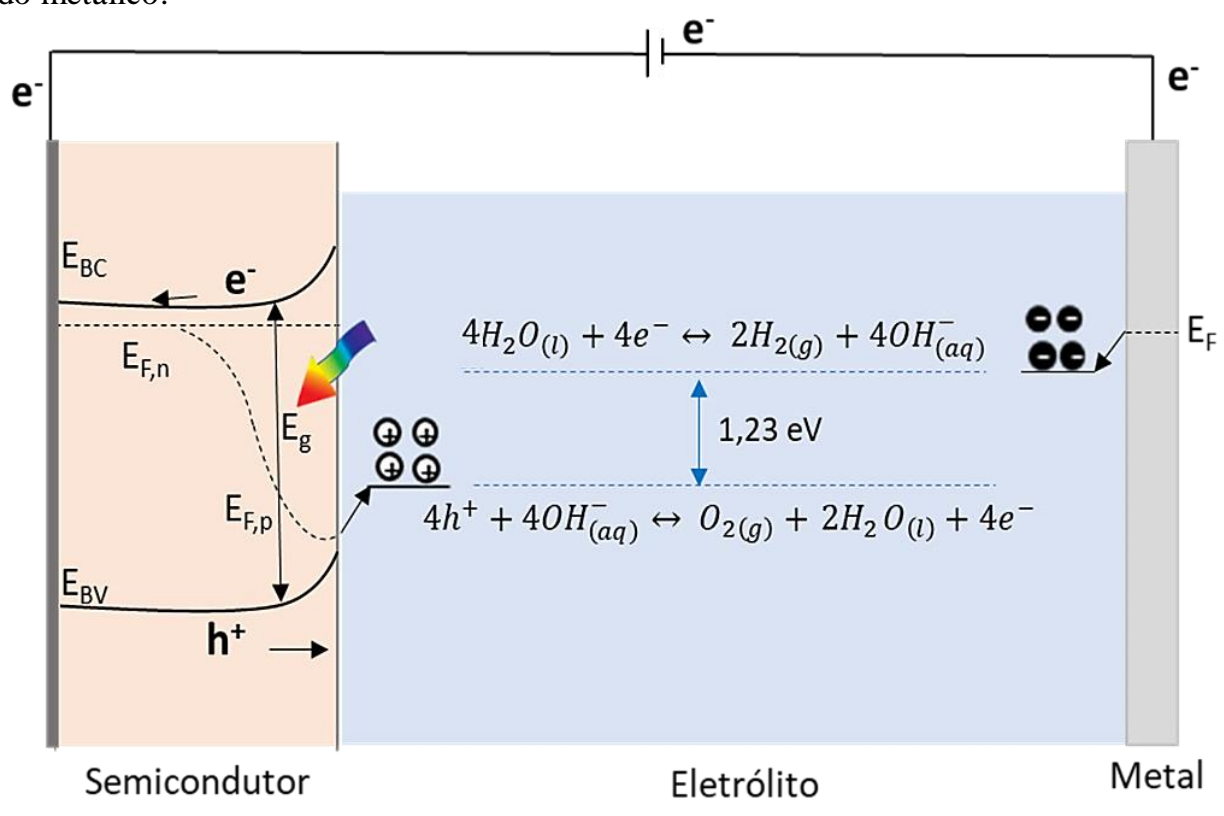

Fonte: Adaptado de Jiang et al 2017 [17].

Nessa ilustração, o processo fotoeletroquímico de Water Splitting pode ser resumido em três etapas físico-químicas principais: a absorção de luz pelo semicondutor, separação e 
transporte de cargas e reações redox na superfície [17]. Para o caso de um fotoanodo, na primeira etapa, o semicondutor absorve os fótons com energia maior que a energia de seu band gap, excitando os elétrons ( $\left.\mathrm{e}^{-}\right)$para a banda de condução (BC) deixando buracos $\left(\mathrm{h}^{+}\right)$na banda de valência (BV) (Equação 2) [26].

$$
S C+4 h v \rightarrow 4 h^{+}+4 e^{-}
$$

Equação (2)

A segunda etapa consiste na separação e migração dos pares fotogerados. Os buracos carregados positivamente são direcionados à interface semicondutor/eletrólito e oxidam a água ou íons hidroxila, dependendo de $\mathrm{pH}$ da solução, produzindo $\mathrm{O}_{2}$. Os elétrons fotogerados são direcionados para o cátodo através do circuito externo, enquanto íons $\mathrm{H}^{+}$gerados a partir da oxidação da água se difundem através do eletrólito para o catodo [3,27]. As Equações 3 e 4 mostram as reações que ocorrem no fotoanodo e no catodo em eletrólito alcalino.

$$
\begin{aligned}
& 4 \mathrm{OH}_{(a q)}^{-}+4 h^{+} \rightarrow \mathrm{O}_{2(g)}+2 \mathrm{H}_{2} \mathrm{O}_{(l)}+4 e^{-} \\
& 4 \mathrm{H}_{2} \mathrm{O}_{(l)}+4 e^{-} \rightarrow 2 \mathrm{H}_{2(g)}+4 O H_{(a q)}^{-}
\end{aligned}
$$

Equação (3)

Equação (4)

A semi-reação de oxidação dos íons $\mathrm{OH}^{-}$ou da água requer múltiplas etapas de transferência de elétron e de prótons para a formação das ligações sigma e pi da molécula de oxigênio $\left(\mathrm{O}_{2}\right)$, resultando em uma cinética lenta [6,28]. A reação de evolução de oxigênio (REO) se apresenta como etapa limitante na sua aplicação em sistemas de conversão de energia, implicando em um elevado sobrepotencial $(\eta)$ experimental [28]. A combinação destes fatores resultam no favorecimento de recombinação das cargas fotogeradas na interface semicondutoreletrólito e, consequentemente, na diminuição da eficiência da célula PEC [27]. Deste modo, a busca por materiais semicondutores que apresentem elevada atividade, estabilidade em meios oxidantes e isentos recombinação de cargas, tem sido cada vez mais evidenciada para superar a barreira de energia correspondente a reação de REO e, assim, alcançar maior eficiência na conversão de energia.

\subsection{FOTOELETROCATALISADORES PARA A REO}

A escolha dos materiais semicondutores ideais para fotoanodos aplicados na reação de evolução de oxigênio é baseada principalmente na posição de bandas destes materiais visto que, para sua utilização, a energia da banda de valência (energia do nível de Fermi do buraco) do 
semicondutor deve ter um valor de potencial acima do potencial de oxidação da água $(1,23 \mathrm{~V})$ [3]. Deste modo, para que a fotoeletrólise em células fotoeletroquímicas ocorra com elevada eficiência, os semicondutores devem atender alguns requisitos [3,7], como:

i) Energia de band gap e posição de bandas adequadas;

ii) Eficiente separação e transporte dos portadores de carga;

iii) Rápida cinética de transferência de carga na interface semicondutor-eletrólito;

iv) Resistência à corrosão e fotocorrosão.

Além dos requisitos apresentados acima, é importante que estes materiais sejam atóxicos, de baixo custo e constituídos de materiais abundantes [29]. Nos últimos anos, diversos materiais fotoativos com posições de bandas adequadas para promover a reação de evolução de oxigênio foram empregados como fotoanodos em células PEC, podendo ser citados: trióxido de tungstênio $\left(\mathrm{WO}_{3}\right)$ [30], vanadato de bismuto $\left(\mathrm{BiVO}_{4}\right)$ [31,32], dióxido de titânio $\left(\mathrm{TiO}_{2}\right)$ [33], nitreto de tântalo $\left(\mathrm{Ta}_{3} \mathrm{~N}_{5}\right)$ [34] e oxinitreto de tântalo $\left.(\mathrm{TaON}){ }^{35}\right]$. A Figura 4 ilustra o diagrama de bandas e energia de band gap de diferentes semicondutores, juntamente com o potencial de oxidação e redução da água [7].

Figura 4- Posições de band gap de semicondutores em contato com o eletrólito aquoso em pH = 0 em relação ao Eletrodo Padrão de Hidrogênio EPH.

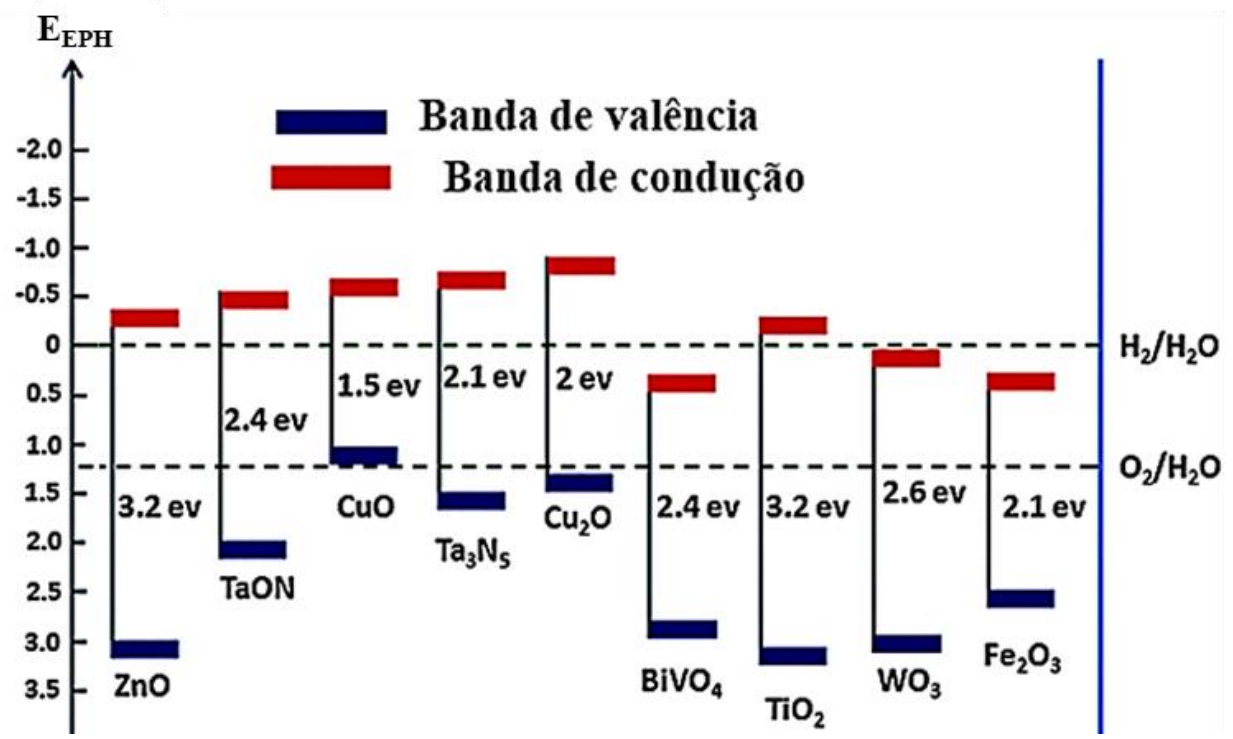

Fonte: Adaptado de Tamirat et al 2016 [7]

Apesar destes materiais apresentarem grande potencial para a REO diversos fatores limitam sua performance PEC [36]. $\mathrm{O} \mathrm{TiO}_{2}$ possui band gap elevado, sendo ineficiente para absorver na região do visível correspondente à maior faixa do espectro solar [33]. Já o $\mathrm{WO}_{3} \mathrm{e}$ o $\mathrm{BiVO}_{4}$ apesar de apresentarem band gap capaz de absorver na região do visível, são estáveis 
somente em domínios específicos de $\mathrm{pH}$ (ácido e neutro, respectivamente) [31,37]. Os materiais baseados em oxinitretos e nitretos possuem posição de banda adequada tanto para realizar reações de redução e quanto de oxidação da água, no entanto as eficiências de conversão estudadas ainda são muito baixas [35]. Comparado a estes materiais, a hematita $\left(\alpha-\mathrm{Fe}_{2} \mathrm{O}_{3}\right)$ é considerada promissora para aplicação como fotoanodo no splitting da água devido sua estabilidade em eletrólito alcalino, atoxicidade, baixo custo, abundância e, principalmente, ao seu band gap $\left(\mathrm{E}_{\mathrm{g}} \sim 2,1 \mathrm{eV}\right)$, que permite absorção em uma ampla faixa de absorção na região do visível, [7,26].

\subsubsection{Hematita}

A hematita $\left(\alpha-\mathrm{Fe}_{2} \mathrm{O}_{3}\right)$ é a forma mais termodinamicamente estável do óxido de ferro, em condições normais de temperatura e pressão [38]. A hematita possui arranjo cristalográfico romboédrico (tipo coríndon), com ânions $\mathrm{O}_{2}$ - dispostos em um retículo hexagonal ao longo da direção [001] e cátions $\mathrm{Fe}^{+3}$ que ocupam dois terços dos interstícios octaédricos nos planos basais $(001)$ [38,39]. A hematita apresenta parâmetros de rede $\mathrm{a}=\mathrm{b}=0,5034 \mathrm{~nm} \mathrm{e} \mathrm{c}=1,374$ nm [40]. A célula unitária da hematita é composta de pares de octaedros que compartilham uma das faces formando dímeros de $\mathrm{Fe}_{2} \mathrm{O}_{9}$ ao longo da direção [001] [40,41], como mostrado na Figura 5. A proximidade dos átomos $\mathrm{Fe}^{+3}$ nos dímeros levam a distorção do octaedro devido as repulsões eletrostáticas, e essa distorção reflete nas propriedades ópticas e elétricas deste material [27]. As vacâncias de oxigênio existentes no bulk da hematita a tornam um semicondutor tipo $\mathrm{n}$, podendo assim ser aplicada para a reação de fotoeletroxidação da água [41].

Figura 5- Célula unitária da hematita (esquerda) e dímeros $\mathrm{Fe}_{2} \mathrm{O}_{9}$ (à direita). Nos dímeros estão representadas as ligações longas (vermelho) e as ligações curtas (marrom).

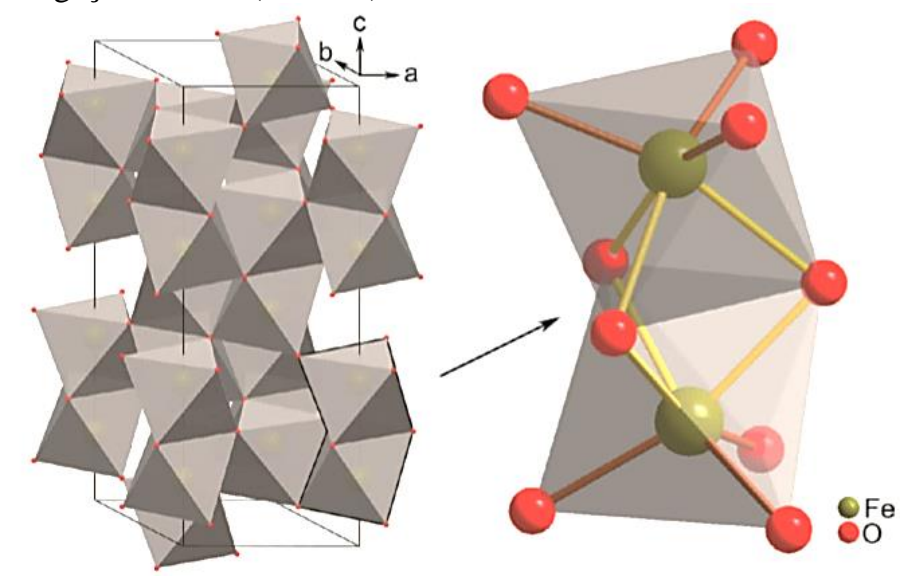

Fonte: Sivula et al., 2010 [40]. 
A hematita inicia a absorção de fótons na região do infravermelho próximo e se estende até a região do ultravioleta (UV), o que atribui a este material a coloração levemente avermelhada [38]. O espectro de absorção da hematita é resultado de três tipos de transições eletrônicas: (i) transições de campo ligante (d-d), (ii) transferência de carga do ligante para o metal $\left(\mathrm{Fe}^{+3}-\mathrm{O}\right)$ ou metal-metal $\left(\mathrm{Fe}^{+2}-\mathrm{Fe}^{+3}\right)$ e (iii) excitação dos pares resultante da excitação de dois cátion $\mathrm{Fe}^{+3}$ que ocupam sítios adjacentes [7,15]. As transições que envolvem transferência de carga que envolvem $\mathrm{Fe}^{+3}-\mathrm{O}$ e $\mathrm{Fe}^{+2}-\mathrm{Fe}^{+3}$ são os principais responsáveis para a absorção de luz na região do visível [15]. A hematita possui transições eletrônicas diretas, que correspondem às transições entre o orbital antiligante $2 \mathrm{p}$ do $\mathrm{O}$ e o orbital $3 \mathrm{~d}$ do $\mathrm{Fe}^{+3}$, observado em aproximadamente $400 \mathrm{~nm}$, e transições indiretas que correspondente a banda de absorção observada em torno de $590 \mathrm{~nm}$, e são atribuídas as transições eletrônicas entre os orbitais d-d do $\mathrm{Fe}^{+3}$ da BV e BC [27,42]. Em materiais semicondutores, a energia de band gap é importante para entendimento da performance como fotoanodo em sistemas PEC, já que não é possível o estabelecimento de condutividade elétrica no material, através excitação dos elétrons da BV, se o material é irradiado com energia menor que seu band gap. A energia de band gap reportada para a hematita se encontra entre 1,9 e 2,2 eV que corresponde a absorção na faixa 650 a 590 $\mathrm{nm}[43]$.

\subsubsection{Métodos de síntese da $\alpha-\mathrm{Fe}_{2} \mathrm{O}_{3}$}

O método de preparação do material semicondutor influencia diretamente em sua energia de band gap e propriedades PEC. A hematita é comumente sintetizada na forma de filmes sobre substratos constituídos de camadas de óxido de estanho dopado com flúor (FTO) e óxido de estanho dopado com índio (ITO), para serem aplicados na fotoeletrólise da água.

Diversos métodos podem ser utilizados para a fabricação de desses filmes como os métodos de spray pirólise [44], atomic layer deposition (ALD) [45], hidrotermal [46,47], deposição química na fase vapor a pressão atmosférica (APCDV) [48] e eletrodeposição [49,50].

Em comparação aos métodos citados, a deposição eletroquímica se apresenta como uma alternativa mais simples, barata e prática para a produção dos filmes, podendo ser aplicada para diferentes tipos e tamanhos de substratos. Além disso, controlando os parâmetros de deposição como o potencial aplicado e concentração de precursores, é possível controlar a morfologia da superfície, a espessura do filme e as propriedades físico-químicas do material 
[51,52]. A síntese eletroquímica de filmes de hematita é feita geralmente pela deposição anódica de filmes de $\mathrm{FeOOH}$ amorfo e/ou deposição catódica de filmes de $\mathrm{FeOOH}$ ou de $\mathrm{Fe}$ metálico [51]. Em ambos os métodos citados, após a eletrodeposição, os filmes são submetidos a tratamento térmico para conversão em hematita [49]. A síntese de filmes de hematita via eletrodeposição de Fe permite maior controle do processo de deposição quando comparado com o método anódico (deposição de $\mathrm{FeOOH}$ ), tendo em vista que este processo de deposição é direto enquanto o processo anódico se dá por meio da oxidação de íons $\mathrm{Fe}^{+2}$ seguido de precipitação no substrato [49,51].

Kimmich e colaboradores, compararam os métodos de eletrodeposição anódico e catódico em função das atividades fotoeletroquímicas dos filmes de hematita. O filme preparado por deposição catódica apresentou propriedades fotoeletroquímicas superiores ao filme preparado por deposição anódica, atribuída principalmente pela maior capacidade de espalhamento "scattering" da luz irradiada sob este filme devido a sua morfologia constituída de aglomerado de nanopartículas esféricas [53].

Apesar das vantagens de utilização dos métodos eletroquímicos de preparação de filmes de hematita, as densidades de fotocorrentes alcançadas por estes filmes ainda são menores que filmes preparados por outros métodos, como o hidrotermal como pode ser observado na Tabela 1 (Anexo A). Assim, o estudo de métodos de preparação de filmes de hematita a partir da síntese eletroquímica é de extrema importância tendo em vista que este método apresenta menor tempo de preparação e maior facilidade de preparação em maior escala em comparação aos demais métodos.

\subsection{DESAFIOS E PERSPECTIVAS DA APLICAÇÃO DA $\alpha$-Fe $\mathrm{F}_{2} \mathrm{O}_{3}$ EM PEC}

Como mencionado anteriormente, o grande interesse na aplicação da hematita como material para fotoanodos para a oxidação da água está associado ao seu band gap, que possibilita absorção espectral na região do visível e permite alcançar $15 \%$ teórica de conversão de energia solar a gás hidrogênio (Solar to Hydrogen - STH) [27,39]. Esta eficiência teórica de conversão equivale a $12,5 \mathrm{~mA} \mathrm{~cm}^{-2}$ de densidade de fotocorrente e potencial de onset igual ao potencial de flat band (0,4 a 0,6 vs ERH), como demonstrado na Figura 6 [39]. No entanto, a performance teórica desse material ainda não foi alcançada devido ao baixo tempo de vida dos portadores de cargas, pequeno comprimento de difusão de buracos (2-4 nm), baixa condutividade elétrica $\left(10^{-14} \Omega^{-1} \mathrm{~cm}^{-1}\right)$ e lenta cinética de transferência de carga na interface eletrodo/eletrólito que resultam na recombinação das cargas fotogeradas no bulk, na superfície 
e na interface semicondutor-eletrólito [7,41]. A Figura 6 demonstra as estratégias que podem ser utilizadas para contornar as limitações da performance PEC de fotoanodos de hematita. O aumento do platô de fotocorrente pode ser alcançado a partir da nanoestruturação e/ou dopagem dos filmes, enquanto a melhora do potencial de onset para a REO pode ser feita através modificações superficiais $[27,41,39]$.

Figura 6- Performance fotoeletroquímica de um fotoanodo de hematita ideal alcançado por meio da combinação de controle morfológico e/ou dopagem e modificação da superfície do semicondutor.

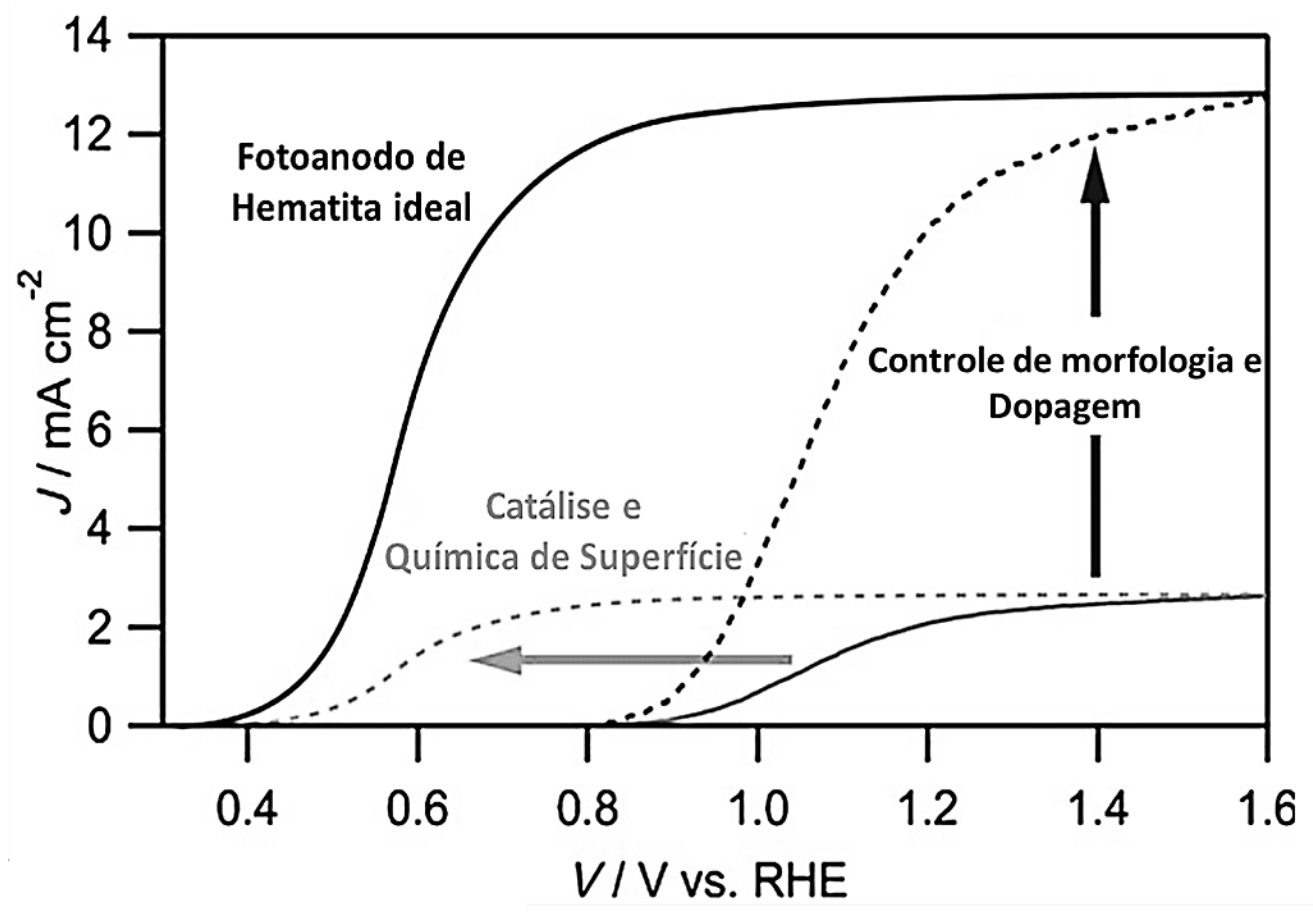

Fonte: Adaptado de Sivula et al., 2011 [39].

\subsubsection{Estratégias para a modificação do bulk da $\alpha$-Fe $\mathrm{F}_{2} \mathrm{O}_{3}$}

Nos últimos anos, diversos avanços foram feitos para a síntese de filmes de hematita nanoestruturados, em diversas morfologias, como nanopartículas, nanotubos, nanobastões e nanofios, pois estas morfologias proporcionam maior interface semicondutor-eletrólito e diminuição do comprimento de difusão de $\mathrm{h}^{+}$até a superfície do eletrodo, apresentando melhor separação de carga no bulk do semicondutor [7,41,54]. Uma estratégia para a nanoestruturação destes filmes é a formação de nanoestruturas nos próprios substratos condutores previamente a deposição dos filmes de hematita, a fim de melhorar a área superficial para absorção de fótons e a transferência de carga $[38,55]$. Yang e colaboradores compararam a performance PEC de fotoanodos de hematita preparados em ITO planar (diretamente sobre a placa) e sobre nanofios 
de ITO. O filme de hematita sobre o substrato nanoestruturado apresentou melhor performance PEC, atribuído à menor resistência na interface substrato-hematita e maior eficiência de coleta das cargas fotogeradas [56]. Francisco et al. também observaram melhora na resposta PEC dos fotoanodos de hematita preparados sobre substrato funcionalizado com template de $\mathrm{SiO}_{2}-\mathrm{TiO}_{2}$, a melhora foi atribuída a diminuição da taxa de recombinação de cargas no bulk do fotoanodo, tanto pela nanoestruturação quanto pela dopagem com titânio [57].

Além dos materiais citados, a modificação dos substratos foi realizada com quantum dots [58], grafeno [59], óxido de grafeno [60], óxido de alumínio [61], destacando-se os óxidos metálicos condutores como nanoestruturas de óxido de estanho e antimônio (ATO) devido a sua excelente condutividade e estabilidade em diferentes pH [38,62-65]. Peng e colaboradores verificaram que fotoanodos de óxido de titânio depositados sobre nanopartículas de ATO resultaram na formação de estruturas do tipo core-shell que favoreceram o transporte de elétrons do semicondutor para o substrato enquanto inibiram a recombinação de cargas [66]. Wang e colaboradores depositaram filmes de hematita por APCVD sobre nanopartículas de ATO e observaram aumento na densidade de fotocorrente de $0,3 \mathrm{~mA} \mathrm{~cm}^{-2}$ para $0,83 \mathrm{~mA} \mathrm{~cm}{ }^{-2}$ a 1,23 V (vs. ERH) [55]. É importante destacar que a nanoestruturação de filmes de hematitas preparados por eletrodeposição com modificação do substrato com óxidos metálicos ainda é pouco reportada na literatura, especialmente para filmes depositados catodicamente.

Apesar dos avanços relacionados a nanoestruturação dos filmes de hematita, a baixa mobilidade dos portadores de carga ainda é considerada um dos maiores obstáculos para a eficiência da oxidação da água PEC. Diversos autores [67-70] demonstraram que o processo de dopagem de fotoanodos nanoestruturados é benéfico para diferentes semicondutores pois pode promover aumento da densidade de portadores de carga (condutividade elétrica) e ainda auxiliar no transporte de buracos para a interface. A dopagem dos filmes de hematita com dopantes tipo $\mathrm{n}$ como $\mathrm{Ti}^{+4}, \mathrm{Sn}^{+4}$ e $\mathrm{Zr}^{+4}, \mathrm{Si}^{+4}$ tem sido amplamente investigada para contornar os problemas relacionados ao transporte de cargas e condutividade de fotoanodos de hematita $[71,72]$.

O Sn é um dos dopantes mais investigados para melhorar a performance de filmes de hematita [73-78]. O efeito do Sn nas propriedades PEC da hematita foi primeiramente reportado por Sivula et al. em 2010 [40], na qual a incorporação de Sn foi feita via difusão do substrato (FTO) para o filme de hematita (preparado por deposição de nanocristais coloidais) durante tratamento térmico a $800^{\circ} \mathrm{C}$. Xi e colaboradores [75] demonstraram que a dopagem de nanobastões de hematita com Sn, através do método químico, reduziu a recombinação dos pares 
na interface eletrodo-eletrólito, resultando em menor sobrepotencial para fotocorrente e melhorou a magnitude da fotocorrente.

Carvalho e Souza [73] observaram que a modificação com $\mathrm{Sn}^{+4}$ pode promover a formação de uma superfície mais hidrofílica favorecendo a reação química na interface semicondutor-eletrólito. $\mathrm{O}$ aumento da condutividade do filme, pelo aumento concentração de portadores de carga, e a alteração na absorção dos filmes de hematita são outros efeitos, descritos na literatura, que podem promovidos pela dopagem com Sn [76,77,79]. Visto as melhorias na performance PEC dos fotoanodos que podem ser alcançadas pela dopagem com Sn, é evidenciada a necessidade de estudar novos métodos de dopagem e o mecanismo do efeito do Sn nestes filmes, principalmente em filmes de hematita preparados por rota eletroquímica.

Geralmente, a dopagem de filmes de hematita é feita pós crescimento dos mesmos, através de métodos químicos como drop casting ou dip coating em soluções aquosas de $\mathrm{Sn}^{+4}$ por um determinado período $[75,80]$. A partir da aplicação destes métodos não é possível ter um controle prévio da quantidade de Sn que será incorporado no filme, pois as únicas variáveis que podem ser avaliadas são a concentração da solução e no caso do dip coating o tempo de imersão nesta solução. Além disso, já foi reportado que, dependendo da espessura da camada superficial dopada o efeito na resposta PEC pode ser maléfico, aumentando a taxa de recombinação superficial [75]. A utilização de métodos eletroquímicos para a modificação de filmes de hematita apresenta como característica a possibilidade de controle da carga de dopante a ser incorporada sobre o filme, podendo ser vantajoso para estudos sistemáticos da relação propriedades PEC-carga de dopante.

\subsubsection{Estratégias para modificação superficial da $\alpha-\mathrm{Fe}_{2} \mathrm{O}_{3}$}

A recombinação de cargas na superfície do semicondutor ocorre devido à alta densidade de estados superficiais $\left(10^{13}-10^{14} \mathrm{~cm}^{-2}\right)$ [81]. Os estados superficiais, que geralmente formam defeitos de mid-gap, ou seja, estados eletrônicos criados dentro da banda proibida (band gap), ocorrem devido a defeitos na rede cristalina do material $[81,82]$. Em fotoanodos, os estados superficiais podem atuar como mediadores de transferência das cargas fotogerados, porém também podem atuar como centros de recombinação das mesmas, competindo com a transferência de cargas na interface, já que os estados superficiais atuam como "armadilha" das cargas fotogeradas (Figura 7) [82,83]. Assim é de grande interesse, suprimir o efeito de recombinação destes estados superficiais a fim de melhorar a performance PEC. Existem diversas as estratégias que podem ser utilizadas para reduzir as recombinações superficiais, 
podendo ser citadas a dopagem, tratamento químico da superfície, modificação superficial com camadas passivadoras de óxidos metálicos e com eletrocatalisadores ativos para a REO $[41,71,84]$.

Figura 7-Comparação da estrutura de banda de um fotoanodo de semicondutor tipo na ausência e na presença de camadas passivadoras: (a) estados superficiais, (b) camada passivadora não-catalítica e (c) camada de catalisador ativo para REO
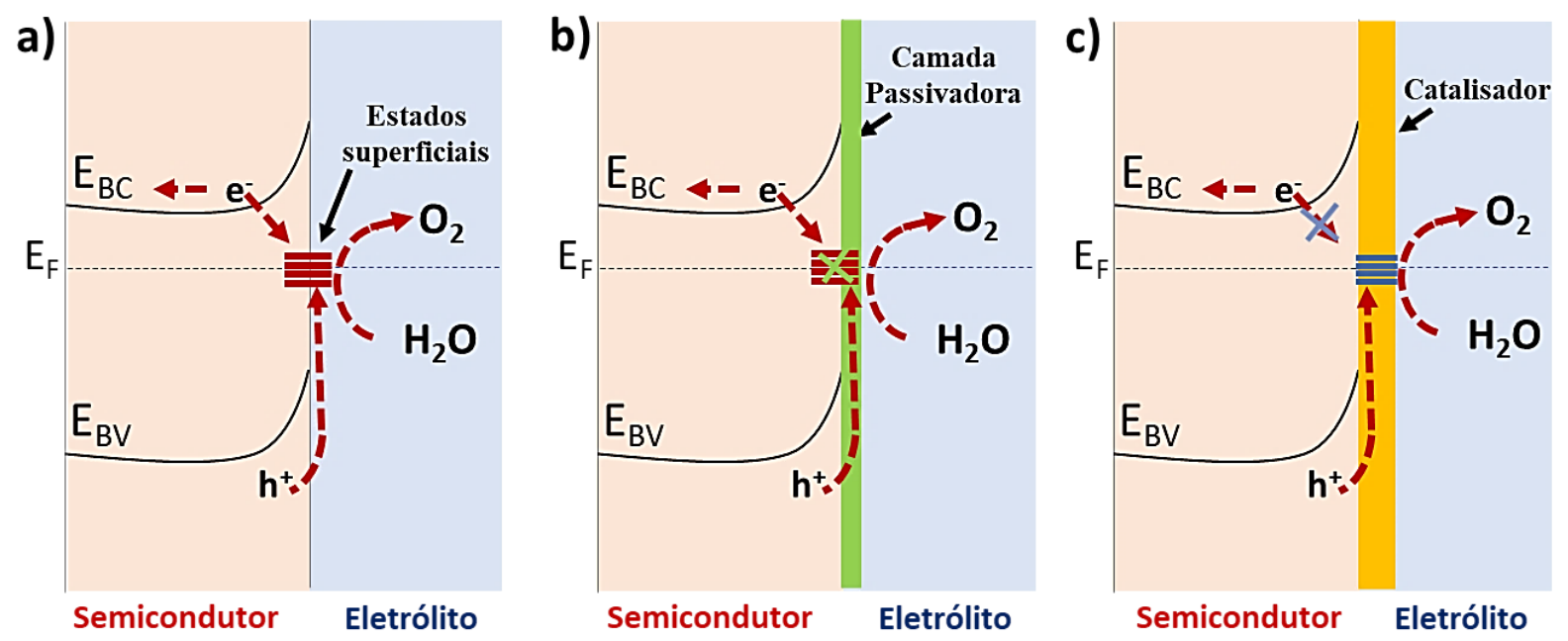

Fonte: Adaptado de Tamirat et al., $2016\left[^{7}\right]$.

A dopagem superficial com íons metálicos pode promover a formação de uma camada de óxido de ferro dopada que passiva os estados superficiais, promovendo melhor separação de cargas, como pode ser observado na Figura 7-b [7,84]. Hufnagel e colaboradores [76] demonstraram que a dopagem da superfície de filmes de hematita com Sn minimiza os estados superficiais e diminui o sobrepotencial necessário para a REO. Xi et al. [75] reportaram que a dopagem com Sn leva a formação de um camada de $\mathrm{Fe}_{\mathrm{x}} \mathrm{Sn}_{1-\mathrm{x}} \mathrm{O}_{4}$ que diminui a recombinação de cargas na superfície de filmes de hematita preparados por síntese hidrotermal. A deposição de finas camadas de óxidos metálicos, como $\mathrm{Al}_{2} \mathrm{O}_{3}$ [85], $\mathrm{TiO}_{2}$ [86], $\mathrm{Nb}_{2} \mathrm{O}_{5}$ [69] e $\mathrm{SnO}_{2}$ [87], também promovem o deslocamento do potencial de onset para a fotocorrente para potenciais menos positivos devido a passivação dos estados superficiais que promovem recombinação de cargas no fotoanodo .

A deposição de cocatalisadores como $\mathrm{IrO}_{\mathrm{x}}$ [88], $\mathrm{CoO}_{\mathrm{x}}$ [48], Co-Pi [89], $\mathrm{NiOOH}$ [90], $\mathrm{NiFeO}_{x}$ [91,92] e $\mathrm{CoFeO}_{x}$ [93], vem sendo amplamente empregada para aumentar a eficiência para a evolução de oxigênio e redução do potencial de onset para fotocorrente. Os cocatalisadores atuam como facilitadores da reação na interface, pois são capazes de acomodar os buracos fotogerados, através da oxidação do íon (metálico geralmente) do próprio cocatalisador, mediando o processo de transporte de carga na interface (Figura 7-c) [7,94]. 
Dang e colaboradores [46] estudaram o efeito da presença de níquel-borato sobre o filme de hematita e verificou que a deposição desse cocatalisador possibilitou, além da diminuição da resistência de transferência de carga na interface, a passivação dos defeitos superficiais, permitindo um menor sobrepotencial para fotocorrente. O efeito passivador de defeitos também foi observado para outros catalisadores. Wang e coautores $[95,96]$ observaram que a deposição de $\mathrm{NiFeO}_{\mathrm{x}}$ passivou os defeitos superficiais da hematita e contribuiu para o aumento da fotovoltagem. Barroso e colaboradores também observaram este efeito passivador para o CoPi [97]. No entanto, há uma inconsistência entre os trabalhos da literatura em relação aos mecanismos de operação destes catalisadores, se a sua ação é puramente catalítica ou atua também na passivação de defeitos superficiais $[23,26]$.

A integração de estratégias de modificação superficial e dopagem vem sendo amplamente aplicada para superar as limitações da hematita. O grupo de Wonyong Choi conseguiu obter densidade de fotocorrente de $6,0 \mathrm{~mA} \mathrm{~cm}^{-2} \mathrm{em} \mathrm{1,23} \mathrm{V} \mathrm{vs.} \mathrm{ERH} \mathrm{(em} \mathrm{pH} \mathrm{13,6),}$ o que corresponde a $50 \%$ da densidade de fotocorrente limite teórica, a partir da combinação da adição de cobalto-fosfato (Co-Pi), como cocatalisador, e da passivação da superfície com óxido de titânio [89].

Embora um progresso significativo tenha sido alcançado, o efeito individual de cada estratégia de modificação dos filmes de hematita e como a integração destas estratégias altera a energia e cinética da interface ainda não é claro [45,82]. O entendimento das limitações das estratégias de modificação e como estas afetam a separação e o transporte de carga do material semicondutor pode auxiliar no processo de combinação de estratégicas que terão um efeito sinérgico positivo na resposta PEC [23]. Assim, estudos detalhados dos processos que ocorrem na interface e o papel dos estados superficiais na recombinação de cargas, a partir da utilização de técnicas espectroscópicas e/ou eletroquímicas, são de extrema importância para o desenvolvimento dos fotoeletrodos eficientes [45,98]. 


\section{OBJETIVOS}

Considerando o cenário exposto acima, o objetivo deste trabalho foi sintetizar filmes de hematita por eletrodeposição e estudar a influência da modificação destes filmes nas propriedades morfológicas, estruturais, optoeletrônicas e fotoeletroquímicas destes filmes para a reação de desprendimento de oxigênio em eletrólito alcalino. Foram adotadas duas abordagens de modificação dos filmes de hematita: através da dopagem com estanho e deposição de NiOOH, e pela nanoestruturação do substrato com nanopartículas de ATO.

Neste contexto, os objetivos específicos foram:

(i) Otimizar a carga de eletrodeposição de ferro e a temperatura de tratamento térmico para a obtenção dos filmes de hematita.

(ii) Investigar as melhores condições para eletrodeposição de Sn e do co-catalisador de $\mathrm{NiOOH}$;

(ii) Avaliar o efeito da modificação do substrato com diferentes quantidades de ATO;

(iii)Caracterizar os filmes modificados quanto à morfologia por microscopia eletrônica de varredura (MEV), estrutura cristalina pelas técnicas de difração de Raios X (DRX) e Espectroscopia Raman e ópticas através do cálculo da energia de band gap óptico através de espectrofotometria na região do UV-Vis;

(v) Caracterizar os filmes modificados quanto aos aspectos eletrônicos, determinando o potencial de banda plana $\left(E_{\mathrm{fb}}\right)$ e densidade de portadores $\left(\mathrm{N}_{\mathrm{D}}\right)$;

(vi) Caracterizar os filmes modificados quanto às propriedades eletroquímicas e fotoeletroquímicas, por voltametria linear, transiente de fotopotencial e avaliar a fotoestabilidade por cronoamperometria dos filmes modificados por dopagem com Sn e deposição de $\mathrm{NiOOH}$.

(vii) Caracterizar os filmes modificados quanto as propriedades elétricas por espectroscopia de impedância fotoeletroquímica (PEIS) e estimar as eficiências de separação e injeção de carga.

(viii) Correlacionar as características estruturais e composição com as fotocorrentes obtidas para avançar na compreensão dos parâmetros que governam a atividade fotoeletroquímica da hematita. 


\section{MATERIAIS E MÉTODOS}

Nesta seção serão apresentados os reagentes e a instrumentação utilizados no desenvolvimento do trabalho, assim como a descrição dos procedimentos experimentais desde o processo de preparação dos filmes até as caracterizações físicas e fotoeletroquímicas realizada nestes materiais.

\subsection{REAGENTES E SOLUÇÕES}

Todos os reagentes utilizados na realização dos experimentos foram de pureza analítica e utilizados sem mais purificações. A procedência e pureza dos reagentes estão apresentadas na Tabela 1. Além disso, todas as soluções foram preparadas a partir de água purificada em um sistema Milli-Q®.

Tabela 1- Lista da procedência e pureza dos reagentes utilizados.

\begin{tabular}{ccc}
\hline Reagentes & Procedência & Pureza (\%) \\
Acetona & Applichem Pancreac & 99,8 \\
Álcool isopropílico & Applichem Pancreac & 99,8 \\
Citrato trissódico dihidratado & Sigma-Aldrich & $\geq 99,0$ \\
Cloreto de estanho & Sigma-Aldrich & 99,0 \\
Etanol & Applichem Pancreac & 99,8 \\
Etilenoglicol & Synth & 98 \\
Hidróxido de potássio & Sigma-Aldrich & 99,90 \\
Hidroquinona & Merck & $>90,0$ \\
Nafion ${ }^{\circledR}$ & Dupont & \\
(®) & Alfa Aesar & $\geq 98,5$ \\
Sulfato de ferro (II) amoniacal & Sigma-Aldrich & 99,99 \\
Sulfato de níquel hexaidratado & Sigma-Aldrich & 99,0 \\
Sulfato de sódio & Sigma-Aldrich & $\geq 99,5$ \\
\hline Óxido de estanho antimônio & &
\end{tabular}

Fonte: Autoria própria. 


\subsection{INSTRUMENTAÇÃO}

A preparação dos eletrodos, os ensaios eletroquímicos e fotoeletroquímicos foram realizados em um Potenciostato/Galvanostato Autolab modelo PGSTAT128N da MetrohmEcoChemie controlado pelo software NOVA 2.1.4®. Os ensaios fotoeletroquímicos foram realizados utilizando um simulador solar com lâmpada de xenônio de $100 \mathrm{~W}$ Newport modelo 94011 A com filtro AM 1.5G. A potência de $1 \mathrm{sol}\left(100 \mathrm{mWcm}^{-2}\right)$, foi ajustada e calibrada na posição do fotoanodo investigado utilizando um medidor de potência óptica da Newport (843R-USB). Foi utilizada uma célula eletroquímica de três eletrodos com janela de quartzo de diâmetro de $1 \mathrm{~cm}$, sendo composta pelo eletrodo de trabalho (FTO-depositado), eletrodo de referência $\mathrm{Ag} / \mathrm{AgCl} / \mathrm{Cl}^{-}(\mathrm{KCl}$ sat.) e um contra eletrodo de placa de platina. A representação esquemática da célula fotoeletroquímica está apresentada na Figura 8.

Figura 8-Representação esquemática da célula de três eletrodos com janela de quartzo utilizada nos experimentos fotoeletroquímicos

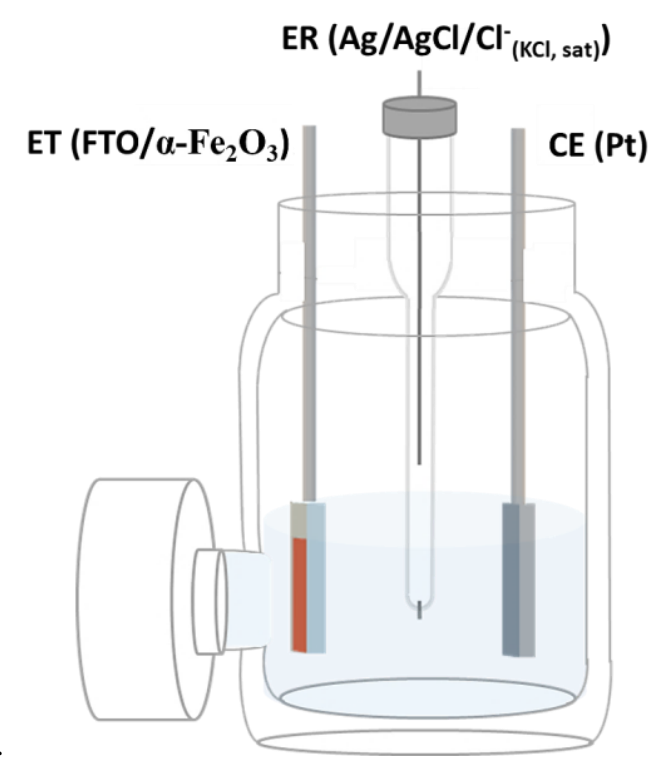

Fonte: Autoria própria.

No preparo das soluções, foram utilizadas micropipetas Eppendorf Research com ponteiras descartáveis (10-100 $\mu \mathrm{L}$ e 100-1000 $\mu \mathrm{L})$. Nas pesagens, foi empregada uma balança analítica da Shimadzu modelo X200, as correções de pH um potenciômetro da Metrohm modelo 827 pH lab e agitador magnético Gehaka (AA-1840). Para a limpeza dos substratos foram utilizados banho ultrassônico Sonitech. O tratamento térmico dos filmes foi realizado em mufla Furnatec. 
Os espectros de absorção na região do UV-vis foram obtidos em um espectrofotômetro UV-Vis SHIMADZU modelo UV-2600. A faixa de comprimento de onda investigado foi de 200 a $800 \mathrm{~nm}$. Os difratogramas de raios X (DRX) foram obtidos em um difratômetro de raios X Bruker modelo D8 Advance. Os programas utilizados para indexação das fases cristalinas e para o cálculo dos parâmetros de rede foram o Crytallographica Search-Match e UnitCell. Foram realizadas análises do filme de hematita modificado com óxido de níquel em espectrômetro de fluorescência de raio X (PANalytical - Modelo: MiniPaI4).

As micrografias dos filmes foram obtidas usando um microscópio eletrônico de varredura (MEV) em um equipamento LEO-440 (Cambridge, England) com detector OXFORD (modelo 7060), e em microscópio eletrônico de varredura FEI modelo Philip XL-30 FEG. As amostras foram recobertas com $6 \mathrm{~nm}$ de ouro em um metalizador Coating System BAL-TEC MED 020 (BAL-TEC, Liechtenstein) e mantidas em dessecador até o momento de análise. Condições de metalização: pressão na câmara $=2,00 \times 10^{-2}$ mbar; corrente $=60 \mathrm{~mA}$; taxa de deposição $0,60 \mathrm{~nm} \mathrm{~s}^{-1}$ ).

\subsection{PARTE EXPERIMENTAL}

\subsubsection{Limpeza dos substratos}

Neste trabalho, todos os eletrodos foram preparados utilizando como substrato placas de vidro com filmes de óxido de estanho dopado com flúor (FTO), obtidos comercialmente da Sigma-Aldrich ${ }^{\circledR}$, de 2,5x1,0 cm, restringindo-se a área de $1,0 \mathrm{~cm}^{2}$ em contato com o eletrólito para todos os filmes estudados. Previamente a preparação dos eletrodos, as placas de FTO foram cortadas e limpas por sonicação em banho ultrassônico em acetona, álcool isopropílico e água deionizada, respectivamente, com um tempo de sonicação de 10 minutos em cada solvente. Por fim, as placas foram secadas ao ar e armazenadas a seco.

\subsubsection{Preparação e Otimização dos filmes de $\alpha-\mathrm{Fe}_{2} \mathrm{O}_{3}$}

Os filmes de hematita foram preparados através do método de eletrodeposição catódica de Fe seguido de tratamento térmico, utilizando FTO como substrato, baseando-se na metodologia descrita por Liang et al. (2018) [49]. A solução de eletrodeposição foi preparada utilizando como solvente uma proporção de 1:8 de volume de etilenoglicol em água deionizada. Em seguida, foram adicionados $0,05 \mathrm{~mol} \mathrm{~L}^{-1}$ de sulfato de ferro (II) amoniacal $\left(\mathrm{NH}_{4}\right)_{2} \mathrm{Fe}\left(\mathrm{SO}_{4}\right)_{2}$, 
0,1 mol L ${ }^{-1}$ de sulfato de sódio $\left(\mathrm{Na}_{2} \mathrm{SO}_{4}\right)$ e o pH da solução ajustado a 2,1 com solução de ácido sulfúrico $\left(\mathrm{H}_{2} \mathrm{SO}_{4}\right) 1,0 \mathrm{~mol} \mathrm{~L}^{-1}$.

A eletrodeposição dos filmes foi realizada em uma célula convencional de três eletrodos; FTO como eletrodo de trabalho, um contra-eletrodo de platina $(1,0$ x 1,0 cm) e um eletrodo de referência de $\mathrm{Ag} / \mathrm{AgCl} / \mathrm{Cl}^{-}{ }_{\text {(KCl sat.). }}$ Previamente a deposição dos filmes, a voltametria cíclica foi utilizada para avaliar os processos redox sobre o FTO e selecionar potenciais para a deposição dos filmes de Fe. Os filmes de Fe metálico foram depositados por cronoamperometria $-1,0,-1,1,-1,3 \mathrm{~V}$ ( $v s . \mathrm{Ag} / \mathrm{AgCl} / \mathrm{Cl}^{-}{ }_{(\mathrm{KCl}}$ sat.)$)$. Os filmes preparados foram aquecidos em ar, inicialmente a uma temperatura de $200^{\circ} \mathrm{C}$ por 30 min e, posteriormente, a $650^{\circ} \mathrm{C}$ por $60 \mathrm{~min}$. Após o tratamento térmico, os filmes foram resfriados livremente à temperatura ambiente $\left(25^{\circ} \mathrm{C}\right)$.

Posteriormente, foi avaliada a variação da carga de deposição de ferro (300, 500 e $1000 \mathrm{mC} \mathrm{cm}^{-2}$ ), e consequentemente a espessura, e a temperatura de tratamento térmico (600, $650,700{ }^{\circ} \mathrm{C}$ ) na resposta PEC do filme de hematita. Como o FTO perda de condutividade em temperaturas elevadas [99], para o tratamento térmico a $700^{\circ} \mathrm{C}$ o eletrodo foi mantido nesta temperatura por apenas $15 \mathrm{~min}$. Todos os filmes utilizados no estudo da otimização dos parâmetros de síntese foram preparados em duplicata.

\subsubsection{Dopagem do filme de $\alpha-\mathrm{Fe}_{2} \mathrm{O}_{3} \operatorname{com} \mathrm{Sn}$}

A modificação dos filmes de hematita com estanho foi feita a partir da eletrodeposição de uma fina camada de estanho metálico sobre o filme de ferro metálico, antes do processo de tratamento térmico. $\mathrm{O}$ banho de deposição de estanho foi preparado solubilizando $0,01 \mathrm{~mol} \mathrm{~L}^{-1}$ de cloreto de estanho $\left(\mathrm{SnCl}_{2}\right), 0,1 \mathrm{~mol} \mathrm{~L}{ }^{-1}$ de citrato de sódio $\left(\mathrm{Na}_{3} \mathrm{C}_{6} \mathrm{H}_{5} \mathrm{O}_{7}\right)$ e $0,01 \mathrm{~mol} \mathrm{~L}^{-1}$ de hidroquinona $\left(\mathrm{C}_{6} \mathrm{H}_{6} \mathrm{O}_{2}\right)$ em água deionizada [100,101]. A hidroquinona atua como um antioxidante no banho de deposição de estanho evitando que os íons $\mathrm{Sn}^{+2}$ se oxidem para $\mathrm{Sn}^{+4}$, enquanto os íons citrato complexam os íons $\mathrm{Sn}^{+2}$ acelerando a cinética de deposição e melhora a adesão do filme [102,103].

O filme de estanho metálico foi depositado aplicando $-0,85 \mathrm{~V}\left(v s . \mathrm{Ag} / \mathrm{AgCl} / \mathrm{Cl}^{-}{ }_{(\mathrm{KCl} \text { sat. })}\right)$. Foram avaliadas diferentes densidades de carga de eletrodeposição: 5, 10 e $20 \mathrm{mC} \mathrm{cm}^{-2}$ que correspondem a 1, 2 e 4\% de Sn atômico em relação aos átomos de Fe nos filmes depositados. Após as eletrodeposições, os filmes foram tratados termicamente em ar a $200^{\circ} \mathrm{C}$ por $30 \mathrm{~min}$, seguido por aquecimento a $650^{\circ} \mathrm{C}$ por $60 \mathrm{~min}$, sendo resfriados livremente até a temperatura 
ambiente. Os filmes obtidos foram comparados com o filme de hematita pura em relação as características fotoeletroquímicas, e o filme dopado que apresentou melhor resposta foi utilizado para testes posteriores.

\subsubsection{Deposição de NiOOH em filmes de $\alpha-\mathrm{Fe}_{2} \mathrm{O}_{3}$ e $\alpha-\mathrm{Fe}_{2} \mathrm{O}_{3} / \mathrm{Sn}$-dopado}

Os filmes hematita e hematita dopada com a melhor carga de estanho foram modificados com óxido-hidróxido de níquel a partir do método de eletrodeposição adaptado de Wu et al. [104]. Para a deposição, o filme de hematita foi imerso em uma solução aquosa de sulfato de sódio $0,1 \mathrm{~mol} \mathrm{~L}^{-1}$ e $0,13 \mathrm{~mol} \mathrm{~L}^{-1}$ acetato de sódio contendo $3 \mathrm{mmol} \mathrm{L}^{-1} \mathrm{NiSO}_{4} \cdot 6 \mathrm{H}_{2} \mathrm{O}$. A deposição foi realizada por eletrodeposição pulsada com dois potenciais, $0,3 \mathrm{~V}$ e $1,1 \mathrm{~V}$ ( $v s$. $\left.\mathrm{Ag} / \mathrm{AgCl} / \mathrm{Cl}^{-}{ }_{(\mathrm{KCl} \text { sat. })}\right)$, e usando ciclos com tempo de de 1 segundo em cada potencial, para atingir uma baixa taxa de deposição para cada ciclo. A quantidade de carga de $\mathrm{NiOOH}$ foi otimizada para garantir o maior desempenho PEC. Após a otimização da carga de deposição, os filmes modificados foram avaliados quanto às suas propriedades fotoeletroquímicas.

\subsubsection{Nanoestruturação do filme de $\alpha-\mathrm{Fe}_{2} \mathrm{O}_{3}$ pela modificação do substrato FTO com ATO}

A modificação de substratos foi feita a partir da deposição de nanopartículas de óxido de estanho antimônio (ATO) $<50 \mathrm{~nm}$ sobre o substrato FTO. Para a deposição de ATO, foi preparada uma suspensão de $3 \mathrm{mg}$ de nanopartículas de ATO em $2 \mathrm{~mL}$ de etanol e $20 \mu \mathrm{L}$ de Nafion ${ }^{\circledR} 5 \% \mathrm{v} / \mathrm{v}$, em seguida esta suspensão foi ultrassonicada e posteriormente depositada sobre o substrato pelo método dropping. Foram depositados diferentes volumes da suspensão, 50; $100 ; 200$ e $300 \mu \mathrm{L} \mathrm{cm}^{-2}$, sobre o substrato a fim de avaliar o efeito da carga de ATO na resposta fotoeletroquímica dos filmes de hematita.

Os substratos modificados foram então submetidos a deposição do filme de Ferro metálico utilizando o banho de deposição descrito na Seção 3.3.3.1, com a carga de deposição otimizada. Previamente investigou-se o potencial de deposição dos filmes de hematita neste substrato a partir de voltametria cíclica, e o potencial selecionado para a deposição do filme metálico foi $-1,8 \mathrm{~V}$ (vs. $\mathrm{Ag} / \mathrm{AgCl} / \mathrm{Cl}^{-}{ }_{(\mathrm{KCl}}$ sat.)$)$. Os filmes foram tratados termicamente em ar a $200^{\circ} \mathrm{C}$ por $30 \mathrm{~min}$, seguido por aquecimento a $650^{\circ} \mathrm{C}$ por $60 \mathrm{~min}$, e resfriados até a temperatura ambiente. Posteriormente, os filmes modificados foram avaliados quanto às suas propriedades fotoeletroquímicas. 


\subsubsection{Caracterização Física}

Os filmes $\mathrm{Fe}_{2} \mathrm{O}_{3}$ preparados para otimização da síntese (espessura do filme e temperatura de tratamento térmico), os filmes dopados com estanho $\mathrm{Fe}_{2} \mathrm{O}_{3} / \mathrm{Sn}$ e os filmes modificados com ATO foram caracterizados quanto a morfologia por microscopia eletrônica de varredura (MEV) e quanto suas estruturas por difração de raio X (DRX).

Os valores de band gap dos filmes de hematita modificados foram estimados a partir de espectros de absorção na região de 200 a 800 nm registrados em um espectrômetro UV-Vis. A energia de band gap foi calculada usando a seguinte equação:

$$
(\alpha h v)^{n}=A\left(h v-E_{g}\right)
$$

Equação (5)

em que, $\alpha$ é o coeficiente de absorção, $h$ a constante de Planck, $v$ a frequência e $n$ assume os valores de 2 ou 2/3 para transição direta (permitido e proibido, respectivamente) e $1 / 2$ ou 1/3 para indiretos (permitido e proibido, respectivamente).

\subsubsection{Caracterização Eletroquímica e Fotoeletroquímica}

Os filmes preparados foram caracterizados por voltametria linear na presença e na ausência de luz, monitorando o potencial de onset $\left(E_{\mathrm{ON}}\right)$ a densidade de fotocorrente no potencial termodinâmico 1,23 V ( $v s$. ERH). Os eletrólitos utilizados foram soluções de $\mathrm{KOH}$ 1,0 mol L ${ }^{-1}$ e KOH 1,0 mol L-1 $+\mathrm{H}_{2} \mathrm{O}_{2} 0,5 \mathrm{~mol} \mathrm{~L}^{-1}$. Experimentos de transiente de potencial de circuito aberto (OCPT) foram realizados sob iluminação solar simulada manualmente ligada e desligada (chopped). Foram realizados testes de estabilidade sobre iluminação aplicando 1,6 e 1,23 V (vs. ERH) por 15 horas. Para fins de comparação, todos os potenciais apresentados nos resultados foram convertidos em relação escala do eletrodo reversível de hidrogênio (ERH) utilizando a equação:

$$
E_{E R H}=E_{A g / \mathrm{AgCl} \mathrm{Cl}_{(\mathrm{KCl} \mathrm{sat.}}^{-}}+0,197 \mathrm{~V}+(0,0592 \times p H) \quad \text { Equação (6) }
$$

O potencial de banda plana $\left(\mathrm{E}_{f b}\right)$, o tipo de semicondutor e a densidade dos portadores de carga $\left(\mathrm{N}_{D}\right)$ dos filmes de hematita puro e modificados foram determinados por experimentos Mott-Schottky (Equação 6) utilizando-se a técnica de espectroscopia de impedância eletroquímica. Para isso, aplicou-se um sinal de excitação senoidal de 0,01 Vrms com 
frequência de 0,$5 ; 1,0 ; 2,5 ;$ e 5,0 kHz. Estes experimentos foram realizados utilizando como eletrólito uma solução de $\mathrm{KOH} \mathrm{1,0} \mathrm{mol} \mathrm{L-1}(\mathrm{pH}$ 13,6).

$$
\frac{1}{C_{S C}^{2}}=\frac{2}{\varepsilon_{r} \varepsilon_{0} e N_{D}}\left(E-E_{f b}-\frac{k T}{e}\right)
$$

em que, $e$ é a carga elementar, $\mathrm{N}_{D}$ é a densidade do portador de carga (i.e., a densidade de doadores para semicondutores de tipo-n), $\varepsilon_{0}$ é a permissividade no vácuo, $\varepsilon_{\text {r }}$ é a constante dielétrica do semicondutor, $E$ é o potencial aplicado, $E_{f b}$ é o potencial da banda plana, k é a constante de Boltzmann e T é a temperatura absoluta.

As medidas de espectroscopia de impedância fotoeletroquímica (PEIS) foram realizadas a $1,23 \mathrm{~V}$ (vs. ERH), com a faixa de frequência ajustada entre $100 \mathrm{kHz}$ e $0,1 \mathrm{~Hz}, \mathrm{a}$ uma amplitude de $10 \mathrm{mV}$, sob irradiação luminosa, em 1,0 mol L-1 KOH (pH 13,6) e 1,0 mol $\mathrm{L}^{-1} \mathrm{KOH}+0,5$ mol L $\mathrm{L}^{-1}$ de $\mathrm{H}_{2} \mathrm{O}_{2}$. Os dados foram ajustados aos circuitos simulados com o software Z-view®. 


\section{RESULTADOS DISCUSSÃO}

Os resultados apresentados e discutidos nesta seção estão divididos em três partes. A Parte A refere-se ao estudo da carga de deposição de Fe metálico e da temperatura de tratamento térmico na morfologia, estrutura e propriedades fotoeletroquímicas do filme de hematita. $\mathrm{Na}$ Parte B estão apresentados os estudos da dopagem superficial dos filmes de hematita com diferentes níveis de $\mathrm{Sn}$ e da deposição de $\mathrm{NiOOH}$, nas propriedades físicas e fotoeletroquímicas dos filmes de hematita. Por fim, na Parte C, estão expostos estudos da modificação do substrato com nanopartículas de ATO na resposta PEC dos filmes de hematita.

\subsection{PARTE A: ESTUdO DOS PARÂMETROS DE SÍNTESE DOS FILMES DE HEMATITA}

\subsubsection{Obtenção dos filmes de hematita}

Os filmes de hematita foram preparados a partir do tratamento térmico de filmes de ferro metálico depositados eletroquimicamente seguido de tratamento térmico para conversão de $\mathrm{Fe}(0)$ em $\alpha-\mathrm{Fe}_{2} \mathrm{O}_{3}$. Previamente à preparação dos filmes de Fe metálico para a síntese dos filmes de hematita, foi determinado o perfil voltamétrico da superfície do substrato (FTO) na solução de deposição. O voltamograma cíclico, apresentado na Figura 9, foi registrado entre os potenciais de 0,35 e $-1,5 \mathrm{~V}$ (vs. $\left.\mathrm{Ag} / \mathrm{AgCl} / \mathrm{Cl}^{-}{ }_{(\mathrm{KCl} \text { sat. })}\right)$ a $20 \mathrm{mV} \mathrm{s}^{-1}$. A deposição do filme de $\mathrm{Fe}$ metálico sobre o substrato inicia em torno de $-1 \mathrm{~V}$ (vs. $\mathrm{Ag} / \mathrm{AgCl} / \mathrm{Cl}^{-}{ }_{(\mathrm{KCl}}$ sat.) $)$ ao longo da varredura de potencial para valores negativos. Observa-se que a medida em que o potencial diminuía (sentido para mais negativo), a reação de desprendimento de hidrogênio compete fortemente como processo de deposição do filme de ferro, levando a formação de um filme nãouniforme. Durante a varredura reversa, para valores mais positivos, o filme de ferro metálico depositado na superfície do substrato é oxidado levando ao aparecimento de picos anódicos em aproximadamente $-0,2$ e $-0,05 \mathrm{~V}\left(v s . \mathrm{Ag} / \mathrm{AgCl} / \mathrm{Cl}^{-}(\mathrm{KCl}\right.$ sat. $\left.)\right)$ referentes à oxidação de $\mathrm{Fe}(0)$ à espécies de Fe (II) e de Fe(II) a Fe (III), respectivamente [105,106]. 
Figura 9 - Voltametria cíclica do FTO em solução de 0,05 mol L ${ }^{-1}$ de $\left(\mathrm{NH}_{4}\right)_{2} \mathrm{Fe}\left(\mathrm{SO}_{4}\right)_{2}+0,1 \mathrm{~mol} \mathrm{~L}^{-1} \mathrm{Na}_{2} \mathrm{SO}_{4} \mathrm{em}$ 1:8 etilenoglicol e água. $\mathrm{v}=20 \mathrm{mV} \mathrm{s}-1 . \mathrm{T}=25^{\circ} \mathrm{C}$.

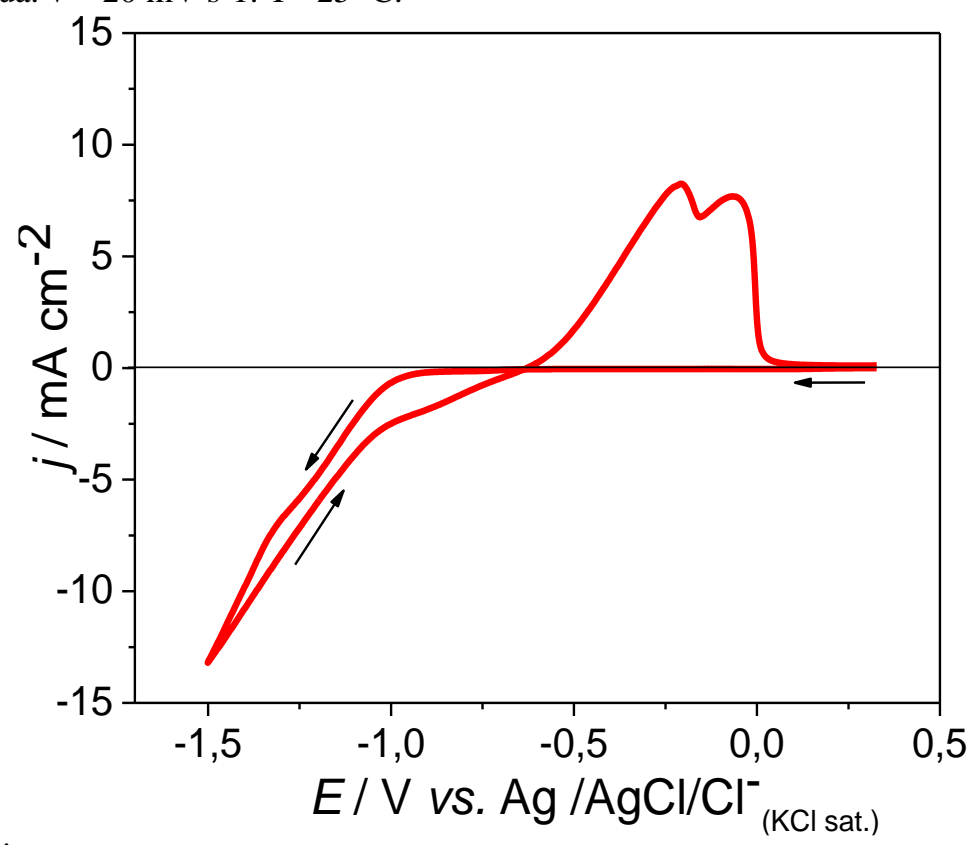

Fonte: Autoria própria.

A partir do estudo do comportamento eletroquímico do substrato em meio a solução de deposição, foram selecionados os potenciais de $-1,0,-1,1$ e $-1,3 \mathrm{~V}$ (vs. $\mathrm{Ag} / \mathrm{AgCl} / \mathrm{Cl}^{-}{ }_{\text {(KCl sat.) }}$ ) para avaliação do potencial ideal para eletrodeposição do filme de ferro metálico. Para isso, foram preparados filmes de $\mathrm{Fe}(0)$ com $500 \mathrm{mC} \mathrm{cm}^{-2}$ de carga depositados nos potenciais selecionados, mantendo-os constantes durante as eletrodeposições. Na Figura A1 (Apêndice A), está apresentado um cronoamperograma de deposição do filme de ferro metálico registrado aplicando $-1,3 \mathrm{~V}$ (vs. $\mathrm{Ag} / \mathrm{AgCl} / \mathrm{Cl}^{-}{ }_{(\mathrm{KCl} \text { sat.)})}$ ). Após as deposições, os filmes de ferro metálico foram submetidos a tratamento térmico a $650^{\circ} \mathrm{C}$ por uma hora para conversão à hematita. Os filmes de hematita preparados pela deposição de Fe aplicando -1,0 e -1,1 V (vs. $\mathrm{Ag} / \mathrm{AgCl} / \mathrm{Cl}^{-}$ (KCl sat.) apresentaram baixa aderência no substrato e desplacaram durante o tratamento térmico. Já o filme preparado utilizando $-1,3 \mathrm{~V}$ ( $v s . \mathrm{Ag} / \mathrm{AgCl} / \mathrm{Cl}^{-}{ }_{(\mathrm{KCl}}$ sat.)$)$ mostrou-se aparentemente compacto e, assim, este potencial foi selecionado para o crescimento dos filmes de $\mathrm{Fe}(0)$ utilizados em investigações posteriores. Após o tratamento térmico, o filme de ferro metálico apresentou alteração na coloração de cinza metálico para vemelho-alaranjada, coloração característica da hematita [7]. 


\subsubsection{Otimização dos parâmetros de síntese}

Como mencionado anteriormente, os parâmetros investigados para o preparo dos filmes de hematita foram: temperatura de tratamento térmico e carga de deposição de $\mathrm{Fe}(0)$.

\subsubsection{Efeito da temperatura de tratamento térmico}

\subsection{Caracterização Física}

Inicialmente, avaliou-se o efeito da temperatura de tratamento térmico (TT) na morfologia dos filmes de hematita depositados com $500 \mathrm{mC}$ de carga total. As micrografias obtidas para os filmes de ferro metálico sem tratamento e tratados termicamente a $600^{\circ}, 650^{\circ} \mathrm{e}$ $700^{\circ} \mathrm{C}$ estão apresentadas na Figura $\mathbf{1 0}$.

Figura 10 - Micrografias obtidas por MEV das superfícies dos filmes de hematita preparados com $500 \mathrm{mC}$ submetidos a diferentes temperaturas de tratamento térmico: (a) não-tratado, (b) $600{ }^{\circ} \mathrm{C}$, (c) $650^{\circ} \mathrm{C} \mathrm{e} \mathrm{(d)} 700^{\circ} \mathrm{C}$.
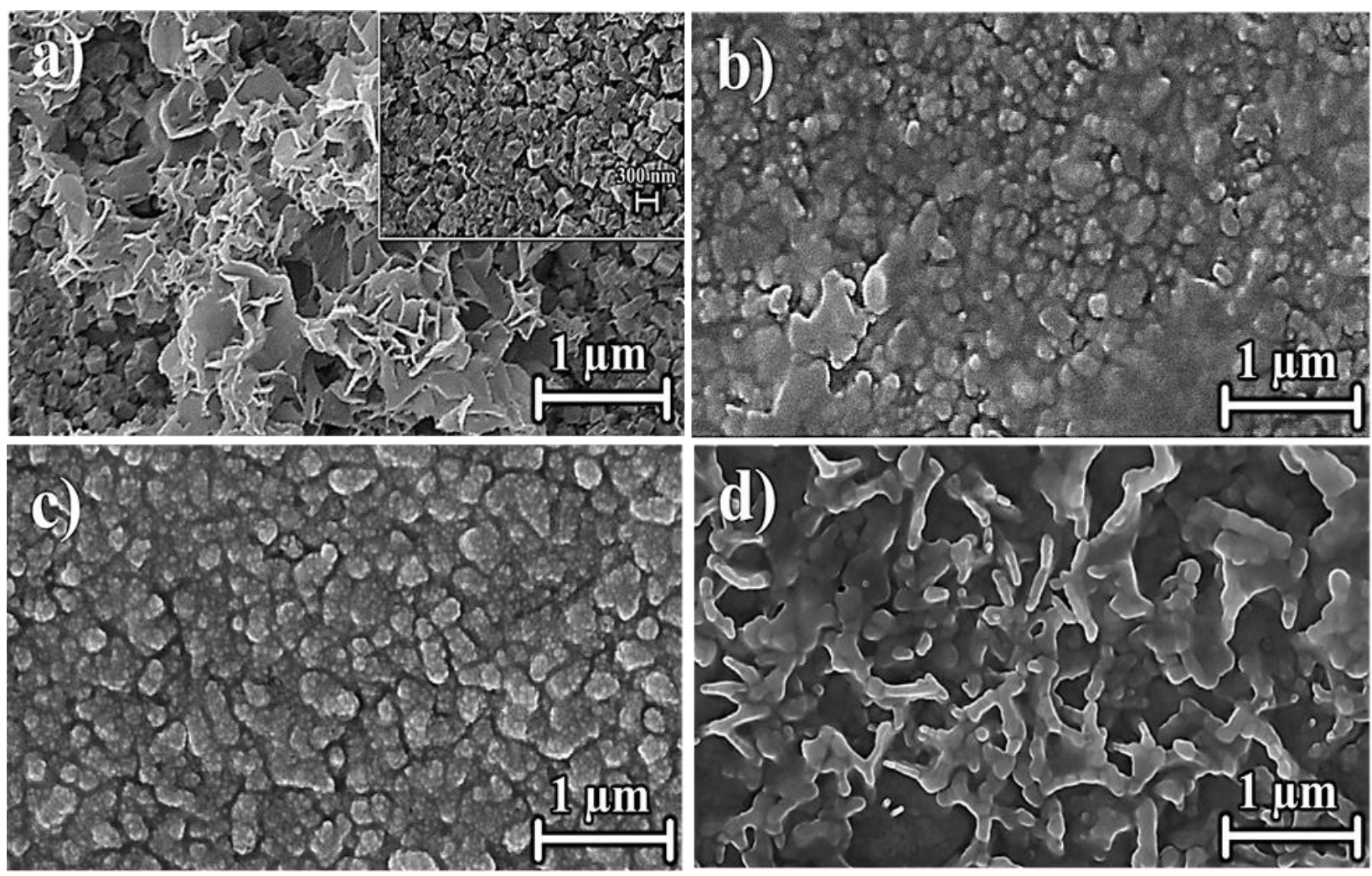

Fonte: Autoria própria.

Como pode ser observado na Figura 10-a, o filme não tratado, constituído de ferro metálico, apresentou partículas ortorrômbicas atribuídas às nanoestruturas de ferro metálico 
[107] e nanofolhas atribuídos à formação de oxihidróxido de ferro [108] devido a exposição do filme de ferro ao gás oxigênio e humidade atmosférica antes das análises de microscopia. Após o tratamento térmico, todo os filmes apresentaram aglomerados de nanopartículas globulares. No entanto, a temperatura utilizada no processo de TT (para a conversão de $\mathrm{Fe}(0)$ à $\alpha-\mathrm{Fe}_{2} \mathrm{O}_{3}$ ) influenciou aparentemente no tamanho dos aglomerados dos filmes obtidos. O aumento da temperatura de tratamento levou a um aumento do tamanho das nanopartículas, este comportamento foi observado por Liang et al. [49] e outros diversos pesquisadores $[48,109,110]$. Kimura et al. relaciona o aumento do tamanho das partículas com a maior migração de átomos da superfície que favorecem a incorporação de átomos de ferro e oxigênio na rede cristalina $[49,111]$.

Os filmes preparados também foram avaliados quanto a sua estrutura por difratometria de Raios X. Nos difratogramas obtidos, mostrados na Figura 11, nota-se que todos os picos para as amostras dos filmes podem ser associados à fase $\alpha-\mathrm{Fe}_{2} \mathrm{O}_{3}$ (JCPDS 33-664) ou ao substrato $\left(\mathrm{SnO}_{2}\right.$, atribuído pelo símbolo "\#", JCPDS 77-451), não sendo identificada nenhuma outra fase de óxido de ferro. Os parâmetros de rede e o volume de célula dos materiais foram calculados para o pico de maior intensidade, expressos na Tabela A1 (Apêndice A), e os valores são concordantes com os reportados na literatura [40].

Figura 11-Difratogramas de Raios X dos filmes de hematita crescidos com diferentes temperaturas. Os padrões de difração de $\mathrm{SnO}_{2}$ (representando FTO, JCPDS 77-451) e $\alpha-\mathrm{Fe}_{2} \mathrm{O}_{3}$ (JCPDS 33-664) são mostrados na região inferior do gráfico para comparação.

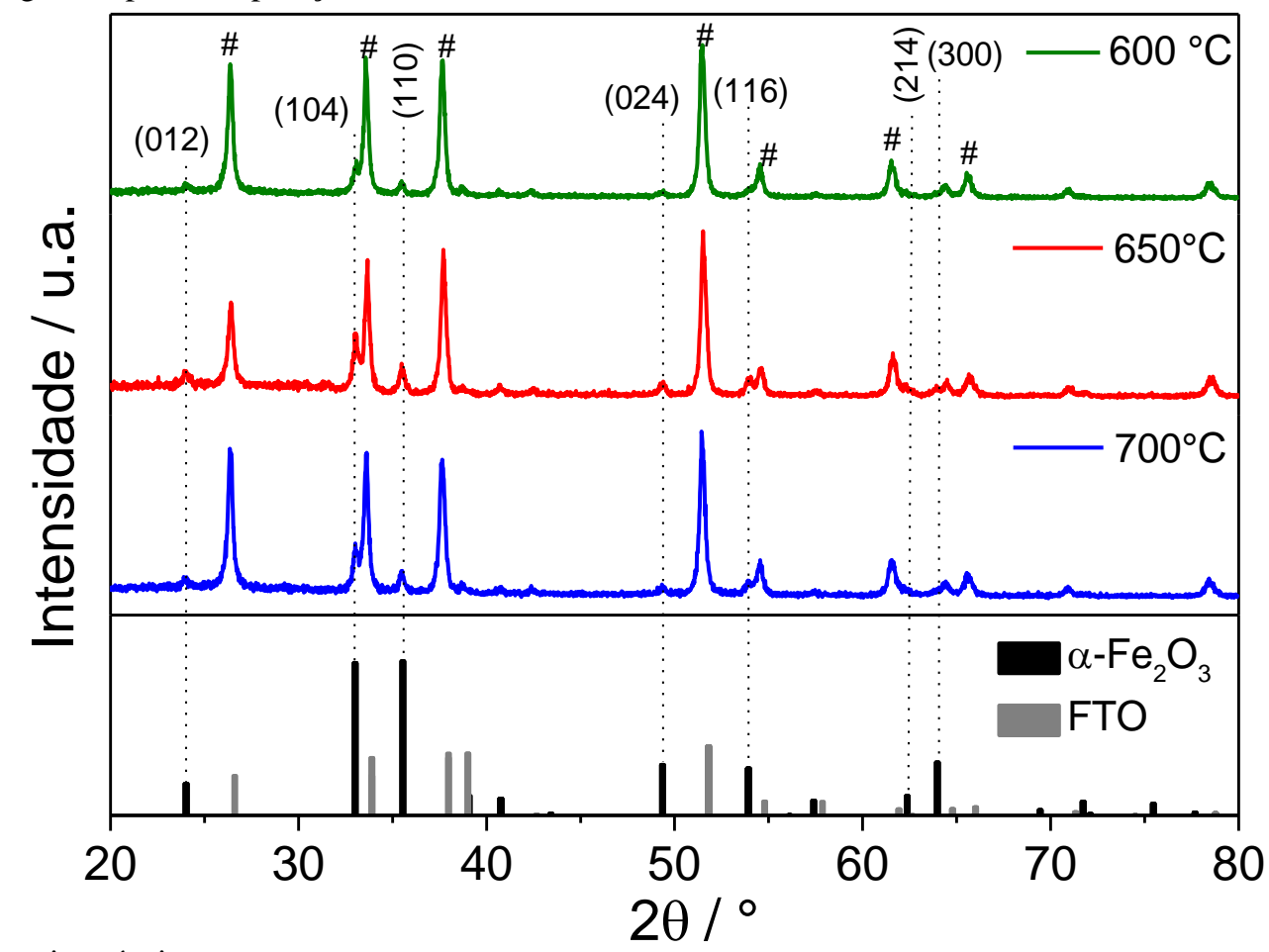

Fonte: Autoria própria. 
$\mathrm{Na}$ Figura 11, é possível verificar que o filme de hematita crescido a $600^{\circ} \mathrm{C}$ apresentou menor intensidade dos picos de difração referentes à fase $\alpha-\mathrm{Fe}_{2} \mathrm{O}_{3}$ (em relação aos picos do substrato), quando comparado com os filmes crescidos a temperaturas superiores, sugerindo menor cristalinidade deste filme. A avaliação da cristalinidade dos filmes pôde ser feita pelo valor de largura à meia altura (Full Width at Half Maximum-FWHM) calculado a partir de um pico do difratograma de Raio X obtido para as amostras [112,113]. O FWHM é relacionado com a cristalinidade do material em uma determinada direção. O valor de FWHM para filmes é alterado de acordo com a variação da microsestrutura e da tensão da deformação no material [112]. Na Tabela 2, estão apresentados os valores de FWHM calculados através do pico de difração referente ao plano (110) para os filmes de hematita tratados com diferentes temperaturas. O valor de FWHM é inversamente proporcional a cristalinidade do filme, assim quanto maior o valor de calculado, menor é a cristalinidade do filme de hematita. O filme tratado a $600^{\circ} \mathrm{C}$ apresentou maior valor de FWHM, quando comparado aos demais apresentando assim menor cristalinidade. O aumento da cristalinidade com o aumento da temperatura de TT está relacionado com a redução dos defeitos dos contornos de grão e diminuição do estresse cristalino [114]. Além disso, filmes de hematita com maior cristalinidade tende a ter maior absorção da luz visível, podendo assim promover melhores respostas PEC [109].

Tabela 2- Largura à meia altura (FWHM), coeficiente de textura relativo $\left(\mathrm{CT}_{\mathrm{Rel}}\right)$, composição e energia de band gap $\left(E_{\mathrm{g}}\right)$ para os filmes $\alpha-\mathrm{Fe}_{2} \mathrm{O}_{3}$ submetidos a diferentes temperaturas de tratamento térmico.

\begin{tabular}{|c|c|c|c|}
\hline Filmes & FWHM (grau) ${ }^{a}$ & $\mathbf{C T}_{\text {Rel }}{ }^{b}$ & $\begin{array}{c}E_{g} \\
(e V)^{d}\end{array}$ \\
\hline $\mathrm{Fe}_{2} \mathrm{O}_{3} / 600^{\circ} \mathrm{C}$ & 0,42 & 2,37 & 2,07 \\
\hline $\mathrm{Fe}_{2} \mathrm{O}_{3} / 650^{\circ} \mathrm{C}$ & 0,36 & 1,80 & 2,12 \\
\hline $\mathrm{Fe}_{2} \mathrm{O}_{3} / 700^{\circ} \mathrm{C}$ & 0,30 & 1,64 & 2,11 \\
\hline ICSD-64599 & - & 1,00 & - \\
\hline
\end{tabular}

a. Largura à meia altura (FWHM) para o pico de difração referente ao plano (110).

b. Coeficiente de textura relativo da razão entre os picos referentes aos planos (012) e (110) do DRX (Figura 11).

c. Energias de band gap obtidas a partir das curvas de Tauc (Figura 12-b).

Fonte: Autoria própria.

Os filmes de hematita podem crescer orientados preferencialmente em diferentes direções como [110], [104], [012] e [300] [115]. O filmes com superfície orientada na direção 
[110] é dominada por terminações Fe (III) [115,116]. Segundo Souza (2018), filmes de hematita que são texturizados na direção do plano (110) tendem a apresentar maior condutividade eletrônica e maior eficiência de separação das cargas fotogeradas [27]. A partir da análise dos padrões de DRX, foram calculdos os coeficientes de texturização relativo $\left(\mathrm{CT}_{\mathrm{Rel}}\right)$ paras os filmes preparados com diferentes temperaturas de TT. Este coeficiente foi calculado a partir da razão das intensidades dos planos (012) e (110) em comparação à mesma razão do padrão não texturizado da $\alpha-\mathrm{Fe}_{2} \mathrm{O}_{3}$ (ICSD- 64599). Esta comparação foi feita por meio da Equação 8 e os dados também estão organizados na Tabela 2.

$$
C T_{\text {Rel }}=\frac{I[012]_{\text {Filme }} / I[110]_{\text {Filme }}}{I[012]_{\text {Padrão }} / I[110]_{\text {Padrão }}}
$$

Os filmes eletrodepositados e tratados termicamente apresentaram um favorecimento a texturização na direção [012]. O filme tratado termicamente a $600^{\circ} \mathrm{C}$ foi o que apresentou menor cristalinidade e maior texturização nessa direção; e os filmes tratados em temperaturas superiores além de apresentarem maior cristalinidade, apresentaram menores coeficientes de texturização. Menores coeficientes de texturização podem estar associados à maior texturização na direção do plano (110), e provavelmente maior condutividade e transporte de cargas nos filmes. Assim, observando apenas os difratogramas e os parâmetros calculados, pode-se esperar que o filme tratado a $700^{\circ} \mathrm{C}$ apresente melhor resposta $\mathrm{PEC}$ frente a reação de fotoeletroxidação da água, quando comparado com os demais filmes.

A energia de band gap $\left(E_{\mathrm{g}}\right)$ dos filmes de hematita preparados de diferentes temperaturas de tratamento térmico foram avaliados por UV-VIS, e os espectros de absorbância estão apresentados na Figura 12-a. Nos espectros registrados, pode ser observada duas bandas de absorção com intensidade elevada., sendo a primeira está localizada na região de 250-400 nm e a segunda entre 410 a $600 \mathrm{~nm}$. A banda de absorção na região de 250-400 nm está associada às transições de transferência de carga, enquanto a banda entre 410-600 nm é atribuída às transições de campo cristalino local e ao processo de excitações de pares [40,117]. Através dos espectros da Figura 12-a, pode-se verificar que o aumento da temperatura de tratamento térmico promoveu aumento na absorção dos filmes. Os gráficos de Tauc $(\alpha h v)^{1 / 2} v s$. energia do fóton obtidos para os filmes obtidos através das diferentes temperaturas de TT, estão apresentados na Figura 12. Os valores de band gap foram obtidos a partir da extrapolação das regiões lineares da curva e estão expressos na Tabela 2. Na Tabela 2, as energias de band gap obtidas foram aproximadamente $2,1 \mathrm{eV}$ para todos os filmes crescidos nas diferentes 
temperaturas, estando de acordo com os valores de band gap relatados na literatura $[7,40,49,50]$.

Figura 12-(a) Espectro de absorção dos filmes de hematita crescidos a diferentes temperaturas e (b) Gráfico de $(\alpha h v)^{1 / 2} v s$. energia do fóton para os filmes de hematita crescidos em diferentes temperaturas de TT.
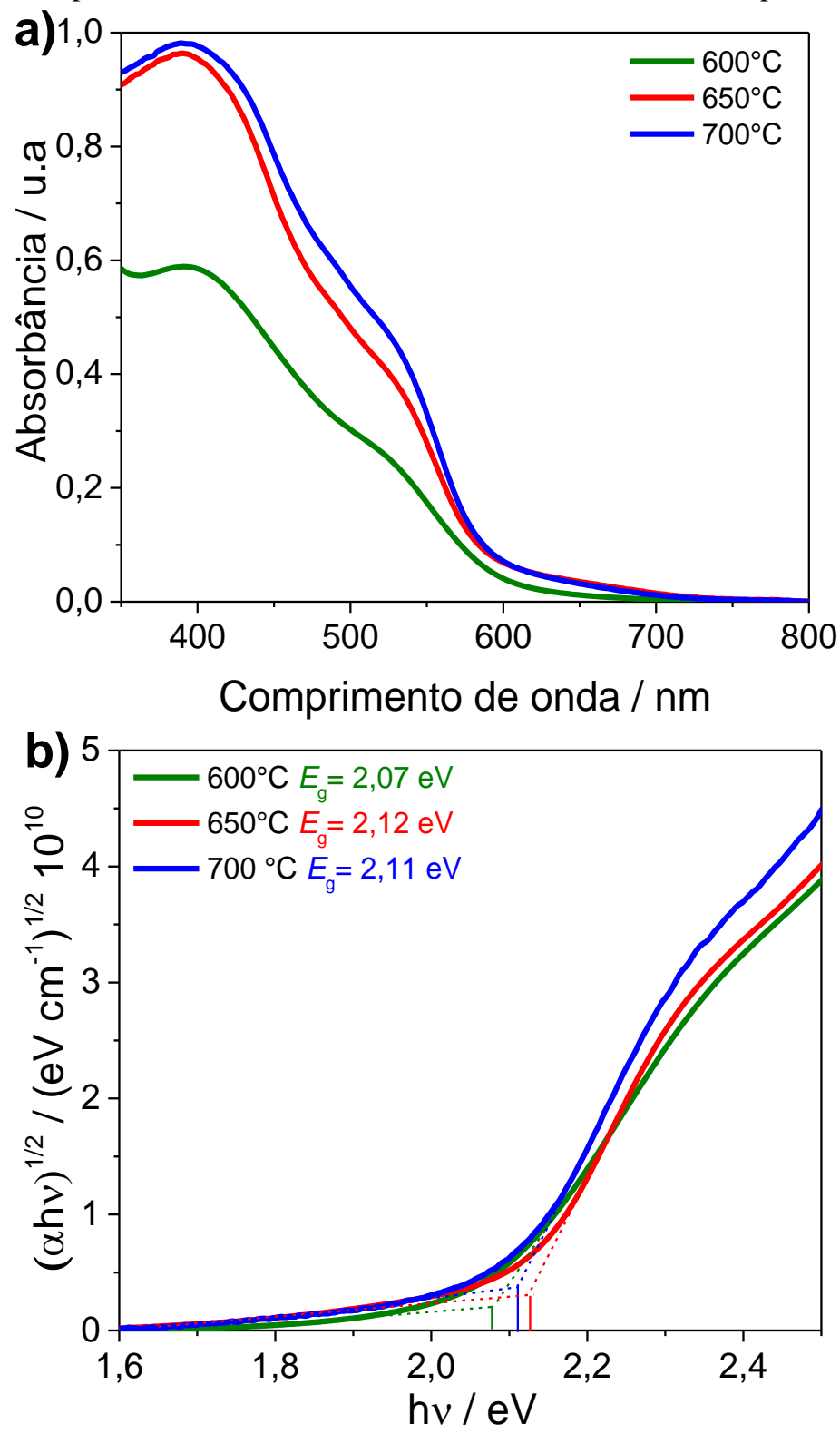

Fonte: Autoria própria.

\subsection{Caracterização Fotoeletroquímica}

Os filmes de hematita preparados foram avaliados quanto ao seu comportamento fotoeletroquímico para a reação de evolução de oxigênio. A avaliação das propriedades fotoeletroquímicas dos filmes preparados foi realizada através de voltametria linear em

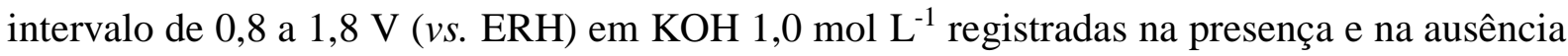


de iluminação de um simulador solar. Os voltamogramas obtidos e a densidade de fotocorrente no potencial termodinâmico estão apresentados na Figura 13-a e 13-b, respectivamente.

Nos voltamogramas registrados sob iluminação, Figura 13-a, é observada uma fotocorrente anódica, característica de semicondutores tipo $\mathrm{n}$ para todos os filmes avaliados. $\mathrm{O}$ maior valor de densidade de fotocorrente, Figura 13-b, no potencial equivalente a 1,23V ( $v s$. $\mathrm{ERH}$ ), foi obtida para o filme de hematita tratado termicamente a $650^{\circ} \mathrm{C}$ e não para o filme tratado em $700^{\circ} \mathrm{C}$. como era esperado. Na Figura 13-a, é possível verificar que o aumento da temperatura de TT para $700^{\circ} \mathrm{C}$ resultou no deslocamento do potencial de onset da reação de evolução de oxigênio para potenciais mais positivos, tanto na ausência e na presença de iluminação. A diminuição da performance PEC para o filme tratado termicamente a $700^{\circ} \mathrm{C}$ está associado à diminuição da condutividade elétrica do substrato devido a elevada temperatura. Li e colaboradores também verificaram a diminuição da performance de filmes de hematita tratados em temperaturas mais elevadas, e associaram este comportamento ao aumento da resistividade elétrica do filme por deterioração do substrato FTO [50]. A melhora da performance PEC obtida para o filme de hematita crescido à $650^{\circ} \mathrm{C}$, em comparação ao filme crescido a $600^{\circ} \mathrm{C}$, está relacionado com o aumento do tamanho e da cristalinidade das partículas em temperaturas maiores, como foi verificado anteriormente nas caracterizações físicas (seção 4.1.2.1), levando a redução de defeitos e melhor fluxo de fotocorrente.

Figura 13- (a) Voltamogramas lineares registrados a $20 \mathrm{mVs}^{-1}$ no escuro (linha tracejada) e sob iluminação com simulador solar (100 mW cm $\mathrm{m}^{-1}$, com filtro A.M. 1.5) (linha contínua) para os filmes de $\mathrm{Fe}_{2} \mathrm{O}_{3}$ tratados com

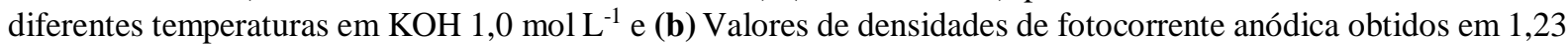
V vs. ERH.

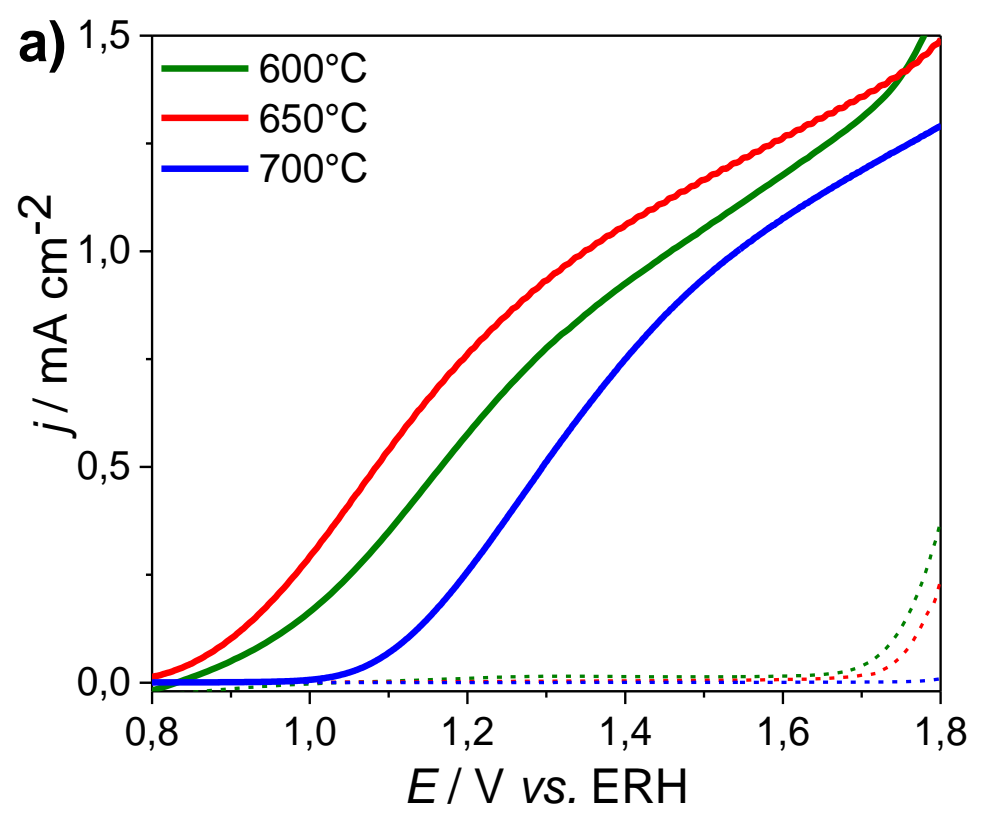




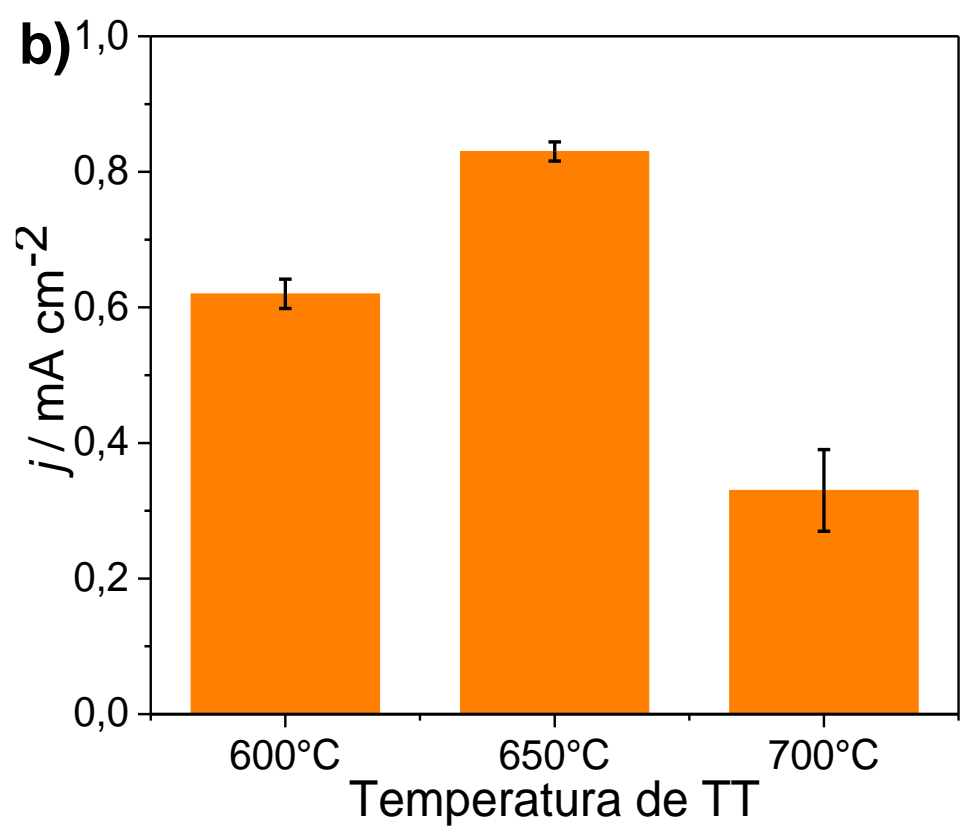

Fonte: Autoria própria.

\subsubsection{Efeito da carga de deposição de Fe (0)}

Dentre os parâmetros que governam a conversão fotoeletroquímica dos íons $\mathrm{OH}^{-}$em gás oxigênio, a espessura do filme tem grande influência na absorção de fótons e na separação de cargas, tendo em vista que filmes menos espessos permitem menor resistência de transferência de carga (menor resistência em série) enquanto filmes mais espessos podem apresentar maior absorção dos fótons [7,118]. Deste modo, foi realizado um estudo para investigar o efeito da carga de ferro depositada sobre a morfologia, estrutura, e propriedades ópticas e fotoeletroquímicas dos filmes de hematita.

\subsection{Caracterização Física}

Filmes de hematita foram preparados com cargas de ferro metálico $300 \mathrm{mC}, 500 \mathrm{mC}$ e $800 \mathrm{mC}$ de Fe eletrodepositado e tratados termicamente a $200^{\circ} \mathrm{C}$ por 30 min e $650{ }^{\circ} \mathrm{C}$ por $1 \mathrm{~h}$. A morfologia da superfície destes filmes e da superfície do substrato foi analisada por MEV e as micrografias estão apresentadas na Figura 14. Através da Figura 14, é possível verificar que o filme de hematita preparado com $300 \mathrm{mC} \mathrm{cm}^{-2}$ se apresentou não-homogêneo sendo possível observar nanopartículas referentes à hematita e algumas partes do substrato exposto. Com o aumento da carga de deposição, houve aumento e aglomeração das nanopartículas globulares, indicando a formação de um filme mais espesso. 
Figura 14- Micrografias obtidas por MEV das superfícies do substrato de FTO (a) e dos filmes de hematita preparados com diferentes cargas de deposição: (b) $300 \mathrm{mC}$, (c) $500 \mathrm{C}$ e (d) $800 \mathrm{mC}$.
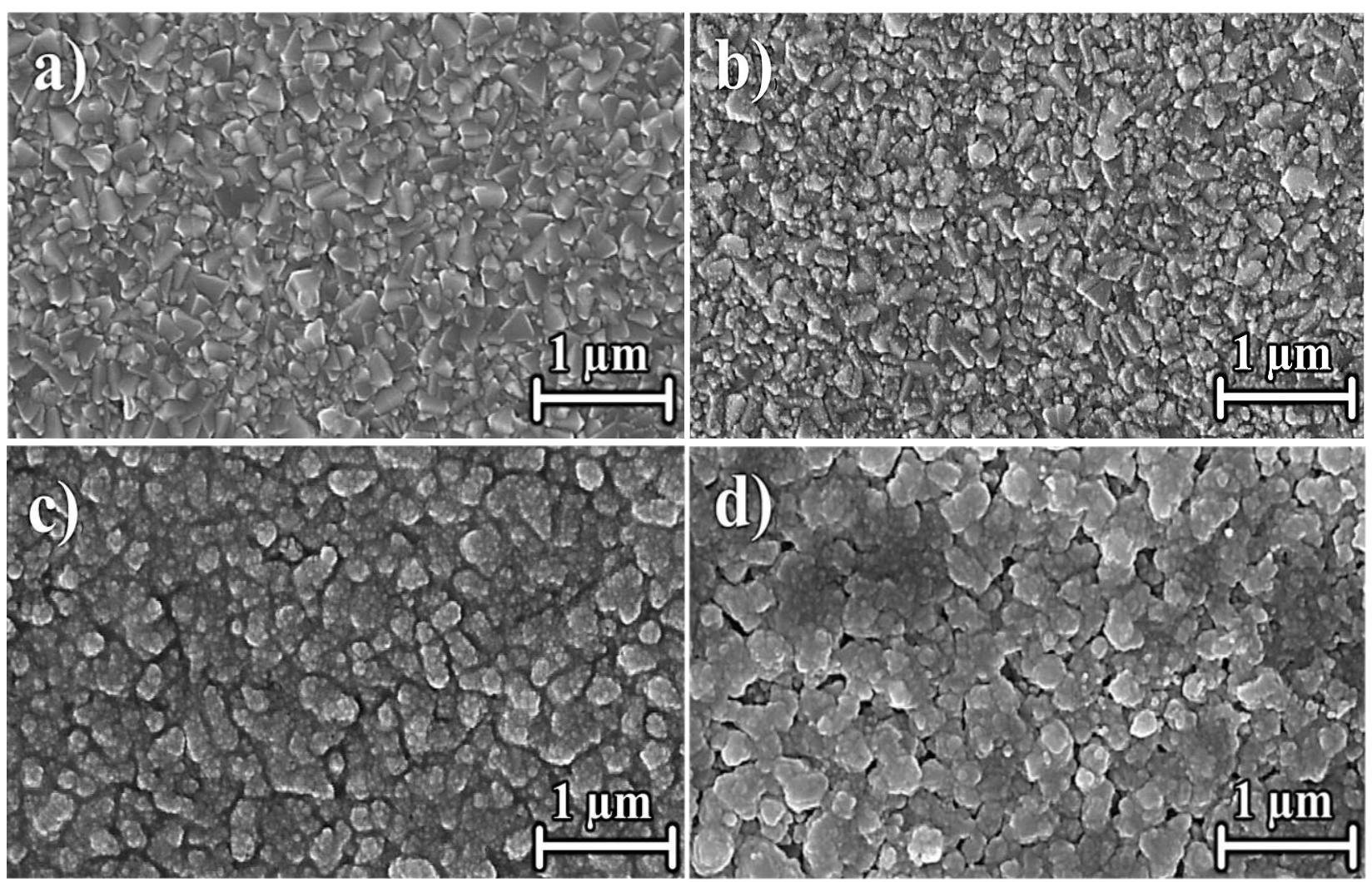

Fonte: Autoria própria.

Na sequência, a estrutura cristalina dos filmes foi avaliada por DRX, sendo os padrões de difração estão apresentados na Figura 15. Como pode ser observado, todos os picos de difração obtidos para as amostras dos filmes podem ser associados à fase $\alpha-\mathrm{Fe}_{2} \mathrm{O}_{3}$ (JCPDS 33664) ou ao substrato $\left(\mathrm{SnO}_{2}\right.$, atribuído pelo símbolo "\#", JCPDS 77-451). Na Figura 15, verifica-se que, diferentemente dos demais filmes, o filme de hematita crescido com $300 \mathrm{mC}$ apresentou maior intensidade para o pico de difração referente ao plano (012) da hematita em relação aos demais picos, evidenciando que esse filme apresenta acentuada texturização na direção [012]. Além disso, no DRX para este filme, a intensidade dos demais picos de difração em relação aos picos do FTO parece menor, o que se deve a menor espessura. 
Figura 15- Difratogramas de Raios $X$ dos filmes de hematita crescidos com diferentes cargas de deposição de Fe. Os padrões de difração de $\mathrm{SnO}_{2}$ (representando FTO, JCPDF 77-451) e $\alpha-\mathrm{Fe}_{2} \mathrm{O}_{3}$ (JCPDF 33-664) são mostrados na região inferior do gráfico para comparação.

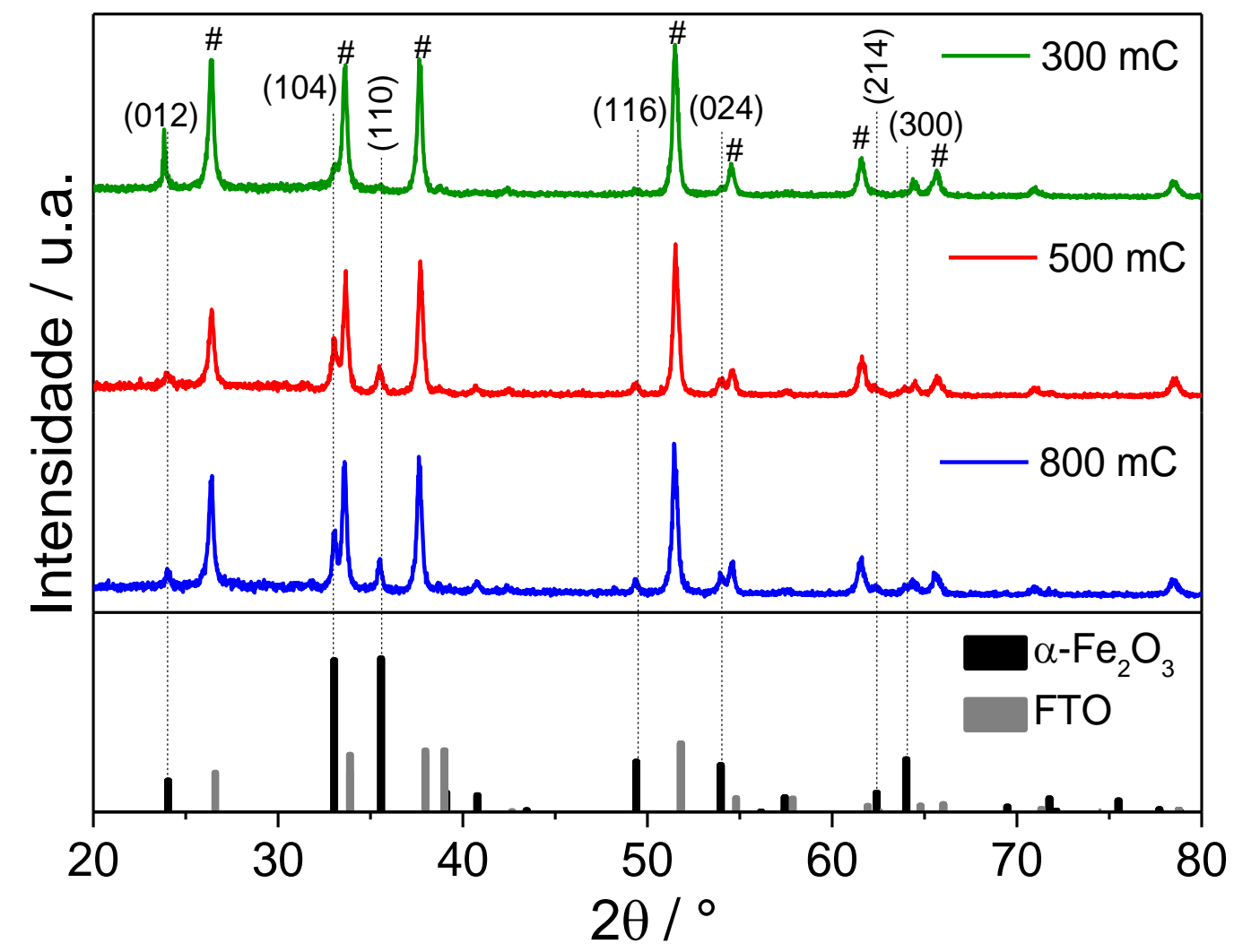

Fonte: Autoria própria.

A avaliação da cristalinidade dos filmes foi feita a partir do cálculo da largura à meia altura (FWHM) calculado através do pico referente ao plano (110) para os filmes de hematita tratados crescidos com diferentes cargas de deposição de Fe. Os valores de FWHM estão apresentados na Tabela 3. A análise dos resultados mostra que o aumento da carga de deposição de Fe resultou em um aumento da cristalinidade do filme de hematita sendo que o filme de 800 $\mathrm{mC}$ apresentou maior cristalinidade, podendo apresentar maior absorção da luz visível [109]. Os parâmetros de rede dos materiais foram calculados e estão expressos na Tabela A1 (Apêndice A). Os valores são concordantes com os reportados na literatura [40], sendo que não houve alterações significativas dos valores em relação as diferentes cargas de deposição. 
Tabela 3- Largura à meia altura (FWHM), coeficiente de textura relativo $\left(\mathrm{CT}_{\mathrm{Rel}}\right)$, composição e energia de band gap $\left(E_{\mathrm{g}}\right)$ para os filmes $\alpha-\mathrm{Fe}_{2} \mathrm{O}_{3}$ crescidos com diferentes cargas de $\mathrm{Fe}$.

\begin{tabular}{cccc}
\hline Filmes & ${\text { FWHM }(\mathbf{g r a u})^{\mathbf{a}}}$ & $\mathbf{C T}_{\text {Rel }^{\mathbf{b}}}$ & $\begin{array}{c}\boldsymbol{E}_{\mathbf{g}} \\
(\mathbf{e V})^{\mathbf{c}}\end{array}$ \\
\hline $\mathrm{Fe}_{2} \mathrm{O}_{3} / \mathbf{3 0 0 m C}$ & - & 3,11 & 2,09 \\
$\mathrm{Fe}_{2} \mathrm{O}_{3} / \mathbf{5 0 0 m C}$ & 0,36 & 1,81 & 2,12 \\
$\mathbf{F e}_{2} \mathbf{O}_{3} / \mathbf{8 0 0 m C}$ & 0,26 & 1,74 & 2,10 \\
$\mathbf{I C S D} \mathbf{6 4 5 9 9}$ & - & 1,00 & - \\
\hline
\end{tabular}

a. Largura à meia altura (FWHM) para o pico de difração referente ao plano (110).

b. Coeficiente de textura relativo da razão entre os picos referentes aos planos (012) e (110) do DRX (Figura 15).

c. Energias de band gap obtidas a partir das curvas de Tauc (Figura 16-b).

Fonte: Autoria própria.

A partir da análise dos padrões de DRX, foram calculados os coeficientes de texturização relativo $\left(\mathrm{CT}_{\mathrm{Rel}}\right)$, os valores obtidos estão expressos na Tabela 3. O filme com menor carga de depósito apresentou o maior coeficiente, devido a menor intensidade nos planos avaliados. Os filmes de $500 \mathrm{mC}$ e $800 \mathrm{mC}$ apresentaram menor coeficiente demonstrando que esse filme cresceram mais texturizados na direção (110), podendo apresentar melhor resposta PEC.

Os espectros de absorção obtidos para os filmes preparados com diferentes cargas estão apresentados na Figura 16-a. Os resultados mostram que a quantidade carga de $\mathrm{Fe}(0)$ depositada tem influência na capacidade de absorção do filme, e que o filme preparado com $300 \mathrm{mC}$ apresenta baixa absorção da luz enquanto os filmes com maiores cargas apresentaram maiores absorção da luz, como já era esperado, já que esse filme é o menos espesso. Os gráficos de $(\alpha h v)^{1 / 2} v s$. energia do fóton estão apresentados na Figura 16. Os valores de band gap, foram aproximadamente 2,1 eV para todos os filmes, estando de acordo com os valores de band gap relatados na literatura $[7,40,49,50]$, indicando que a variação deste parâmetro não influenciou nos valores de band gap do material. 
Figura 16- (a) Espectro de absorção dos filmes de hematita crescidos a diferentes cargas e (b) Gráfico de $(\alpha h v)^{1 / 2}$ vs. energia do fóton para os filmes de hematita crescidos com diferentes cargas de Fe depositado.
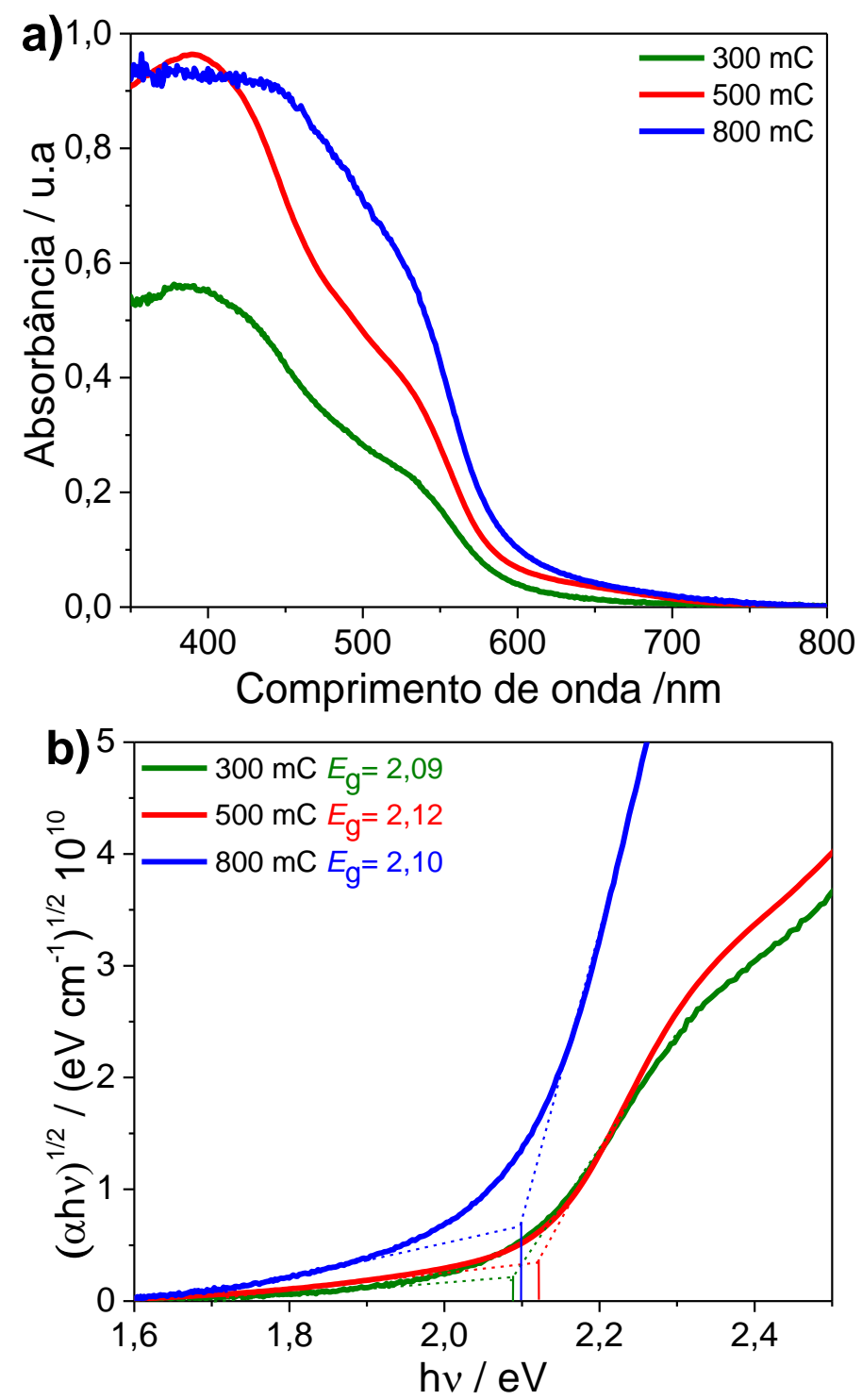

Fonte: Autoria própria.

\subsection{Caracterização Fotoeletroquímica}

A avaliação das propriedades fotoeletroquímicas dos filmes preparados foram feitas por voltametria linear no escuro e sob iluminação. Os voltamogramas lineares, expressos na Figura 17-a, foram registrados no intervalo de potencial de 0,8 a 1,8 V (vs. ERH) em solução de hidróxido de potássio 1,0 $\mathrm{mol} \mathrm{L}^{-1}$. Na Figura 17-b, estão apresentados os valores de densidade de fotocorrente obtidas para os filmes com diferentes carga de deposição em KOH 1 mol L ${ }^{-1}$. Como demonstrado na Figura 17-a, o filme preparado com $500 \mathrm{mC}$ apresentou a maior densidade de fotocorrente no potencial equivalente a 1,23 V ( vs. ERH). O filme preparado com $800 \mathrm{mC} \mathrm{cm}^{-2}$ apresentou maior densidade de fotocorrente comparado ao filme preparado com 
$300 \mathrm{mC} \mathrm{cm}^{-2}$. Este comportamento, que também foi verificado por Li et al [50], está associado com a maior capacidade dos filmes mais espessos de absorver fótons, podendo permitir melhor resposta PEC. No entanto, já foi reportado na literatura [7,49] que filmes muito espessos podem apresentar maior resistência ôhmica que resultam na recombinação das cargas fotogeradas no bulk do material, e consequentemente na diminuição da eficiência de transferência de carga na interface eletrodo/eletrólito, como foi observado na Figura 17-a.

Figura 17 - (a) Voltamogramas lineares registrados a $20 \mathrm{mVs}^{-1}$ no escuro (linha tracejada) e sob iluminação com simulador solar ( $100 \mathrm{~mW} \mathrm{~cm}{ }^{-1}$, com filtro A.M. 1.5) (linha contínua) para os filmes de $\mathrm{Fe}_{2} \mathrm{O}_{3}$ preparados com diferentes cargas de deposição de Fe em KOH 1,0 mol L-1 e (b) Valores de densidades de fotocorrentes anódicas em 1,23 V vs. ERH.
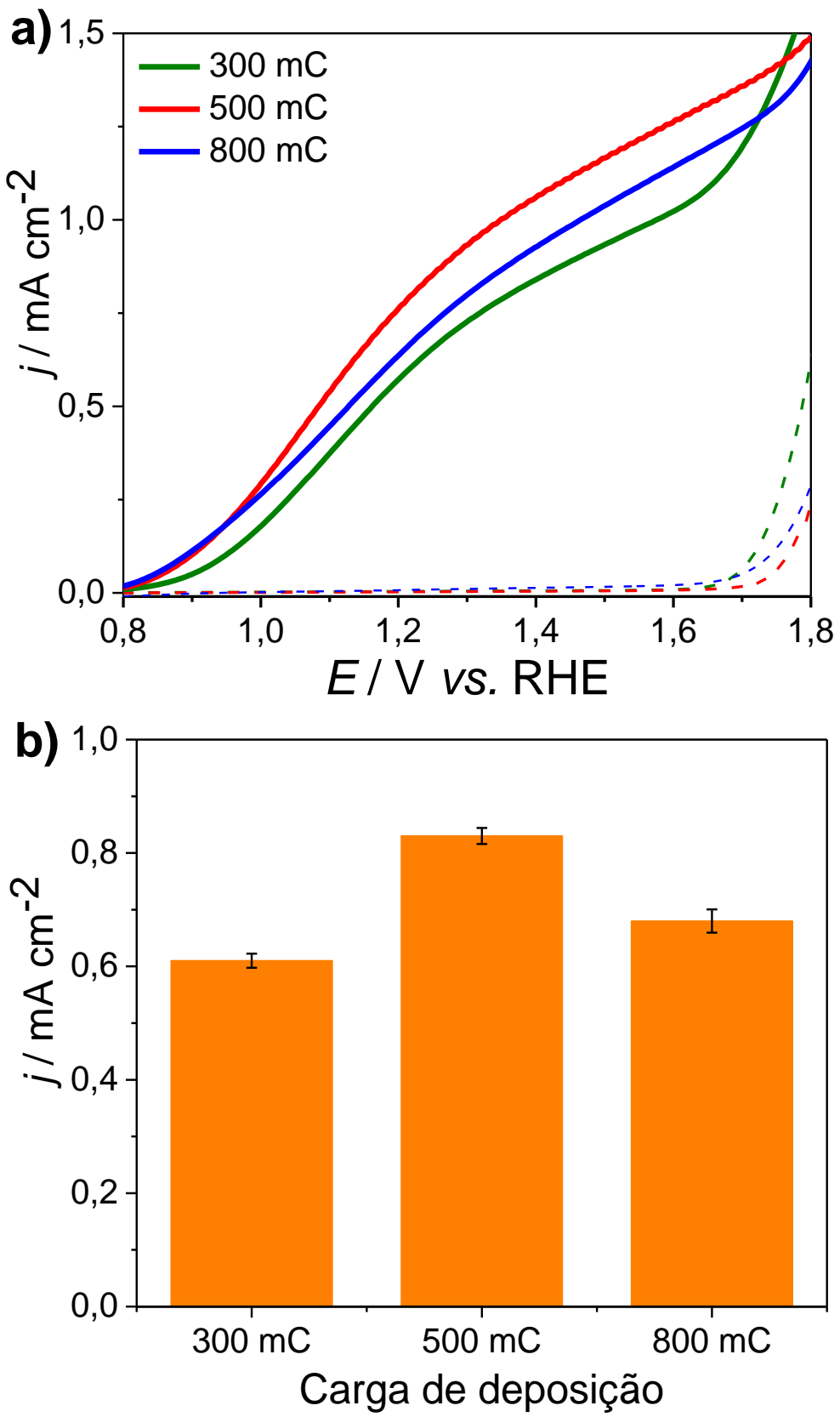

Fonte: Autoria própria. 
Os resultados dos testes de otimização demonstraram que maior valor de densidade de fotocorrente foram obtidos com $500 \mathrm{mC} \mathrm{cm}^{-2}$ de carga de depósito, seguido de tratamento térmico a $650^{\circ} \mathrm{C}$. A densidade de fotocorrente para este filme, $0,83 \mathrm{~mA} \mathrm{~cm}{ }^{-2}$, é superior as reportadas na literatura para filmes preparados por eletrodeposição catódica e anódica, Tabela 1 (Anexo), sendo comparáveis as obtidas outros métodos de síntese.

\subsection{PARTE B: ESTUDO DA MODIFICAÇÃO SUPERFICIAL PELA DOPAGEM COM Sn E DEPOSIÇÃO DE NiOOH}

\subsubsection{Estudo da dopagem com diferentes quantidades de Sn}

A dopagem do filme de hematita com estanho foi feita pré tratamento térmico a partir da eletrodeposição de uma fina camada de estanho metálico sobre o filme de ferro metálico. Para isso, filmes de ferro metálico com $500 \mathrm{mC} \mathrm{cm}^{-2}$ foram modificados pela deposição de 5, 10 e $20 \mathrm{mC} \mathrm{cm}^{-2}$ de $\mathrm{Sn}$ metálico, equivalentes a $1 \%, 2 \%$ ou $4 \%$ atômico de $\mathrm{Sn}$ em relação ao Fe (calculado pela lei de Faraday). Inicialmente, foi estudado o efeito do dopante sobre as propriedades morfológicas, estruturais e ópticas e posteriormente sobre as propriedades optoeletrônicas dos filmes de $\alpha-\mathrm{Fe}_{2} \mathrm{O}_{3}$.

\subsubsection{Caracterização Física}

A morfologia dos filmes foi caracterizada por MEV-FEG e as imagens da vista superior de filmes de hematita sem modificação e modificados com Sn são mostrados na Figura 18. As imagens revelam uma morfologia globular para todos os filmes; no entanto, o aumento na carga total Sn eletrodepositado sobre o filme de Fe metálico parece levar à formação de uma estrutura mais compacta, como é visto principalmente na Figura 18-d. Xi e colaboradores [75] também observaram que a modificação de filme de hematita em solução com elevada concentração de estanho levou à uma estrutura mais compacta devido à formação de uma fina camada interfacial de $\mathrm{Fe}_{\mathrm{x}} \mathrm{Sn}_{1-\mathrm{x}} \mathrm{O}_{4}$. 
Figura 18-Micrografias obtidas por MEV-FEG das superfícies do dos filmes de hematita não-dopados e dopados com diferentes cargas de estanho: (a) não-dopado, (b) $5 \mathrm{mC}$, (c) $10 \mathrm{mC} \mathrm{e} \mathrm{(d)} 20 \mathrm{mC}$.
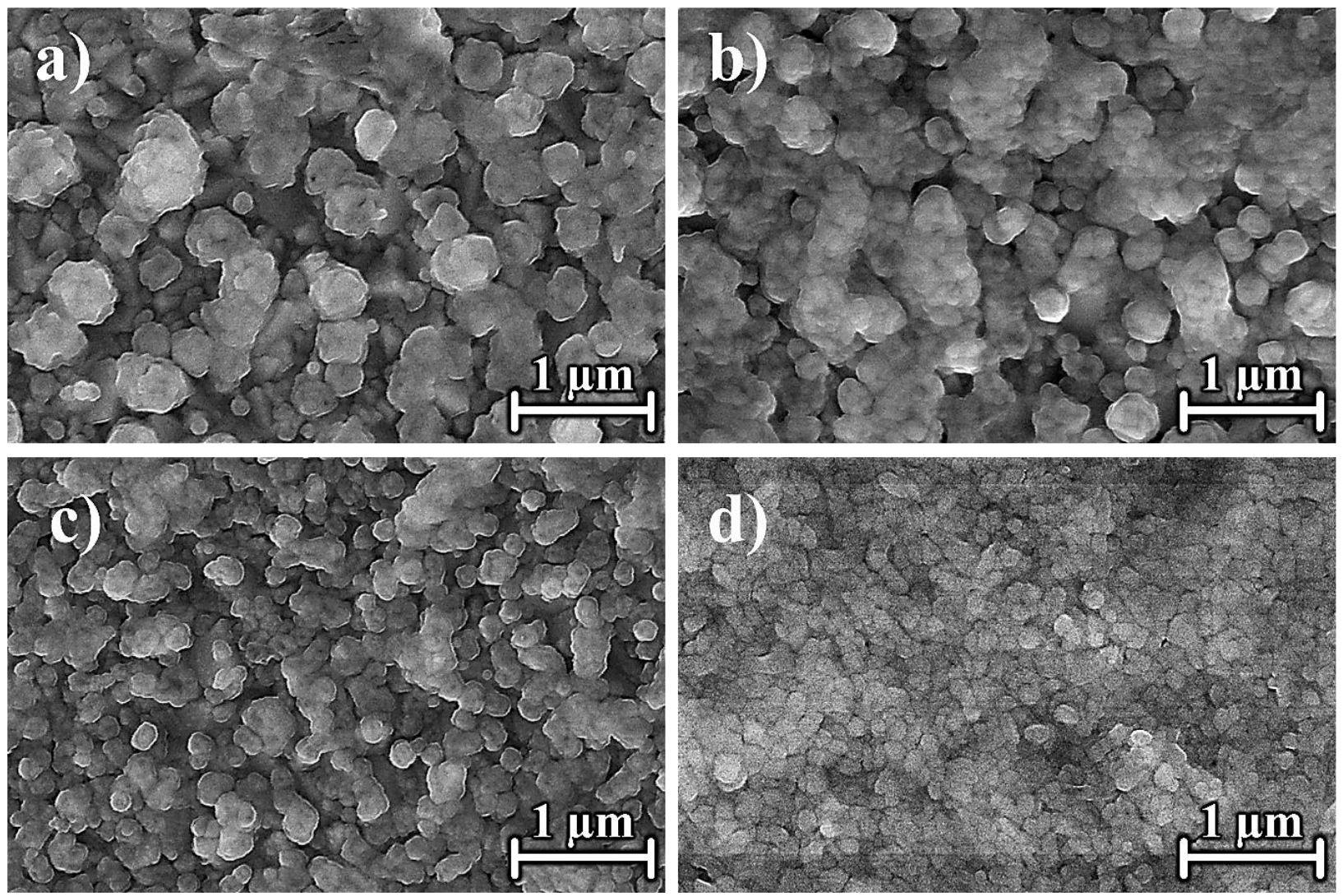

Fonte: Autoria própria.

A caracterização estrutural dos filmes foi feita por difração de Raios X. Nos difratogramas da Figura 19, todos os picos de difração presentes correspondentes ao substrato ( $\mathrm{SnO}_{2}$, JCPDS 77-451), simbolizado por (“\#”) e a hematita (JCPDS 33-664) podem ser associados. Não foram observadas mudanças nos picos de difrações para amostras modificadas com Sn. Como demonstrado na Tabela B1 (Apêndice B), não houve alteração nos parâmetros de rede para os filmes modificados com estanho. 
Figura 19- Difratogramas de Raios $X$ dos filmes de hematita sem modificação e modificados com diferentes cargas de Sn. Os padrões de difração de $\mathrm{SnO}_{2}$ (representando FTO, JCPDS 77-451), $\alpha-\mathrm{Fe}_{2} \mathrm{O}_{3}$ (JCPDS 33-664) e $\mathrm{Fe}_{1,727} \mathrm{Sn}_{0,205} \mathrm{O}_{3}$ (JPDS 01-088-0434) são mostrados na região inferior do gráfico para comparação.

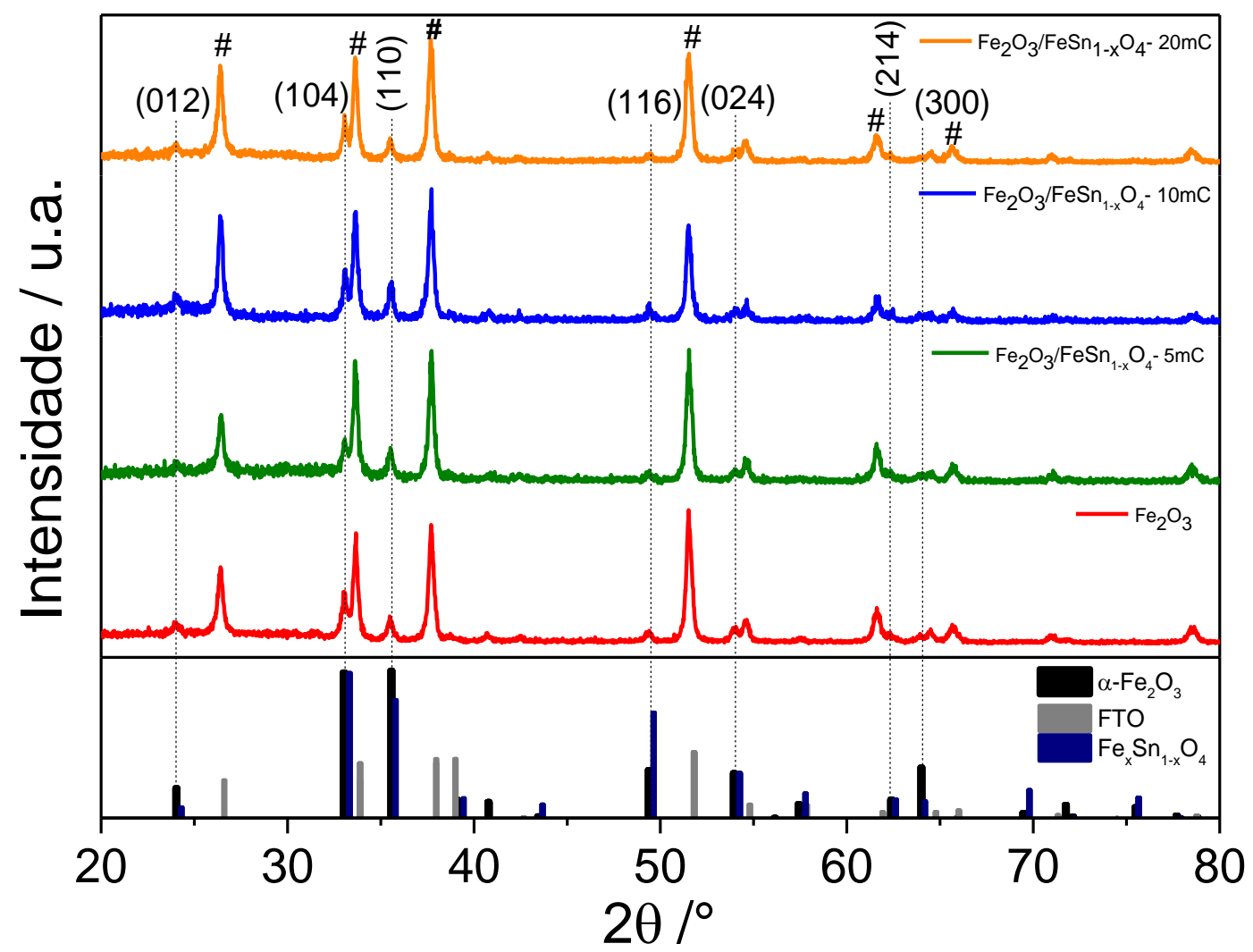

Fonte: Autoria própria.

Através da avaliação da cristalinidade dos filmes dopados com Sn, com base na largura total de meia-altura (FWHM) para o pico do DRX relacionado ao plano (110) da hematita, foi possível verificar variação na cristalinidade dos filmes com a dopagem com $\mathrm{Sn}$, como pode ser visto nos dados organizados na Tabela 4. Os filmes de hematita não-modificado e modificado com $20 \mathrm{mC}$ de $\mathrm{Sn}\left(\mathrm{Fe}_{2} \mathrm{O}_{3} / \mathrm{Fe}_{\mathrm{x}} \mathrm{Sn}_{1-\mathrm{x}} \mathrm{O}_{4}-20 \mathrm{mC}\right)$ apresentaram a maior valor de FWHM, ou seja, a menor cristalinidade dentre os filmes avaliados. Com base neste resultado, pode-se concluir que a cristalinidade da hematita pode ser melhorada pelo baixo nível de dopagem da superfície do filme com Sn, como observado para os filmes de modificados com $5 \mathrm{mC}\left(\mathrm{Fe}_{2} \mathrm{O}_{3} / \mathrm{Fe}_{\mathrm{x}} \mathrm{Sn}_{1-\mathrm{x}} \mathrm{O}_{4-}\right.$ $5 \mathrm{mC})$ e $10 \mathrm{mC}\left(\mathrm{Fe}_{2} \mathrm{O}_{3} / \mathrm{Fe}_{\mathrm{x}} \mathrm{Sn}_{1-\mathrm{x}} \mathrm{O}_{4}-10 \mathrm{mC}\right)$ de dopante. Por sua vez, a cristalinidade inferior dos filmes de $\mathrm{Fe}_{2} \mathrm{O}_{3} / \mathrm{Sn}$-20, em comparação com os outros filmes modificados com $\mathrm{Sn}$, pode ser explicada pela provável segregação de $\mathrm{Sn}$ nos contornos de grãos. Este fenômeno foi previamente discutido na literatura por Soares et al [119]. A segregação dos íons $\mathrm{Sn}^{+4}$ é impulsionada pela baixa solubilidade de Sn na rede da hematita, causando difusão de curto alcance da superfície do filme de ferro metálico para o bulk do material durante a etapa de tratamento térmico [76,119]. Deste modo, é provável que uma camada muito fina de $\mathrm{Fe}_{\mathrm{x}} \mathrm{Sn}_{1-}$ 
${ }_{\mathrm{x}} \mathrm{O}_{4}$ esteja presente na superfície de filmes modificados por Sn [120]. É importante comentar que a presença dessa camada altamente dopada não foi possível de ser confirmada pelos padrões de DRX, devido ao conteúdo muito baixo de $\mathrm{Sn}(\leq 4 \%$ atômico em relação aos átomos de Fe) e à superposição dos picos de DRX de camada dopada com as fases referentes à hematita $[73,75]$.

Tabela 4- Largura à meia altura (FWHM), composição e energia de band gap ( $\left.E_{\mathrm{g}}\right)$ para os filmes $\alpha-\mathrm{Fe}_{2} \mathrm{O}_{3}$ modificados com diferentes cargas de $\mathrm{Sn}$.

\begin{tabular}{|c|c|c|}
\hline Filmes & FWHM (grau) $)^{\mathbf{a}}$ & $\begin{array}{c}E_{\mathrm{g}} \\
(\mathrm{eV})^{\mathbf{b}}\end{array}$ \\
\hline $\mathrm{Fe}_{2} \mathrm{O}_{3}$ & 0,36 & 2,12 \\
\hline $\mathrm{Fe}_{2} \mathrm{O}_{3} / \mathrm{Fe}_{\mathrm{x}} \mathrm{Sn}_{1-\mathrm{x}} \mathrm{O}_{4-5} \mathrm{mC}$ & 0,29 & 2,11 \\
\hline $\mathrm{Fe}_{2} \mathrm{O}_{3} / \mathrm{Fe}_{x} \mathrm{Sn}_{1-\mathrm{x}} \mathrm{O}_{4}-10 \mathrm{mC}$ & 0,28 & 2,12 \\
\hline $\mathrm{Fe}_{2} \mathrm{O}_{3} / \mathrm{Fe}_{\mathrm{x}} \mathrm{Sn}_{1-\mathrm{x}} \mathrm{O}_{4-20 \mathrm{mC}}$ & 0,32 & 2,12 \\
\hline
\end{tabular}

a. Largura à meia altura (FWHM) para o pico de difração referente ao plano (110).

b. Energias de band gap obtidas a partir das curvas de Tauc (Figura 20-b).

Fonte: Autoria própria.

A caracterização óptica dos filmes de $\mathrm{Fe}_{2} \mathrm{O}_{3}$ e $\mathrm{Fe}_{2} \mathrm{O}_{3} / \mathrm{Fe}_{\mathrm{x}} \mathrm{Sn}_{1-\mathrm{x}} \mathrm{O}_{4}$ modificados com diferentes cargas de $\mathrm{Sn}$ consistiu em estimar os valores de faixa energética de band gap $\left(E_{\mathrm{g}}\right)$ através dos espectros de absorção UV-Vis. A Figura 20-a mostra os espectros de absorbância registrados para os filmes preparados. Através dos espectros de absorção foi possível verificar que as propriedades ópticas do filme de hematita não foi afetada pela dopagem superficial com estanho. Os valores de band gap apresentados na Tabela 4 foram obtidos a partir das curvas de Tauc (Figura 20-b) e ficaram entre 2,10 - 2,12 eV. Não foram observadas alterações significativas nos valores band gap do filme de hematita modificado, apontando que o estanho está presente em baixas concentrações. Natarajan et al [74] também verificou que a dopagem de filmes de hematita com baixo teor de Sn não causa mudança significativa no band gap. 
Figura 20-(a) Espectro de absorção dos filmes de hematita modificados com diferentes cargas de Sn e (b) Gráfico de $(\alpha h v)^{1 / 2} v s$. energia do fóton para os filmes de hematita modificados com diferentes cargas de Sn.
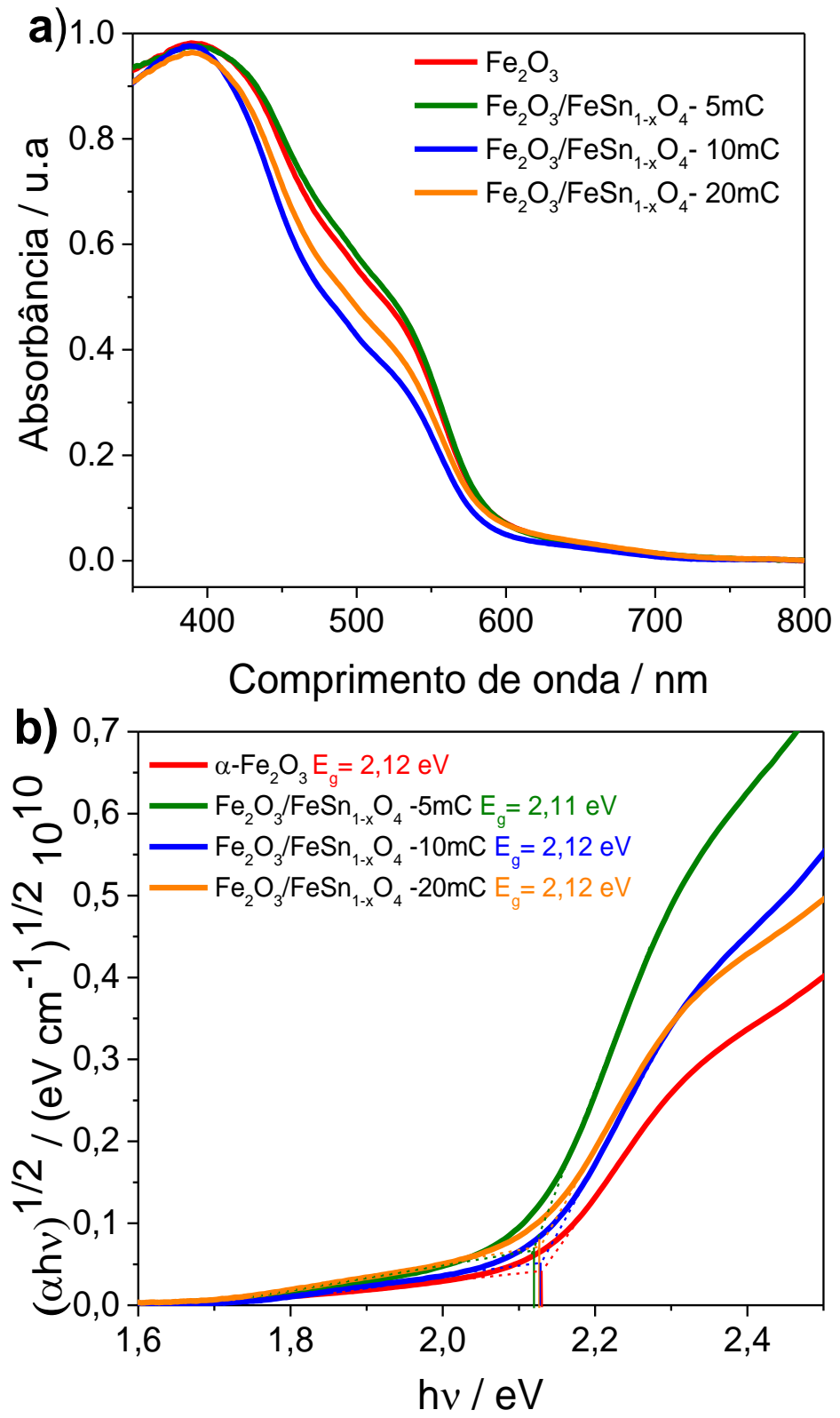

Fonte: Autoria própria.

\subsubsection{Caracterização Eletroquímica e Fotoeletroquímica}

Para identificar o efeito dos baixos níveis de dopagem com Sn nas propriedades eletrônicas dos filmes de hematita, foram realizados experimentos de Mott-Schottky (MS). Nos gráficos de MS apresentados na Figura 21, pode-se observar que todos os filmes mostraram uma inclinação positiva característica dos semicondutores do tipo $\mathrm{n}$ que indica que os elétrons são os portadores de carga majoritário [68,121]. Os valores dos potenciais de banda plana $\left(E_{\mathrm{fb}}\right)$ e da densidade de doadores de elétrons $\left(\mathrm{N}_{\mathrm{D}}\right)$, calculados a partir das inclinações dos gráficos 
MS, são apresentados na Tabela 5. Através dos gráficos da Figura 21 e dos dados expressos na Tabela 5, pode-se verificar uma diferença expressiva nos potenciais de banda plana para os filmes modificados com Sn em comparação ao filme de hematita não-modificado. O filme nãomodificado apresentou $E_{\mathrm{fb}}$ de 0,68 V (vs. ERH), um pouco maior do que os relatados anteriormente para este material geralmente na faixa de 0,4-0,6 V (vs. ERH) [61,111]. Esse elevado $E_{\mathrm{fb}}$ pode estar relacionado à alta densidade de defeitos na superfície, que podem levar ao pinning do nível de Fermi e, consequentemente, menor fotovoltagem, sendo necessária a aplicação de maior energia potencial para alcançar melhores respostas PEC [45,81]. O pequeno deslocamento negativo no potencial de $E_{\mathrm{fb}}$ observado para as amostras de $\mathrm{Fe}_{2} \mathrm{O}_{3} / \mathrm{Fe}_{\mathrm{x}} \mathrm{Sn}_{1-\mathrm{x}} \mathrm{O}_{4-}$ $5 \mathrm{mC}$ e $\mathrm{Fe}_{2} \mathrm{O}_{3} / \mathrm{Fe}_{\mathrm{x}} \mathrm{Sn}_{1-\mathrm{x}} \mathrm{O}_{4}-10 \mathrm{mC}$ indica a passivação de defeitos superficiais pela incorporação do Sn. Por sua vez, o fotoanodo $\mathrm{Fe}_{2} \mathrm{O}_{3} / \mathrm{Fe}_{\mathrm{x}} \mathrm{Sn}_{1-\mathrm{x}} \mathrm{O}_{4}-20 \mathrm{mC}$ revelou o $E_{\mathrm{fb}}$ menos positivo entre as amostras analisadas; esta grande mudança pode ser causada pela formação de uma camada mais espessa de $\mathrm{Fe}_{\mathrm{x}} \mathrm{Sn}_{1-\mathrm{x}} \mathrm{O}_{4}$ na superfície do filme de hematita.

Figura 21-Gráficos de Mott-Schottky registrados com frequência de $1 \mathrm{kHz}$ em KOH 1 mol L-1 (pH 13,6) para os filmes: (a) $\mathrm{Fe}_{2} \mathrm{O}_{3}$, (b) $\mathrm{Fe}_{2} \mathrm{O}_{3} / \mathrm{Fe}_{\mathrm{x}} \mathrm{Sn}_{1-\mathrm{x}} \mathrm{O}_{4-5 m C}$, (c) $\mathrm{Fe}_{2} \mathrm{O}_{3} / \mathrm{Fe}_{\mathrm{x}} \mathrm{Sn}_{1-\mathrm{x}} \mathrm{O}_{4-10 m C}$ e (d) $\mathrm{Fe}_{2} \mathrm{O}_{3} / \mathrm{Fe}_{\mathrm{x}} \mathrm{Sn}_{1-\mathrm{x}} \mathrm{O}_{4}-20 m C$.
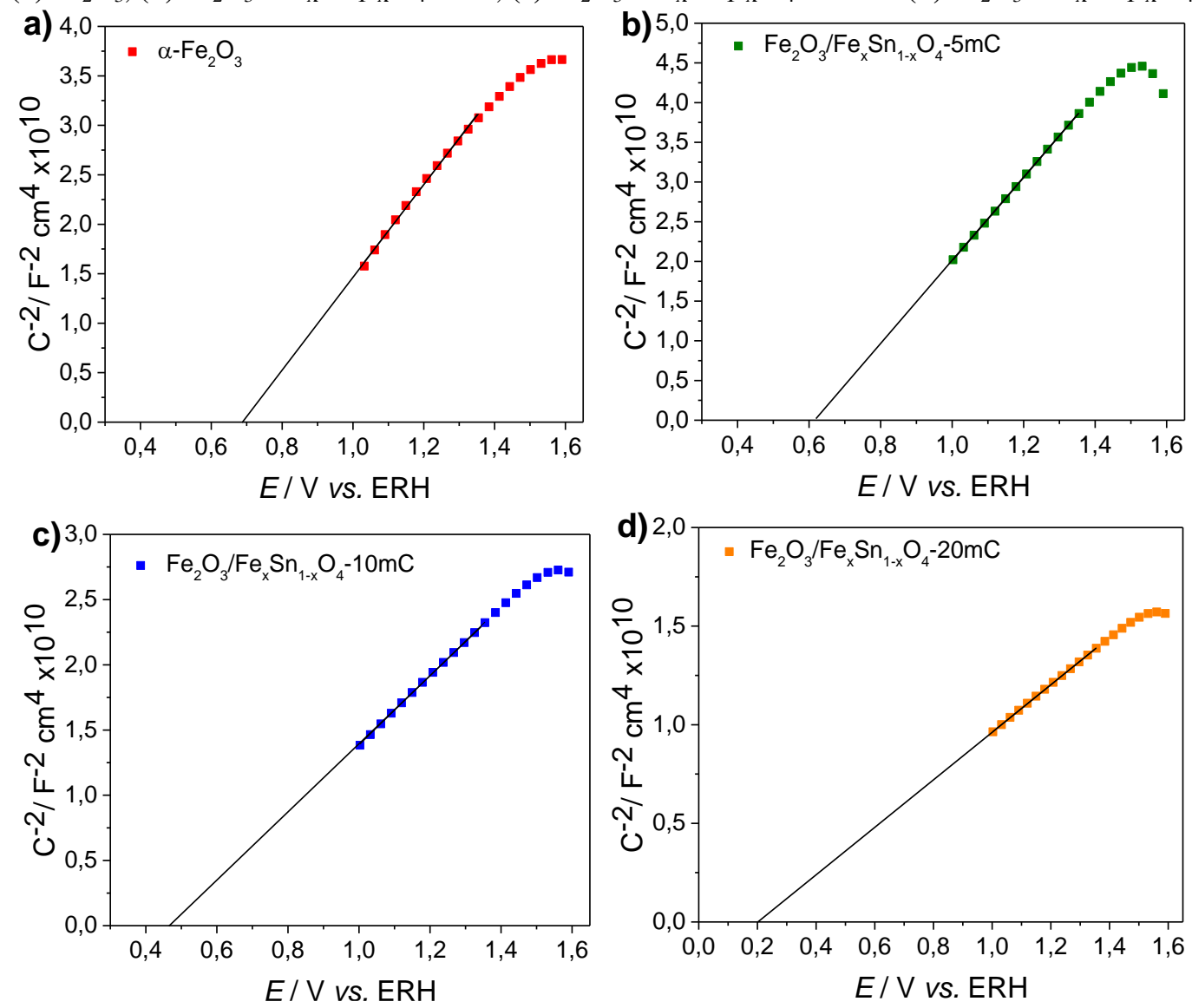

Fonte: Autoria própria. 
A densidade de doadores dos filmes de hematita modificados com $5 \mathrm{mC}$ e $10 \mathrm{mC}$ de Sn $\left(\mathrm{Fe}_{2} \mathrm{O}_{3} / \mathrm{Fe}_{\mathrm{x}} \mathrm{Sn}_{1-\mathrm{x}} \mathrm{O}_{4-}-5 \mathrm{mC}\right.$ e $\mathrm{Fe}_{2} \mathrm{O}_{3} / \mathrm{Fe}_{\mathrm{x}} \mathrm{Sn}_{1-\mathrm{x}} \mathrm{O}_{4-}$ 10mC, respectivamente) permaneceram na mesma ordem de magnitude $\left(10^{19} \mathrm{~cm}^{-3}\right)$ que o filme de hematita sem modificação. As mudanças desprezíveis na $\mathrm{N}_{\mathrm{D}}$ do filme modificado com $5 \mathrm{mC}$ de $\mathrm{Sn}$ podem estar associadas à baixa difusão de $\mathrm{Sn}^{4+}$ para o bulk da hematita, durante o processo de tratamento térmico. Como comentado anteriormente, o Sn tende a segregar nos contornos de grão de hematita [76]e, assim, a baixa quantidade de Sn que pode ter se difundida para o bulk da hematita foi insuficiente para alterar suas propriedades optoeletrônicas $[73,75,76,120]$. O filme de hematita modificado com $10 \mathrm{mC} \mathrm{cm}^{-2}$ apresentou um aumento de 2 vezes na densidade de portadores de cargas do filme de hematita não-modificado. O filme $\mathrm{Fe}_{2} \mathrm{O}_{3} / \mathrm{Fe}_{\mathrm{x}} \mathrm{Sn}_{1-\mathrm{x}} \mathrm{O}_{4}-20 \mathrm{mC}$ apresentou densidade de portadores uma ordem de magnitude maior que todos os outros filmes, que está associado à maior dopagem do filme de hematita com Sn. Este fato pode ser uma indicação de que este filme possui maior quantidade de Sn nos contornos de grão, o que também pode estar associado à sua menor cristalinidade em comparação aos outros filmes modificados por Sn. Miao et al [122] reportou que o aumento da densidade de portadores de cargas minoritários pode reduzir a recombinação das cargas fotogeradas, aumentar o tempo de vida e melhorar a eficiência da reação de oxidação da água.

Tabela 5- Potencial de banda plana $\left(E_{\mathrm{fb}}\right)$ e densidade de portadores $\left(\mathrm{N}_{\mathrm{D}}\right)$ para filmes de hematita não modificado e modificados com diferentes cargas de $\mathrm{Sn}$.

\begin{tabular}{|c|c|c|}
\hline Filmes & $\begin{array}{c}\boldsymbol{E}_{\mathbf{f b}} \\
(\mathbf{V} v \boldsymbol{v s} . \mathbf{E R H})^{\mathbf{a}}\end{array}$ & $\begin{array}{c}N_{\mathrm{D}} \\
\left(\mathrm{x10}^{19} \mathrm{~cm}^{-3}\right)^{\mathrm{a}}\end{array}$ \\
\hline$\alpha-\mathrm{Fe}_{2} \mathrm{O}_{3}$ & 0,68 & 3,82 \\
\hline $\mathrm{Fe}_{2} \mathrm{O}_{3} / \mathrm{Fe}_{x} \mathrm{Sn}_{1-x} \mathrm{O}_{4-5 m C}$ & 0,59 & 3,35 \\
\hline $\mathrm{Fe}_{2} \mathrm{O}_{3} / \mathrm{Fe}_{\mathrm{x}} \mathrm{Sn}_{1-\mathrm{x}} \mathrm{O}_{4}-10 \mathrm{mC}$ & 0,45 & 7,62 \\
\hline $\mathrm{Fe}_{2} \mathrm{O}_{3} / \mathrm{Fe}_{\mathrm{x}} \mathrm{Sn}_{1-\mathrm{x}} \mathrm{O}_{4-20 \mathrm{mC}}$ & 0,21 & 14,61 \\
\hline
\end{tabular}

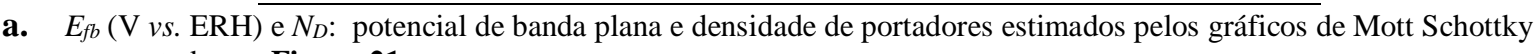
apresentados na Figura 21.

Fonte: Autoria própria.

O comportamento fotoeletroquímico dos fotoanodos de hematita modificados com $\mathrm{Sn}$ para a REO foi investigado por voltametria linear em eletrólito alcalino $\left(1,0 \mathrm{~mol} \mathrm{~L}{ }^{-1} \mathrm{KOH}, \mathrm{pH}\right.$ 13,6), no escuro e sob iluminação simulada. Os voltamogramas lineares estão apresentados na 
Figura 22 e os valores de potencial de onset e densidade de fotocorrente nos potenciais 1,23 e $1,60 \mathrm{~V}(v s$. ERH) estão apresentados na Tabela 5.

Figura 22-Voltamogramas lineares registrados a $20 \mathrm{mVs}^{-1}$ no escuro (linha tracejada) e sob iluminação com simulador solar (100 mW cm$~^{-1}$, com filtro A.M. 1.5) (linha contínua) para os filmes de hematita não-modificados e modificados com diferentes cargas de Sn em KOH 1,0 mol L $^{-1}$.

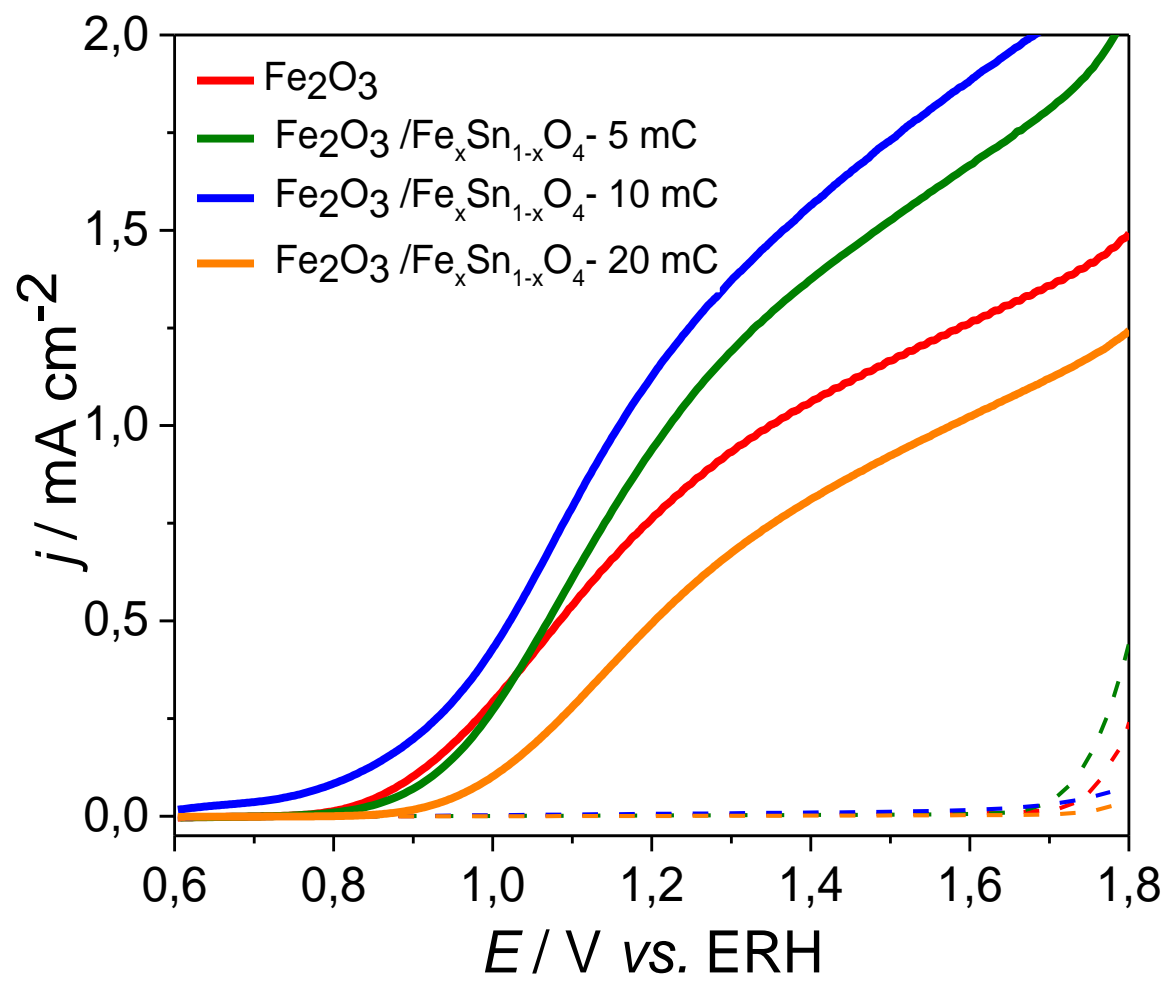

Fonte: Autoria própria.

Como mostrado na Figura 22-a, o filme de hematita não modificado exibiu uma densidade de fotocorrente de $0,83 \mathrm{~mA} \mathrm{~cm}^{-2}$ a 1,23V ( $v s$. ERH) e um potencial de onset $\left(E_{\text {on }}\right)$ de $\sim 0,90 \mathrm{~V}$. Em comparação com a hematita não-modificado, o filme $\mathrm{Fe}_{2} \mathrm{O}_{3} / \mathrm{Fe}_{\mathrm{x}} \mathrm{Sn}_{1-\mathrm{x}} \mathrm{O}_{4}-20$ mostrou uma diminuição de $35 \%$ na densidade de fotocorrente e um deslocamento de $50 \mathrm{mV}$ no $E_{\text {on }}$ em direção a potenciais mais positivos. Comportamento semelhante foi relatado anteriormente por Hufnagel e coautores [76] para filmes com alto nível de dopagem com Sn. $\mathrm{Xi}$ et al [75] discutiram que esses efeitos podem estar relacionados à formação da camada superficial espessa de $\mathrm{Fe}_{\mathrm{x}} \mathrm{Sn}_{1-\mathrm{x}} \mathrm{O}_{4}$, que bloqueia tanto transporte de elétrons e buracos e aumenta o pinning do nível de Fermi. O pinning do nível de Fermi causa o deslocamento das bordas das bandas, que dificulta a separação das cargas fotogeradas, uma vez que o aumento do potencial aplicado não leva a uma melhor separação de cargas [45,81]. Este efeito leva a diminuição da fotovoltagem do filme de hematita e diminuição das propriedades PEC [81]. Outro fato que observado foi a diminuição da cristalinidade do filme em comparação com os outros filmes 
modificados por $\mathrm{Sn}$, que também podem estar associados com a diminuição da performance PEC [76].

A modificação da superfície em $10 \mathrm{mC}$ de $\mathrm{Sn}$ (2\% atômico de Sn em relação aos átomos de Fe) promoveu um aumento de $48 \%$ e $49 \%$ na densidade de fotocorrente em 1,23 V (vs. ERH) e 1,60 V (vs. ERH), respectivamente, e um deslocamento no $E_{\text {on }}$ de $\sim 100 \mathrm{mV}$ em direção a potenciais menos positivos. Estes resultados indicam que parte dos estados superficiais foi passivada pela formação de uma fina camada de $\mathrm{Fe}_{\mathrm{x}} \mathrm{Sn}_{1-\mathrm{x}} \mathrm{O}_{4}$, reduzindo simultaneamente a recombinação de carga dos transportadores fotogerados e o pinning nível de Fermi na superfície do filme $[47,75]$. Curiosamente, o filme modificado com a menor carga de $\mathrm{Sn}\left(\mathrm{Fe}_{2} \mathrm{O}_{3} / \mathrm{Fe}_{\mathrm{x}} \mathrm{Sn}_{1-\mathrm{x}} \mathrm{O}_{4}-5 \mathrm{mC}\right)$ não mostrou mudança significativa no $E_{\mathrm{on}}$, apesar da melhoria superior a $21 \%$ e $32,5 \%$ na fotocorrente em 1,23 V (vs. ERH) e 1,60 V (vs. ERH), respectivamente. Este resultado mostra que, mesmo em um nível baixo de dopagem superficial, a modificação $\mathrm{Sn}$ pode melhorar o transporte de carga e diminuir a recombinação através dos estados superficiais ou dos contornos de grãos, resultando em um aumento da densidade de fotocorrente mesmo sem eliminar significativamente o pinning do nível Fermi que pode ser a causa da ausência de mudança de $E_{\text {on }}$ [123]. Além disso, o aprimoramento da propriedade PEC desses filmes também pode estar associado à melhoria da cristalinidade do filme anteriormente observada nos resultados de DRX, o que também diminui a recombinação das cargas no bulk e nos contornos de grão.

Tabela 6- Parâmetros da performance fotoeletroquímica dos filmes de hematita não modificados e modificados com diferentes cargas de $\mathrm{Sn}$.

\begin{tabular}{|c|c|c|c|c|}
\hline Filmes & $\begin{array}{c}\text { j, REO } \\
\left(\mathrm{mA} \mathrm{cm}^{-2}\right)^{\mathrm{a}}\end{array}$ & $\begin{array}{c}\mathbf{j}, 1.60 \mathrm{~V} \\
\left(\mathrm{~mA} \mathrm{~cm}^{-2}\right)^{\mathrm{a}}\end{array}$ & $\begin{array}{c}E_{\text {on }} \\
(\mathbf{V})^{\mathbf{b}}\end{array}$ & $\begin{array}{l}\mathrm{V}_{\text {OC }} \\
(\mathrm{V})^{\mathrm{c}}\end{array}$ \\
\hline $\mathrm{Fe}_{2} \mathrm{O}_{3}$ & 0,83 & 1,26 & 0,90 & 0,32 \\
\hline $\mathrm{Fe}_{2} \mathrm{O}_{3} / \mathrm{Fe}_{\mathrm{x}} \mathrm{Sn}_{1-\mathrm{x}} \mathrm{O}_{4-5} \mathrm{mC}$ & 1,01 & 1,67 & 0,80 & 0,32 \\
\hline $\mathrm{Fe}_{2} \mathrm{O}_{3} / \mathrm{Fe}_{\mathrm{x}} \mathrm{Sn}_{1-\mathrm{x}} \mathrm{O}_{4-10 \mathrm{mC}}$ & 1,22 & 1,88 & 0,80 & 0,31 \\
\hline $\mathrm{Fe}_{2} \mathrm{O}_{3} / \mathrm{Fe}_{\mathrm{x}} \mathrm{Sn}_{1-\mathrm{x}} \mathrm{O}_{4}-20 \mathrm{mC}$ & 0,54 & 1,02 & 0,90 & 0,13 \\
\hline
\end{tabular}

a. $\mathrm{j}$, REO e j,1,6v: Densidade de fotocorrente a 1,23 V e 1,60 V (vs ERH), respectivamente, em $1 \mathrm{~mol} \mathrm{~L}^{-1} \mathrm{KOH}(\mathrm{pH} 13,6)$ sob iluminação solar simulada $100 \mathrm{~mW} \mathrm{~cm} \mathrm{~cm}^{-2}$. b. $\boldsymbol{E}_{\text {on }}$ (V vs. RHE): Potencial de onset para fotocorrente. c. Voc (V vs. ERH): Fotovoltagem em KOH $1 \mathrm{~mol} \mathrm{~L}^{-1}$.

Fonte: Autoria própria.

Por fim, foram realizados estudos de fotoestabilidade dos filmes $\mathrm{Fe}_{2} \mathrm{O}_{3}$ (não modificado) e $\mathrm{Fe}_{2} \mathrm{O}_{3} / \mathrm{Fe}_{\mathrm{x}} \mathrm{Sn}_{1-\mathrm{x}} \mathrm{O}_{4}-10 \mathrm{mC}$, aplicando 1,6 V (vs. ERH), sob iluminação solar 
simulada em KOH $1 \mathrm{~mol} \mathrm{~L}^{-1}$ (pH 13,6). Os cronoamperogramas estão apresentados na Figura 23. Nota-se que mesmo o filme de hematita dopado com estanho apresentou alta estabilidade por um período de $15 \mathrm{~h}$. Embora não tenha sido possível identificar na análise de DRX, a camada de passivação formada na superfície do filme de hematita modificado com Sn é provavelmente composta de $\mathrm{Fe}_{\mathrm{x}} \mathrm{Sn}_{1-\mathrm{x}} \mathrm{O}_{4}$, uma vez que o $\mathrm{SnO}_{2}$ é quimicamente instável em $\mathrm{pH}$ alcalinos e elevados potenciais[75].

Figura 23-Cronoamperogramas registrados a 1,6 V (vs. ERH) em hidróxido de potássio $1,0 \mathrm{~mol} \mathrm{~L}^{-1}$ sob iluminação solar simulada para os filmes de $\mathrm{Fe}_{2} \mathrm{O}_{3}$ e $\mathrm{Fe}_{2} \mathrm{O}_{3} / \mathrm{Fe}_{\mathrm{x}} \mathrm{Sn}_{1-\mathrm{x}} \mathrm{O}_{4}-10 \mathrm{mC}$.

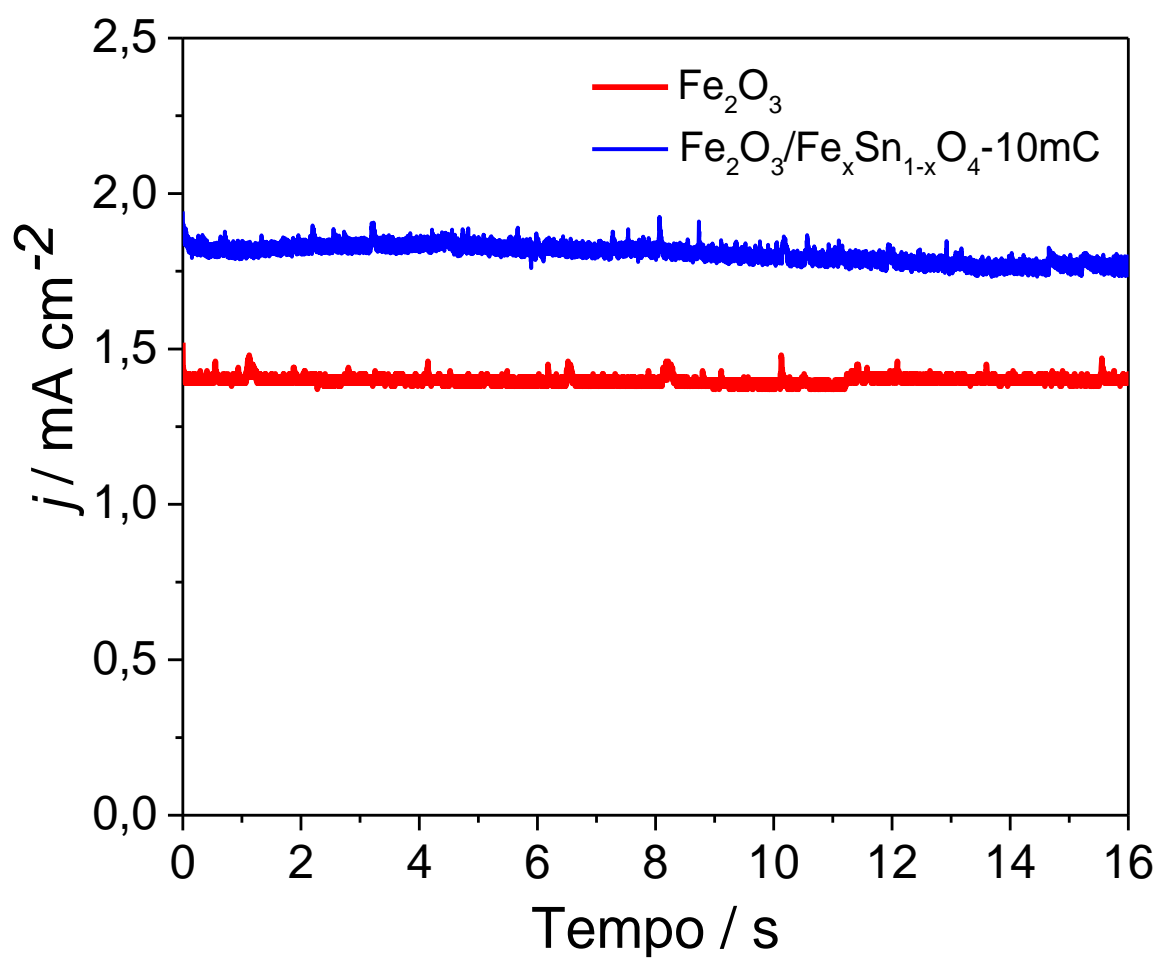

Fonte: Autoria própria.

Para entender os efeitos da dopagem com diferentes níveis estanho na reposta fotoeletroquímica dos fotoanodos de hematita foram realizados experimentos de transientes de potencial de circuito aberto (OCPT) e as curvas de OCPT são apresentadas na Figura 24. Na Tabela 5 estão apresentados os valores de fotovoltagem, calculados a partir da diferença de potencial de circuito aberto no escuro e sob iluminação, para os filmes analisados. Todos os filmes apresentaram uma mudança negativa no potencial de circuito aberto $\left(E_{\mathrm{OC}}\right)$ após a iluminação, característica dos semicondutores do tipo n. 
Figura 24- Curvas de OCP para os filmes de hematita não-modificado e modificados com diferentes níveis de $\mathrm{Sn}$ em hidróxido de potássio $1 \mathrm{~mol} \mathrm{~L}^{-1}$ (pH 13,6) com intervalo de iluminação:10 s escuro-140s claro-150 s escuro.

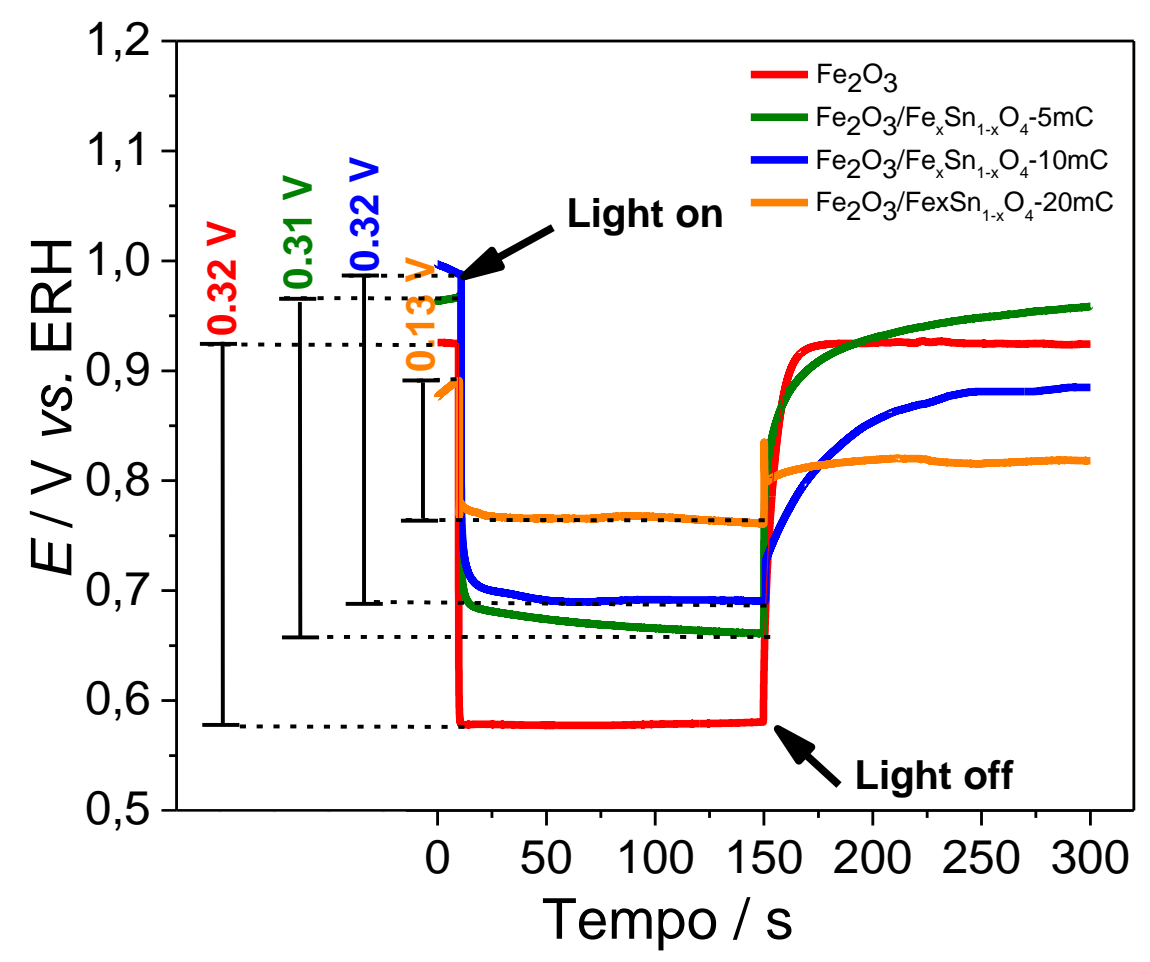

Fonte: Autoria própria.

A modificação com $20 \mathrm{mC}$ de estanho levou a uma diminuição da fotovoltagem do filme para $0,15 \mathrm{~V}$. A menor fotovoltagem desta amostra pode estar relacionada com o aumento do pinning do nível de Fermi pela formação de uma camada mais grossa de $\mathrm{Fe}_{\mathrm{x}} \mathrm{Sn}_{1-\mathrm{x}} \mathrm{O}_{4}$ na superfície do filme, justificando seu fraco desempenho PEC. Embora o valor de $V_{\text {OC }}$ tenha permanecido semelhante ao filme de hematita não-modificado, foi observado um deslocamento para potenciais mais positivos no potencial de circuito aberto $\left(E_{\mathrm{OC}}\right)$ no escuro para os filmes modificados $\mathrm{Fe}_{2} \mathrm{O}_{3} / \mathrm{Fe}_{\mathrm{x}} \mathrm{Sn}_{1-\mathrm{x}} \mathrm{O}_{4}-5 \mathrm{mC}$ e $\mathrm{Fe}_{2} \mathrm{O}_{3} / \mathrm{Fe}_{\mathrm{x}} \mathrm{Sn}_{1-\mathrm{x}} \mathrm{O}_{4}-10 \mathrm{mC}$. O deslocamento do $E_{\mathrm{OC}}$ é um indicativo da passivação dos defeitos na superfície, uma vez que esses defeitos são a principal causa da pinning do nível de Fermi que torna o $E_{\mathrm{OC}}$ no escuro mais baixo que o potencial de equilíbrio para a reação de evolução de oxigênio [46]. Apesar da modificação do Sn promover passivação dos defeitos da superfície dos filmes de hematita, estes apresentaram a mesma fotovoltagem que o filme não-modificado. A fotovoltagem é governada pela natureza da junção semicondutor-eletrólito [20]; no entanto, vários trabalhos - incluindo os resultados de Durrant e coautores [124,125], apontam que a recombinação de cargas no bulk também pode estar propensa a afetar o $\mathrm{V}_{\mathrm{OC}}$ dos fotoeletrodos de hematita. Assim, o fenômeno observado mostra que o $\mathrm{V}_{\mathrm{OC}}$ nesses filmes eletrodepositados é provavelmente mais influenciado por defeitos eletrônicos do bulk. 
Além disso, a modificação com Sn promoveu alteração no perfil da curva OCPT, quando a luz é apagada, sendo possível observar duas constantes de tempo de recombinação de cargas diferentes [125]. A recombinação rápida faz o potencial de circuito aberto aumentar rapidamente em direção ao $E_{\mathrm{OC}}$ no escuro. Após este aumento abrupto, a recombinação mais lenta domina o processo, aumentando o potencial exponencialmente na direção do $E_{\mathrm{OC}}$ escuro. A recombinação lenta está associada ao tempo no qual os portadores minoritários retidos nos estados superficiais [76] podem ser coletados pelas moléculas de água, em eletrólito alcalino íons hidroxila, antes de recombinar. Assim, o maior tempo gasto para que o potencial de circuito aberto retorne para $E_{\mathrm{OC}}$ no escuro indica que os buracos estão menos propensos a recombinação e podem estar associados com melhora no desempenho PEC [125]. A modificação da superfície do filme de hematita tonou mais lenta a recombinação de carga na superfície, sugerindo passivação dos estados superficiais que atuam como centro de recombinação. A amostra de $\mathrm{Fe}_{2} \mathrm{O}_{3} / \mathrm{Fe}_{x} \mathrm{Sn}_{1-\mathrm{x}} \mathrm{O}_{4}-10 \mathrm{mC}$ revelou o maior atraso na recombinação da carga superficial justificando o aprimoramento do desempenho da PEC observado na Figura 22.

De fato, a partir dos estudos realizados, o melhor comportamento fotoeletroquímico, menor potencial de banda plana, a maior densidade de portadores de carga, a melhora na densidade de fotocorrente, menor potencial de onset, e aparente maior constante de tempo para recombinação de cargas superficiais foi alcançado para o fotoanodo de hematita modificado na superfície com $10 \mathrm{mC}$ de $\mathrm{Sn}$; portanto, este filme foi selecionado para estudos de estudos subsequentes com deposição de cocatalisador.

\subsubsection{Estudo da modificação dos filmes $\mathrm{Fe}_{2} \mathrm{O}_{3}$ e $\mathrm{Fe}_{2} \mathrm{O}_{3} / \mathrm{Sn}-10 \mathrm{mC}$ com $\mathrm{NiOOH}$}

A partir do filme de hematita não-modificado e modificado com $10 \mathrm{mC}$ de $\mathrm{Sn}$, foram realizados estudos para verificar o efeito da deposição de uma fina camada $\mathrm{NiOOH}$ como cocatalisador nas propriedades eletrônicas e fotoeletroquímicas destes filmes.

\subsubsection{Otimização da carga $\mathrm{NiOOH}$ depositado}

Inicialmente foi avaliada a carga ótima de cocatalisador depositado sobre o filme de hematita para garantir o melhor desempenho PEC. Na Figura 25 estão apresentados os voltamogramas lineares registrados para o filme de hematita não-modificado após diferentes ciclos de deposição em eletrólito alcalino 1,0 $\mathrm{mol} \mathrm{L}^{-1} \mathrm{KOH}$, no escuro e sob iluminação 
simulada. Conforme observado na Figura 25, a deposição de uma fina camada amorfa de $\mathrm{NiOOH}$ sobre hematita levou ao aumento da densidade de fotocorrente de 0,83 para 1,05 mA $\mathrm{cm}^{-2}$ e ao deslocamento potencial $E_{\text {on }}$ de $\sim-100 \mathrm{mV}$. A melhora na performance PEC, pode estar associada à capacidade do cocatalisador de mediar a transferência de carga na interface, melhorando a cinética de transferência de carga, portanto, a fotocorrente [126]. Zhang e colaboradores observaram que a deposição de óxido de níquel também melhora o desempenho de fotoanodos constituídos de $\mathrm{BiVO}_{4}$ [127]. A camada de cocatalisador pode atuar coletando os buracos presos nos estados superficiais, reduzindo a recombinação de carga na junção semicondutor-eletrólito e diminuindo o pinning nível de Fermi [22,123].

Figura 25- Voltamogramas lineares registrados a $20 \mathrm{mVs}^{-1}$ no escuro (linha tracejada) e sob iluminação com simulador solar (100 $\mathrm{mW} \mathrm{cm}^{-1}$, com filtro A.M. 1.5) (linha contínua) para os filmes de hematita não-modificados e modificados com diferentes ciclos de deposição de $\mathrm{NiO}_{\mathrm{x}}$ em $\mathrm{KOH} 1,0 \mathrm{~mol} \mathrm{~L}^{-1}$.

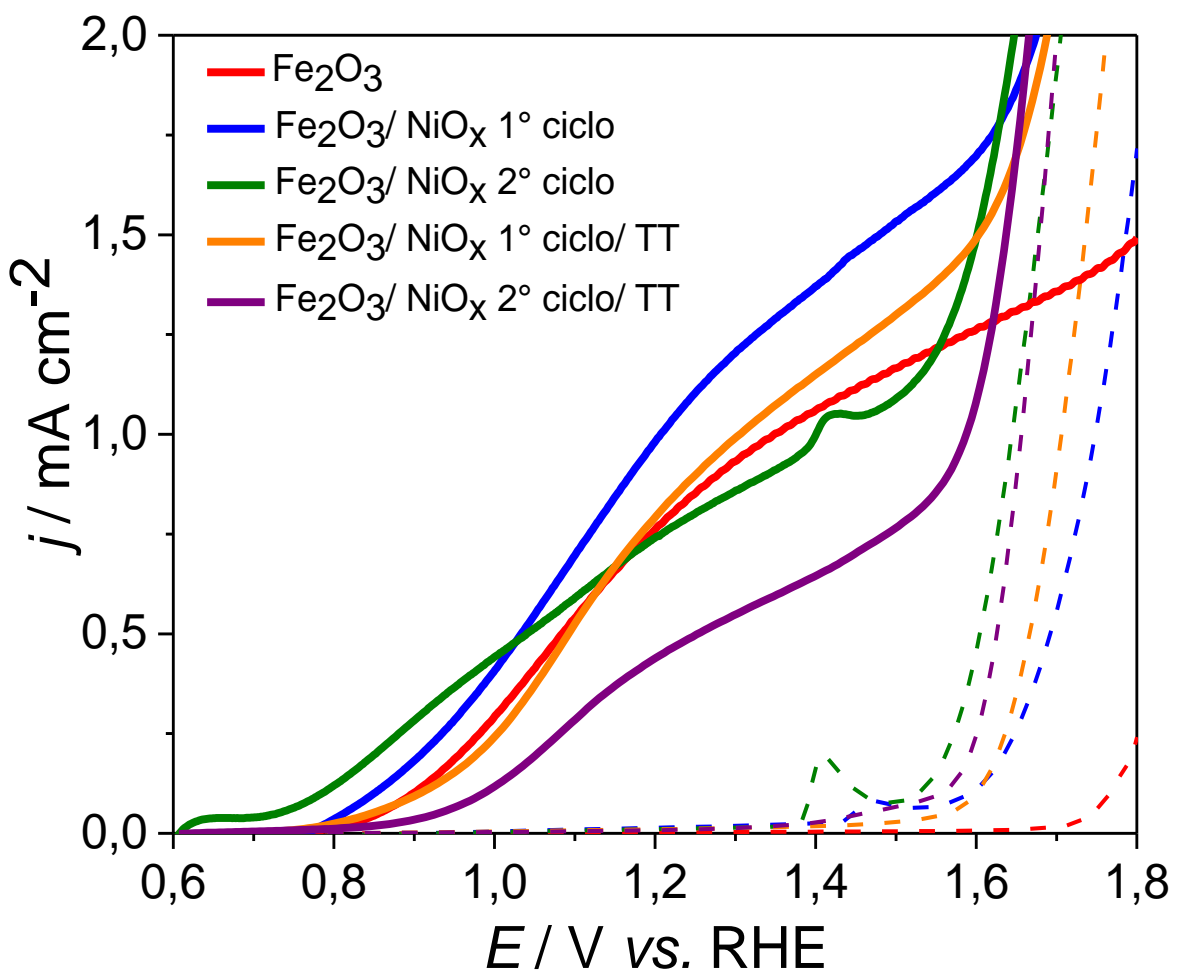

Fonte: Autoria própria.

Através dos voltamogramas da Figura 25, também é possível verificar claramente, que o aumento do número de ciclos de deposições levou a uma diminuição na densidade de fotocorrente. A deposição de uma camada mais espessa de cocatalisador resulta na criação de alta densidade de estados na superfície do filme de hematita, levando ao pinning do nível de Fermi. Assim, as cargas fotogeradas são direcionadas principalmente para oxidar o cocatalisador tendo em vista que o potencial do nível de Fermi do semicondutor se tornou mais 
alto que o potencial de oxidação da água [127]. Além disso, foi observado que a melhoria da resposta fotoeletroquímica do filme de hematita é observada apenas para a camada de cocatalisador amorfa. Morales-Guio et al [94], demonstraram que a deposição de finas camadas transparentes de $\mathrm{NiO}_{\mathrm{x}}$ como cocatalisador em filmes de hematita. Após o tratamento térmico dos mesmos a $300^{\circ} \mathrm{C}$ por $30 \mathrm{~min}$, verificou-se que a fotoatividade do filme, avaliada por iluminação frontal do filme de hematita, é reduzida.

\subsubsection{Caracterização Eletroquímica e Fotoeletroquímica}

Como o filme de NiOOH depositado sobre o fotoanodo de hematita não modificado e modificado com estanho é amorfo e extremamente fino, não foi possível observar diferenças na morfologia, estrutura entre os filmes de hematita não-modificados e modificados com óxido de níquel. Como pode ser observado na Figura B1 (Apêndice B), as propriedades ópticas dos filmes não foram alteradas com a deposição do cocatalisador. Também não foi possível identificar ou quantificar o co-catalisador depositado sobre o filme de hematita por EDS (Figura B2 Apêndice B). Provavelmente a quantidade de óxido de níquel depositada se encontra abaixo de limite de deteç̧ão dos equipamentos utilizados. A presença de níquel no filme pôde ser comprovada apenas por espectroscopia de fluorescência de Raio X, como pode ser verificado no espectro de fluorescência da Figura B3 (Apêndice B). Mesmo neste caso, ainda sim as intensidades observadas para este elemento são extremamente baixas. Deste modo, nesta seção serão apresentados apenas os resultados de caracterizações das propriedades eletrônicas e fotoatividade dos filmes modificados com o cocatalisador a partir de ensaios MottSchottky e voltametria linear em eletrólito alcalino.

Os gráficos de MS obtidos para as amostras estão apresentados na Figura 26 e os valores dos potenciais de banda plana $\left(E_{\mathrm{fb}}\right)$ e da densidade de doadores de elétrons $\left(\mathrm{N}_{\mathrm{D}}\right)$, calculados a partir das inclinações dos gráficos MS, estão apresentados na Tabela 7. Através da Figura 26 pode-se observar que a deposição a camada de óxido de níquel sobre os filmes não alterou a inclinação positiva da curva MS, indicando que mesmo após a deposição do mesmo os filmes continuam semicondutores do tipo $\mathrm{n}$ [121]. 
Figura 26- Gráfico de Mott-Schottky registrados com frequência de $1 \mathrm{kHz}$ em KOH $1 \mathrm{~mol} \mathrm{~L}^{-1}(\mathrm{pH}$ 13,6) para os filmes: (a) $\mathrm{Fe}_{2} \mathrm{O}_{3}$, (b) $\mathrm{Fe}_{2} \mathrm{O}_{3} / \mathrm{NiO}_{\mathrm{x}}$, (c) $\mathrm{Fe}_{2} \mathrm{O}_{3} / \mathrm{Fe}_{\mathrm{x}} \mathrm{Sn}_{1-\mathrm{x}} \mathrm{O}_{4}-10 \mathrm{mC}$ e (d) $\mathrm{Fe}_{2} \mathrm{O}_{3} / \mathrm{Fe}_{\mathrm{x}} \mathrm{Sn}_{1-\mathrm{x}} \mathrm{O}_{4}-10 \mathrm{mC} / \mathrm{NiO}_{\mathrm{x}}$.

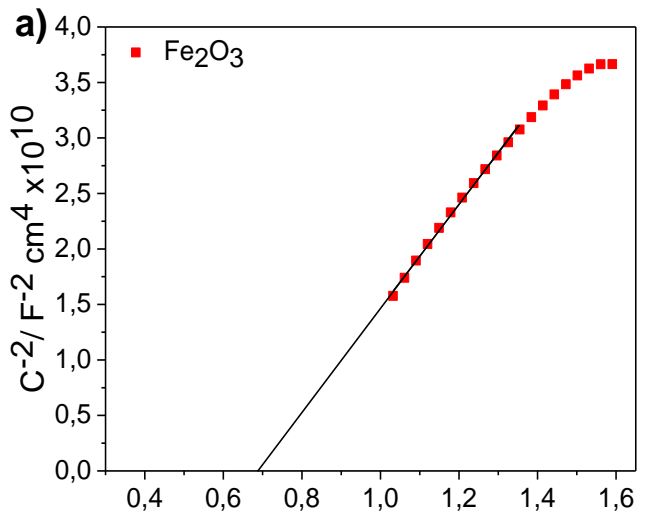

E / V vs. ERH

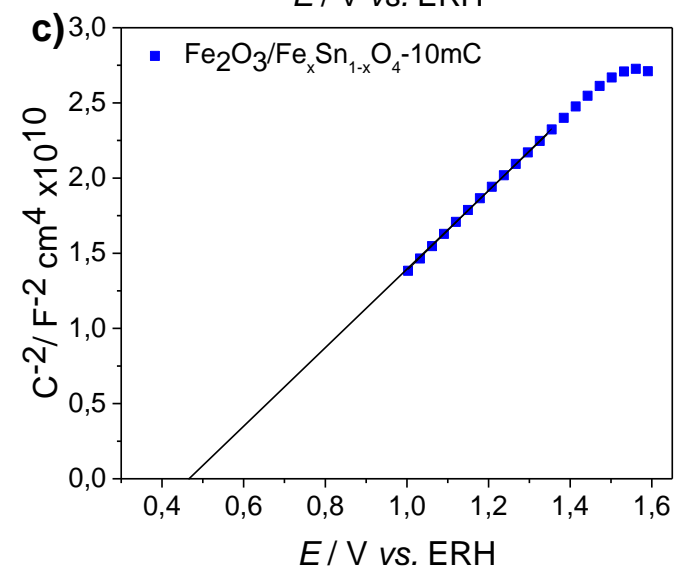

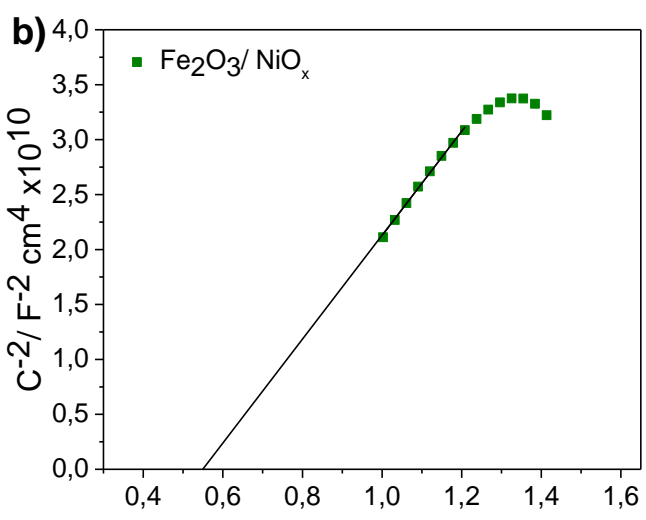

$E / \mathrm{V}$ vs. ERH

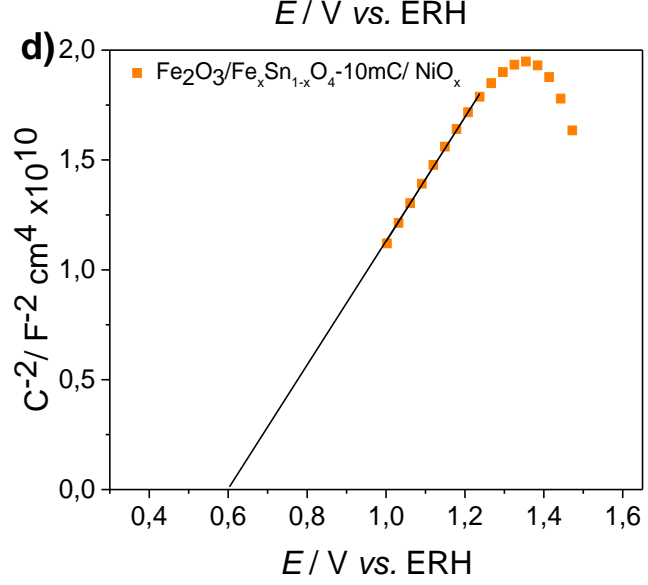

Fonte: Autoria própria.

A partir dos gráficos da Figura 26 e dos dados expressos na Tabela 7, pode-se observar que a deposição do cocatalisador sobre filme de hematita não-modificado resultou no deslocamento do $E_{\mathrm{fb}}$ para potenciais mais negativos, assim como foi observado para os filmes dopados com Sn. Este comportamento indica que a camada de catalisador também atua como passivador dos estados superficiais do filme de hematita. Para o filme de hematita dopado com o estanho, com estados superficiais parcialmente passivados, a deposição do cocatalisador promoveu um pequeno deslocamento do $E_{\mathrm{fb}}$ para potenciais positivos, mas ainda se manteve na faixa de potencial esperado para fotoanodos de hematita. A densidade de doadores dos filmes $\mathrm{Fe}_{2} \mathrm{O}_{3} / \mathrm{NiO}_{\mathrm{x}}$ e $\mathrm{Fe}_{2} \mathrm{O}_{3} / \mathrm{Fe}_{\mathrm{x}} \mathrm{Sn}_{1-\mathrm{x}} \mathrm{O}_{4}-10 \mathrm{mC} / \mathrm{NiO}_{\mathrm{x}}$ permaneceram semelhantes aos filmes não modificados com o catalisador. A alteração da densidade de portadores pela deposição do catalisador não era esperada, uma vez que os íons $\mathrm{Ni}^{2+}$ presentes neste cocatalisador não se difundem para o bulk da hematita tendo em vista que o fotoanodo não foi tratado termicamente após a deposição do catalisador. 
Tabela 7- Potencial de banda plana $\left(\mathrm{E}_{\mathrm{fb}}\right)$ e densidade de portadores $\left(\mathrm{N}_{\mathrm{D}}\right)$ para filmes de hematita e hematita dopada com $\mathrm{Sn}$ modificados com $\mathrm{NiO}_{x}$.

\begin{tabular}{|c|c|c|}
\hline Filmes & $\begin{array}{c}E_{\mathrm{fb}} \\
(\mathbf{V} v s . \mathbf{E R H})^{\mathbf{a}}\end{array}$ & $\begin{array}{c}N_{\mathrm{D}} \\
\left(\mathbf{x 1 0}^{19} \mathrm{~cm}^{-3}\right)^{\mathrm{a}}\end{array}$ \\
\hline$\alpha-\mathrm{Fe}_{2} \mathrm{O}_{3}$ & 0,68 & 3,82 \\
\hline $\mathrm{Fe}_{2} \mathrm{O}_{3} / \mathrm{NiO}_{x}$ & 0,55 & 3,70 \\
\hline $\mathrm{Fe}_{2} \mathrm{O}_{3} / \mathrm{Fe}_{\mathrm{x}} \mathrm{Sn}_{1-\mathrm{x}} \mathrm{O}_{4}-10 \mathrm{mC}$ & 0,45 & 7,62 \\
\hline $\mathrm{Fe}_{2} \mathrm{O}_{3} / \mathrm{Fe}_{\mathrm{x}} \mathrm{Sn}_{1-\mathrm{x}} \mathrm{O}_{4}-10 \mathrm{mC} / \mathrm{NiO}_{\mathrm{x}}$ & 0,60 & 7,71 \\
\hline
\end{tabular}

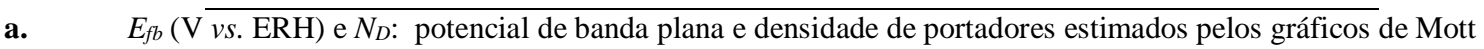
Schottky apresentados na Figura 26.

Fonte: Autoria própria.

O comportamento fotoeletroquímico dos fotoanodos modificados pela deposição do catalisador foi investigado por voltametria linear no mesmo eletrólito, no escuro e sob iluminação solar simulada. Os voltamogramas lineares estão apresentados na Figura 27 e os valores de potencial de onset e densidade de fotocorrente nos potenciais 1,23 e 1,60 V ( $v s . \mathrm{ERH})$ estão apresentados na Tabela 8. Na Figura 27, é possível observar que os filmes de $\mathrm{Fe}_{2} \mathrm{O}_{3} / \mathrm{NiO}_{\mathrm{x}}$ e $\mathrm{Fe}_{2} \mathrm{O}_{3} / \mathrm{Fe}_{x} \mathrm{Sn}_{1-\mathrm{x}} \mathrm{O}_{4} / \mathrm{NiO}_{\mathrm{x}}$ exibiram uma mudança de $~ 100$ e $250 \mathrm{mV}$ em $E_{\text {on }}$ em direção a potenciais menos positivos, em comparação com os respectivos filmes sem a camada de cocatalisador. Como discutido na seção 4.2.2.1, além da melhoria na cinética de transferência, a deposição do cocatalisador também é responsável por mitigar o pinning do nível de Fermi na interface, levando a um aumento na fotoatividade [123,127].

A partir da Figura 27 dos dados da Tabela 8, nota-se modificação do fotoanodo de hematita através da deposição de $\mathrm{NiO}_{\mathrm{x}}$ e da dopagem com $\mathrm{Sn}$ apresentou deslocamento $E_{\text {on }}$ semelhante quando comparado com o fotoanodo de hematita não-modificado, o que sugere efeito similar de ambas as estratégias de modificação na passivação dos estados superficiais [93,123]. A deposição do cocatalisador sobre a superfície de hematita parcialmente passivada por $\mathrm{Sn}$ resultou em $E_{\text {on }}$ menos positivo e na maior densidade de fotocorrente, $1,35 \mathrm{~mA} \mathrm{~cm} \mathrm{ca}^{-2}$ 1,23 V (vs. ERH), conforme resumido na Tabela 8. Liardet et al [93], também observaram melhor contribuição da camada do cocatalisador depositada sobre superfície de hematita previamente passivada por camada de óxido metálico. Embora os estados da superfície da hematita tenham sido parcialmente passivados pela camada $\mathrm{Fe}_{\mathrm{x}} \mathrm{Sn}_{1-\mathrm{x}} \mathrm{O}_{4}$, o cocatalisador depositado pode ter passivado os estados superficiais restantes, portanto, recombinação de 
carga na superfície é ainda menor que para o filme sem a camada de cocatalisador, justificando o melhor desempenho alcançado.

Figura 27- Voltamogramas lineares registrados a $20 \mathrm{mVs}^{-1}$ no escuro (linha tracejada) e sob iluminação com simulador solar (100 mW cm${ }^{-1}$, com filtro A.M. 1.5) (linha contínua) para os filmes modificados $\operatorname{com} \mathrm{NiO}_{\mathrm{x}}$ em $\mathrm{KOH} 1,0 \mathrm{~mol} \mathrm{~L}^{-1}$.

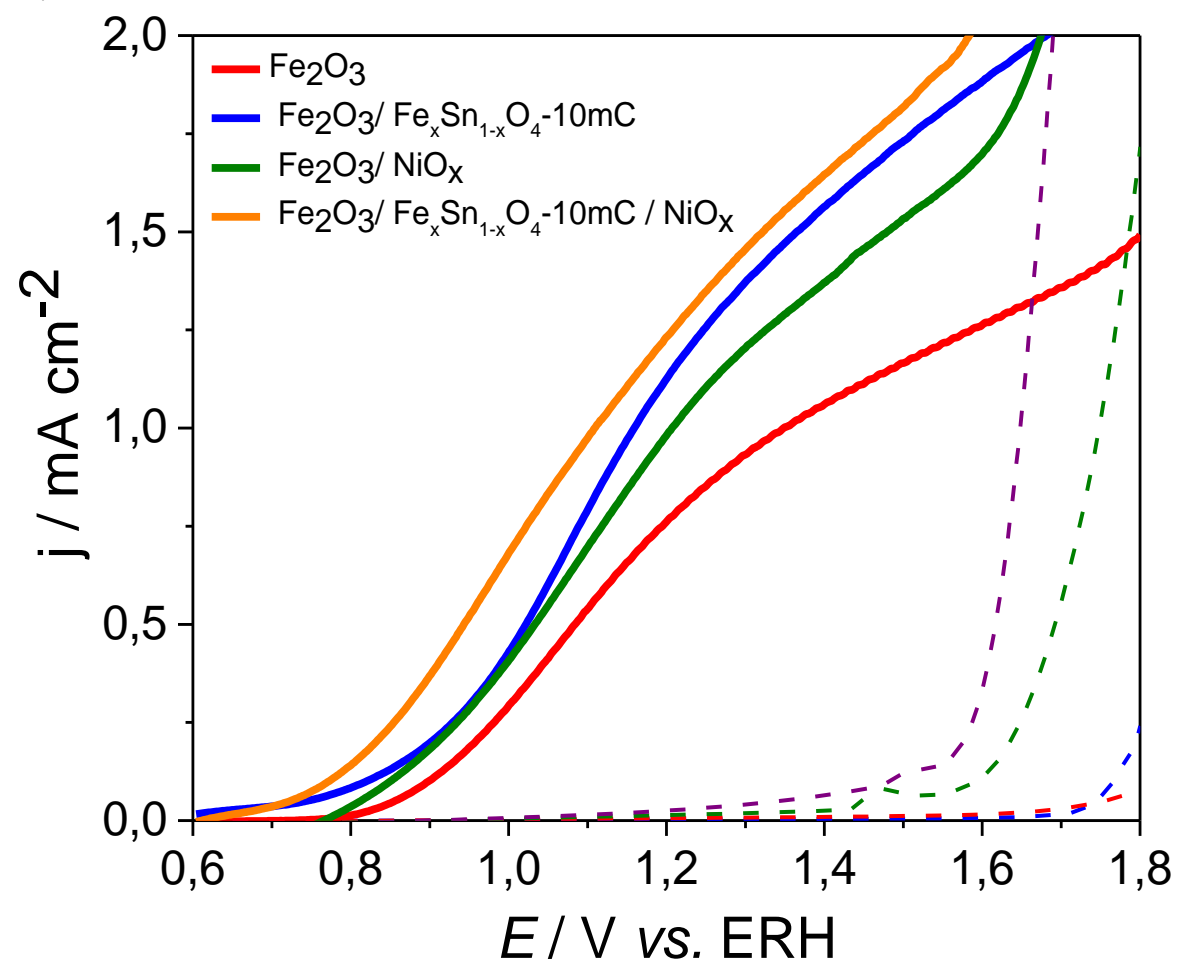

Fonte: Autoria própria.

Tabela 8- Parâmetros da performance fotoeletroquímica dos filmes de hematita não modificados e modificados com diferentes cargas de $\mathrm{Sn}$.

\begin{tabular}{|c|c|c|c|c|}
\hline Filmes & $\begin{array}{c}\mathbf{j}, \text { REO } \\
\left(\mathrm{mA} \mathrm{cm}^{-2}\right)^{a}\end{array}$ & $\begin{array}{c}\mathbf{j}, 1.60 \mathrm{~V} \\
\left(\mathrm{~mA} \mathrm{~cm}^{-2}\right)^{\mathrm{a}}\end{array}$ & $\begin{array}{l}E_{\text {on }} \\
(\mathbf{V})^{\mathbf{b}}\end{array}$ & $\begin{array}{l}\text { Voc } \\
(\mathbf{V})^{\mathrm{c}}\end{array}$ \\
\hline $\mathrm{Fe}_{2} \mathrm{O}_{3}$ & 0,83 & 1,26 & 0,90 & 0,32 \\
\hline $\mathrm{Fe}_{2} \mathrm{O}_{3} / \mathrm{NiO}_{x}$ & 1,05 & 1,75 & 0,80 & 0,27 à 0,41 \\
\hline $\mathrm{Fe}_{2} \mathrm{O}_{3} / \mathrm{Fe}_{x} \mathrm{Sn}_{1-\mathrm{x}} \mathrm{O}_{4-10 \mathrm{mC}}$ & 1,22 & 1,88 & 0,80 & 0,30 \\
\hline $\mathrm{Fe}_{2} \mathrm{O}_{3} / \mathrm{Fe}_{\mathrm{x}} \mathrm{Sn}_{1-\mathrm{x}} \mathrm{O}_{4}-10 \mathrm{mC} / \mathrm{NiO}_{\mathrm{x}}$ & 1,35 & 2,03 & 0,65 & 0,30 \\
\hline
\end{tabular}

a. j, REO e j,1,6v: Densidade de fotocorrente a 1,23 V e 1,60 V (vs ERH), respectivamente, em $1 \mathrm{~mol} \mathrm{~L}^{-1} \mathrm{KOH}(\mathrm{pH} \mathrm{13,6)}$ sob iluminação solar simulada $100 \mathrm{~mW} \mathrm{~cm}^{-2}$. b. $\boldsymbol{E}_{\text {on }}(\mathrm{V} v$ s. RHE): Potencial de onset para fotocorrente. c. Voc $(\mathrm{V} v s$. ERH): Fotovoltagem em KOH 1 mol L-1. d. $V_{\text {oc }}\left(V\right.$ vs. ERH): Fotovoltagem em KOH $1 \mathrm{~mol} \mathrm{~L}^{-1}+\mathrm{H}_{2} \mathrm{O}_{2} 0,5 \mathrm{~mol} \mathrm{~L}^{-1}$.

Fonte: Autoria própria.

Em seguida, foram realizados estudos de fotoestabilidade dos filmes $\mathrm{Fe}_{2} \mathrm{O}_{3}$ (não modificado) e $\mathrm{Fe}_{2} \mathrm{O}_{3} / \mathrm{Fe}_{\mathrm{x}} \mathrm{Sn}_{1-\mathrm{x}} \mathrm{O}_{4}-10 \mathrm{mC}$ modificados com $\mathrm{NiO}_{\mathrm{x}}$, aplicando 1,6 V (vs. ERH), sob 
iluminação solar simulada em KOH $1 \mathrm{~mol} \mathrm{~L}^{-1}(\mathrm{pH}$ 13,6). Os cronoamperogramas estão apresentados na Figura 28. Nota-se que mesmo após a modificação com o cocatalisador os filmes apresentaram alta estabilidade por um período de $15 \mathrm{~h}$.

Figura 28- Cronoamperogramas registrados a 1,6 V (vs. ERH) em hidróxido de potássio 1,0 mol $\mathrm{L}^{-1} \mathrm{sob}$ iluminação simulada para os filmes de $\mathrm{Fe}_{2} \mathrm{O}_{3}, \mathrm{Fe}_{2} \mathrm{O}_{3} / \mathrm{Fe}_{\mathrm{x}} \mathrm{Sn}_{1-\mathrm{x}} \mathrm{O}_{4-1}-10 m C, \mathrm{Fe}_{2} \mathrm{O}_{3} / \mathrm{NiO}_{\mathrm{x}}$ e $\mathrm{Fe}_{2} \mathrm{O}_{3} / \mathrm{Fe}_{\mathrm{x}} \mathrm{Sn}_{1-\mathrm{x}} \mathrm{O}_{4}-$ $10 \mathrm{mC} / \mathrm{NiO}_{\mathrm{x}}$.

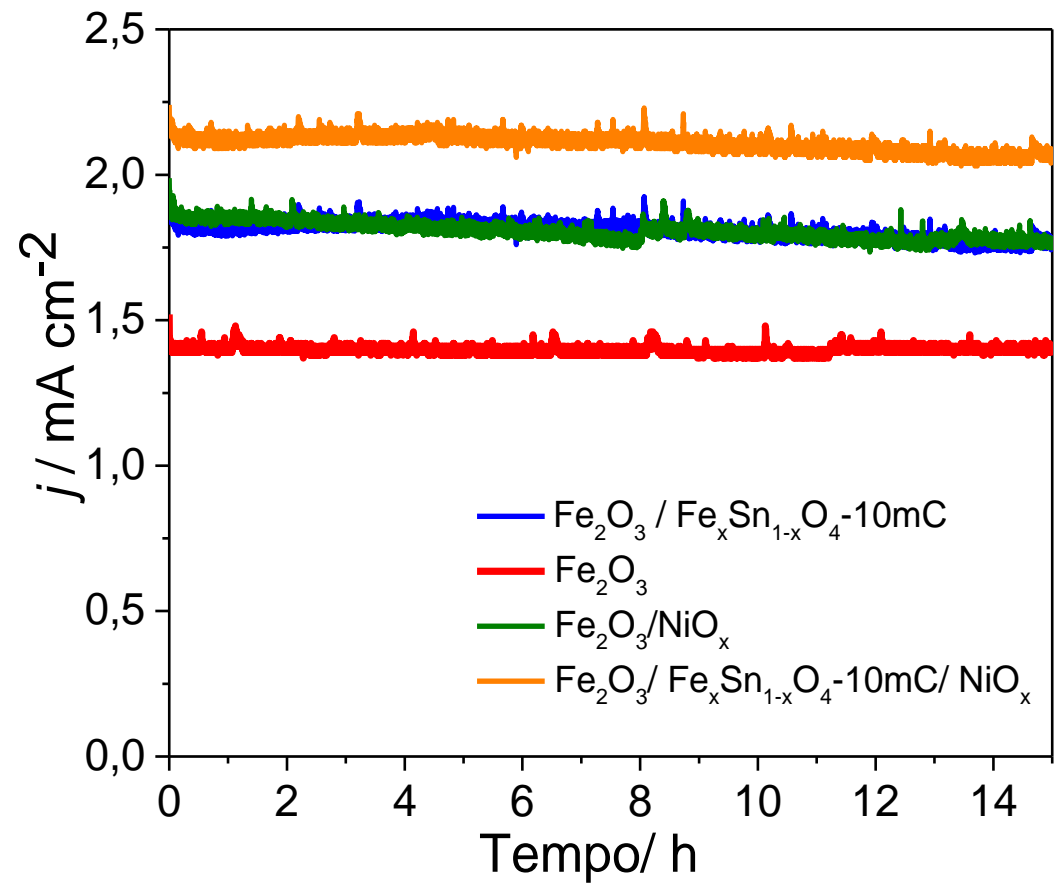

Fonte: Autoria própria.

Posteriormente, foram realizados experimentos de transientes de potencial de circuito aberto (OCPT) para verificar se a deposição da camada de cocatalisador afetaria o perfil curvas de OCPT e os valores de potencial de fotovoltagem. As curvas de OCPT, estão apresentadas na Figura 29 e os valores de fotovoltagem, calculados a partir da diferença de potencial de circuito aberto no escuro e sob iluminação, para os filmes analisados estão expressos na Tabela 8. Nas curvas da Figura 29, pode-se observar que todos os filmes apresentaram uma mudança negativa $E_{\mathrm{OC}}$ após a iluminação, confirmando que a deposição do catalisador não alterou a característica de semicondutores do tipo $\mathrm{n}$ dos fotoanodos de hematita. O perfil da curva OCPT para o filme $\mathrm{Fe}_{2} \mathrm{O}_{3} / \mathrm{NiO}_{\mathrm{x}}$ é o mais diferente em comparação aos dos outros filmes. Logo após a iluminação ser ligada, o $V_{\mathrm{OC}}$ atinge um valor máximo de $0,41 \mathrm{~V}$, que é o mais alto entre os filmes; e então esse $V_{\mathrm{OC}}$ diminui exponencialmente para $0,27 \mathrm{~V}$, em $\sim 50 \mathrm{~s}$. Após esse período, o $E_{\mathrm{OC}}$ é mantido estável por mais de $50 \mathrm{~s}$, então, o $V_{\mathrm{OC}}$ aumenta levemente para $0,30 \mathrm{~V}$, estabilizando-se no valor semelhante ao observado para os outros filmes. Essa oscilação pode ser causada pelo fenômeno da mediação da transferência de carga associada ao eletrocatalisador $\mathrm{NiO}_{\mathrm{x}}$; os buracos 
fotogerados oxidam os íons $\mathrm{Ni}^{3+}$ [128], que transferem cargas pela oxidação dos íons $\mathrm{OH}^{-}$, retornando ao estado original de oxidação. A dinâmica dos diferentes estados de oxidação do íon níquel causa a oscilação do EOC. Curiosamente, o OCPT para a amostra de $\mathrm{Fe}_{2} \mathrm{O}_{3} / \mathrm{Fe}_{x} \mathrm{Sn}_{1}$ ${ }_{x} \mathrm{O}_{4}-10 \mathrm{mC} / \mathrm{NiO}_{\mathrm{x}}$ nota-se também uma oscilação no $E_{\mathrm{OC}}$, mas com uma constante de tempo maior.

Figura 29 -Curvas de OCP para os filmes modificados pela deposição de $\mathrm{NiO}_{x}$ como cocatalisador em hidróxido de potássio $1 \mathrm{~mol} \mathrm{~L}^{-1}$ (pH 13,6) com intervalo de iluminação:10 s escuro-140s claro-150 s escuro.

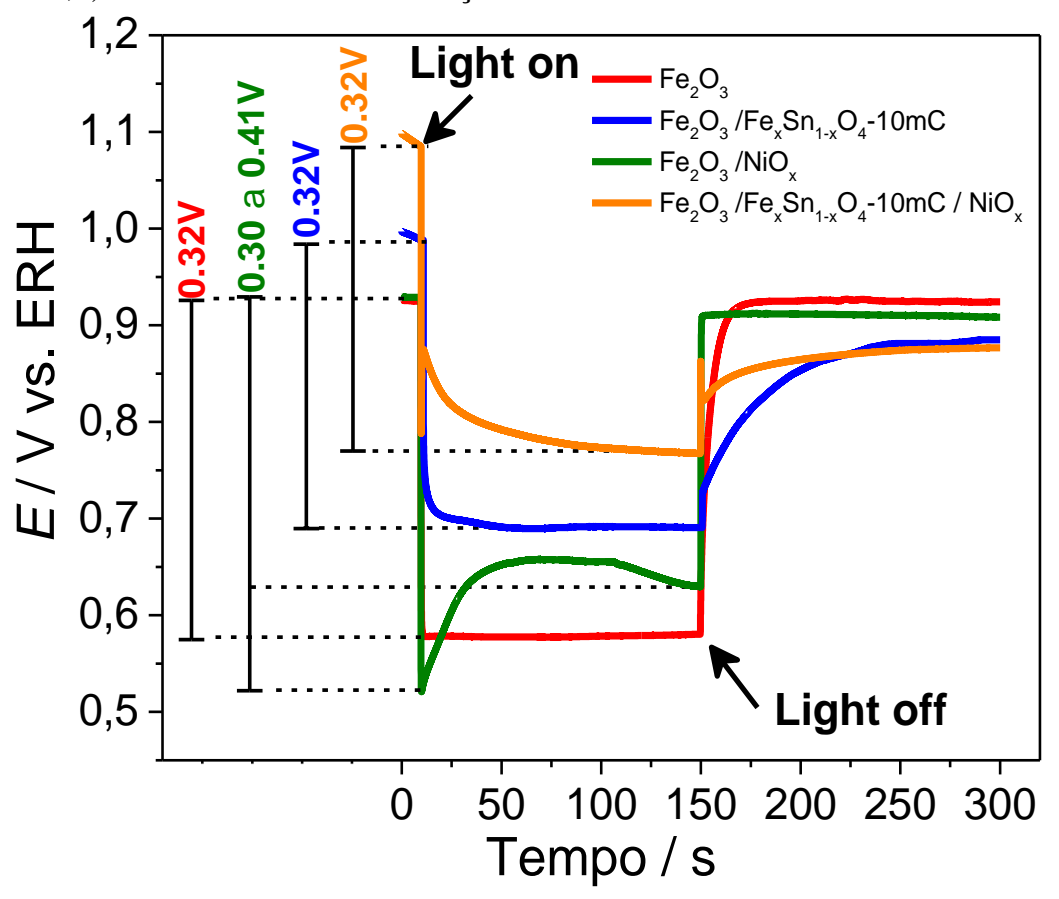

Fonte: Autoria própria.

\subsubsection{Estudos fotoeletroquímicos do efeito dos defeitos superficiais na resposta PEC}

Para avaliar o efeito das diferentes modificações superficiais nas propriedades elétricas e nos estados superficiais dos fotoanodos de hematita, foram realizados experimentos de espectroscopia de impedância fotoeletroquímica (PEIS) a 1,23V (vs. ERH) em KOH 1,0 mol $\mathrm{L}^{-1}$. Este potencial foi selecionando pois, além de ser o potencial termodinâmico para a REO, é em uma região da curva j vs. $E$ na qual a corrente não é limitada pelo fluxo de luz e a REO no escuro não está ocorrendo. Os espectros de Nyquist experimentais obtidos e o circuito equivalente no qual foram matematicamente ajustados estão apresentados na Figura 30-a e 30b, respectivamente e os resultados estão organizados na Tabela 9. Os Diagramas Bode obtidos para os fotoanodos estão apresentados na Figura B4 (Apêndice B).

Nos espectros de Nyquist apresentados na Figura 30-a, é possível observar a presença de dois semicírculos. Diversos autores $[46,93,129,130]$ reportaram na literatura gráficos de 
Nyquist para fotoanodos de hematita semelhantes aos obtidos neste trabalho. O primeiro semicírculo observado está associado a resistência de transferência de carga do bulk do fotoanodo para a superfície [93], enquanto o segundo semicírculo à transferência de carga na interface semicondutor/eletrólito mediada pelos defeitos superficiais [129]. O circuito equivalente (Figura 30-b) que melhor descreve os espectros obtidos foi desenvolvido por Klahr et al. [130]. Neste circuito, estão indicados: uma resistência da solução $\left(R_{\mathrm{S}}\right)$, em série com a resistência de transferência de carga do bulk do fotoanodo para os estados superficiais $\left(R_{\text {trapping }}\right)$ em paralelo com a capacitância do bulk $\left(C_{b u l k}\right)$, e em série com a resistência de transferência de carga nos estados superficiais $\left(R_{\mathrm{ct}, \mathrm{ss}}\right)$ em paralelo com a capacitância destes estados $\left(C_{\mathrm{ss}}\right)$.

Figura 30- (a) Gráficos de Nyquist para os fotoanodos de hematita registrados a 1,23V (vs. RHE) em $1 \mathrm{~mol} \mathrm{~L}^{-1}$ $\mathrm{KOH}$ sob iluminação com simulador solar $\left(100 \mathrm{~mW} \mathrm{~cm}^{-1}\right.$, com filtro A.M. 1.5). Os valores experimentais estão representados pelos símbolos e os ajustados matematicamente estão apresentados por linhas. (b) Circuito equivalente.

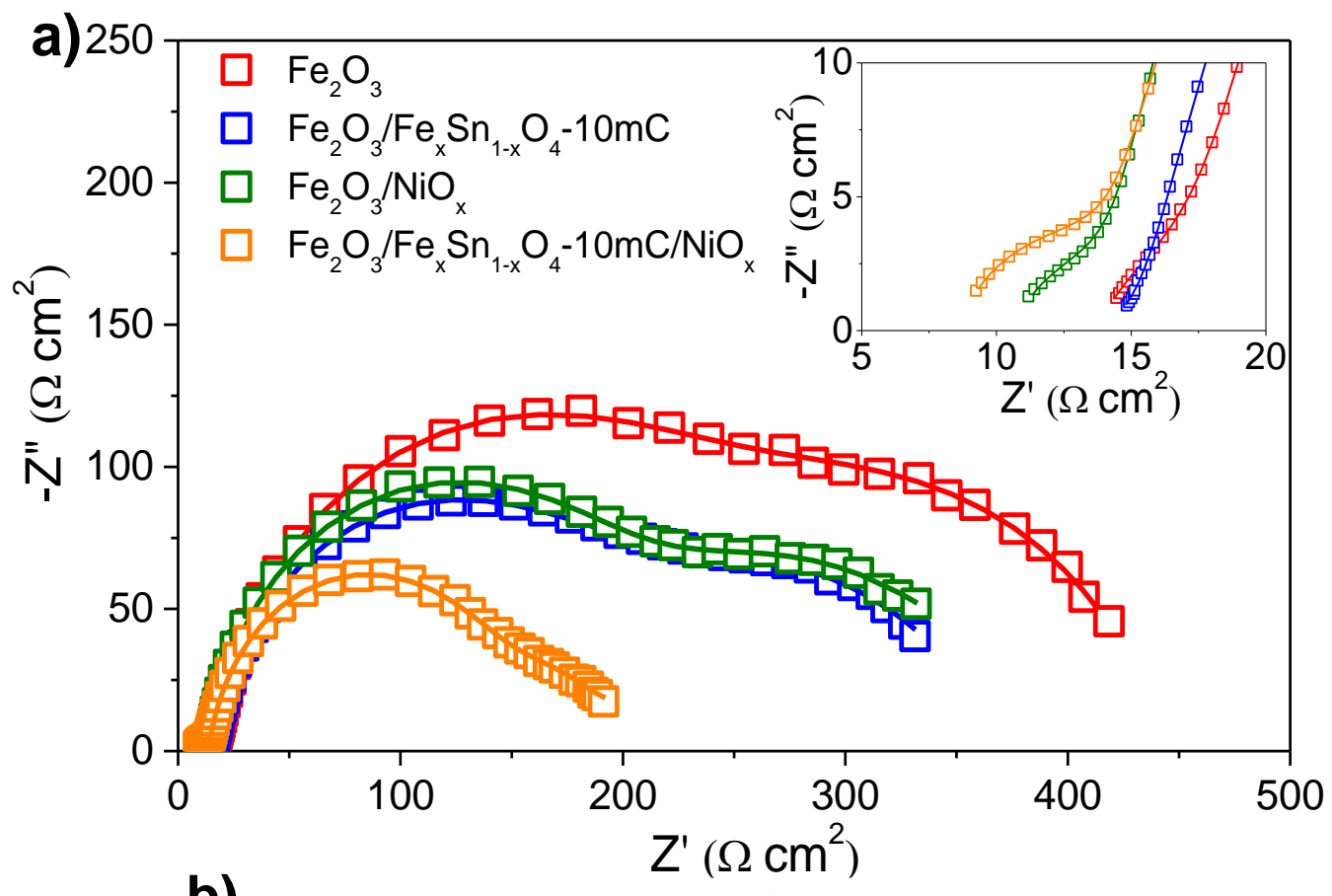

b)

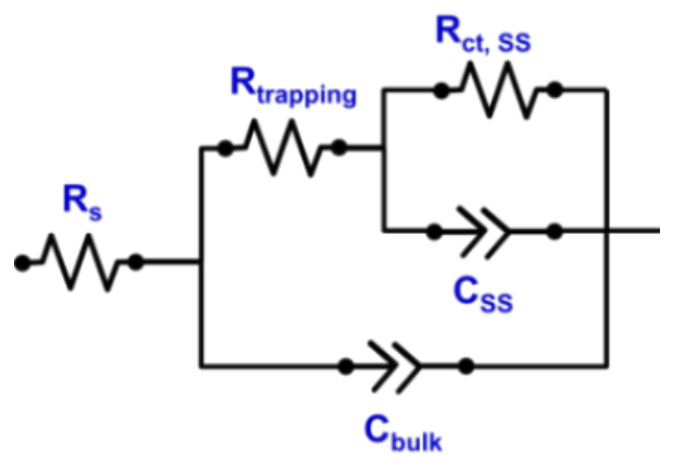

Fonte: Autoria própria. 
Analisando os espectros da Figura 30-a e os dados expressos na Tabela 9, pode-se verificar que a modificação dos filmes de hematita pela dopagem com Sn e pela deposição do cocatalisador contribuiu para a diminuição da resistência de transferência de carga total e aumento da capacitância dos estados superficiais do filme de hematita. A capacitância dos estados superficiais está associada com sua capacidade de acúmulo das cargas fotogeradas. Deste modo, o aumento desta capacitância está relacionado com o aumento da densidade de estados superficiais ativos que acumulam cargas fotogeradas (no caso, buracos) tempo suficiente para serem transferidos de modo mais eficiente para captadores na solução[93]. Li e coautores [131] também observaram que a deposição de NiOOH em fotoanodos de hematita aumentam $\mathrm{C}_{\mathrm{ss}}$ e promove a diminuição da resistência de transferência de carga total do sistema para a reação REO. Os fotoanodos $\mathrm{Fe}_{2} \mathrm{O}_{3} / \mathrm{NiO}_{\mathrm{x}}$ e $\mathrm{Fe}_{2} \mathrm{O}_{3} / \mathrm{Fe}_{\mathrm{x}} \mathrm{Sn}_{1-\mathrm{x}} \mathrm{O}_{4}-10 \mathrm{mC}$ exibiram valores de resistência de transferência de carga e capacitância de estados de superfície semelhantes, o que é indicativo de que ambas estratégias de modificação promovem efeito semelhante na superfície do filme de hematita. Para o filme $\mathrm{Fe}_{2} \mathrm{O}_{3} / \mathrm{Fe}_{\mathrm{x}} \mathrm{Sn}_{1-\mathrm{x}} \mathrm{O}_{4}-10 \mathrm{mC} / \mathrm{NiO}_{\mathrm{x}}$, no qual foram combinadas as duas estratégias de modificação superficial, a diminuição da resistência de transferência de carga foi a mais pronunciada, e o semicírculo referente aos estados superficiais foi diminuído consideravelmente, indicando maior passivação dos defeitos superficiais corroborando com os a melhora na performance PEC observada nos gráficos da Figura 27.

Tabela 9- Parâmetros matematicamente ajustados ao circuito equivalente para os fotoanodos de hematita em 1 mol L ${ }^{-1} \mathrm{KOH}$.

\begin{tabular}{|c|c|c|c|c|c|}
\hline Filmes & $\mathbf{R}_{S}(\Omega)$ & $\mathbf{R}_{\text {trapping }}(\mathbf{\Omega})$ & $\mathrm{C}_{\text {bulk }}(\mu \mathrm{F})$ & $\mathbf{R}_{\mathrm{ct}, \mathrm{SS}}(\mathbf{\Omega})$ & $\operatorname{Css}(\mu F)$ \\
\hline $\mathrm{Fe}_{2} \mathrm{O}_{3}$ & 13,7 & 170,7 & 13,3 & 452,6 & 346,0 \\
\hline $\mathrm{Fe}_{2} \mathrm{O}_{3} / \mathrm{Fe}_{\mathrm{x}} \mathrm{Sn}_{1-\mathrm{x}} \mathrm{O}_{4-10 \mathrm{mC}}$ & 13,3 & 165,4 & 11,1 & 348,0 & 552,2 \\
\hline $\mathrm{Fe}_{2} \mathrm{O}_{3} / \mathrm{NiO}_{x}$ & 10,7 & 142,0 & 12,2 & 352,9 & 574,4 \\
\hline $\mathrm{Fe}_{2} \mathrm{O}_{3} / \mathrm{Fe}_{x} \mathrm{Sn}_{1-\mathrm{x}} \mathrm{O}_{4}-10 \mathrm{mC} / \mathrm{NiO}_{\mathrm{x}}$ & 8,6 & 40,44 & 15,6 & 178,1 & 868,2 \\
\hline
\end{tabular}

Fonte: Autoria própria.

Experimentos de espectroscopia de impedância fotoeletroquímica também foram realizados na presença de peróxido de hidrogênio $\left(\mathrm{H}_{2} \mathrm{O}_{2}\right)$, o qual atua como hole scavenger (sequestrador de buracos) e suprime a recombinação dos buracos fotogerados nos estados superficiais. $\mathrm{O} \mathrm{H}_{2} \mathrm{O}_{2}$ tem sido amplamente utilizado para o estudo dos efeitos da presença de 
estados superficiais, pois a oxidação dessa molécula tem constante de velocidade 10 a 100 vezes maior que da água e de íons $\mathrm{OH}^{-}$[132]. Os experimentos de PEIS foram realizados a 1,23V ( $v s$. ERH) em KOH $1 \mathrm{~mol} \mathrm{~L}^{-1}+0,5 \mathrm{~mol} \mathrm{~L}^{-1} \mathrm{H}_{2} \mathrm{O}_{2}(\mathrm{pH} \mathrm{13,6)}$. Os espectros de Nyquist experimentais obtidos e o circuito equivalente no qual foram matematicamente ajustados estão apresentados na Figura 31-a e 31-b, respectivamente, os resultados estão organizados na Tabela 10. Os Diagramas Bode obtidos para os fotoanodos estão apresentados na Figura B5 (Apêndice B).

Nos gráficos de Nyquist apresentados na Figura 31-a, é possível observar que na presença do peróxido há apenas um semicírculo referente a transferência de carga do sistema. O desaparecimento do segundo semicírculo, verificado na Figura 30-a, está associado a capacidade do hole scavenger em eliminar o efeito de mediação da transferência de buracos a partir dos estados superficiais. Assim, o circuito equivalente (Figura 31-b) que descreve os espectros obtidos é constituído de uma resistência da solução $\left(R_{\mathrm{S}}\right)$, em série com a resistência interna do bulk $\left(R_{\text {bulk }}\right)$ em paralelo com a capacitância do interna do bulk $\left(C_{b u l k}\right)$, e em série com a resistência de transferência de carga na interface $\left(R_{\mathrm{ct}}\right)$ em paralelo com a capacitância da interface semicondutor-eletrólito $\left(C_{\mathrm{ct}}\right)$.

Figura 31-(a) Gráficos de Nyquist para os fotoanodos de hematita registrados a 1,23V (vs. RHE) em $1 \mathrm{~mol} \mathrm{~L}^{-1}$ $\mathrm{KOH}+0,5 \mathrm{~mol} \mathrm{~L}^{-1}$ de $\mathrm{H}_{2} \mathrm{O}_{2}$ sob iluminação com simulador solar (100 mW cm $\mathrm{m}^{-1}$, com filtro A.M. 1.5). Os valores experimentais estão representados pelos símbolos e os ajustados matematicamente estão apresentados por linhas. (b) Circuito equivalente.

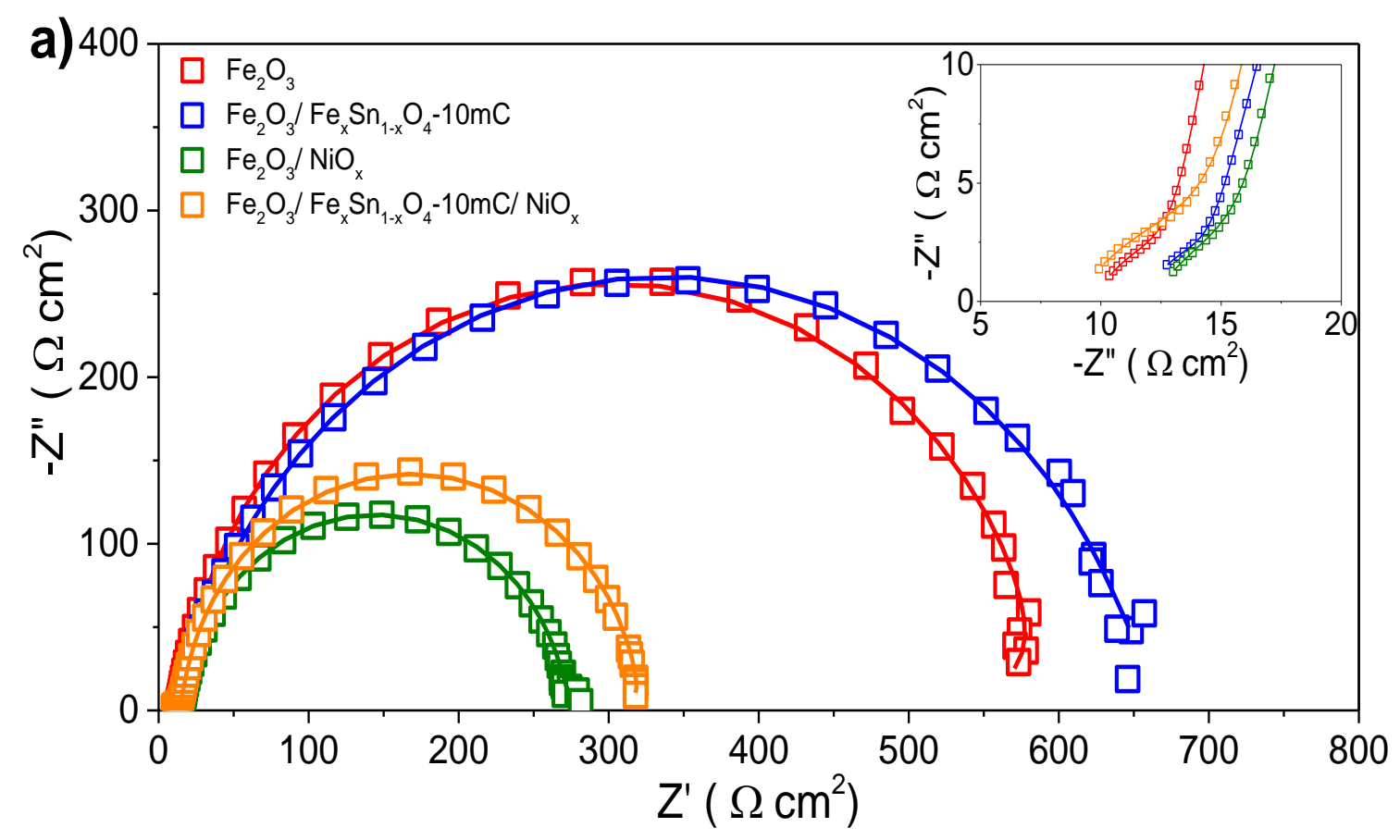




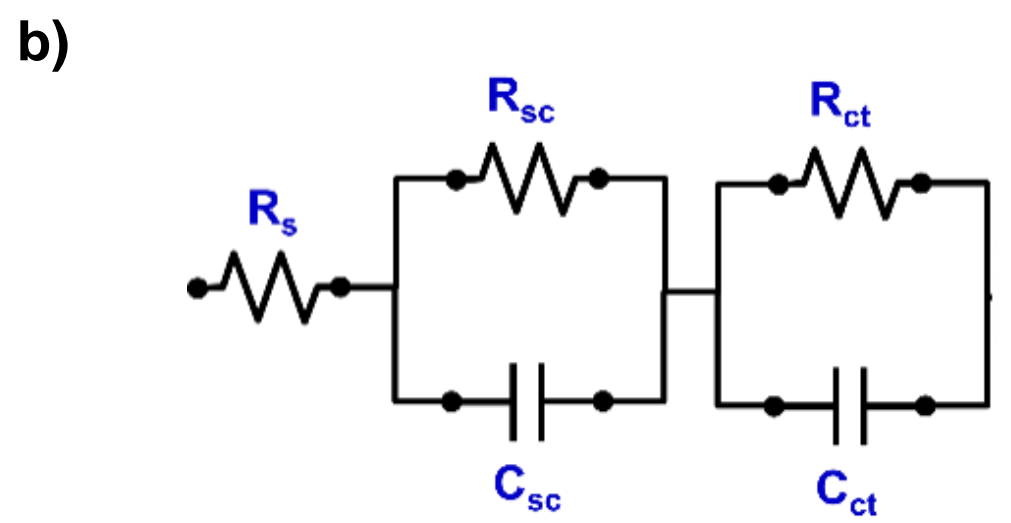

Fonte: Autoria própria.

Como mostrado na Figura 31-a, a deposição de cocatalisador melhorou expressivamente a cinética de transferência de carga na interface semicondutor / eletrólito para os fotoanodos de hematita (não-modificado) e modificado com Sn (Tabela 9). No caso da hematita não-modificada, a melhoria adquirida pela deposição cocatalisador é mais acentuada do que a observada para os espectros registrados apenas no eletrólito $1 \mathrm{~mol} \mathrm{~L}^{-1} \mathrm{KOH}$ (Figura 30-a). Na presença de peróxido no eletrólito, a transferência de carga na interface não ocorre via defeitos superficiais, isto indica que a presença destes estados na superfície dos fotoanodos de hematita é limitante para a REO em eletrólito livre de peróxido, devido à recombinação das cargas fotogeradas na superfície. Deste modo, nos experimentos PEIS realizados apenas KOH, no filme $\mathrm{Fe}_{2} \mathrm{O}_{3} / \mathrm{NiO}_{\mathrm{x}} \mathrm{o}$ óxido de níquel não está atuando primordialmente como acelerador da cinética de transferência de carga, mas sim como passivador da recombinação de buracos e elétrons na superfície dos fotoanodos, o que justifica o comportamento semelhante ao do filme modificado com Sn. De fato, Du et al. [95] observaram que a camada de $\mathrm{NiFeO}_{\mathrm{x}}$ depositada em fotoanodo de hematita se comporta em maior extensão como camada passivadora de estados superficiais. Em relação ao filme modificado com Sn, pode-se verificar que a passivação dos defeitos parece ter inibido a reação de transferência de carga na oxidação do peróxido.

O cocatalisador depositado no filme de hematita previamente passivado pela dopagem com Sn, apresentou o melhor desempenho e aumento significativo da taxa de transferência de carga em KOH $1 \mathrm{~mol} \mathrm{~L}^{-1}$. Este aumento está relacionado com a capacidade dos íons $\mathrm{Ni}^{+3} \mathrm{de}$ atuar como coletores dos buracos fotogerados que se encontram afastados dos centros de recombinação. 
Tabela 10- Parâmetros matematicamente ajustados ao circuito equivalente para os fotoanodos de hematita em 1 $\mathrm{mol} \mathrm{L}-1 \mathrm{KOH}+0,5 \mathrm{~mol} \mathrm{~L}^{-1} \mathrm{H}_{2} \mathrm{O}_{2}$.

\begin{tabular}{|c|c|c|c|c|c|}
\hline Filmes & $\begin{array}{c}R_{\mathrm{s}} \\
\left(\Omega \mathrm{cm}^{2}\right)\end{array}$ & $\begin{array}{c}R_{\text {bulk }} \\
\left(\Omega \mathrm{cm}^{2}\right)\end{array}$ & $\begin{array}{c}C_{\text {bulk }} \\
\left(\mu \mathrm{F} \mathrm{cm}^{2}\right)\end{array}$ & $\begin{array}{c}\mathbf{R}_{\mathrm{ct}} \\
\left(\Omega \mathrm{cm}^{2}\right)\end{array}$ & $\begin{array}{c}\mathrm{C}_{\mathrm{ct}} \\
\left(\mu \mathrm{F} \mathrm{cm}^{2}\right)\end{array}$ \\
\hline $\mathrm{Fe}_{2} \mathrm{O}_{3}$ & 10,98 & 3,17 & 15,01 & 585,0 & 14,93 \\
\hline $\mathrm{Fe}_{2} \mathrm{O}_{3} / \mathrm{Fe}_{x} \mathrm{Sn}_{1-\mathrm{x}} \mathrm{O}_{4}-10 \mathrm{mC}$ & 11,92 & 2,35 & 3,46 & 645,5 & 15,36 \\
\hline $\mathrm{Fe}_{2} \mathrm{O}_{3} / \mathrm{NiO}_{x}$ & 12,12 & 4,48 & 44,39 & 256,2 & 9,55 \\
\hline $\mathrm{Fe}_{2} \mathrm{O}_{3} / \mathrm{Fe}_{x} \mathrm{Sn}_{1-\mathrm{x}} \mathrm{O}_{4}-10 \mathrm{mC} / \mathrm{NiO}_{\mathrm{x}}$ & 10,00 & 6,86 & 41,40 & 305,5 & 11,97 \\
\hline
\end{tabular}

Fonte: Autoria própria.

Para melhor compreensão dos efeitos das modificações pela dopagem com Sn e deposição de $\mathrm{NiOOH}$ na recombinação de cargas no bulk e na superfície dos fotoanodos, utilizou-se método descrito por Dotan et al. [132] para calcular as eficiências de separação $\left(\eta_{\text {sep }}\right)$ e injeção $\left(\eta_{\text {inj}}\right)$ de cargas. A densidade de fotocorrente é o produto da densidade de fotocorrente teórica máxima $\left(\mathrm{j}_{\max }\right)$, da eficiência de separação dos portadores de carga fotogerados no bulk do fotoanodo $\left(\eta_{\text {sep }}\right)$ e eficiência de injeção das cargas nas eficiências do eletrólito ( $\eta_{\text {inj }}$ ) (Equação 9) [132]. A densidade de fotocorrente experimental obtida em $1 \mathrm{~mol} \mathrm{~L}^{-1} \mathrm{KOH}\left(\mathrm{j}_{\mathrm{KOH}}\right)$ é obtida pela (Equação 10). Na presença do $\mathrm{H}_{2} \mathrm{O}_{2}$, que atua como sequestrador de buracos, e, portanto, pode coletar os buracos fotogerados que atingem a interface semicondutor/eletrólito, a eficiência da injeção de carga $\left(\eta_{\text {inj }}=1\right)[93,132]$, então a densidade de corrente pode ser calculada pela Equação 11.

$$
\begin{gathered}
j=j \cdot \eta_{\text {sep }} \cdot \eta_{i n j} \\
j(K O H)=j_{\text {max }} \cdot \eta_{s e p} \cdot \eta_{i n j} \\
j\left(K O H+H_{2} O_{2}\right)=j_{\text {max }} \cdot \eta_{s e p}
\end{gathered}
$$

Equação (9)

Assim, a partir das Equações 10 e 11, $\eta_{\text {sep }}$ e $\eta_{\text {inj }}$ podem ser obtidos por simples rearranjo e substituição:

$$
\begin{aligned}
& \eta_{i n j}=\frac{j(\mathrm{KOH})}{j\left(\mathrm{KOH}+\mathrm{H}_{2} \mathrm{O}_{2}\right)} \\
& \eta_{\text {sep }}=\frac{j\left(\mathrm{KOH}+\mathrm{H}_{2} \mathrm{O}_{2}\right)}{j_{\max }}
\end{aligned}
$$


$\mathrm{O}$ valor de $\mathrm{j}_{\max }$ foi determinado a partir da integração do espectro de absorção dos fotoanodos de hematita com o espectro solar AM 1,5G $\left(100 \mathrm{~mW} \mathrm{~cm}^{-2}\right)$, e o valor calculado corresponde a $3,97 \mathrm{~mA} \mathrm{~cm}$, levando em consideração a espessura estimada do filme. Os valores de densidades de fotocorrentes utilizadas para o cálculo das eficiências foi estimado por voltametria linear realizada a $20 \mathrm{mV} \mathrm{s}^{-1}$ em eletrólito alcalino na presença e ausência de peróxido de hidrogênio. Os voltamogramas obtidos para os fotoanodos analisados estão apresentados na Figura B6 (Apêndice B). Nestes voltamogramas é possível observar que a adição do $\mathrm{H}_{2} \mathrm{O}_{2}$ no eletrólito desloca potencial de onset para fotocorrente em direção a potenciais menos positivos devido à baixa constante de velocidade de oxidação do peróxido em comparação aos íons hidróxido [132]. A partir dos cálculos realizados foram construídos os gráficos que relacionam as eficiências de separação e de injeção de carga em função do potencial aplicado, estes estão apresentados na Figura B7-a e B7-b (Apêndice B), respectivamente. Para facilitar a visualização, as eficiências calculadas no potencial termodinâmico estão apresentadas no gráfico da Figura 32.

Figura 32- Gráfico da eficiência de separação e eficiência de injeção de carga dos fotoanodos de hematita nãomodificado e modificados à $1,23 \mathrm{~V}$ vs. ERH em KOH $1 \mathrm{~mol} \mathrm{~L}^{-1}$.

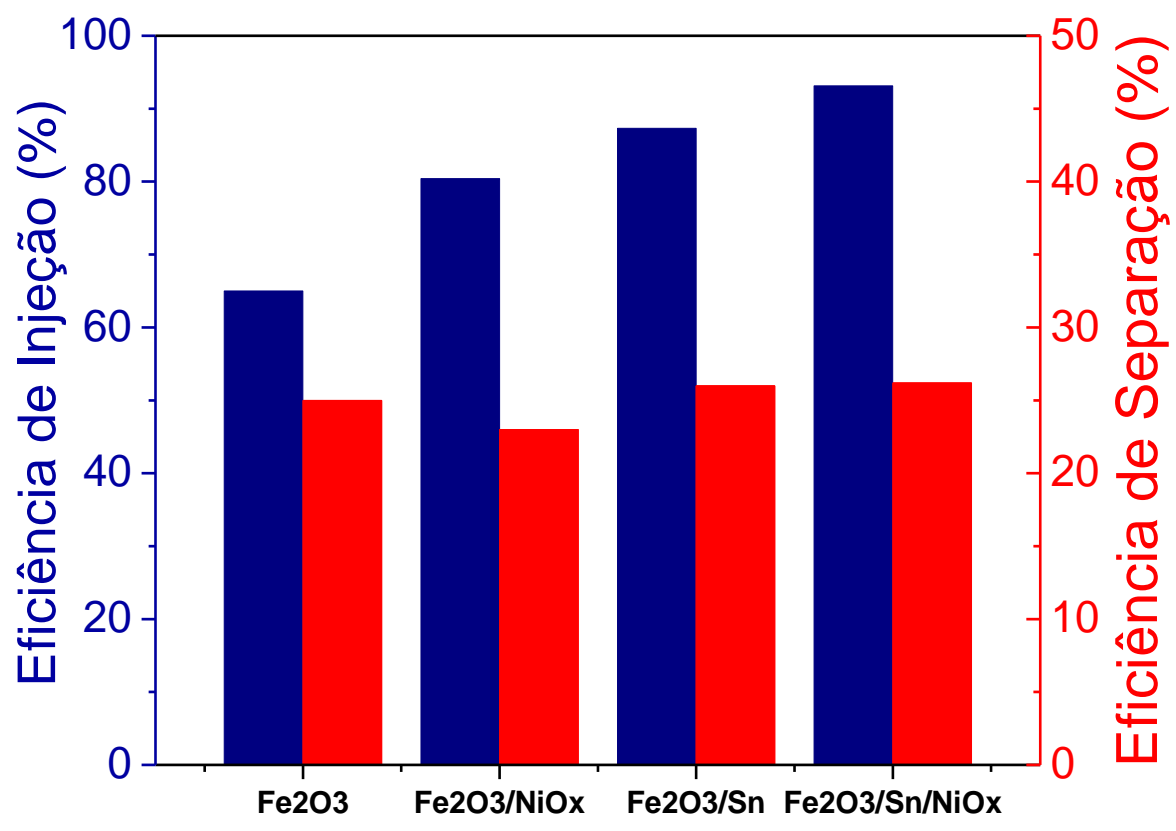

Fonte: Autoria própria.

Na Figura 32, pode-se observar que o fotoanodo de hematita não-modificado apresentou valores de $\eta_{\text {sep }}$ e $\eta_{\text {inj }}$ de $~ 25$ e $65 \%$ em 1,23V (vs. ERH). Como esperado, apenas a propriedade de superfície, eficiência de injeção, foi influenciada pela dopagem com Sn e deposição de $\mathrm{NiOOH}$, assim, a eficiência da separação da carga não foi significativamente 
alterada. A combinação da dopagem com Sn e deposição de cocatalisador resultou na melhoria de 30\% na eficiência da injeção de carga, atingindo um máximo de eficiência no potencial termodinâmico. Já os filmes modificados pela dopagem com $\mathrm{Sn}$ e deposição de $\mathrm{NiOOH}$ apresentaram aumento na eficiência de injeção de 22 e 17\%, respectivamente.

Embora, comparado ao fotoanodo de hematita não-modificado, o filme de $\mathrm{Fe}_{2} \mathrm{O}_{3} / \mathrm{Fe}_{\mathrm{x}} \mathrm{Sn}_{1-\mathrm{x}} \mathrm{O}_{4}-10 \mathrm{mC} / \mathrm{NiO}_{\mathrm{x}}$ tenha apresentado melhora significativa na resistência de transferência e na eficiência de injeção de carga, esperava-se um aumento mais pronunciado na densidade de fotocorrente obtida para este filme. No entanto, deve-se considerar que neste estudo foram investigadas somente estratégias para a modificação da superfície dos filmes de hematita, e que mesmo que as propriedades da superfície deste filme tenham sido aprimoradas, a resposta PEC obtida deve estar próxima a fotocorrente máxima experimental que o material utilizado pode alcançar, levando em consideração as limitações do bulk. Deste modo, para garantir uma melhora mais significativa na performance destes fotoanodos, foi proposto estudar a modificação do bulk por nanoestruturação do substrato coletor de carga.

\subsection{PARTE C: ESTUDO DO EFEITO DA NANOESTRUTURAÇÃO DE FILMES DE HEMATITA COM ATO}

A modificação da hematita com óxido de estanho e antimônio, foi feita a partir da deposição das nanopartículas de ATO com tamanho < $50 \mathrm{~nm}$ sob o substrato FTO previamente a deposição do filme de ferro metálico. Para isso, foram depositadas por dropping diferentes quantidades da suspensão de ATO em etanol (1,5 $\left.\mathrm{mg} \mathrm{mL}^{-1}\right)$ sobre o substrato FTO, os volumes de suspensão estudados foram 100, 200 e $300 \mu \mathrm{L}$ e as amostras foram denominadas ATO$100 \mu \mathrm{1} / \mathrm{Fe}_{2} \mathrm{O}_{3}$, ATO- $200 \mu \mathrm{L} / \mathrm{Fe}_{2} \mathrm{O}_{3}$ e ATO-300 $\mu \mathrm{L} / \mathrm{Fe}_{2} \mathrm{O}_{3}$, respectivamente. Inicialmente, avaliouse o efeito da camada de nanopartículas de ATO sobre as propriedades morfológicas, estruturais e ópticas dos filmes de hematita e posteriormente sobre as propriedades optoeletrônicas e fotoeletroquímicas.

\subsubsection{Caracterização Física}

A morfologia dos filmes foi caracterizada por MEV-FEG as imagens da vista superior dos filmes de hematita sintetizados sobre o substrato sem modificação (FTO) e modificado com nanopartículas de ATO (FTO-ATO) são mostrados na Figura 33. As imagens obtidas mostram que os filmes de hematita depositados sobre o substrato modificado apresentaram aumento no 
tamanho dos aglomerados de nanopartículas quando comparado ao filme preparado sobre o substrato não-modificado. E ainda, o aumento da quantidade de ATO depositado sobre o substrato levou ao aumento no tamanho destes aglomerados. Além disso, as nanopartículas de ATO depositadas sobre o substrato proporcionaram a formação de estruturas aparentemente mais porosas, isto pode ser um indicativo de que a camada de ferro metálico depositou sobre a camada condutora formada por nanopartículas de ATO, demonstrada na Figura C1 (Apêndice C).

Figura 33- Micrografias obtidas por MEV-FEG das superfícies dos filmes de hematita depositados sobre o substrato não-modificado (a) e modificado com diferentes quantidades de nanopartículas de ATO: (b) $100 \mu \mathrm{L}$, (c) $200 \mu \mathrm{L}$ e (d) $300 \mu \mathrm{L}$.
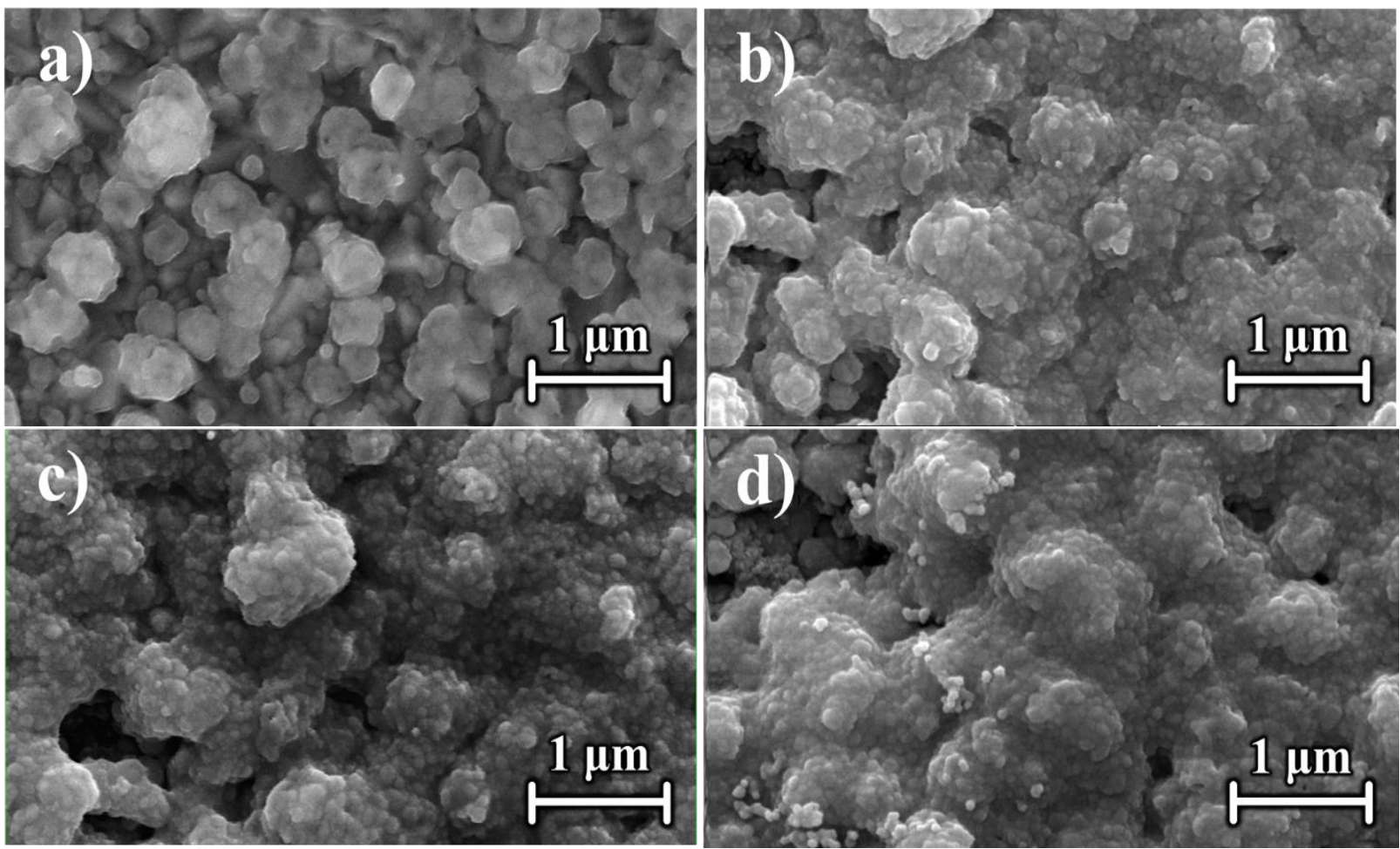

Fonte: Autoria própria.

A caracterização estrutural dos filmes foi feita por difração de Raios X. Nos difratogramas da Figura 34, todos os picos de difração presentes foram associados ao substrato ( $\mathrm{SnO}_{2}$, JCPDS 77-451), simbolizado por (“\#”) e a hematita (JCPDS 33-664). Não foi observado aparecimento de picos referentes a outras fases para amostras sintetizadas sobre o substrato modificado com ATO assim como repostado por Sun e colaboradores [133]. Na Figura 34, observa-se que, os filmes de hematita crescidos sobre o substrato modificado com ATO, apresentaram aumento aparente na intensidade dos picos de difração referentes a hematita em 
comparação ao filme preparado no substrato não-modificado, especialmente referente ao plano (110).

Figura 34- Difratogramas de Raios $X$ dos filmes de hematita preparados sobre o substrato sem modificação e modificados com diferentes cargas de ATO. Os padrões de difração de $\mathrm{SnO}_{2}$ (representando FTO, JCPDS 77-451), $\alpha-\mathrm{Fe}_{2} \mathrm{O}_{3}$ (JCPDS 33-664) são mostrados na região inferior do gráfico para comparação.

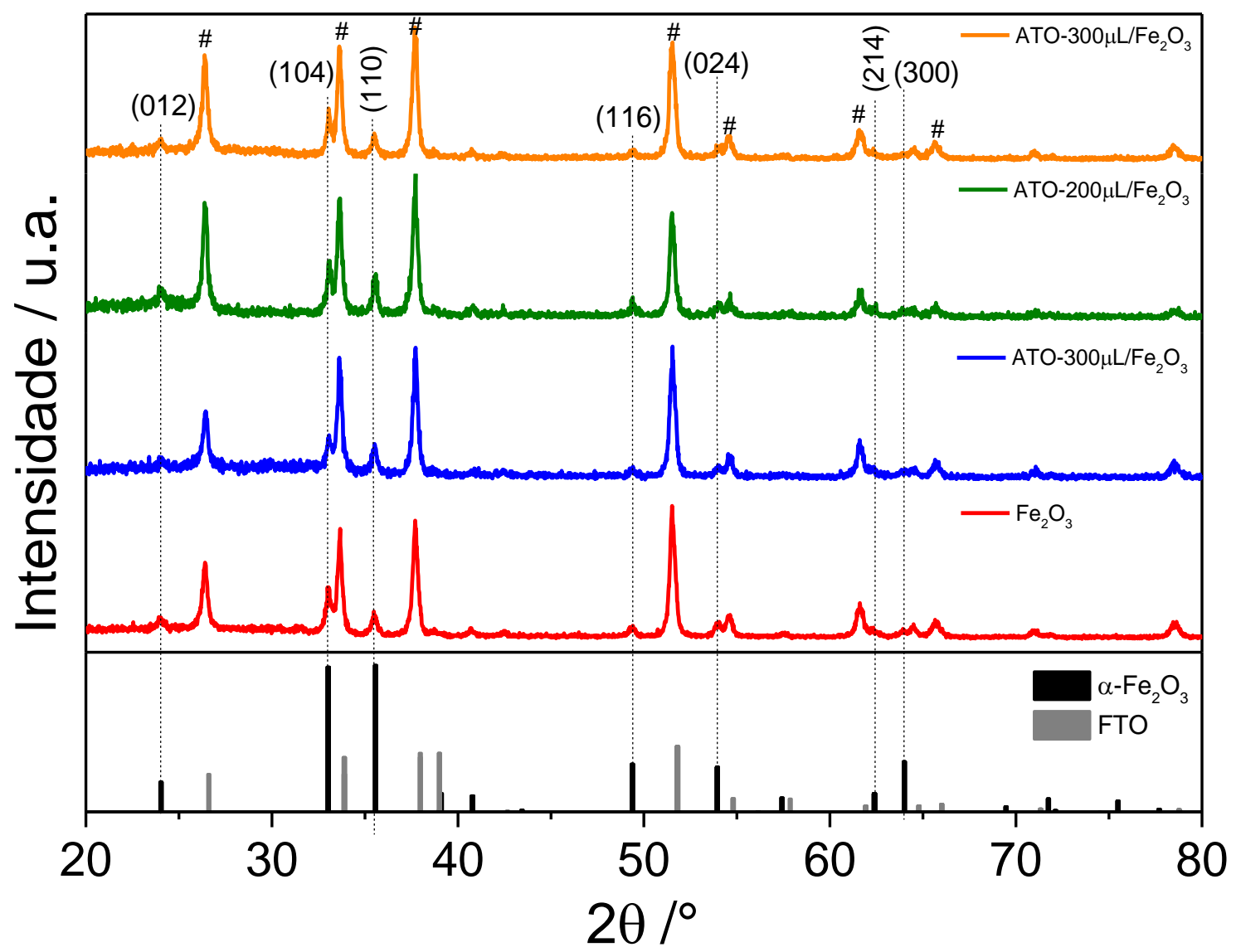

Fonte: Autoria própria.

Foram realizados cálculos dos valores de largura à meia-altura (FWHM) referentes ao pico do DRX relacionado ao plano (110) da hematita, e os valores obtidos estão apresentados na Tabela 11. Através dos valores apresentados, verifica-se que os filmes de hematita preparados sobre o substrato modificado apresentaram maior cristalinidade, menor valor de FWHM, quando comparado ao filme de hematita preparado no FTO não-modificado. Wang e colaboradores [64] também verificaram aumento da cristalinidade do filme de nanobastões de hematita crescidos sobre a superfície de FTO modificada com ATO, visto a influência do substrato no processo de crescimento dos filmes. 
Tabela 11- Largura à meia altura (FWHM), composição e energia de band gap $\left(E_{\mathrm{g}}\right)$ para os filmes $\alpha-\mathrm{Fe}_{2} \mathrm{O}_{3}$ preparados sobre o substrato não-modificado e modificados com diferentes cargas de ATO.

\begin{tabular}{|c|c|c|}
\hline Filmes & FWHM (grau) ${ }^{\mathrm{a}}$ & $E_{\mathrm{g}}(\mathbf{e V})^{\mathrm{b}}$ \\
\hline $\mathrm{Fe}_{2} \mathrm{O}_{3}$ & 0,36 & 2,12 \\
\hline $\mathrm{ATO}-100 \mu \mathrm{L} / \mathrm{Fe}_{2} \mathrm{O}_{3}$ & 0,29 & 2,10 \\
\hline $\mathrm{ATO}-200 \mu \mathrm{L} / \mathrm{Fe}_{2} \mathrm{O}_{3}$ & 0,28 & 2,09 \\
\hline $\mathrm{ATO}-300 \mu \mathrm{l} / \mathrm{Fe}_{2} \mathrm{O}_{3}$ & 0,30 & 2,12 \\
\hline
\end{tabular}

a. Largura à meia altura (FWHM) para o pico de difração referente ao plano (110).

b. Energias de band gap obtidas a partir das curvas de Tauc (Figura 35-b).

Fonte: Autoria própria.

Posteriormente, avaliou-se o efeito da subcamada de nanopartículas de ATO nas propriedades ópticas do filme de hematita. Na Figura 35-a estão apresentados os espectros de absorção na região do UV-Vis registrados para os filmes preparados. Através desses espectros foi possível verificar que a modificação do substrato promoveu um aumento significativo na absorção dos filmes de hematita. Wang e coautores também obtiveram melhora na absorção óptica dos filmes de hematita sintetizados por APCVD sobre o substrato modificado com nanopartículas de ATO [55]. Como o ATO não absorve na região do visível, a melhoria na absorção de luz dos filmes pode ser atribuída ao prolongamento do comprimento óptico do filme devido a nanoestrutura desordenada das nanopartículas de ATO formada na camada condutora [55,65]. Os gráficos de $(\alpha h v)^{1 / 2} v s$. energia do fóton estão apresentados na Figura 35-b. Os valores de band gap estão apresentados na Tabela 11, e foram aproximadamente 2,1 eV para todos os filmes, demonstrando que a modificação do substrato não influenciou neste parâmetro. 
Figura 35-(a) Espectro de absorção dos filmes de hematita sintetizados sobre o substrato não modificado e modificados com diferentes cargas ATO e (b) Gráfico de $(\alpha h v)^{1 / 2} v s$. energia do fóton para os filmes de hematita sintetizados sobre o substrato não modificado e modificados com diferentes cargas ATO.
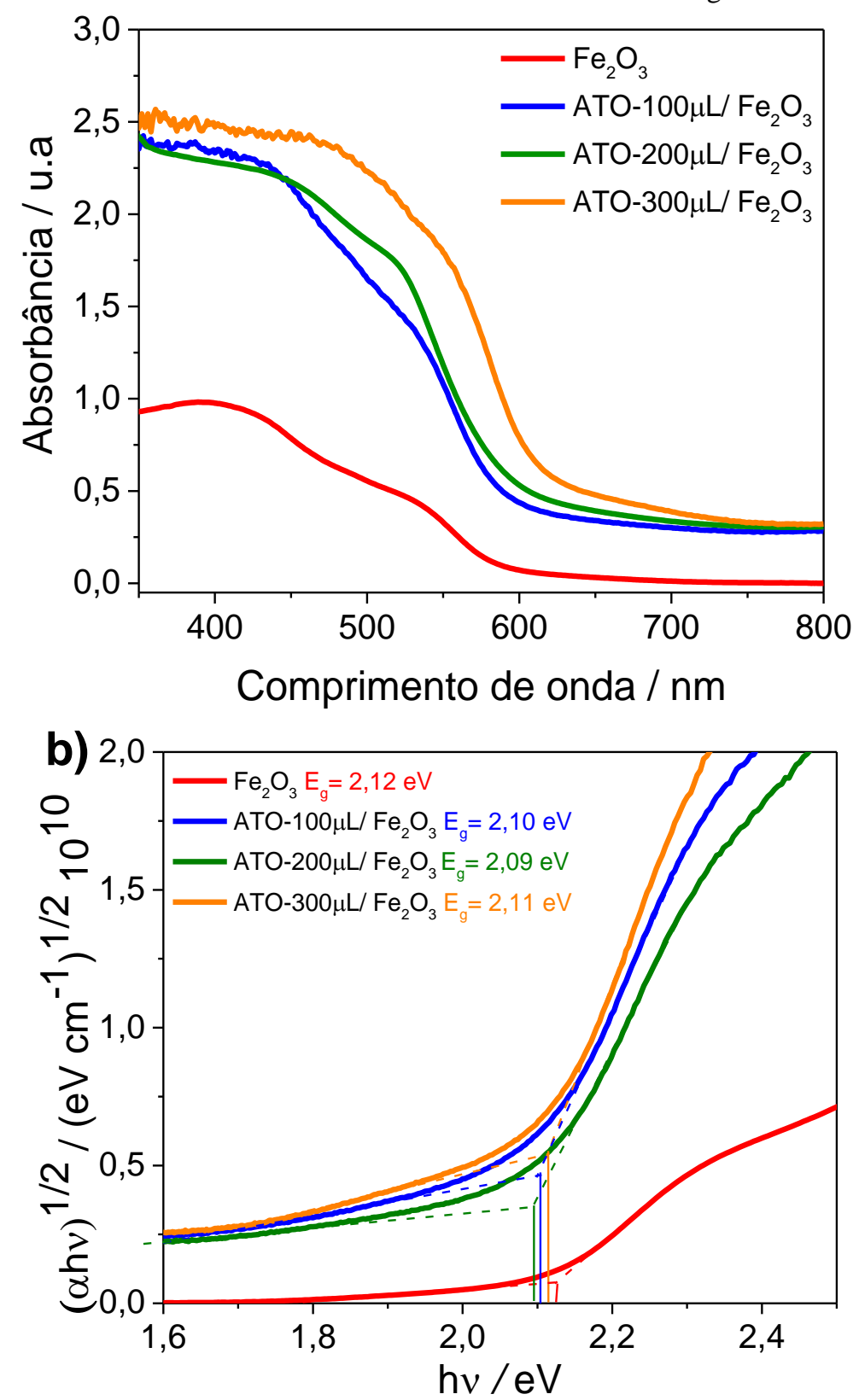

Fonte: Autoria própria.

\subsubsection{Caracterização Eletroquímica e Fotoeletroquímica}

Para avaliar o efeito da subcamada de ATO nas propriedades eletrônicas dos filmes de hematita nas propriedades eletrônicas dos filmes de hematita, foram realizados experimentos de Mott-Schottky (MS). Os gráficos de MS estão apresentados na Figura 36 e os valores de potenciais de banda plana e densidade de doadores de carga estão expressos na Tabela 12. Nos 
gráficos de MS da Figura 36, pode-se observar que todos os filmes apresentaram a inclinação positiva característica dos semicondutores do tipo $\mathrm{n}[68,121]$.

Figura 36- Gráfico de Mott-Schottky registrados com frequência de $1 \mathrm{kHz}$ em KOH $1 \mathrm{~mol} \mathrm{~L}^{-1}(\mathrm{pH}$ 13,6) para os filmes: (a) ATO- $100 \mu \mathrm{L} / \mathrm{Fe}_{2} \mathrm{O}_{3}$, (b ATO- $200 \mu \mathrm{L} / \mathrm{Fe}_{2} \mathrm{O}_{3}$, (c) ATO- $300 \mu \mathrm{L} / \mathrm{Fe}_{2} \mathrm{O}_{3} \mathrm{e}$ (d) FTO/ ATO.
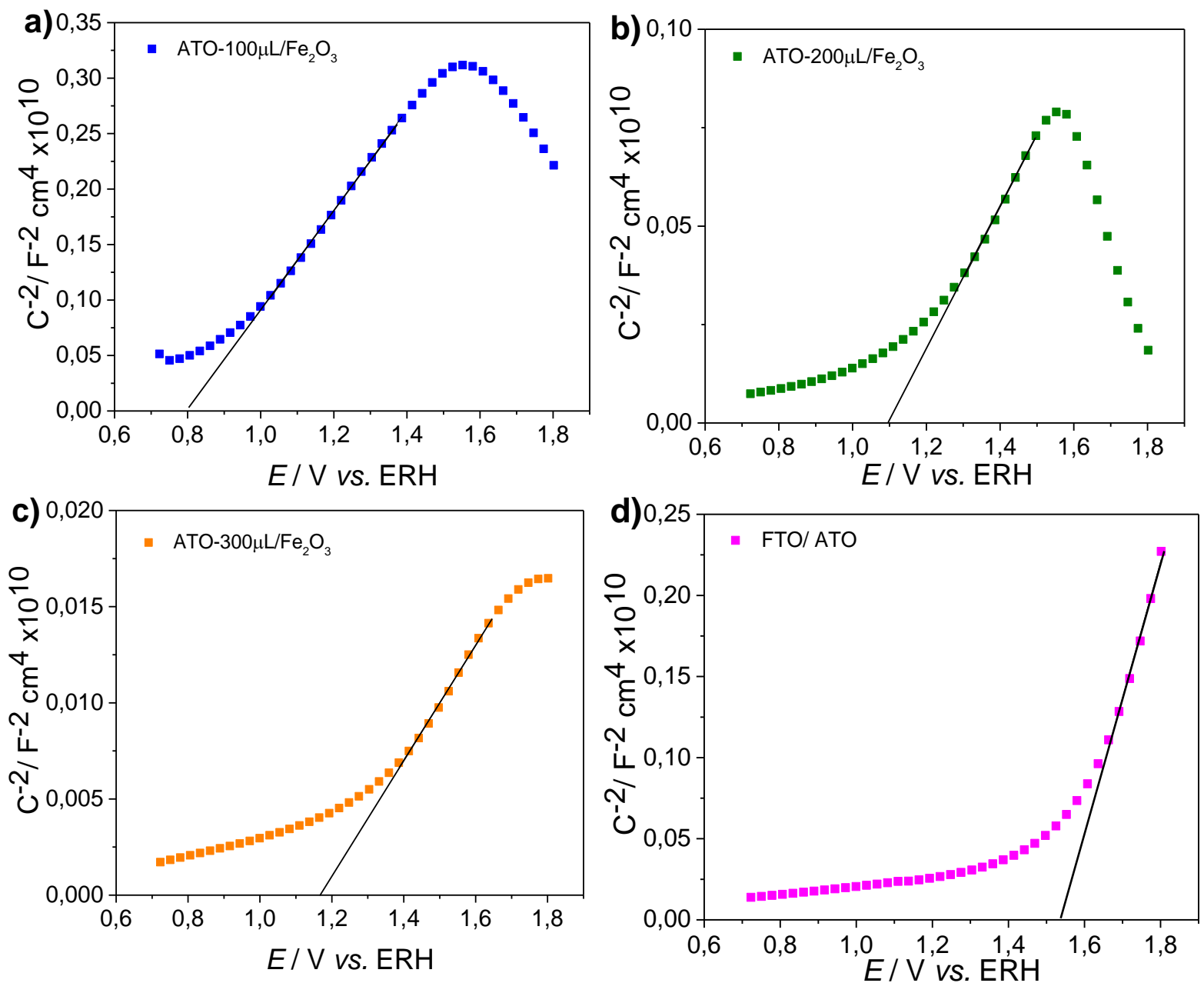

Fonte: Autoria própria.

Através dos gráficos de MS (Figura 36) e dos dados expressos na Tabela 11, verificase um deslocamento expressivo nos potenciais de banda plana para valores mais positivos para os filmes de hematita preparados no substrato FTO/ATO em comparação ao filme de hematita preparado em FTO (Figura 21-a e 26-a). Os filmes preparados nos substratos modificados com 100, 200 e $300 \mu \mathrm{L}$ da suspensão de nanopartículas de ATO apresentaram deslocamento de $+120,+320$ e $+470 \mathrm{mV}$ no $E_{\mathrm{fb}}$. A medida em que a quantidade de ATO foi aumentada, o deslocamento do potencial de banda plana para os filmes de hematita foi maior. Este deslocamento ocorreu em direção ao $E_{\mathrm{fb}}$ observado para o ATO sem o filme de hematita (Figura 36-d). Isto pode ser um indicativo de que para elevadas quantidades de nanopartículas de ATO 
utilizadas na modificação do filme de hematita, esta subcamada passa a ter maior efeito na análise de Mott-Schottky. Nogueira e colaboradores [134] verificaram deslocamento anódico do no potencial de banda plana para filmes de hematita modificados com $\mathrm{Sb}$, e atribuíram à alta dispersão do Sb nas fronteiras de grão de hematita levando ao aumento do band bending. Assim, o aumento do $E_{\mathrm{fb}}$ observado para as amostras modificadas com ATO pode auxiliar no processo de separação das cargas fotogeradas resultando na melhor da performance PEC dos fotoanodos de hematita.

Além do deslocamento do potencial de banda plana, os filmes modificados com ATO apresentaram aumento significativo na densidade de doadores de carga em uma ordem de magnitude para os filmes modificados com 100 e $200 \mu \mathrm{L}$ da suspensão de ATO e duas ordens de magnitude para o filme preparados com $300 \mu \mathrm{L}$, revelando alta dopagem dos filmes estudados e consequentemente aumento da condutividade elétrica. $\mathrm{O}$ aumento da densidade de portadores dos filmes de hematita modificados com subcamada de ATO foi reportado anteriormente na literatura [55,64,133]. Annamalai et al. [135] verificaram aumento na densidade de portadores de carga e deslocamento positivo do $E_{\mathrm{fb}}$ de filmes de hematita altamente dopados com antimônio. Assim, o deslocamento positivo do $E_{\mathrm{fb}}$ observado para os filmes modificados com ATO, apresentados neste trabalho, pode estar relacionado com a alta dopagem com Sb constituinte da subcamada de nanopartículas de ATO [81].

Tabela 12- Potencial de banda plana $\left(E_{\mathrm{fb}}\right)$ e densidade de portadores $\left(\mathrm{N}_{\mathrm{D}}\right)$ para filmes de hematita preparados no substrato não modificado e modificado com ATO.

\begin{tabular}{|c|c|c|}
\hline Filmes & $\begin{array}{c}E_{\mathbf{f b}} \\
(\mathbf{V} v s . \mathbf{E R H})^{\mathbf{a}}\end{array}$ & $\begin{array}{c}N_{\mathrm{D}} \\
\left(\times 10^{20} \mathrm{~cm}^{-3}\right)^{\mathrm{a}}\end{array}$ \\
\hline$\alpha-\mathrm{Fe}_{2} \mathrm{O}_{3}$ & 0,68 & 0,38 \\
\hline $\mathrm{ATO}-100 \mu \mathrm{L} / \mathrm{Fe}_{2} \mathrm{O}_{3}$ & 0,80 & 3,89 \\
\hline $\mathrm{ATO}-200 \mu \mathrm{L} / \mathrm{Fe}_{2} \mathrm{O}_{3}$ & 1,00 & 8,61 \\
\hline $\mathrm{ATO}-300 \mu \mathrm{l} / \mathrm{Fe}_{2} \mathrm{O}_{3}$ & 1,15 & 54,80 \\
\hline FTO/ & 1,53 & - \\
\hline
\end{tabular}

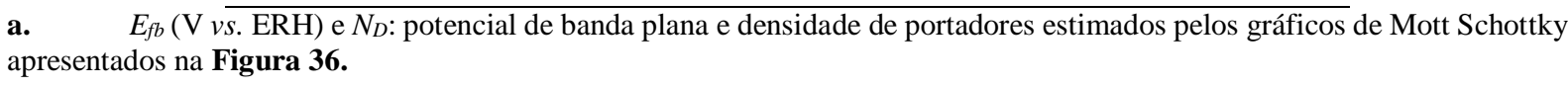

Fonte: Autoria própria.

O comportamento fotoeletroquímico dos fotoanodos de hematita modificados com

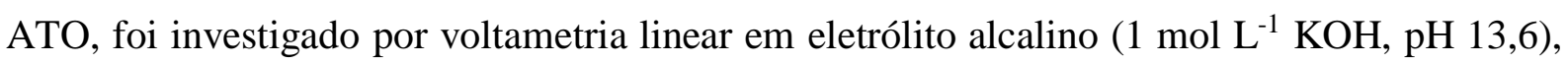


no escuro e sob iluminação solar simulada. Os voltamogramas lineares estão apresentados na Figura 37 e os valores de potencial de onset e densidade de fotocorrente para os potenciais de 1,23 e 1,60 V (vs. ERH) estão apresentados na Tabela 12.

Figura 37- Voltamogramas lineares registrados a $20 \mathrm{mVs}^{-1}$ no escuro (linha tracejada) e sob iluminação com simulador solar (100 mW cm${ }^{-1}$, com filtro A.M. 1.5) (linha contínua) para os filmes modificados com ATO em $\mathrm{KOH} 1,0 \mathrm{~mol} \mathrm{~L}^{-1}$.

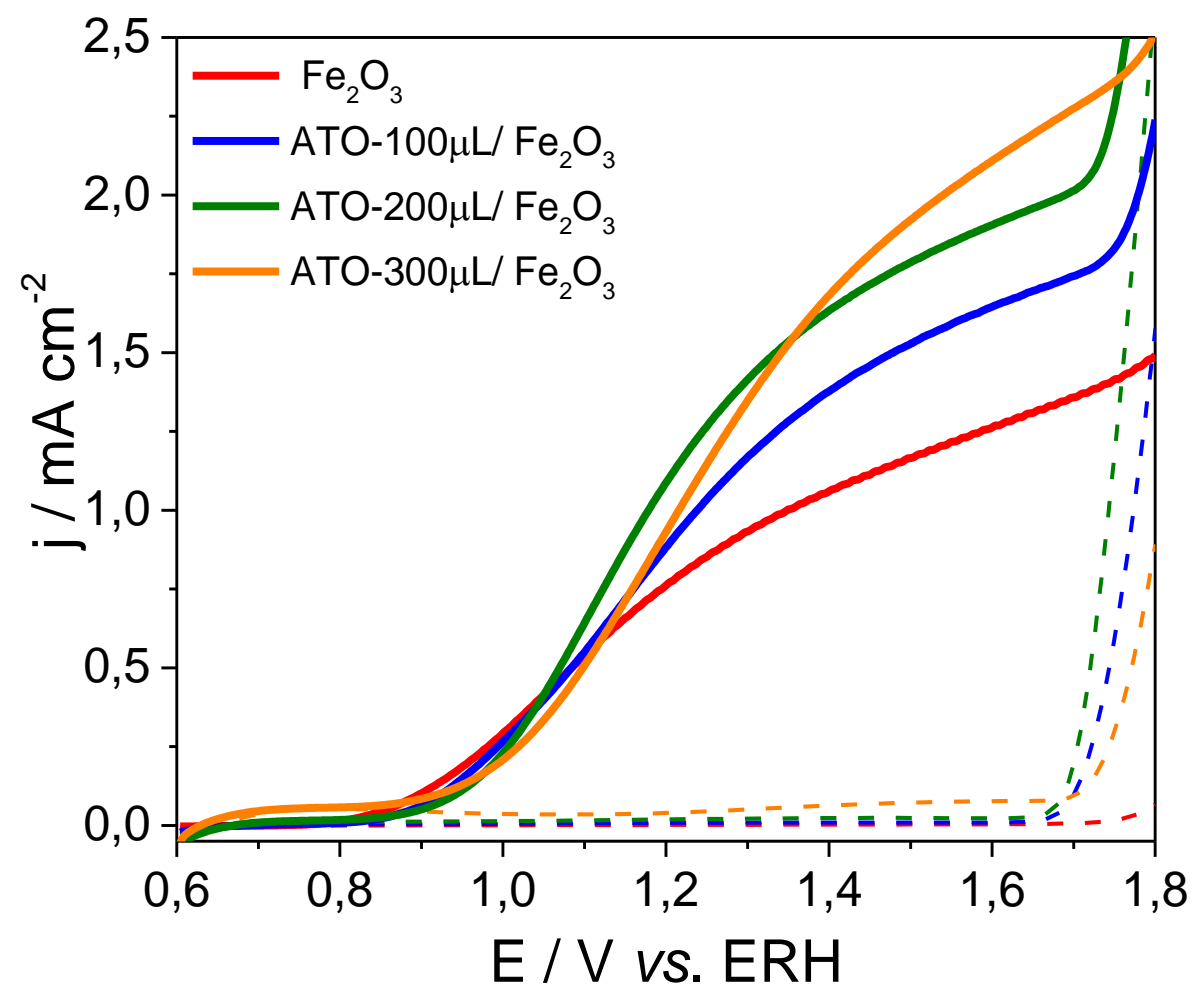

Fonte: Autoria própria.

Como demonstrado na Figura 37, a modificação do substrato com as nanopartículas de ATO promoveu aumento significativo na densidade de fotocorrente do filme de hematita para todas as quantidades de ATO avaliadas. Em comparação ao filme de hematita depositado sobre o substrato não-modificado, os filmes ATO- $100 \mu \mathrm{L} / \mathrm{Fe}_{2} \mathrm{O}_{3}$, ATO- $200 \mu \mathrm{L} / \mathrm{Fe}_{2} \mathrm{O}_{3}$ e ATO$300 \mu \mathrm{L} / \mathrm{Fe}_{2} \mathrm{O}_{3}$ apresentaram aumento de $12 \%, 50 \%$ e $27,7 \%$ na densidade de fotocorrente a 1,23V (vs. ERH), respectivamente. Essas melhoras podem estar relacionadas com diversos fatores como o aumento da capacidade de absorção de luz dos filmes; a subcamada de ATO nanoestuturada pode atuar como armadilha de fótons absorvidos aumentando a capacidade de espalhamento da luz nos filmes [65]. Além disso, esse efeito também pode estar associado ao aumento da cristalinidade dos filmes observada nos resultados de DRX e da densidade de portadores observado nos experimentos de MS. A nanoestruturação do substrato com as nanopartículas de ATO permite melhor coleta de cargas diminuindo o caminho pelo qual as 
cargas devem percorrer para serem coletadas [62,64]. Apesar do aumento expressivo na densidade de fotocorrente, os filmes modificados com a suspensão de ATO apresentaram um pequeno descolamento no potencial de onset em direção a potenciais mais positivos. Wang e colaboradores, previamente, atribuíram este deslocamento ao aumento de estados superficiais devido à dopagem dos filmes de hematita com Sb [64].

Tabela 13- Parâmetros da performance fotoeletroquímica dos filmes de hematita modificados com diferentes cargas de ATO.

\begin{tabular}{|c|c|c|c|c|}
\hline Filmes & $\begin{array}{c}\text { j, REO } \\
\left(\mathrm{mA} \mathbf{c m}^{-2}\right)^{\mathrm{a}}\end{array}$ & $\begin{array}{c}\mathbf{j}, 1.60 \mathrm{~V} \\
\left(\mathrm{~mA} \mathrm{~cm}^{-2}\right)^{\mathrm{a}}\end{array}$ & $\begin{array}{l}E_{\text {on }} \\
(\mathbf{V})^{\mathbf{b}}\end{array}$ & $\begin{array}{l}\text { VoC } \\
(\mathbf{V})^{\mathbf{c}}\end{array}$ \\
\hline $\mathrm{Fe}_{2} \mathrm{O}_{3}$ & 0,83 & 1,26 & 0,90 & 0,32 \\
\hline $\mathrm{ATO}-100 \mu \mathrm{L} / \mathrm{Fe}_{2} \mathrm{O}_{3}$ & 0,93 & 1,66 & 0,87 & 0,23 \\
\hline $\mathrm{ATO}-200 \mu \mathrm{L} / \mathrm{Fe}_{2} \mathrm{O}_{3}$ & 1,25 & 1,88 & 0,93 & 0,23 \\
\hline $\mathrm{ATO}-300 \mu \mathrm{l} / \mathrm{Fe}_{2} \mathrm{O}_{3}$ & 1,06 & 2,11 & 0,95 & 0,24 \\
\hline
\end{tabular}

a. $\quad \mathrm{j}$, REO e j,1,6v: Densidade de fotocorrente a 1,23 V e 1,60 V (vs ERH), respectivamente, em $1 \mathrm{~mol} \mathrm{~L}^{-1} \mathrm{KOH}(\mathrm{pH} \mathrm{13,6)}$ sob iluminação solar simulada $100 \mathrm{~mW} \mathrm{~cm} \mathrm{~cm}^{-2}$. b. $\boldsymbol{E}_{\text {on }}(\mathrm{V} v$ s. RHE): Potencial de onset para fotocorrente. c. Voc $(\mathrm{V} v s$. ERH): Fotovoltagem em KOH 1 mol L-1. d. Voc $\left(V\right.$ vs. ERH): Fotovoltagem em KOH 1 mol L-1 $+\mathrm{H}_{2} \mathrm{O}_{2} 0,5 \mathrm{~mol} \mathrm{~L}^{-1}$.

Fonte: Autoria própria.

Posteriormente, foram realizados experimentos de transientes de potencial de circuito aberto (OCPT) e as curvas de OCPT são apresentadas na Figura 38. Na Tabela 11 estão apresentados os valores de fotovoltagem, calculados a partir da diferença de potencial de circuito aberto no escuro e sob iluminação, para os filmes analisados. Todos os filmes apresentaram mudança negativa no potencial de circuito aberto $\left(E_{\mathrm{OC}}\right)$ após a iluminação, característica dos semicondutores do tipo n. Para todas as quantidades de nanopartículas de ATO avaliadas, observou-se a diminuição da fotovoltagem do filme de hematita. As menores fotovoltagens destas amostras podem estar relacionadas com o processo de pinning do nível de Fermi devido aos estados superficiais. Além disso, a modificação com ATO, assim como observado para a modificação com Sn, promoveu alteração no perfil da curva OCPT. A modificação do filme de hematita com subcamada de ATO tonou mais lenta a recombinação da carga na superfície, indicando maior tempo de vida das cargas fotogeradas. Assim, a alta densidade de portadores de carga e maior tempo de vida destes portadores podem permitir melhor separação de cagas resultando na melhoria da performance PEC dos fotoanodos de hematita, observada nos voltamogramas da Figura 37. 
Figura 38-Curvas de OCP para os filmes de hematita preparados em substrato não-modificado e modificado com diferentes quantidades de ATO em hidróxido de potássio $1 \mathrm{~mol} \mathrm{~L}^{-1}(\mathrm{pH} \mathrm{13,6)} \mathrm{com} \mathrm{intervalo} \mathrm{de} \mathrm{iluminação:10} \mathrm{s}$ escuro-140s claro-150 s escuro.

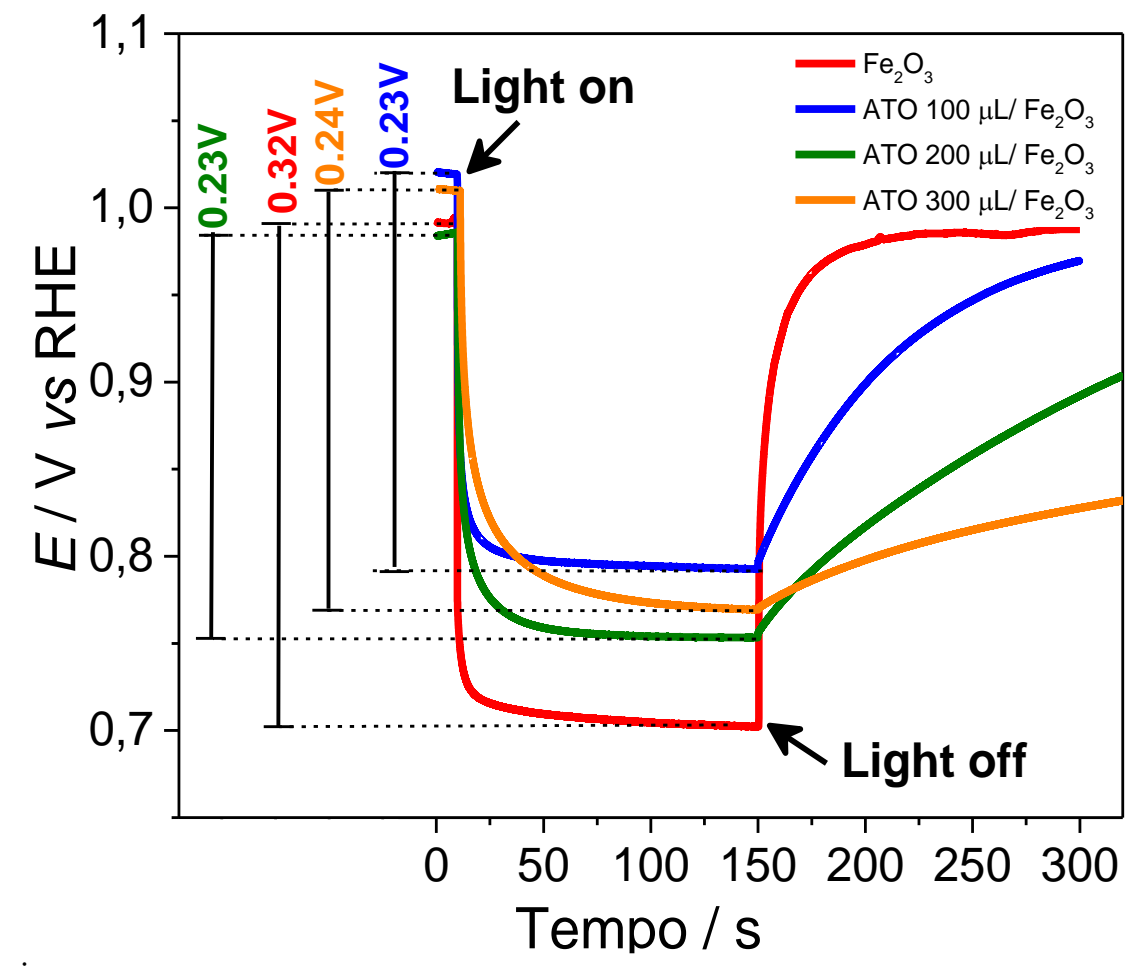

Fonte: Autoria própria.

O efeito da modificação do substrato com nanopartículas de ATO nas propriedades elétricas dos fotoanodos de hematita foi avaliado por experimentos de espectroscopia de impedância fotoeletroquímica (PEIS) a 1,23V (vs. ERH) em KOH 1 mol L-1 (pH 13,6). Os espectros de Nyquist experimentais obtidos estão apresentados na Figura 39 e os diagramas Bode estão apresentados na Figura C2. O circuito equivalente no qual os diagramas de Nyquist foram matematicamente ajustados é o mesmo apresentado apresentados na Figura 30-b, e os resultados estão organizados na Tabela 14.

Analisando os diagramas da Figura 39 e os dados expressos na Tabela 9, pode-se verificar que a modificação do substrato com ATO contribuiu para a diminuição da resistência de transferência de carga total do filme de hematita. Claramente, o semicírculo localizado a baixas frequências, relacionado ao transporte de carga do bulk para a superfície do fotoanodo, diminuiu drasticamente em comparação ao perfil obtido para o fotoanodo preparado sobre o substrato não modificado. A diminuição da resistência $\mathrm{R}_{\text {trapping, }}$, pode estar relacionada com a maior condutividade do bulk dos filmes modificados com ATO e ao maior tempo de vida das cargas fotogeradas, corroborando com os resultados obtidos nas análises de MS e OCPT. Os filmes de hematita modificados com ATO apresentaram menor capacitância dos estados superficiais que o fotoanodo de hematita pura, ou seja, menor densidade de defeitos, e esses 
defeito têm menor resistência a injetar carga na solução. Deste modo, o efeito da subcamada de ATO nos filmes de hematita está associado tanto à menor recombinação das cargas fotogeradas no bulk, devido a menor resistência, quanto na superfície, pois a dopagem com Sb e Sn também passivou alguns defeitos superficiais e tornos os defeitos remanescente mais ativos a REO [46].

Figura 39- Gráficos de Nyquist para os fotoanodos de hematita registrados a 1,23V (vs. RHE) em 1 mol L-1 KOH sob iluminação com simulador solar $\left(100 \mathrm{~mW} \mathrm{~cm}^{-1}\right.$, com filtro A.M. 1.5). Os valores experimentais estão representados pelos símbolos e os ajustados matematicamente estão apresentados por linhas.

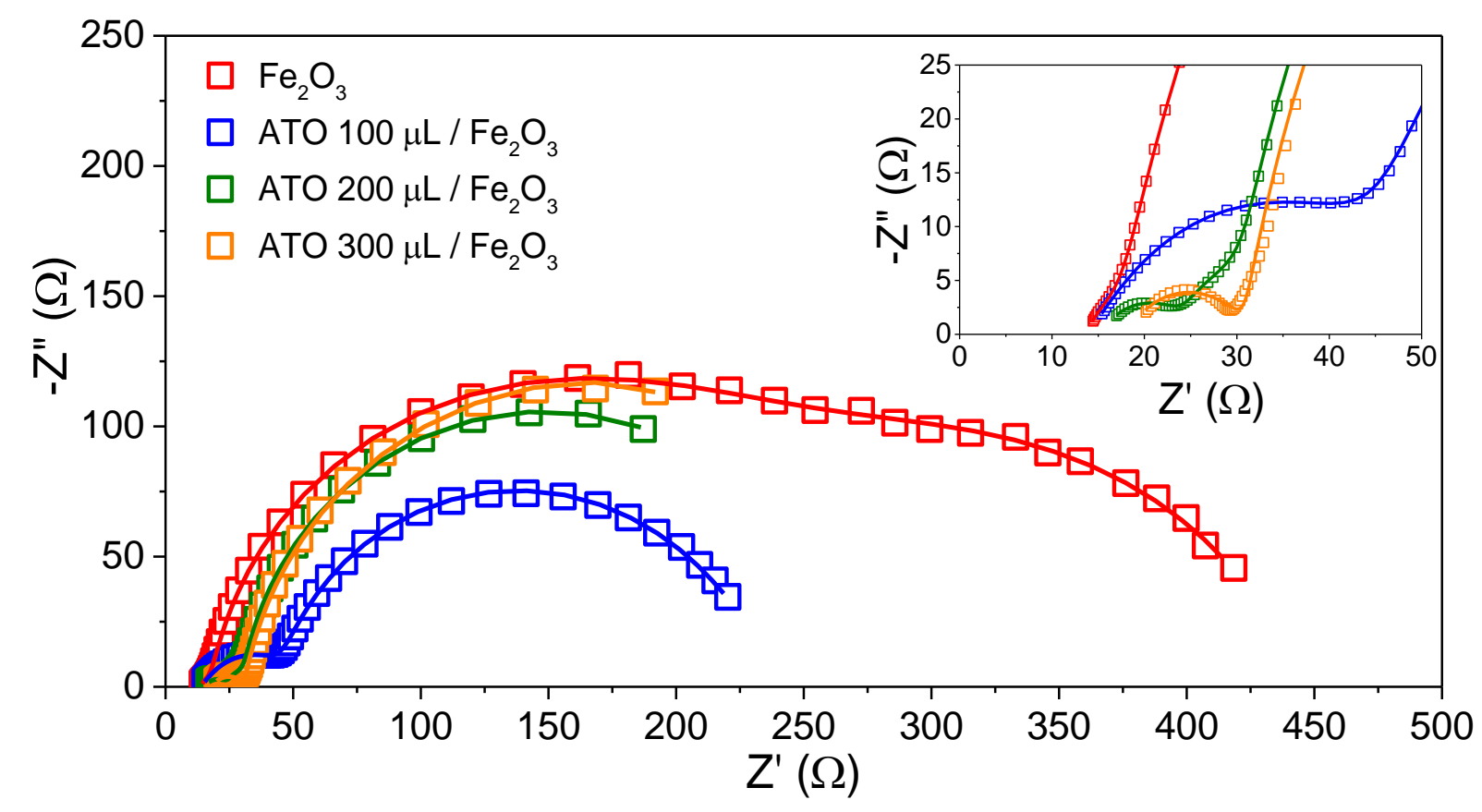

Fonte: Autoria própria.

Tabela 14-Parâmetros matematicamente ajustados ao circuito equivalente para os fotoanodos de hematita em 1 $\mathrm{mol} \mathrm{L}-1 \mathrm{KOH}$.

\begin{tabular}{cccccc}
\hline Filmes & $\mathbf{R s}_{\mathbf{S}}(\boldsymbol{\Omega})$ & $\mathbf{R}_{\text {trapping }}(\boldsymbol{\Omega})$ & $\mathbf{C}_{\text {bulk }}(\boldsymbol{\mu F})$ & $\mathbf{R}_{\text {ct, Ss }}(\boldsymbol{\Omega})$ & $\mathbf{C s s}(\boldsymbol{\mu F})$ \\
\hline $\mathbf{F e}_{2} \mathbf{O}_{3}$ & 13,7 & 170,7 & 13,3 & 452,6 & 346,0 \\
$\mathbf{A T O - 1 0 0} \boldsymbol{\mu} \mathbf{L} / \mathbf{F e}_{2} \mathbf{O}_{3}$ & 14,1 & 32,6 & 24,2 & 212,1 & 154,2 \\
$\mathbf{A T O - 2 0 0} \boldsymbol{\mu} \mathbf{L} / \mathbf{F e}_{2} \mathbf{O}_{3}$ & 15,3 & 12,8 & 16,8 & 242,5 & 274,9 \\
$\mathbf{A T O - 3 0 0} \boldsymbol{\mu l} / \mathbf{F e}_{2} \mathbf{O}_{3}$ & 19,1 & 10,7 & 7,9 & 246,6 & 294,4 \\
\hline
\end{tabular}

Fonte: Autoria própria.

Para melhor compreensão do efeito da modificação com ATO as eficiências de separação $\left(\eta_{\text {sep }}\right)$ e injeção $\left(\eta_{\text {inj }}\right)$ de cargas foram estimadas pelo método descrito por Dotan et al. 
[132]. O valor de $\mathrm{j}_{\max }$ foi determinado a partir da integração do espectro de absorção dos fotoanodos de hematita modificados com diferentes cargas de ATO com o espectro solar AM 1,5G $\left(100 \mathrm{~mW} \mathrm{~cm}^{-2}\right)$, e o valor calculado corresponde a $\sim 5,65 \mathrm{~mA} \mathrm{~cm}{ }^{-2}$, levando em consideração a espessura estimada do filme. Os valores de densidades de fotocorrentes utilizadas para o cálculo das eficiências foi estimado por voltametria linear realizada a $20 \mathrm{mV}$ $\mathrm{s}^{-1}$ em eletrólito alcalino na presença e ausência de peróxido de hidrogênio. Os voltamogramas registrados estão apresentados na Figura C3 (Apêndice C). Nestes voltamogramas é possível observar que a adição do $\mathrm{H}_{2} \mathrm{O}_{2}$ no eletrólito desloca potencial de onset, tanto para a varredura na presença de luz quanto para a varredura ausência de luz, em direção potenciais menos positivos. Os gráficos que relacionam as eficiências de separação e de injeção de carga em função do potencial aplicado, estão apresentados na Figura C4-a e C4-b. No gráfico da Figura 40 estão apresentadas as eficiências de injeção e separação de carga calculadas para os fotoanodos no potencial termodinâmico.

Figura 40- Gráfico da eficiência de separação e eficiência de injeção de carga dos fotoanodos de hematita preparados no substrato não-modificado e modificado com ATO à 1,23 V vs. ERH em KOH 1 mol L'-1 .

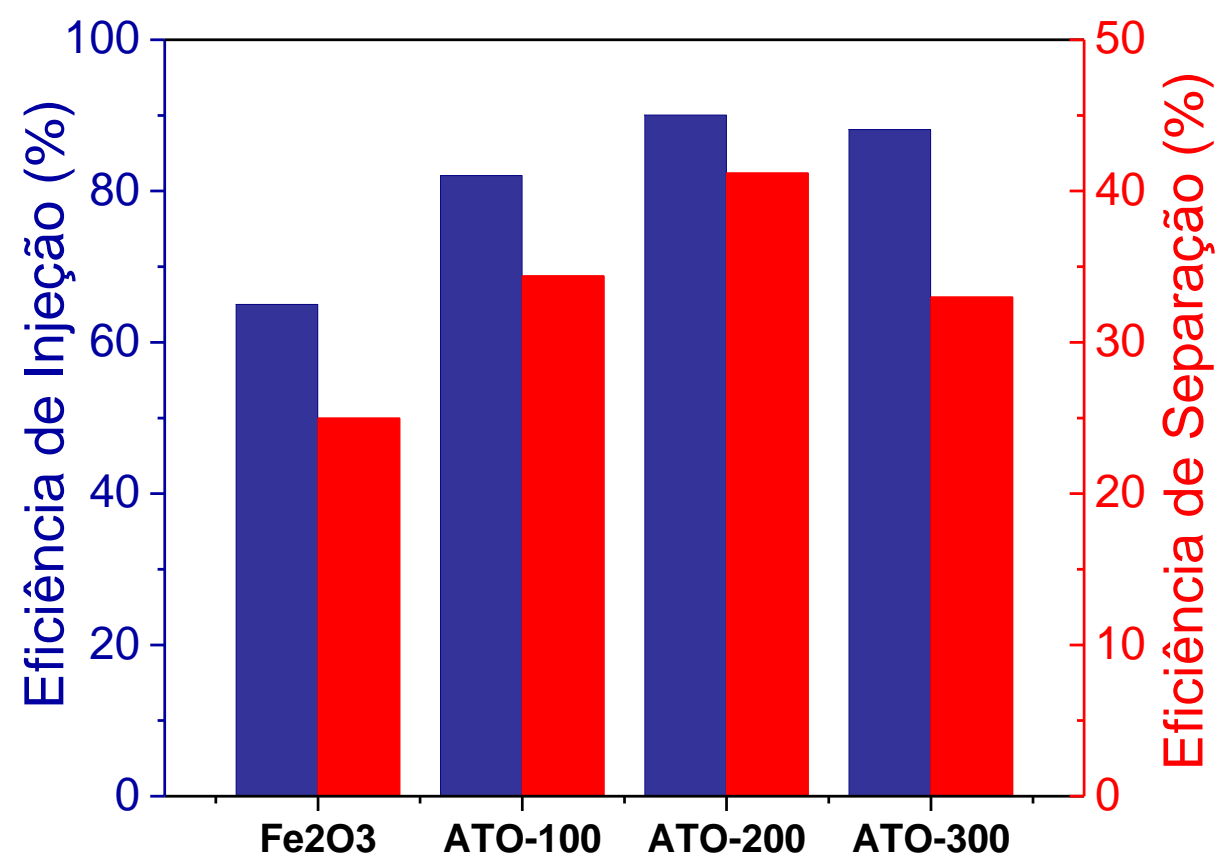

Fonte: Autoria própria.

Através deste gráfico apresentado na Figura 40 pode-se observar que a modificação do filme de hematita com a subcamada de nanopartículas de ATO, promoveu aumento da eficiência de separação de cargas. Em comparação ao filme de hematita não-modificado, os filmes ATO- $100 \mu \mathrm{L} / \mathrm{Fe}_{2} \mathrm{O}_{3}$, ATO- $200 \mu \mathrm{L} / \mathrm{Fe}_{2} \mathrm{O}_{3}$ e ATO-300 $\mu \mathrm{L} / \mathrm{Fe}_{2} \mathrm{O}_{3}$ apresentaram aumento de $\sim 9 \%, 16 \%$ e $10 \%$ na eficiência de separação de cargas a 1,23V (vs. ERH), respectivamente. O 
aumento da eficiência de separação indica menor recombinação de cargas no bulk do fotoanodo [134], justificando a melhora no comportamento PEC observada anteriormente. Os fotoanodos modificados com ATO também apresentaram melhora na eficiência de injeção de carga. $\mathrm{O}$ aumento na eficiência de injeção pode estar associado à diminuição na densidade de defeitos superficiais na interface semicondutor-eletrólito. A quantidade de ATO que apresentou melhores eficiências de separação e injeção de cargas no potencial termodinâmico foi a subcamada preparada com $200 \mu \mathrm{L}$, justificando a melhor resposta de fotocorrente neste potencial em comparação aos outros filmes. 


\section{CONCLUSÕES}

A partir do estudo da otimização da síntese dos filmes de hematita pôde-se verificar que ambos parâmetros avaliados, temperatura de tratamento térmico e carga de Fe metálico depositado, apresentaram influência significativas na resposta fotoeletroquímica destes filmes. A maior densidade de fotocorrente obtida foi $0,83 \mathrm{~mA} \mathrm{~cm}^{-2}$ a $1,23 \mathrm{~V}$ (vs. ERH) para o filme preparado com $500 \mathrm{mC}$ de $\mathrm{Fe}$ eletrodepositado e tratado termicamente a $650^{\circ} \mathrm{C}$. Este valor de fotocorrente obtido é superior aos valores reportados na literatura para filmes preparados por eletrodeposição catódica.

Com base no estudo da modificação da superfície do filme de hematita por dopagem com diferentes cargas de Sn eletrodepositado, pôde-se verificar que a presença de Sn no processo de crescimento dos filmes não alterou significativamente a morfologia e valores band gap dos filmes de hematita. Em comparação às outras cargas de Sn avaliadas, o filme de hematita dopado com $10 \mathrm{mC}$ de $\mathrm{Sn}$ apresentou a maior densidade de fotocorrente e menor potencial de onset sendo 1,2 $\mathrm{mA} \mathrm{cm}^{-2}$ a 1,23 V (vs. ERH) e 0,8 V (vs. ERH), respectivamente. Através dos resultados obtidos pôde-se atribuir a melhora na performance PEC para este filme à maior capacidade de passivação dos defeitos superficiais pela formação de uma fina camada de $\mathrm{Fe}_{\mathrm{x}} \mathrm{Sn}_{1-\mathrm{x}} \mathrm{O}_{4}$, que promove menor recombinação das cargas na interface semicondutoreletrólito. O efeito passivador de defeitos da dopagem com Sn foi comprovado por análises de MS, na qual observou-se a diminuição de $\sim 230 \mathrm{mV}$ no potencial de banda plana e por ensaios de PEIS nos quais foram verificados a diminuição da resistência de transferência de carga nos defeitos. Além disso, nos resultados obtidos pela análise de PEIS foi possível observar que a dopagem com $10 \mathrm{mC}$ de $\mathrm{Sn}$ promoveu diminuição da resistência de transferência de carga total do sistema.

Com base nas investigações realizadas, pode-se verificar que a deposição de uma fina camada de $\mathrm{NiOOH}$, obtida a partir de $1^{\circ}$ ciclo de deposição, apresentou melhora de $22 \%$ na densidade de fotocorrente e deslocamento de $\sim-100 \mathrm{mV}$ no potencial de onset do filme de hematita. Através dos ensaios eletroquímicos e fotoeletroquímicos, pôde-se concluir que em eletrólito alcalino a camada de cocatalisador depositada apresentou efeito semelhante à dopagem com Sn nas propriedades PEC dos filmes de hematita. Esse efeito indica que o $\mathrm{NiOOH}$ depositado atua principalmente passivando os estados superficiais. A combinação das estratégias de modificação superficial, pela deposição de NiOOH sobre a superfície do filme de hematita dopado com Sn apresentou o melhor desempenho PEC dos filmes avaliados, aumento 
na densidade de fotocorrente de $\sim 60 \%$ a $1,23 \mathrm{~V}$ ( $v s$. ERH) e deslocamento de $-250 \mathrm{mV}$ no $E_{\text {on }}$. Através dos ensaios de PEIS, pode-se constatar que a melhoria da performance PEC para este filme está relacionada com a maior passivação dos estados superficiais, diminuindo a recombinação das cargas fotogeradas e a resistência de transferência de carga total do filme. Em suma, as modificações pela dopagem com Sn e deposição de co-catalisador melhoraram as eficiências de injeção de carga, tendo em vista a diminuição da taxa de recombinação de cargas na interface. As eficiências de separação de cargas não foram alteradas indicando que as modificações realizadas foram restritas à superfície do filme de hematita.

A modificação dos filmes de hematita pela deposição de nanopartículas de ATO no substrato promoveu melhora nas propriedades optoeletrônicas e fotoeletroquímicas do filme de hematita. A subcamada de nanopartículas de ATO promoveu a formação de estruturas aparentemente mais porosas. A introdução da subcamada de ATO também melhorou a absorção de fótons dos filmes na região do UV-Vis, porém os valores band gap não foram alterados. As propriedades fotoeletroquímicas dos filmes de hematita melhoraram com a modificação com ATO. O filme ATO- $200 \mu \mathrm{L} / \mathrm{Fe}_{2} \mathrm{O}_{3}$ apresentou aumento de $50 \%$ na densidade de fotocorrente a 1,23V (vs. ERH), devido ao aumento da capacidade de absorção de luz dos filmes, da cristalinidade dos filmes, da densidade de portadores calculada nos experimentos de MS e da nanoestruturação do coletor de carga. Através dos experimentos de PEIS, foi possível concluir que a subcamada de ATO promoveu diminuição da resistência de transferência de carga total do filme de hematita. O melhor desempenho PEC do filme modificado com ATO está associado com a maior eficiência de separação e injeção de carga, levando a menor recombinação das cargas fotogeradas. 


\section{REFERÊNCIAS BIBLIOGRÁFICAS}

1. BP Statistical Review of World Energy Statistical Review of World. Ed BP Stat Rev World Energy. 2019. Disponível em: <https://www.bp.com/content/dam/bp/businesssites/en/global/corporate/pdfs/energy-economics/statistical-review/bp-stats-review-2019-fullreport.pdf.>.Acesso em: 15 nov. 2019.

2. STAUB, J. International Energy Outlook. Outlook. v. 0484(July), p. 70-99, 2010.

3. JOY, J.; MATHEW, J.; GEORGE, S. Nanomaterials for Photoelectrochemical Water Splitting- Review. International Jounal Hydrogen Energy, v. 43, n. 10, p. 4804-4817, 2018.

4. CHI, J.; YU, H. Water electrolysis based on renewable energy for hydrogen production. Chinese Jounal of Catalysis, v. 39, n. 3,p. 390-394, 2018.

5. DINCER, I.; ACAR, C. Smart energy systems for a sustainable future. Applied Energy, v. 194, p. 225-235, 2016.

6. LHERMITTE, C.; BARTLETT, B. Advancing the Chemistry of $\mathrm{CuWO}_{4}$ for Photoelectrochemical Water Oxidation. Accounts of chemical research, v. 49, n. 6, p. 11211129, 2016.

7. TAMIRAT, A.; RICK, J.; DUBALE, A.; SU, W.; HWANG B. Using hematite for photoelectrochemical water splitting: A review of current progress and challenges. Nanoscale Horizons, v. 1, n. 4, p. 243-267, 2016.

8. MØLLER, K.; JENSEN, T.; AKIBA, E.; LI, H. Hydrogen - A sustainable energy carrier. Progress in Natural Science: Materials International, v. 27, n. 1, p. 34-40, 2017.

9. LÓPEZ GONZÁLEZ, E.; ISORNA LLERENA, F.; SILVA PÉREZ, M.; ROSA IGLESIAS, F.; GUERRA MACHO, J. Energy evaluation of a solar hydrogen storage facility: Comparison with other electrical energy storage technologies. International Jounal Hydrogen Energy, v. 40, n. 15, p: 5518-5525, 2015.

10. TAHIR, M.; PAN, L.; IDREES, F.; ZHANG, X.; WANG, L.; ZOU, J.;WANG, Z. Electrocatalytic oxygen evolution reaction for energy conversion and storage: A comprehensive review. Nano Energy, v.37, p. 136-157, 2017.

11. NIKOLAIDIS, P.; POULLIKKAS, A. A comparative overview of hydrogen production 
processes. Renewable and sustainable energy reviews, v. 67, p. 597-611, 2017.

12. PASSALACQUA, R.; PERATHONER, S.; CENTI, G. Semiconductor, molecular and hybrid systems for photoelectrochemical solar fuel production. Journal of Energy Chemistry, v. 26, n. 2, p. 219-240, 2017.

13. WANG, Y.; HU, X.; CAO, Z.; GUO, L. Investigations on bubble growth mechanism during photoelectrochemical and electrochemical conversions. Colloids and Surfaces A: Physicochemical and Engineering Aspects, v. 505, p. 86-92, 2016.

14. BACCARO, A.; GUTZ, I. Fotoeletrocatálise Em Semicondutores: Dos Princípios Básicos Até Sua Conformação À Nanoescala. Química Nova. v. 41, n.3, p. 326-339, 2017.

15. CORNELL, R.; SCHWERTMANN, U. The Iron Oxides: Structure, Reactions, Occurences and Uses. 2003.

16. YU, P.; CARDONA, M. Texts in Physics. v, 2, p. 17-106, 2017.

17. JIANG, C.; MONIZ, S.; WANG, A.; ZHANG, T.; TANG, J. Photoelectrochemical devices for solar water splitting-materials and challenges. Chemical Society Reviews, v. 46, n. 15, p. $4645-4660,2017$.

18. BERANEK, R. (Photo)electrochemical methods for the determination of the band edge positions of $\mathrm{TiO}_{2}$-based nanomaterials. Advances in Physical Chemistry, v. 2011:1, p. 8083, 2011.

19. WEI, D.; AMARATUNGA, G. Photoelectrochemical Cell and Its Applications in Optoelectronics. Int. J. Electrochem. Sci. v. 2, p. 897-912, 2007.

20. MAYER, M. Photovoltage at semiconductor-electrolyte junctions. Current Opinion in Electrochemistry, v. 2, n. 1, p. 104-110, 2017.

21. SIVULA, K.; VAN DE KROL, R. Semiconducting materials for photoelectrochemical energy conversion. Nature Reviews Materials, v. 1, n. 2, p. 1-16, 2016.

22. YANG, X.; DU, C.; LIU, R.; XIE, J.; WANG, D. Balancing photovoltage generation and charge-transfer enhancement for catalyst-decorated photoelectrochemical water splitting: A case study of the hematite/MnO ${ }_{\mathrm{x}}$ combination. Journal of Catalysis, v. 304, p. 86-91, 2013.

23. KUANG, Y.; YAMADA, T.; DOMEN, K. Surface and Interface Engineering for Photoelectrochemical Water Oxidation. Joule, v. 1, n. 2, p. 290-305, 2017. 
24. Fujishima, A.; HONDA, K. Electrochemical Photolysis of water at a semiconductor electrode. Nature. v. 238, p. 37-38, 1972.

25. YAO, T.; AN, X.; HAN, H.; CHEN, J.; LI, C. Photoelectrocatalytic Materials for Solar Water Splitting. Advanced Energy Materials, v. 8, n. 21, p. 1-36, 2018.

26. GURUDAYAL; BASSI, P.; SRITHARAN, T.; WONG, L. Recent progress in iron oxide based photoanodes for solar water splitting. Journal of Physics D: Applied Physics, v. 51, n. 47, p. 1-28, 2018.

27. SOUZA, F. Sunlight-driven water splitting using hematite nanorod photoelectrodes. Anais da Academia Brasileira de Ciência. v. 90, n. 1, p. 745-762, 2018.

28. GODWIN, I.; ROVETTA, A.; LYONS, M.; COLEMAN, J. Electrochemical water oxidation: The next five years. Current Opinion in Electrochemistry,. v. 7, p. 31-35, 2018.

29. STEIER, L.; HERRAIZ-CARDONA, I.; GIMENEZ, S.; FABREGAT-SANTIAGO, F.; BISQUERT, J.; TILLEY, D.; GRATZEL, M. Understanding the role of underlayers and overlayers in thin film hematite photoanodes. Advanced Functional Materials, v. 24, n. 48, p. 7681-7688, 2014.

30. LIU, R.; LIN, Y.; CHOU, L.; SHEEHAN, S. W.; HE, W.; ZHANG, F.; HOU, H.; WANG, D. Water splitting by tungsten oxide prepared by atomic layer deposition and decorated with an oxygen-evolving catalyst. Angewandte Chemie International Edition, v. 50, n. 2, p. 499-502, 2011.

31. MA, Y.; PENDLEBURY, S. R.; REYNAL, A.; LE FORMAL, F.; DURRANT, J. Dynamics of photogenerated holes in undoped $\mathrm{BiVO}_{4}$ photoanodes for solar water oxidation. Chemical Science, v. 5, n. 8, p. 2964-2973, 2014.

32. GROMBONI, M.F.; COELHO, D.; MASCARO, L. H.; POCKETT, A.; MARKEN, F. Enhancing activity in a nanostructured $\mathrm{BiVO}_{4}$ photoanode with a coating of microporous A12O3. Applied Catalysis B: Environmental, v. 200, p. 133-140, 2017.

33. ZHANG, X.; CUI, H.; HUMAYUN, M.; QU, Y.; FAN, N.; SUN, X. Exceptional performance of photoelectrochemical water oxidation of single-crystal rutile $\mathrm{TiO}_{2}$ nanorods dependent on the hole trapping of modified chloride. Scientific Reports. v. 6, p. 2143021438, 2016.

34. NURLAELA, E.; ZIANI, A.; TAKANABE, K. Tantalum nitride for photocatalytic water 
splitting : concept and applications. Materials for Renewable and Sustainable Energy, v. 5, n. 4, p. 1-21, 2016.

35. XIAO, M.; WANG, S. THAWEESAK, S.; LUO, B.; WANG, L. Tantalum (Oxy)Nitride: Narrow Bandgap Photocatalysts for Solar Hydrogen Generation. Engineering, v. 3, n. 3, p. 365-378, 2017.

36. LI, C.; LUO, Z.; WANG, T.; GONG, J. Surface, Bulk, and Interface: Rational Design of Hematite Architecture toward Efficient Photo-Electrochemical Water Splitting. Advanced Materials, v. 30, n. 30, p. 1-23, 2018.

37. QIU Y, LIU W, CHEN W, ZHOU, G.; HSU, PC.; ZHANG, R.; LIANG, Z.; FAN, S.; ZHANG, Y.; CUI, Y. Efficient solar-driven water splitting by nanocone $\mathrm{BiVO}_{4}$-perovskite tandem cells. Science Advances. v. 2, n. 6, p. 1-8, 2016.

38. SHEN, S.; LINDLEY, S.; CHEN, X.; ZHANG, J. Hematite heterostructures for photoelectrochemical water splitting: Rational materials design and charge carrier dynamics. Energy \& Environmental Science, v. 9, n. 9, p. 2744-2775, 2016.

39. SIVULA, K.; LE FORMAL, F.; GRÄTZEL, M. Solar water splitting: Progress using hematite $\left(\alpha-\mathrm{Fe}_{2} \mathrm{O}_{3}\right)$ photoelectrodes. ChemSusChem. v. 4, n. 4, p. 432-449, 2011.

40. SIVULA, K.; ZBORIL, R.; LE FORMAL, F.; ROBERT, R.; WEIDENKAFF, A.; TUCEK, J.; FRYDRYCH, J.; GRATZEL, M. Photoelectrochemical water splitting with mesoporous hematite prepared by a solution-based colloidal approach. Journal of the American Chemical Society, v. 132, n. 21, p. 7436- 7444, 2010.

41. BASSI, P.; GURUDAYAL.; WONG, L.; BARBER, J. Iron based photoanodes for solar fuel production. Physical Chemistry Chemical Physics, v. 16, n. 24, p. 11834-11842, 2014. 42. JIA, L.; HARBAUER, K.; BOGDANOFF, P.; HERRMANN-GEPPERT, I.; RAMIREZ, A.; VAN DE KROLA, R.; FIECHTERA, S. $\alpha-\mathrm{Fe}_{2} \mathrm{O}_{3}$ films for photoelectrochemical water oxidation - Insights of key performance parameters. Journal of Materials Chemistry A, v. 2, n. 47, p. 20196-20202, 2014.

43. LINDGREN, T.; VAYSSIERES, L.; WANG, H. Photo-oxidation of water at hematite electrodes. Chemical physics of nanostructured semiconductors, 2003: Ch 3, p. 83-110, 2003.

44. DIAS, P.; VILANOVA, A.; LOPES, T.; ANDRADE, L.; MENDES, A. Extremely stable 
bare hematite photoanode for solar water splitting. Nano Energy. v. 23, p. 70-76, 2016.

45. THORNE, J.; LI, S.; DU, C.; QIN, G.; WANG, D. Energetics at the Surface of Photoelectrodes and Its Influence on the Photoelectrochemical Properties. The journal of physical chemistry letters, v. 6, n. 20, p. 4083-4088, 2015.

46. DANG, K.; WANG, T.; LI, C.; ZHANG, J.; LIU, S.; GONG, J. Improved Oxygen Evolution Kinetics and Surface States Passivation of Ni-Bi Co-Catalyst for a Hematite Photoanode. Engineering. v. 3, p. 3, p. 285-289, 2017.

47. CHO, I.; HAN, H.; LOGAR, M.; PARK, J.; ZHENG, X. Enhancing Low-Bias Performance of Hematite Photoanodes for Solar Water Splitting by Simultaneous Reduction of Bulk, Interface, and Surface Recombination Pathways. Advanced Energy Materials, v. 6, n. 4, p. 1-9, 2016.

48. KAY, A.; CESAR, I.; GRÄTZE, M. New benchmark for water photooxidation by nanostructured $\alpha-\mathrm{Fe}_{2} \mathrm{O}_{3}$ films. Journal of the American Chemical Society, v. 128, n. 49, p. 15714-15721, 2006.

49. LIANG, P.; LI, L.; LIU, C.; WANG, W.; ZHANG, H.; MITSUZAKI, N.; CHEN, Z. Effects of cathodic electrodeposition conditions on morphology and photoelectrochemical response of $\alpha-\mathrm{Fe}_{2} \mathrm{O}_{3}$ photoanode. Thin Solid Films. v. 666, p. 161-171, 2018.

50. LI, L.; ZHANG, H.; LIU, C.; LIANG, P.; MITSUZAKI, N.; CHEN, Z. The effect of annealing regime and electrodeposition time on morphology and photoelecrochemical performance of hematite converted from nanosheet $\gamma$-FeOOH. Journal of Photochemistry and Photobiology A: Chemistry, v. 369, p. 8-15, 2019.

51. PHUAN, Y.; ONG, W.; CHONG, M.; OCON, J. Prospects of electrochemically synthesized hematite photoanodes for photoelectrochemical water splitting: A review.

Journal of Photochemistry and Photobiology C: Photochemistry Reviews, v. 33, p. 54-82, 2017.

52. LEE, C.; WANG, L.; KADO, Y.; KILLIAN, M.; SCHMUKI, P. Anodic nanotubular/porous hematite photoanode for solar water splitting: Substantial effect of iron substrate purity. ChemSusChem. v. 7, n. 3, p. 934-940, 2014.

53. KIMMICH, D.; TAFFA, D.; DOSCHE, C.; WARK, M.; WITTSTOCK, G. Photoactivity and scattering behavior of anodically and cathodically deposited hematite photoanodes - A 
comparison by scanning photoelectrochemical microscopy. Electrochimica Acta, v. 202, p. 224-230, 2016.

54. WHEELER, D.; WANG, G.; LING, Y.; LI, Y; ZHANG, J. Nanostructured hematite: Synthesis, characterization, charge carrier dynamics, and photoelectrochemical properties.

Energy \& Environmental Science, v. 5, n. 5, p. 6682-6702, 2012.

55. WANG, D.; ZHANG, Y.; WANG, J.; PENG, C.; HUANG, Q.; SU, S.; WANG, L.; HUANG, W.; FAN, C. Template-free synthesis of hematite photoanodes with nanostructured ATO conductive underlayer for pec water splitting. ACS Applied Materials \& Interfaces,. v. 6, n. 1, p. 36-40, 2014.

56. YANG, J.; BAO, C.; YU, T.; HU, Y.; LUO, W.; ZHU, W.; FU, G.; LI, Z.; GAO, H.; LI, F.; ZOU, Z. Enhanced performance of photoelectrochemical water splitting with ITO@ $\alpha$ $\mathrm{Fe}_{2} \mathrm{O}_{3}$ core-shell nanowire array as photoanode. ACS Applied Materials \& Interfaces, v. 7, n. 48, p. 26482-26490, 2015.

57. FRANCISCO, F.; DIAS, P.; IVANOU, D.; SANTOS, F.; AZEVEDO, J.; MENDES, A. Synthesis of Host-Guest Hematite Photoelectrodes for Solar Water Splitting.

ChemNanoMat. v. 5, n. 7, p. 911-920, 2019.

58. YU, B.; KWAK, S. Carbon quantum dots embedded with mesoporous hematite nanospheres as efficient visible light-active photocatalysts. Journal of Materials Chemistry, v. 22 , n. 17 , p. 8345-8353, 2012.

59. RAI, S.; IKRAM, A.; SAHAI, S.; DASS, S.; SHRIVASTAV, R.; SATSANGI, V. Morphological, optical and photoelectrochemical properties of $\mathrm{Fe}_{2} \mathrm{O}_{3}-\mathrm{GNP}$ composite thin films. RSC Advances. v. 4, n. 34, p.17671-17679, 2014.

60. ZHANG, H.; ZHU, C.; CHEN, Y.; YANG, M.; YANG, P.; WU, X.; QI, L.; MENG, F. Enhanced photocatalytic activities of net-like hematite nanoparticle/graphene oxide composite. Journal of Materials Chemistry A, v. 3, n. 4, p. 1421-1426, 2015.

61. ZHANG, H.; KIM, J.; KIM, J.; LEE, J. Engineering Highly Ordered Iron Titanate Nanotube Array Photoanodes for Enhanced Solar Water Splitting Activity. Advanced Functional Materials, v. 27, n. 35, p. 1-9, 2017.

62. KONDOFERSKY,I.; DUNN, H.; MÜLLER, A.; MANDLMEIER, B.; FECKL, J.; FATTAKHOVA-ROHLFING, D.; SCHEU, C.; PETER, L.; BEIN, T. Electron collection in 
host-guest nanostructured hematite photoanodes for water splitting: The influence of scaffold doping density. ACS Applied Materials \& Interfaces, v. 7, n. 8, p. 4623-4630, 2015.

63. PARK, S.; KIM, H.; LEE, C.; SONG, H.; SHIN, S.; SEO, S.; PARK, H.; LEE, S.; KIM, D.; HON, K. Sn self-doped $\alpha-\mathrm{Fe}_{2} \mathrm{O}_{3}$ nanobranch arrays supported on a transparent, conductive $\mathrm{SnO} 2$ trunk to improve photoelectrochemical water oxidation. International Jounal Hydrogen Energy, v. 39, n. 29, p. 16459-16467, 2014.

64. WANG, D.; ZHANG, Y.; PENG, C.; WANG, J.; HUANG, Q.; SU, S.; WANG, L.; HUANG, W.; FAN, C. Crystallinity Engineering of Hematite Nanorods for High-Efficiency Photoelectrochemical Water Splitting. Advanced Science. v. 2, n. 4, p. 1-5, 2015.

65. XU, Y-F.; RAO, H-C.; CHEN, B-X, LIN, Y.; CHEN, H-Y, KUANG, D-B, SU, C-Y. Achieving Highly Efficient Photoelectrochemical Water Oxidation with a $\mathrm{TiCl}_{4}$ Treated 3D Antimony-Doped $\mathrm{SnO}_{2}$ Macropore/Branched $\alpha-\mathrm{Fe}_{2} \mathrm{O}_{3}$ Nanorod Heterojunction Photoanode. Advanced Science. v. 2, n. 7, 2015.

66. PENG, Q.; KALANYAN, B.; HOERTZ, P.; MILLER, A.; KIM, D.; HANSON, K.; ALIBABAEI, L.; LIU, J.; MEYER, T.; PARSONS, G.; GLASS, J. Electrical Solutionprocessed, antimony-doped tin oxide colloid films enable high-performance $\mathrm{TiO}_{2}$ photoanodes for water splitting. Nano Letters. v. 13, n. 4, p. 1481-1488, 2013.

67. LIN, Y.; XU, Y.; MAYER, M. T.; SIMPSON, Z. I.; MCMAHON, G.; ZHOU, S.; WANG, D. Growth of p-type hematite by atomic layer deposition and its utilization for improved solar water splitting. Journal of the American Chemical Society, v. 134, n. 12, p. 5508-5511, 2012.

68. ZHANG, Q.; WANG, H.; DONG ,Y.; WU, Q.; XUE, S. Highly efficient hematite films via mid-/ex-situ Sn-doping for photoelectrochemical water oxidation. International Jounal Hydrogen Energy, v. 42, n. 25, p. 16012-16022, 2017.

69. JEON, TH.; BOKARE, AD.; HAN, DS.; ABDEL-WAHAB, A.; PARK, H.; CHOI, W. Dual modification of hematite photoanode by $\mathrm{Sn}$-doping and $\mathrm{Nb}_{2} \mathrm{O}_{5}$ layer for water oxidation. Applied Catalysis B: Environmental, v. 20, p. 591-599, 2017.

70. LI, S.; CAI, J.; LIU, Y.; GAO, M.; CAO, F.; QIN, G. Tuning orientation of doped hematite photoanodes for enhanced photoelectrochemical water oxidation. Solar Energy Materials and Solar Cells, v. 179,p. 328-333, 2017. 
71. WANG, P.; WANG, S.; WANG, H.; WU, Z.; WANG, L. Recent Progress on PhotoElectrocatalytic Reduction of Carbon Dioxide. Particle \& Particle Systems Characterization, v. 35, n. 1, p. 1-25, 2018.

72. ZHANG, Y.; JI, H.; MA, W.; CHEN, C.; SONG, W.; ZHAO, J. Doping-promoted solar water oxidation on hematite photoanodes. Molecules. v. 21, n. 7, p. 1-15, 2016.

73. CARVALHO, W.; SOUZA, F. Hematite Surface Activation by Chemical Addition of Tin Oxide Layer. ChemPhysChem, v. 17, n. 17, p. 2710-2717, 2016.

74. NATARAJAN, K.; BHAT, P.; YADAV, P.; PANDEY, K.; TRIPATHI, B.; KUMAR, M. Investigating the Role of Substrate Tin Diffusion on Hematite Based Photoelectrochemical Water Splitting System. Journal of Nanoscience and Nanotechnology, v. 18, n. 3, p. 1856$1863,2017$.

75. XI, L.; CHIAM, S. Y.; MAK, W. F.; TRAN, P. D.; BARBER, J.; LOO, S.; WONG, L. H. A novel strategy for surface treatment on hematite photoanode for efficient water oxidation. Chemical Science. v. 4, n. 1, p. 164-169, 2013.

76. HUFNAGEL, A. G.; HAJIYANI, H.; ZHANG, S.; LI, T.; KASIAN, O.; GAULT, B.; BREITBACH, B.; BEIN, T.; FATTAKHOVA-ROHFING, D.; SCHEU, C.; PENTCHEVA, R. Why Tin-Doping Enhances the Efficiency of Hematite Photoanodes for Water SplittingThe Full Picture. Advanced Functional Material, v. 28, n. 52, p. 1804472, 2018.

77. JANSI-RANI, B.; RAVI, G.; YUVAKKUMAR, R.; RAVICHANDRAN, S.; AMEEN, F.; ALNADHARY, S. Sn doped A-Fe $\mathrm{O}_{3}(\mathrm{Sn}=0,10,20,30 \mathrm{wt} \%)$ photoanodes for photoelectrochemical water splitting applications. Renewable Energy. v. 3, p. 566-574, 2019.

78. KOTRLA, T.; PAUŠOVÁ; ZLÁMAL, M.; NEUMANN-SPALLART, M.; KRÝSA, J. Preparation of Sn-doped semiconducting $\mathrm{Fe}_{2} \mathrm{O}_{3}$ (hematite) layers by aerosol pyrolysis. Catalysis Today, v. 313, p. 2-5, 2018.

79. CAI, J.; LI, S.; LI, Z.; WANG, J.; REN, Y.; QIN, G. Electrodeposition of Sn-doped hollow $\alpha-\mathrm{Fe}_{2} \mathrm{O}_{3}$ nanostructures for photoelectrochemical water splitting. Journal of Alloys and Compounds, v. 574, p. 421-426, 2013.

80. LING,Y.; LI, Y. Review of Sn-Doped hematite nanostructures for photoelectrochemical water splitting. Particle \& Particle Systems Characterization, v. 31, n. 11, p. 1113-1121, 
2014.

81. BARD, A. J.; BOCARSLY, A. B.; FAN, F.; WALTON, E. G.; WRIGHTON, M. S. The Concept of Fermi Level Pinning at Semiconductor/Liquid Junctions. Consequences for Energy Conversion Efficiency and Selection of Useful Solution Redox Couples in Solar Devices. Journal of the American Chemical Society, v. 102, n. 11, p. 3671-3677, 1980. 82. TANG, P.; ARBIOL, J. Engineering surface states of hematite based photoanodes for boosting photoelectrochemical water splitting. Nanoscale Horizons, p. 15-35, 2019.

83. ZHANG, Z.; YATES, J. T. Band bending in semiconductors: Chemical and physical consequences at surfaces and interfaces. Chemical Reviews, v. 112, n. 10, p. 5520-5551, 2012.

84. XI, L.; LANGE, K. Surface Modification of Hematite Photoanodes for Improvement of Photoelectrochemical Performance. Catalysts. v. 8, n. 11, p. 497, 2018.

85. HISATOMI, T.; LE FORMAL, F.; CORNUZ, M.; BRILLET, J.; TÉTREAULT, N.; SIVULA, K.; GRÄTZEL, M. Cathodic shift in onset potential of solar oxygen evolution on hematite by 13-group oxide overlayers. Energy \& Environmental Science, v. 4, n. 7, p. 2512-2515, 2011.

86. BARRECA, D.; CARRARO, G.; GASPAROTTO, A.; MACCATO, C.; WARWICK, M.; KAUNISTO, K.; SADA, C.; TURNER, S.; GÖNÜLLÜ, Y.; RUOKO, T.; BORGESE, L.; BONTEMPI, E.; TENDELOO, G.; LEMMETYINEN, H.; MATHUR, S. $\mathrm{Fe}_{2} \mathrm{O}_{3}-\mathrm{TiO}_{2} \mathrm{Nano}^{-}$ heterostructure Photoanodes for Highly Efficient Solar Water Oxidation. Advanced Materials Interfaces, v. 2, n. 17, p. 1-11, 2015.

87. WANG L, NGUYEN NT, SCHMUKI P. A facile surface passivation of hematite photoanodes with iron titanate cocatalyst for enhanced water splitting. ChemSusChem. v. 9, n. 16, p. 2018-2053, 2016.

88. TILLEY, S. D.; CORNUZ, M.; SIVULA, K.; GRÄTZEL, M. Light-inducedwater splitting with hematite: Improved nanostructure and iridium oxide catalysis. Angewandte Chemie International Edition, v. 49, n. 36, p. 6405-6408, 2010.

89. JEON, T. H.; MOON, G.; HEE; PARK, H.; CHOI, W. Ultra-efficient and durable photoelectrochemical water oxidation using elaborately designed hematite nanorod arrays. Nano Energy, v. 39, p. 211-218, 2017. 
90. STEIER, L.; LUO, J.; SCHREIER, M.; MAYER, M.T.; SAJAVAARA, T.; GRÄTZEL, M. Low-Temperature Atomic Layer Deposition of Crystalline and Photoactive Ultrathin Hematite Films for Solar Water Splitting. ACS Nano. v. 9, n. 12, p. 11775-11783, 2015. 91. SOHN, W. Y.; THORNE, J. E.; ZHANG, Y.; KUWAHARA, S.; SHEN, Q.; WANG, D.; KATAYAMA, K. L. Charge carrier kinetics in hematite with NiFeOx coating in aqueous solutions: Dependence on bias voltage. Journal of Photochemistry and Photobiology A: Chemistry, v. 353, p. 344-348, 2018.

92. YEN, C. P.; LI, Y.J.; WANG, J.; CHEN, S.Y.; TSENG, C.J. Characteristics of $\mathrm{Ni}_{\mathrm{x}} \mathrm{Fe}_{1-\mathrm{x}} \mathrm{O}_{\mathrm{y}}$ electrocatalyst on hematite as photoanode for solar hydrogen production. Catalysts, v. 7, n. 11, p. 1-15, 2017.

93. LIARDET, L.; KATZ, J. E.; LUO, J.; GRÄTZEL, M; HU, X. An ultrathin cobalt-iron oxide catalyst for water oxidation on nanostructured hematite photoanodes. Journal of Materials Chemistry A, v. 7, n. 11, p. 6012-6020, 2019.

94. Morales-Guio, C. G.; Mayer, M.T.; Yella, A.; Tilley, S.D.; Grätzel, M.; Hu, X. An Optically Transparent Iron Nickel Oxide Catalyst for Solar Water Splitting. Journal of the American Chemical Society, v. 137, n. 31, p. 9927-9936, 2015.

95. DU, C.; YANG, X.; MAYER, M.; HOYT, H.; XIE, J.; MCMAHON, G.; BISCHOPING, G.; WANG, D. Hematite-based water splitting with low turn-on voltages. Angewandte Chemie International Edition, v. 52, n. 48, p. 12692-12695, 2013.

96. JANG, J. W.; DU, C.; YE, Y.; LIN, Y.; YAO, X.; THORNE, J.; LIU, E.; MCMAHON, G.; ZHU, J.; JAVEY, A.; GUO, J.; WANG, D. Enabling unassisted solar water splitting by iron oxide and silicon. Nature communications, v. 6, p. 7447, 2015.

97. BARROSO, M.; COWAN, A. J.; PENDLEBURY, S. R.; GRÄTZEL, M.; KLUG, D. R.; DURRANT, J. R. The role of cobalt phosphate in enhancing the photocatalytic activity of $\alpha$ $\mathrm{Fe}_{2} \mathrm{O}_{3}$ toward water oxidation. Journal of the American Chemical Society, v. 133, n. 38, p. 14868-14871, 2011.

98. ZHANG, J.; ESLAVA, S. Understanding charge transfer, defects and surface states at hematite photoanodes. Sustain Energy Fuels. 2019.

99. YANG, J. K.; LIANG, B.; ZHAO, M. J.; GAO, Y.; ZHANG, F. C.; ZHAO, H. L. Reference of Temperature and Time during tempering process for non-stoichiometric FTO 
films. Scientific reports, v. 5, p. 15001, 2015.

100. LOW, C. T.J.; WALSH, F. C. The influence of a perfluorinated cationic surfactant on the electrodeposition of tin from a methanesulfonic acid bath. Journal of electroanalytical chemistry, v. 615, n. 2, p. 91-102, 2008.

101. HE, A.; LIU, Q.; IVEY, D. G. Electrodeposition of tin: A simple approach. Journal of Materials Science: Materials in Electronics, v. 19, n. 6, p. 553-562, 2008.

102. WALSH, F. C, LOW C. T. J. A review of developments in the electrodeposition of tincopper alloys. Surface and Coatings Technology, v. 304, p. 246-262, 2016.

103. YAPONTSEVA, Y.; KUBLANOVSKY, V. Electrodeposition of tin(II) from citrate complexes. Turkish Journal of Chemistry, v. 43, n. 1, p. 73-83, 2019.

104. WU, M. S.; HUANG, Y.A.; YANG, C. H.; JOW, J. J. Electrodeposition of nanoporous nickel oxide film for electrochemical capacitors. International Journal of Hydrogen Energy, v. 32, n. 17, p. 4153-4159, 2007.

105. LEE, J.; KIM, S.; SHINB, D. Electrodeposition of iron in HNO3 solution containing iron dissolved from copper slag. Journal of The Electrochemical Society, v. 161, n. 14, p. D719D724, 2014.

106. DUSCHEK, K.; UHLEMANN, M.; SCHLÖRB, H.; NIELSCH, K.; LEISTNER, K. Electrochemical and in situ magnetic study of iron/iron oxide films oxidized and reduced in $\mathrm{KOH}$ solution for magneto-ionic switching. Electrochemistry Communications, v. 72, p. 153-156, 2016.

107. CAI, Z.; YE, Y.; WAN, X.; LIU, J.; YANG, S.; XIA, Y.; LI, G.; HE, Q. Morphologydependent electrochemical sensing properties of iron oxide-graphene oxide nanohybrids for dopamine and uric acid. Nanomaterials, v. 9, n. 6, p. 835, 2019.

108. XU, C.; ZENG, Y.; RUI, X.; ZHU, J.; TAN, H.; GUERRERO, A.; TORIBIO, J.; BISQUERT, J.; GARCIA-BELMONTE, G.; Yan, Q. Amorphous iron oxyhydroxide nanosheets: Synthesis, Li storage, and conversion reaction kinetics. The Journal of Physical Chemistry C, v. 117, n. 34, p. 17462-17469, 2013.

109. PHUAN, Y. W; CHONG, M. N.; ZHU, T.; YONG, S. T.; CHAN, E. S. Effects of annealing temperature on the physicochemical, optical and photoelectrochemical properties of nanostructured hematite thin films prepared via electrodeposition method. Materials 
Research Bulletin, v. 69, p. 71-77, 2015.

110. TAMBOLI, S. H.; RAHMAN, G.; JOO, O. S. Influence of potential, deposition time and annealing temperature on photoelectrochemical properties of electrodeposited iron oxide thin films. Journal of Alloys and Compounds, v. 520, p. 232-237, 2012.

111. HO-KIMURA, S.; WILLIAMSON, B. A.; SATHASIVAM, S.; MONIZ, S. J.; HE, G.; LUO, W.; SCANLON, D.; TANG, J.; PARKIN, I. P. Origin of High-Efficiency Photoelectrochemical Water Splitting on Hematite/Functional Nanohybrid Metal Oxide Overlayer Photoanode after a Low Temperature Inert Gas Annealing Treatment. ACS Omega, v. 4, n. 1, p. 1449-1459, 2019.

112. VASHISTA, M.; PAUL S. Correlation between full width at half maximum (FWHM) of XRD peak with residual stress on ground surfaces. Philosophical Magazine, v. 92, n. 33, p. 4194-4204, 2012.

113. SCHWAMINGER, S. P.; SURYA, R.; FILSER, S.; WIMMER, A.; WEIGL, F.; FRAGA-GARCÍA, P.; BERENSMEIER, S. Formation of iron oxide nanoparticles for the photooxidation of water: Alteration of finite size effects from ferrihydrite to hematite.

Scientific reports, v. 7, n. 1, p. 12609, 2017.

114. KIM, J. M.; CHUNG, H. T. Electrochemical characteristics of orthorhombic LiMnO2 with different degrees of stacking faults. Journal of power sources, v. 115, n. 1, p. 125-130, 2003.

115. PETER, L. M, UPUL WIJAYANTHA, K. G. Photoelectrochemical water splitting at semiconductor electrodes: Fundamental problems and new perspectives. ChemPhysChem, v. 15, n. 10, p. 1983-1995, 2014.

116. SHINDE, P. S.; CHOI, S. H.; KIM, Y.; RYU, J.; JANG, J. S. Onset potential behavior in $\alpha$-Fe2O3 photoanodes: the influence of surface and diffusion Sn doping on the surface states. Physical Chemistry Chemical Physics, v. 18, n. 4, p. 2495-2509, 2016.

117. XU, Y. Y.; ZHAO, D.; ZHANG, X. J.; JIN, W. T.; KASHKAROV, P.; ZHANG, H.; Synthesis and characterization of single-crystalline $\alpha-\mathrm{Fe} 2 \mathrm{O} 3$ nanoleaves. Physica E: Lowdimensional Systems and Nanostructures, v. 41, n. 5, p. 806-811, 2009.

118. SU, J.; VAYSSIERES, L. A place in the sun for artificial photosynthesis?. ACS Energy Letters, v. 1, n. 1, p. 121-135, 2016. 
119. SOARES, M. R.; COSTA, C. A.; LANZONI, E. M.; BETTINI, J; RAMIREZ, C. A.; SOUZA, F. L.; LONGO, E.; LEITE, E. R. Unraveling the Role of Sn Segregation in the Electronic Transport of Polycrystalline Hematite: Raising the Electronic Conductivity by Lowering the Grain-Boundary Blocking Effect. Advanced Electronic Materials, v. 5, n. 6, p. 1900065, 2019.

120. ZHANG, J.; ESLAVA, S. Understanding charge transfer, defects and surface states at hematite photoanodes. Sustainable Energy \& Fuels, 2019.

121. LING, Y.; WANG, G.; WHEELER, D. A.; ZHANG, J. Z.; LI, Y. Sn-doped hematite nanostructures for photoelectrochemical water splitting. Nano letters, v. 11, n. 5, p. 2119$2125,2011$.

122. MIAO, C.; JI, S.; XU, G.; LIU, G.; ZHANG, L.; YE, C. Micro-nano-structured $\mathrm{Fe}_{2} \mathrm{O}$ $3: \mathrm{Ti} / \mathrm{ZnFe}_{2} \mathrm{O}_{4}$ heterojunction films for water oxidation. ACS applied materials \& interfaces, v. 4, n. 8, p. 4428-4433, 2012.

123. DIAS, P.; ANDRADE. L.; MENDES, A. Hematite-based photoelectrode for solar water splitting with very high photovoltage. Nano energy, v. 38, p. 218-231, 2017.

124. SORENSON, S.; DRISCOLL, E.; HAGHIGHAT, S.; DAWLATY, J. M. Ultrafast carrier dynamics in hematite films: The role of photoexcited electrons in the transient optical response. The Journal of Physical Chemistry C, v. 118, n. 41, p. 23621-23626, 2014.

125. LE Formal, F.; Pendlebury, S. R.; Cornuz, M.; Tilley, S. D.; Gra, M.; Durrant, J. R. Back Electron - Hole Recombination in Hematite Photoanodes for Water Splitting. Journal of the American Chemical Society, v. 136, n. 6, p. 2564-2574, 2014.

126. ZHANG, J.; GARCÍA-RODRÍGUEZ, R.; CAMERON, P.; ESLAVA, S. Role of cobaltiron (oxy)hydroxide ( $\mathrm{CoFeOx}$ ) as oxygen evolution catalyst on hematite photoanodes.

Energy \& Environmental Science, v. 11, n. 10, p. 2972-2984, 2018.

127. ZHANG, M.; ANTONY, R. P.; CHIAM, S. Y.; ABDI, F. F.; WONG, L. H. Understanding the Roles of NiOx in Enhancing the Photoelectrochemical Performance of BiVO4 Photoanodes for Solar Water Splitting. ChemSusChem, v. 12, n. 9, p. 2022-2028, 2019.

128. CHENG, W.; HE, J.; SUN, Z.; PENG, Y.; YAO, T.; LIU, Q.; JIANG, Y.; HU, F.; XIE, Z.; HE, B.; WEI, S. Ni-doped overlayer hematite nanotube: A highly photoactive architecture 
for utilization of visible light. The Journal of Physical Chemistry C, v. 116, n. 45, p. 2406024067, 2012.

129. UPUL WIJAYANTHA, K. G.; SAREMI-YARAHMADI, S.; PETER, L. M. Kinetics of oxygen evolution at $\alpha-\mathrm{Fe}_{2} \mathrm{O}_{3}$ photoanodes: A study by photoelectrochemical impedance spectroscopy. Physical Chemistry Chemical Physics, v. 13, n. 12, p. 5264-5270, 2011.

130. KLAHR, B.; GIMENEZ, S.; FABREGAT-SANTIAGO, F.; HAMANN, T.; BISQUERT J. Water oxidation at hematite photoelectrodes: The role of surface states. Journal of the American Chemical Society, v. 134, n. 9, p. 4294-4302, 2012.

131. CHEN, S.; LI, J.; BAI, J.; XIA, L.; ZHANG, Y.; LI, L.; XU, Q.; ZHOU, B. Electron blocking and hole extraction by a dual-function layer for hematite with enhanced photoelectrocatalytic performance. Applied Catalysis B: Environmental, v. 237, p. 175-184, 2018.

132. DOTAN, H.; SIVULA, K.; GRÄTZEL, M.; ROTHSCHILD, A.; WARREN, S. C. Probing the photoelectrochemical properties of hematite $\left(\alpha-\mathrm{Fe}_{2} \mathrm{O}_{3}\right)$ electrodes using hydrogen peroxide as a hole scavenger. Energy \& Environmental Science, v. 4, n. 3, p. 958-964, 2011.

133. SUN, Y.; CHEMELEWSKI, W. D.; BERGLUND, S. P.; LI, C.; HE, H.; SHI, G.; MULLINS, C. B. Antimony-doped tin oxide nanorods as a transparent conducting electrode for enhancing photoelectrochemical oxidation of water by hematite. ACS applied materials \& interfaces, v. 6, n. 8, p. 5494-5499, 2014.

134. NOGUEIRA, A. E.; SOARES, M. R.; SOUZA, J. B.; OSPINA, C. A.; SOUZA, F. L.; LEITE, E. R. Discovering a selective semimetal element to increase hematite photoanode charge separation efficiency. Journal of Materials Chemistry A, v. 7, n. 28, p. 1699216998, 2019.

135. ANNAMALAI, A.; SANDSTRÖM, R.; GRACIA-ESPINO, E.; BOULANGER, N.; BOILY, J. F.; MÜHLBACHER, I.; SCHUKAREV, A.; WÅGBERG, T. Influence of $\mathrm{Sb}^{5+}$ as a Double Donor on Hematite $\left(\mathrm{Fe}^{3+}\right)$ Photoanodes for Surface-Enhanced Photoelectrochemical Water Oxidation. ACS applied materials \& interfaces, v. 10, n. 19, p. 16467-16473, 2018. 136. LI, F., LI, J., GAO, L., HU, Y., LONG, X., WEI, S., WANG, C.; JIN, J.; MA, J. Construction of an efficient hole migration pathway on hematite for efficient 
photoelectrochemical water oxidation. Journal of Materials Chemistry A, v. 6, n. 46, p. 23478-23485, 2018.

137. DIAS, P.; ANDRADE. L.; MENDES, A. Hematite-based photoelectrode for solar water splitting with very high photovoltage. Nano energy, v. 38, p. 218-231, 2017.

138. SHINDE, P. S.; ANNAMALAI, A.; KIM, J. Y.; CHOI, S. H.; LEE, J. S.; JANG, J. S. Fine-tuning pulse reverse electrodeposition for enhanced photoelectrochemical water oxidation performance of $\alpha-\mathrm{Fe}_{2} \mathrm{O}_{3}$ photoanodes. The Journal of Physical Chemistry C, v. 119, n. 10, p. 5281-5292, 2015.

139. RAHMAN, G.; JOO, O. S. Electrodeposited nanostructured $\alpha-\mathrm{Fe}_{2} \mathrm{O}_{3}$ thin films for solar water splitting: Influence of Pt doping on photoelectrochemical performance. Materials Chemistry and Physics, v. 140, n. 1, p. 316-322, 2013.

140. FU, L.; YU, H.; LI, Y.; ZHANG, C.; WANG, X.; SHAO, Z.; YI, B. Ethylene glycol adjusted nanorod hematite film for active photoelectrochemical water splitting. Physical Chemistry Chemical Physics, v. 16, n. 9, p. 4284-4290, 2014.

141. CHOI, H.; HONG, Y.; RYU, H.; LEE, W. J. Photoelectrochemical properties of hematite thin films grown via a two-step electrochemical deposition method. Ceramics International, v. 44, n. 4, p. 4105-4113, 2018. 


\section{APÊNDICE A}

Figura A1 - Cronoamperograma de eletrodeposição de Fe sobre FTO registrado a -1,3 V (vs. $\left.\mathrm{Ag} / \mathrm{AgCl} / \mathrm{Cl}^{-}{ }_{(\mathrm{KCl} \text { sat. })}\right)$ em solução de $0,05 \mathrm{~mol} \mathrm{~L}^{-1}$ de $\left(\mathrm{NH}_{4}\right)_{2} \mathrm{Fe}\left(\mathrm{SO}_{4}\right)_{2}+0,1 \mathrm{~mol} \mathrm{~L}^{-1} \mathrm{Na}_{2} \mathrm{SO}_{4} \mathrm{em}$ 1:8 etilenoglicol e água. $\mathrm{v}=20 \mathrm{mV} \mathrm{s}^{-1} . \mathrm{T}=25^{\circ} \mathrm{C}$.

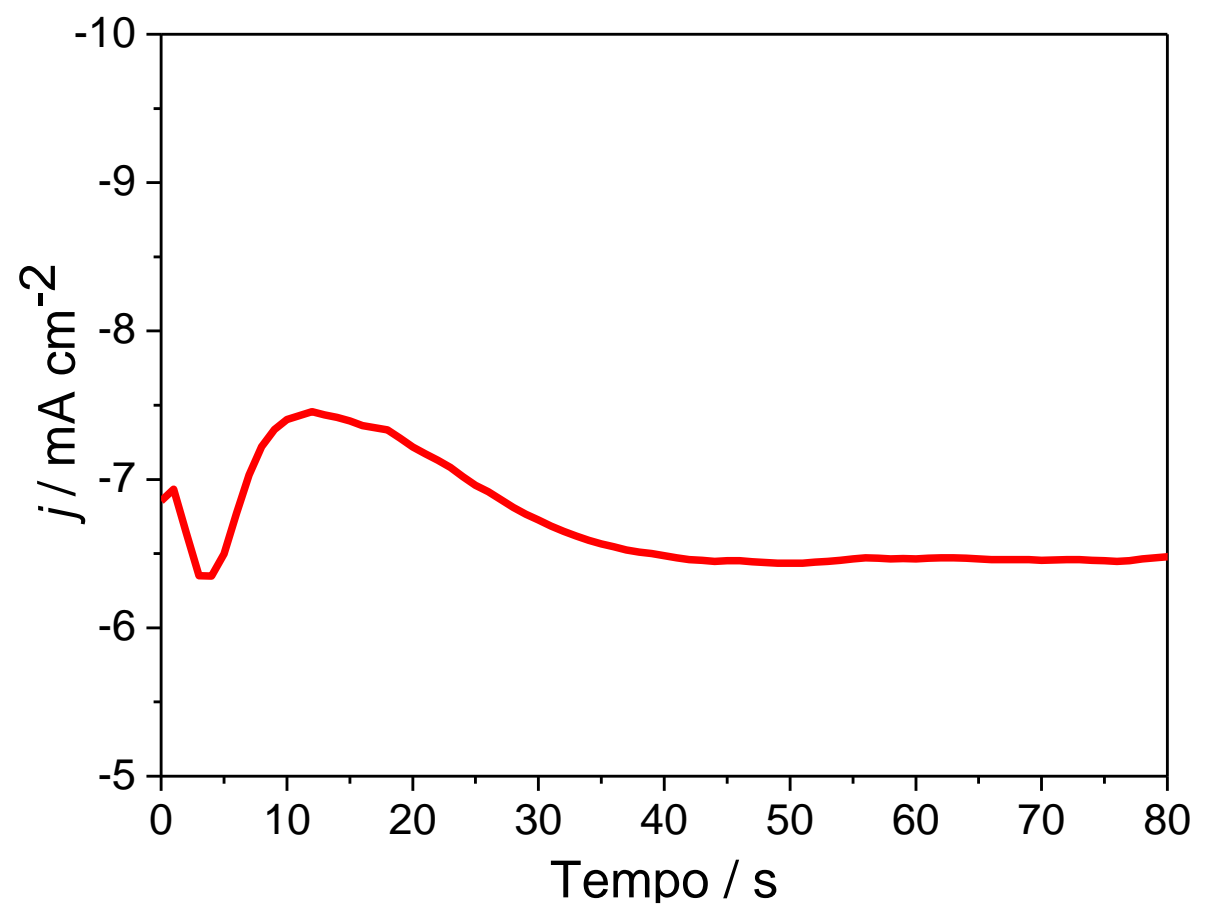

Fonte: Autoria própria.

Tabela A1-Parâmetros de rede e volume de célula para os filmes os $\alpha-\mathrm{Fe}_{2} \mathrm{O}_{3}$ preparados para otimização dos parâmetros de síntese.

\begin{tabular}{|c|c|c|c|}
\hline Filmes & $\begin{array}{l}\mathbf{a}=\mathbf{b} \\
/ \mathbf{n m}\end{array}$ & $\underset{/ \mathrm{nm}}{\mathbf{c}}$ & $\begin{array}{l}\mathbf{V}_{\text {célula }} \\
/ \AA^{3}\end{array}$ \\
\hline $\mathrm{Fe}_{2} \mathrm{O}_{3} / 600^{\circ} \mathrm{C}$ & 0,5056 & 1,3714 & 303,6464 \\
\hline $\mathrm{Fe}_{2} \mathrm{O}_{3} / 650^{\circ} \mathrm{C}$ & 0,5055 & 1,3721 & 303,7255 \\
\hline $\mathrm{Fe}_{2} \mathrm{O}_{3} / 700^{\circ} \mathrm{C}$ & 0.5050 & 1,3776 & 304,3369 \\
\hline $\mathrm{Fe}_{2} \mathrm{O}_{3} / 300 \mathrm{mC}$ & 0,5052 & 1,3699 & 302,7940 \\
\hline $\mathrm{Fe}_{2} \mathrm{O}_{3} / 500 \mathrm{mC}$ & 0,5055 & 1,3721 & 303,7255 \\
\hline $\mathrm{Fe}_{2} \mathrm{O}_{3} / 800 \mathrm{mC}$ & 0,5054 & 1,3760 & 304,4680 \\
\hline
\end{tabular}

Fonte: Autoria própria. 


\section{APÊNDICE B}

Tabela B1- Parâmetros de rede e volume de célula para os filmes os $\alpha-\mathrm{Fe}_{2} \mathrm{O}_{3}$ preparados para otimização dos parâmetros de síntese.

\begin{tabular}{cccc}
\hline Filmes & $\begin{array}{c}\mathbf{a}=\mathbf{b} \\
\text { /nm }\end{array}$ & $\begin{array}{c}\mathbf{c} \\
/ \mathbf{n m}\end{array}$ & $\begin{array}{c}\mathbf{V}_{\text {célula }} \\
/ \mathbf{A}^{\mathbf{3}}\end{array}$ \\
\hline $\mathbf{F e}_{2} \mathbf{O}_{3}$ & 0,5055 & 1,3721 & 303,7255 \\
$\mathbf{F e}_{2} \mathbf{O}_{3} / \mathbf{S n - 5 m C}$ & 0,5053 & 1,3663 & 302,3503 \\
$\mathbf{F e}_{2} \mathbf{O}_{3} / \mathbf{S n - 1 0 m C}$ & 0,5059 & 1,3683 & 303,3503 \\
$\mathbf{F e}_{2} \mathbf{O}_{3} / \mathbf{S n - 2 0 m C}$ & 0,5054 & 1,3695 & 304,0540 \\
\hline
\end{tabular}

Fonte: Autoria própria.

Figura B1- a) Espectro de absorção dos filmes $\mathrm{Fe}_{2} \mathrm{O}_{3}$ e $\mathrm{Fe}_{2} \mathrm{O}_{3} / \mathrm{Sn}-10 \mathrm{mC}$ não modificados e modificados com $\mathrm{NiO}_{x}$. (b) Gráfico de $(\alpha h v)^{1 / 2} v s$. energia do fóton para os filmes dos filmes $\mathrm{Fe}_{2} \mathrm{O}_{3}$ e $\mathrm{Fe}_{2} \mathrm{O}_{3} / \mathrm{Sn}-10 \mathrm{mC}$ não modificados e modificados com $\mathrm{NiO}_{x}$.
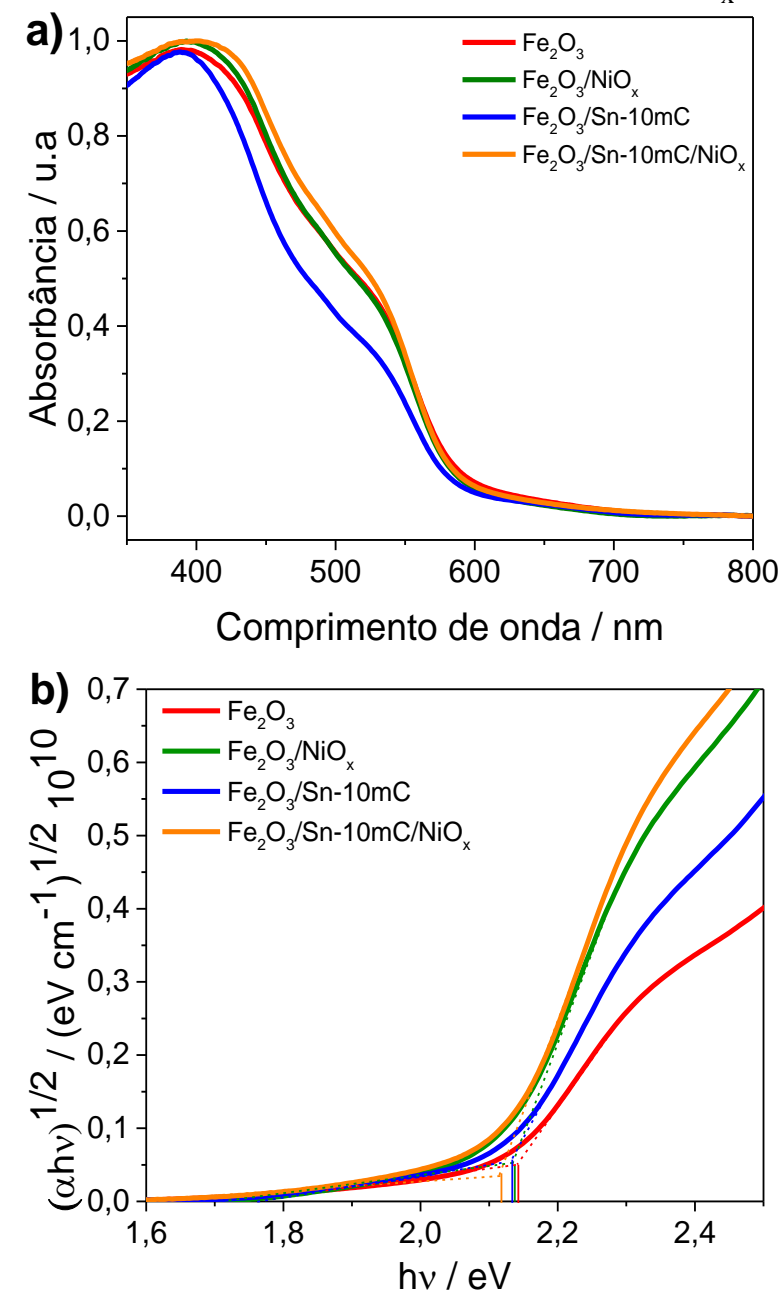

Fonte: Autoria própria. 
Figura B2- Espectros de EDX dos filmes de (a) $\mathrm{Fe}_{2} \mathrm{O}_{3}$, (b) $\mathrm{Fe}_{2} \mathrm{O}_{3} / \mathrm{NiO}_{\mathrm{x}}$.

a)

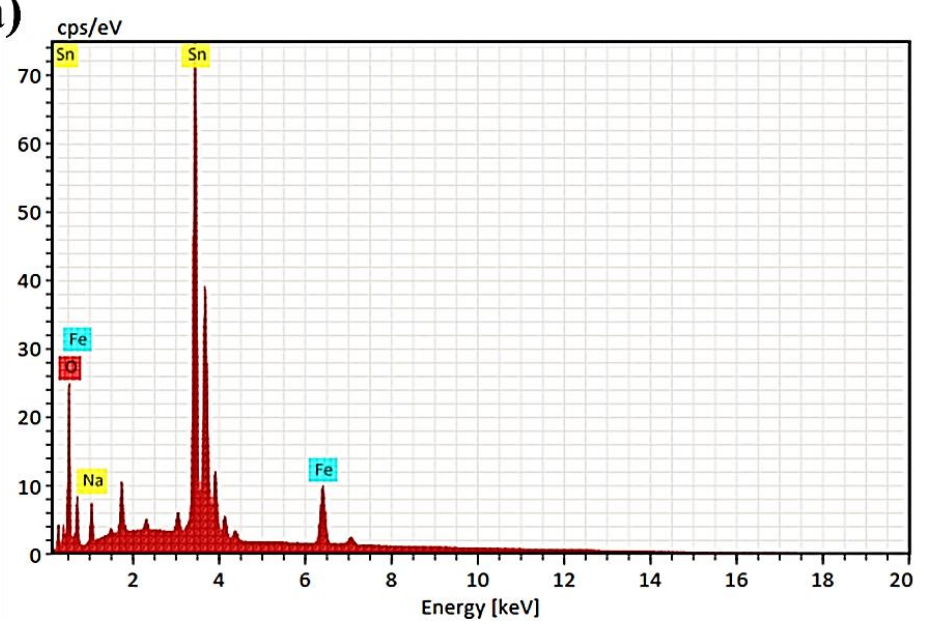

b)

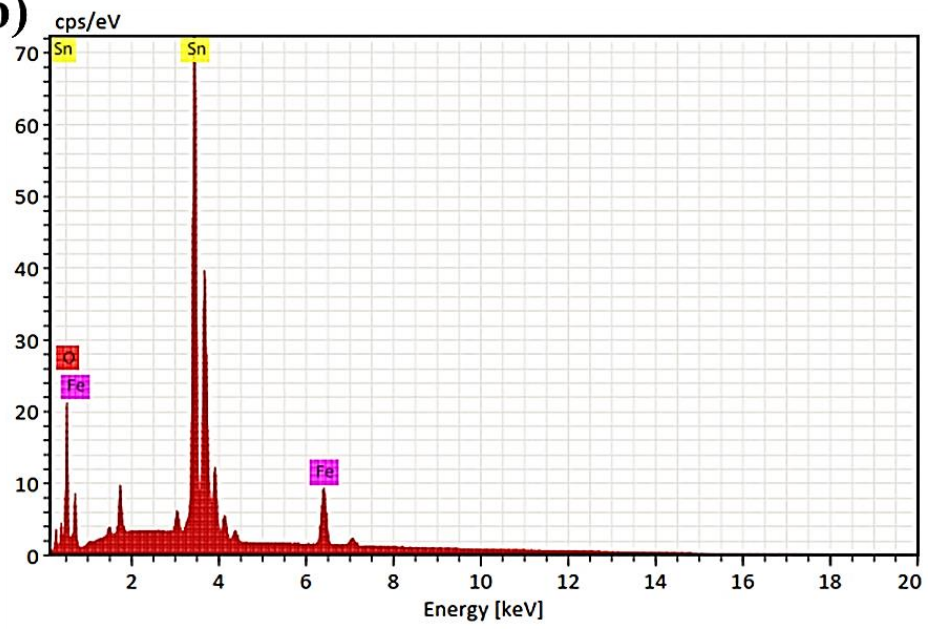

Fonte: Autoria própria.

Figura B3-Espectro de Fluorescência de raio $\mathrm{X}$ obtido para o filme $\mathrm{Fe}_{2} \mathrm{O}_{3} / \mathrm{NiO}_{\mathrm{x}}$.

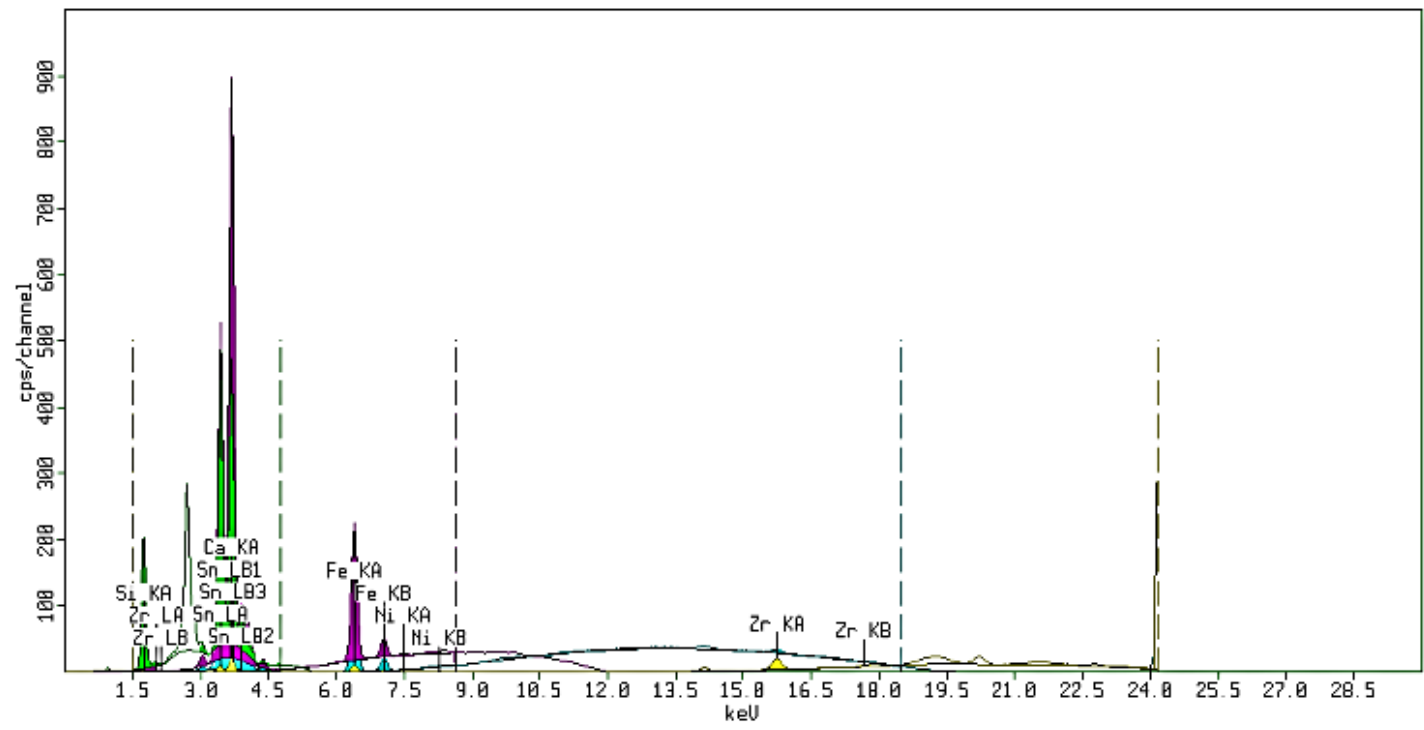

Fonte: Autoria própria. 
Figura B4- Diagramas Bode de módulo (a) e fase (b) em função da frequência para os fotoanodos de hematita em $1 \mathrm{~mol} \mathrm{~L}^{-1} \mathrm{KOH}$. Os valores medidos são representados por símbolos e as linhas sólidas são as curvas ajustadas.
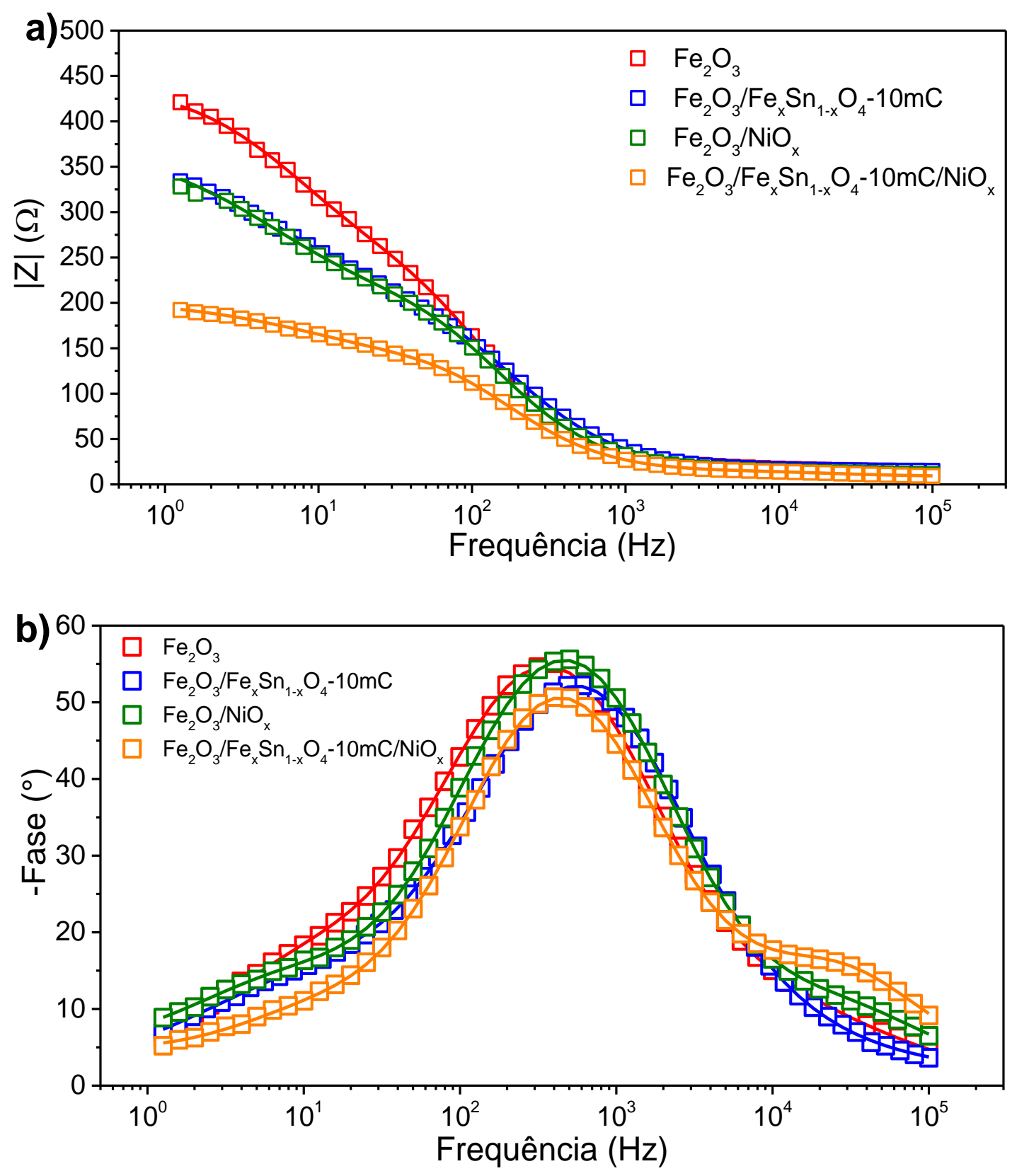
Figura B5- Diagramas Bode de módulo (a) e fase (b) em função da frequência para os fotoanodos de hematita em $1 \mathrm{~mol} \mathrm{~L}^{-1} \mathrm{KOH}+0,5 \mathrm{~mol} \mathrm{~L}^{-1} \mathrm{H}_{2} \mathrm{O}_{2}$. Os valores medidos são representados por símbolos e as linhas sólidas são as curvas ajustadas.
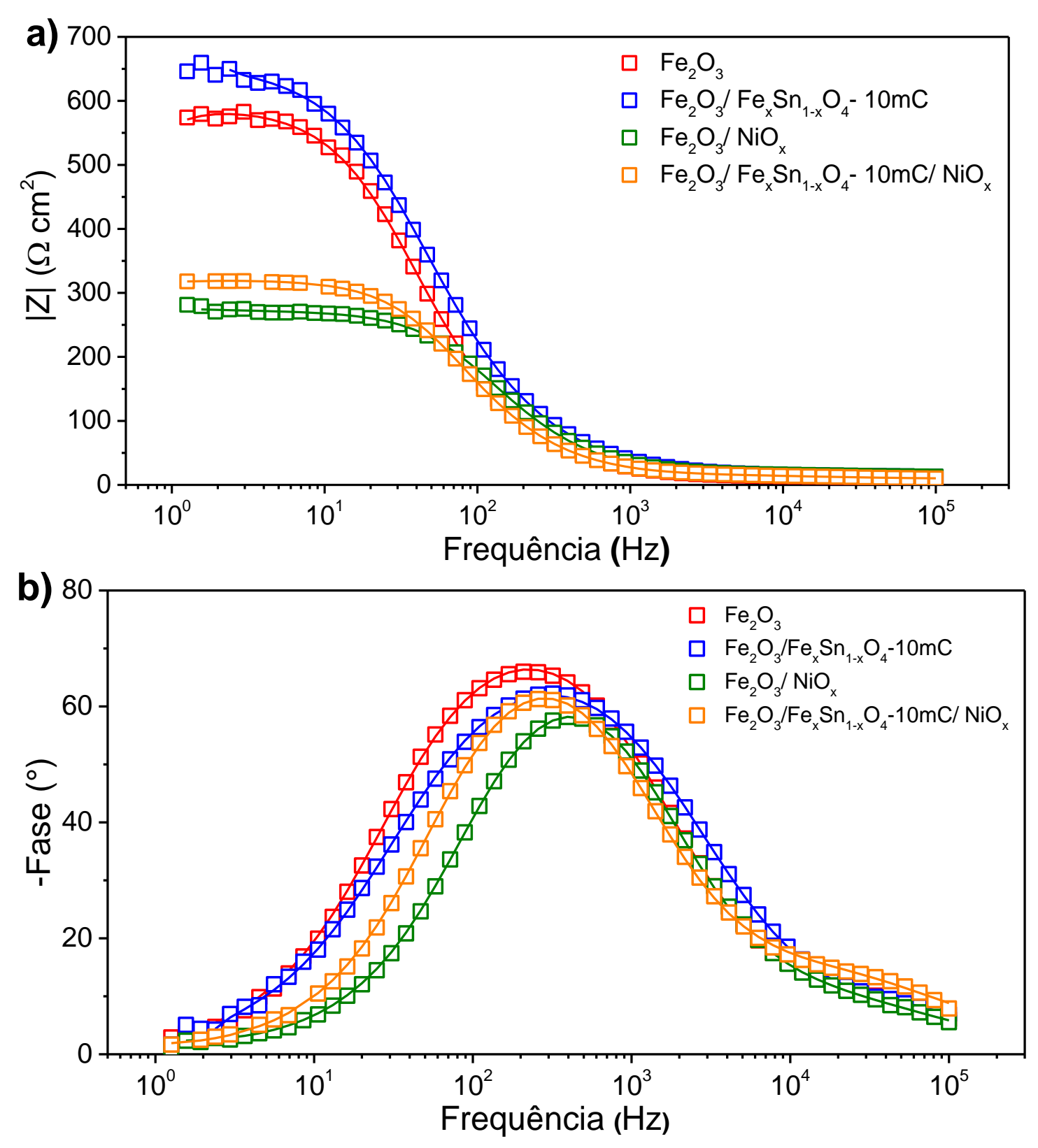

Fonte: Autoria própria. 
Figura B6- Voltamogramas lineares registrados a $20 \mathrm{mVs}^{-1}$ no escuro (linha tracejada) e sob iluminação com simulador solar (100 $\mathrm{mW} \mathrm{cm}^{-1}$, com filtro A.M. 1.5) (linha contínua) em $\mathrm{KOH}$ $1,0 \mathrm{~mol} \mathrm{~L}^{-1}$ e $1 \mathrm{~mol} \mathrm{~L}{ }^{-1} \mathrm{KOH}+0.5 \mathrm{~mol} \mathrm{~L}^{-1} \mathrm{H}_{2} \mathrm{O}_{2}$ para os fotoanodos: a) $\mathrm{Fe}_{2} \mathrm{O}_{3}$, (b) $\mathrm{Fe}_{2} \mathrm{O}_{3} / \mathrm{Sn}$ $10 \mathrm{mC}$, (c) $\mathrm{Fe}_{2} \mathrm{O}_{3} / \mathrm{NiO}_{\mathrm{x}}$ e (d) $\mathrm{Fe}_{2} \mathrm{O}_{3} / \mathrm{Sn}-10 \mathrm{mC} / \mathrm{NiO}_{\mathrm{x}}$.
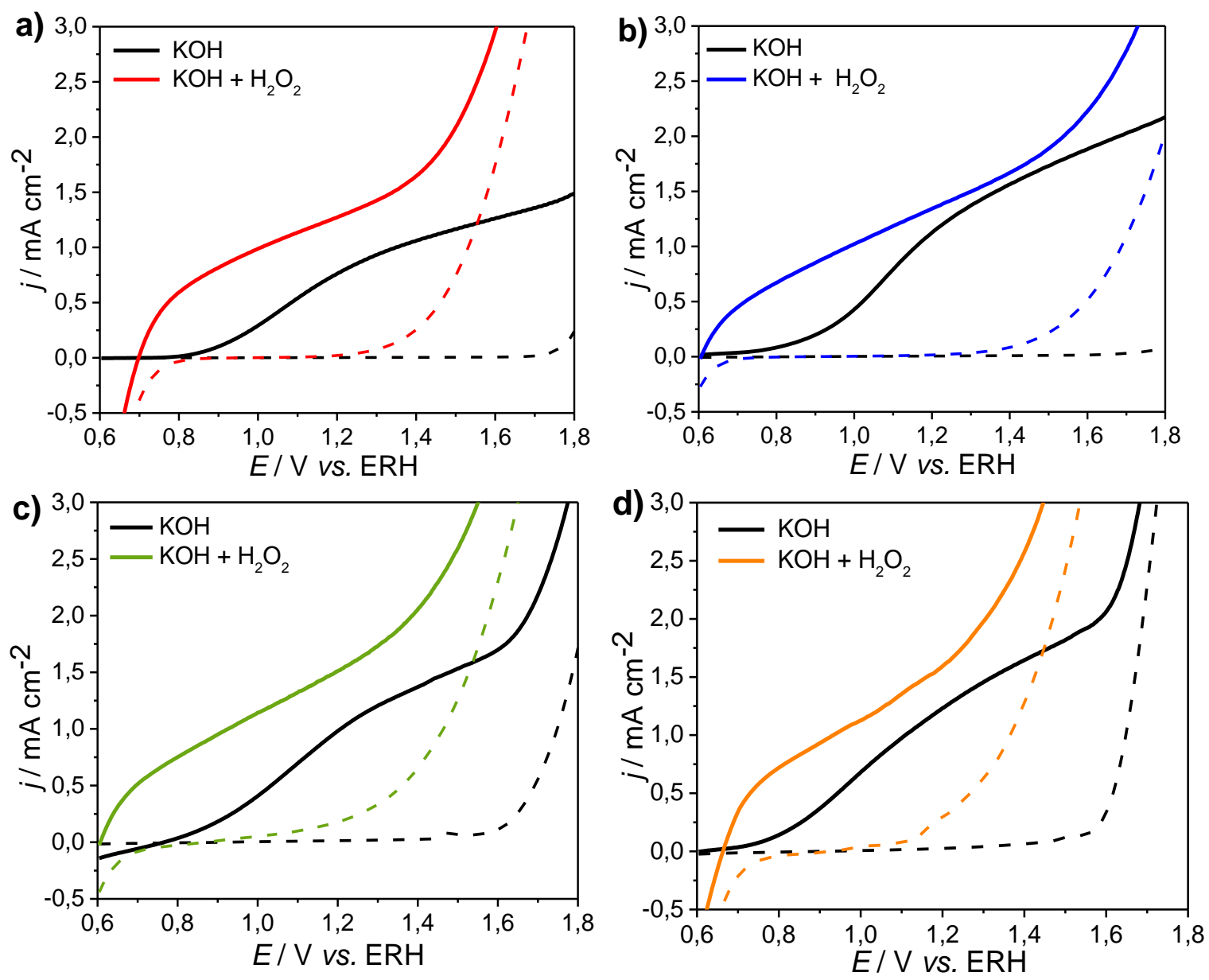

Fonte: Autoria própria. 
Figura B7- (a) Gráfico da eficiência de separação e carga em função do potencial para os fotoanodos de hematita não-modificado e modificados. (b) Gráfico da eficiência de injeção de carga em função do potencial aplicado para os fotoanodos de hematita não-modificado e modificados.
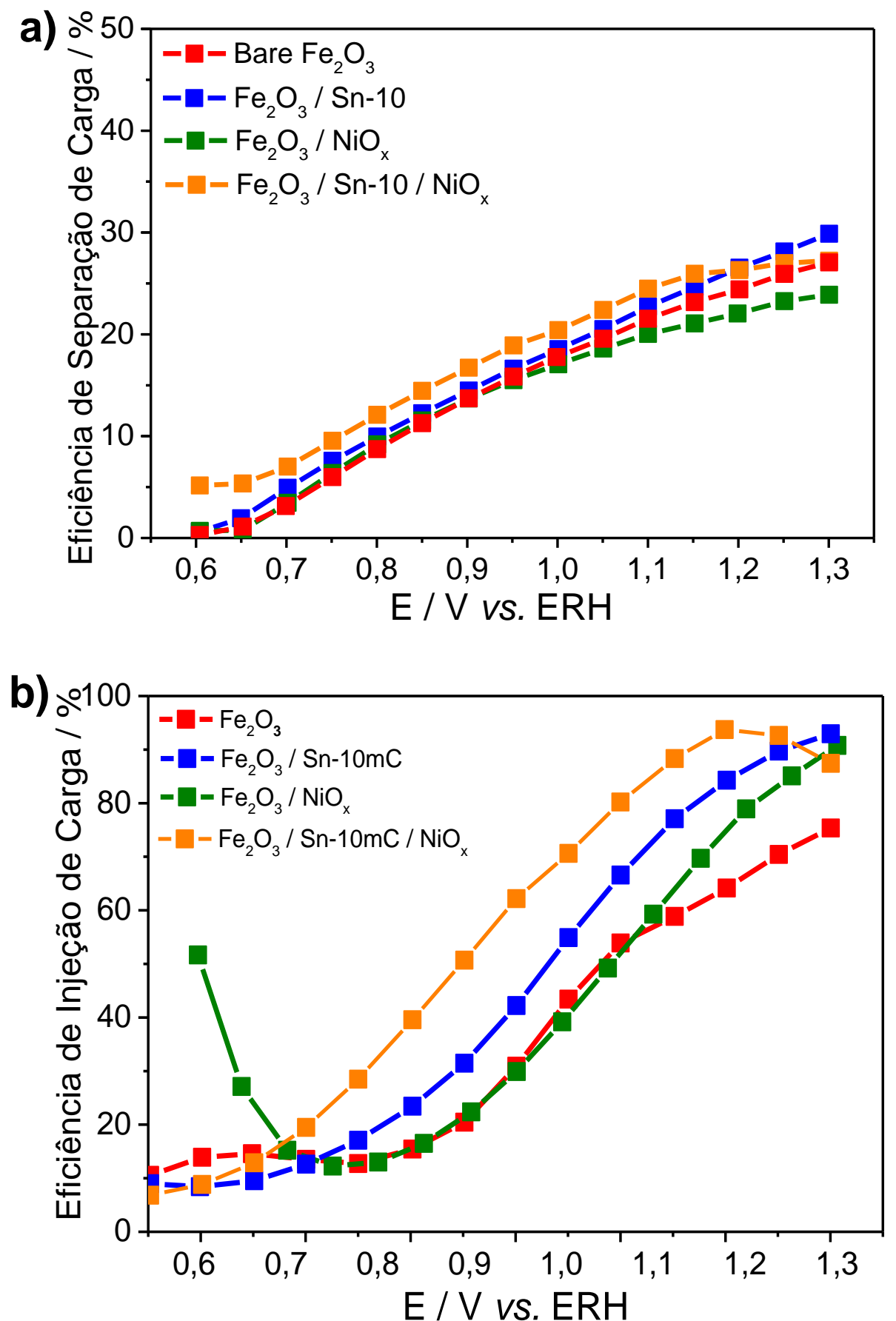

Fonte: Autoria própria. 


\section{APÊNDICE C}

Figura C1- Micrografias obtidas por MEV-FEG das superfícies dos substratos: (a) nãomodificado e (b) modificado com $200 \mu \mathrm{L}$ da solução de ATO.
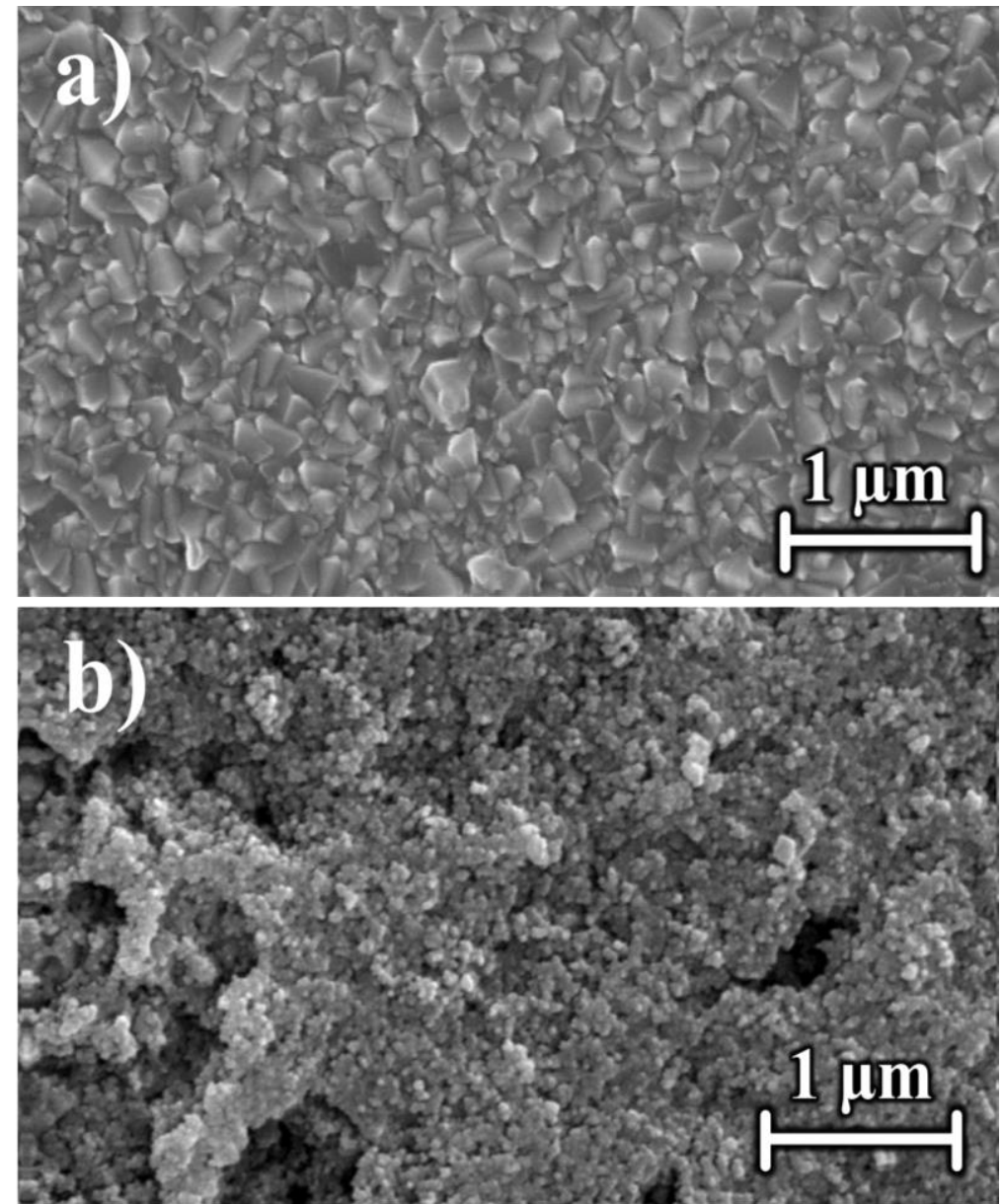

Fonte: Autoria própria. 
Figura C2- Diagramas Bode de módulo (a) e fase (b) em função da frequência para os fotoanodos de hematita em $1 \mathrm{~mol} \mathrm{~L}^{-1} \mathrm{KOH}$. Os valores medidos são representados por símbolos e as linhas sólidas são as curvas ajustadas.
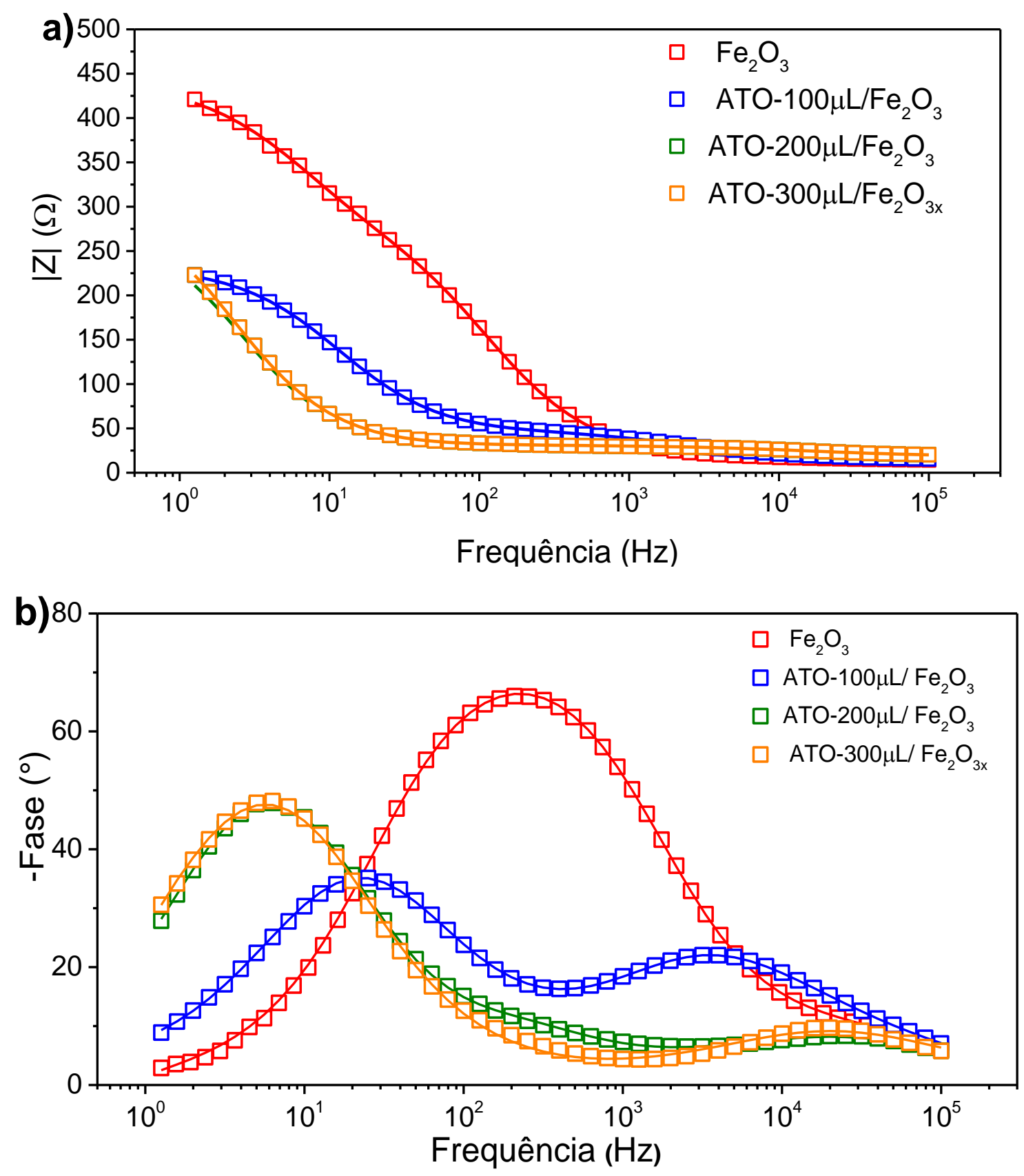
Figura C3- Voltamogramas lineares registrados a $20 \mathrm{mVs}^{-1}$ no escuro (linha tracejada) e sob iluminação com simulador solar ( $100 \mathrm{~mW} \mathrm{~cm}^{-1}$, com filtro A.M. 1.5) (linha contínua) em $\mathrm{KOH}$ $1,0 \mathrm{~mol} \mathrm{~L}{ }^{-1}$ e $1 \mathrm{~mol} \mathrm{~L}^{-1} \mathrm{KOH}+0.5 \mathrm{~mol} \mathrm{~L}{ }^{-1} \mathrm{H}_{2} \mathrm{O}_{2}$ para os fotoanodos: a) ATO-100 $\mu \mathrm{L} / \mathrm{Fe}_{2} \mathrm{O}_{3}$, (b) ATO-200 $\mu \mathrm{L} / \mathrm{Fe}_{2} \mathrm{O}_{3}$ e (c) ATO- $100 \mu \mathrm{L} / \mathrm{Fe}_{2} \mathrm{O}_{3}$.
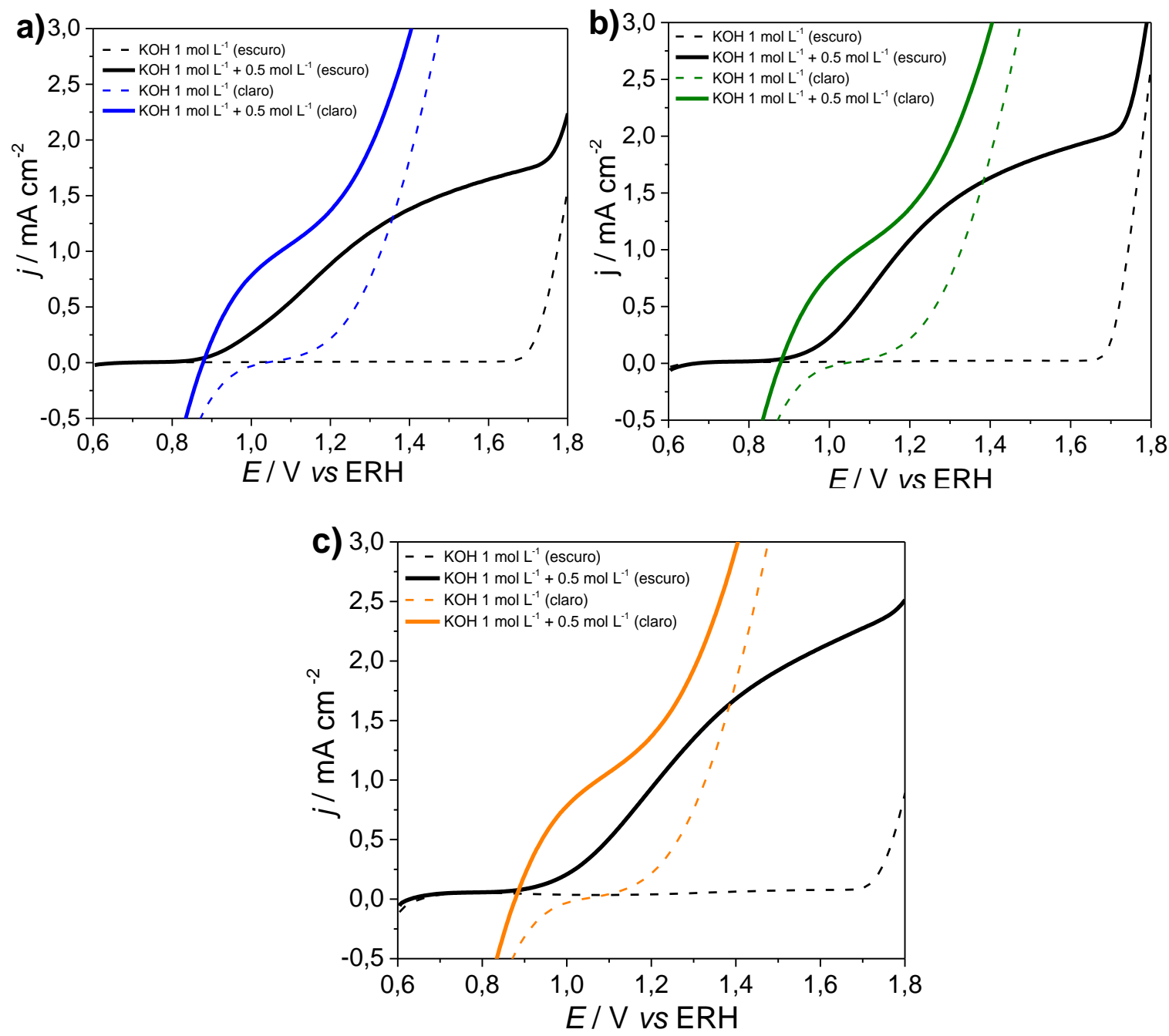

Fonte: Autoria própria. 
Figura C4 - (a) Gráfico da eficiência de separação e carga em função do potencial para os fotoanodos de hematita não-modificado e modificados. (b) Gráfico da eficiência de injeção de carga em função do potencial aplicado para os fotoanodos de hematita não-modificado e modificados.
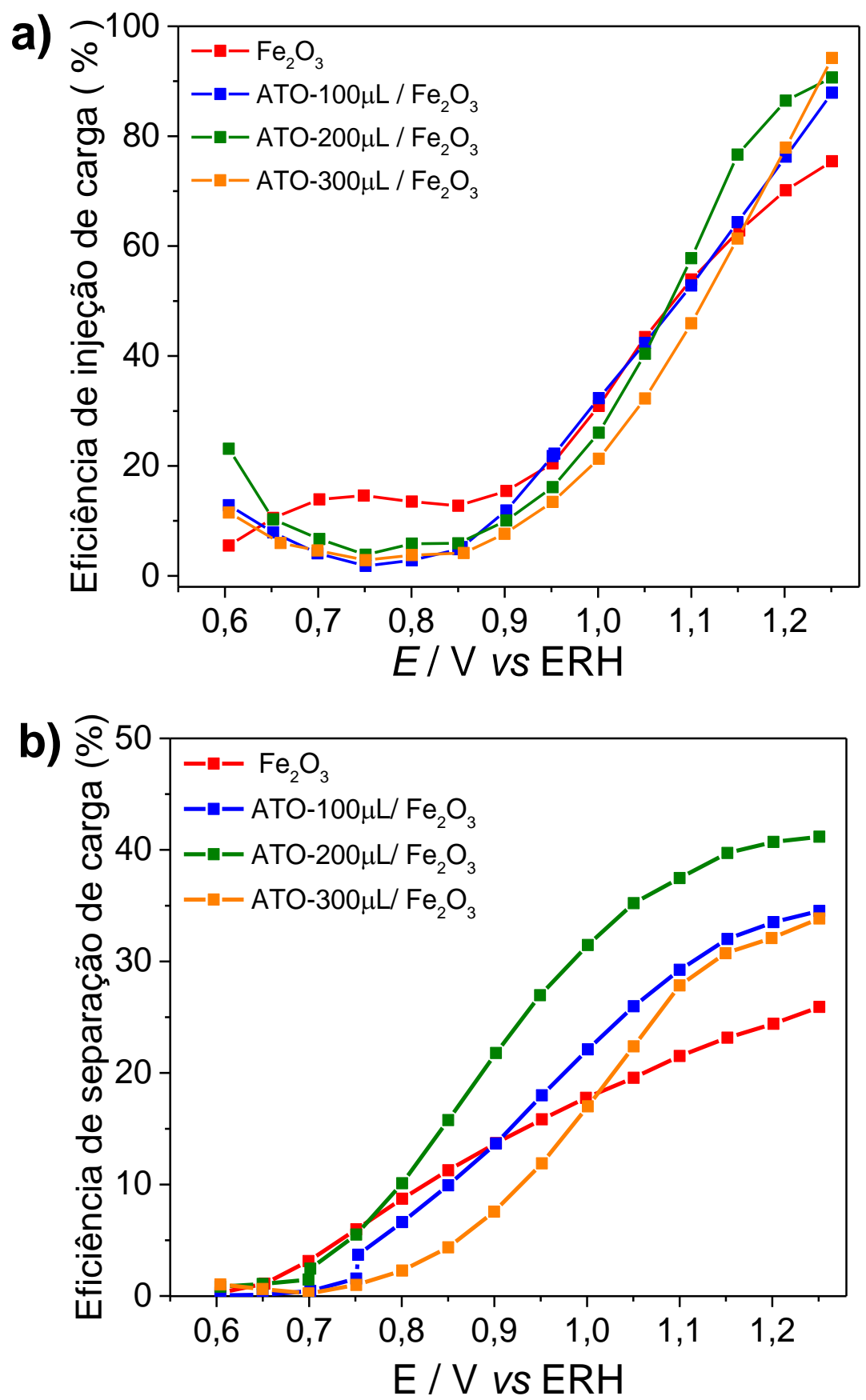

Fonte: Autoria própria. 


\section{ANEXO A}

Tabela 1- Comparação da performance PEC de fotoanodos de hematita preparados por diferentes métodos.

\begin{tabular}{|c|c|c|c|}
\hline Método de síntese & $\begin{array}{c}\text { Eonset }_{\text {o }} \\
\text { V vs ERH }\end{array}$ & $\begin{array}{c}\mathrm{j} / \mathrm{mA} \mathrm{cm}^{-2} \\
(1,23 \mathrm{~V} \text { vs ERH })\end{array}$ & Referência \\
\hline Hidrotermal & 0,81 & 1,12 & $\begin{array}{l}\text { Carvalho \& Souza } \\
\text { (2016) [73] }\end{array}$ \\
\hline Hidrotermal & 0,65 & 0,90 & Jeon et al. (2017) [89] \\
\hline Hidrotermal & 0,80 & 0,73 & Li et al. (2018) [136] \\
\hline Spray pirólise & 1,00 & 0,62 & Dias et al. (2017) [137] \\
\hline $\begin{array}{l}\text { Atomic layer deposition } \\
\text { (ALD) }\end{array}$ & 1,00 & $\sim 0,40$ & Thorne et al. (2015) [45] \\
\hline \multirow{3}{*}{ Eletrodeposição catódica } & 0,90 & 0,26 & Liang et al. (2018) [49] \\
\hline & 0,80 & 0,45 & $\begin{array}{c}\text { Shinde et al. (2015) } \\
\text { [138] }\end{array}$ \\
\hline & 0,90 & 0,29 & $\begin{array}{c}\text { Rahman \& Joo (2013) } \\
\text { [139] }\end{array}$ \\
\hline \multirow{4}{*}{ Eletrodeposição anódica } & 1,0 & 0,40 & $\begin{array}{c}\text { Tamboli et al. (2012) } \\
\text { [110] }\end{array}$ \\
\hline & 1,0 & 0,15 & Fu et al. (2014) [140] \\
\hline & - & 0,28 & Choi et al. (2018) [141] \\
\hline & 0,9 & 0,26 & Li et al. (2019) [50] \\
\hline
\end{tabular}

Fonte: Autoria própria. 